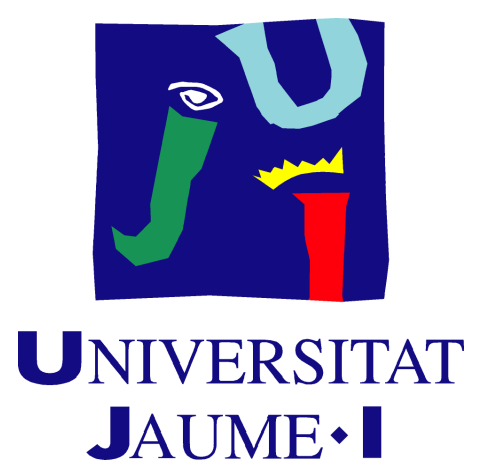

Tesis Doctoral

\title{
Evolución de los clústeres industriales a través de las innovaciones disruptivas.
}

\author{
Doctorando: \\ David Valiente Bordanova \\ Dirigida por: \\ Dr. Francesc Xavier Molina Morales y Dr. Luis Martínez Cháfer
}

Castellón de la Plana, Julio 2019 


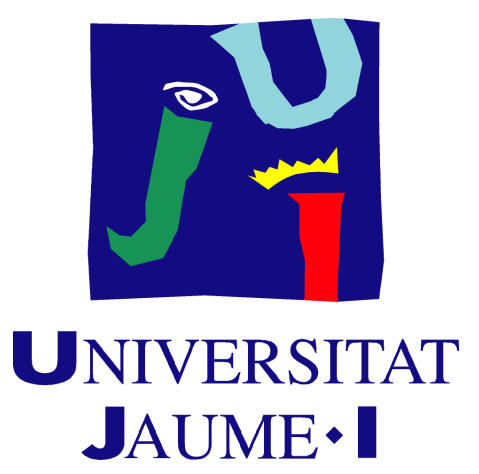

Programa de doctorado en Economía y Empresa

Escuela de Doctorado de la Universitat Jaume I

\section{Evolución de los clústeres industriales a través de las innovaciones disruptivas.}

Memoria presentada por David Valiente Bordanova para optar al grado de doctor por la Universitat Jaume I
David Valiente
Dr. Francesc Xavier
Dr. Luis Martínez
Bordanova
Molina Morales
Cháfer

Castellón de la Plana, Julio 2019 


\section{FINANCIACIÓN RECIBIDA}

Este estudio se ha llevado a cabo gracias a los fondos del proyecto UJI-B2018-29 cuyo título es: "El análisis de las redes interorganizativas en contextos de clúster. Algunas consideraciones sobre los procesos de innovación y creación de empresas", así como también a la financiación del Ministerio de Ciencia e Innovación a través del proyecto ECO2015-67122-R con título: "El impacto de las redes sociales externas de conocimiento y de las capacidades internas en la innovación empresarial. Una aplicación a los contextos de proximidad territorial" 


\section{RESUMEN}

Las aglomeraciones territoriales y más concretamente los clústeres industriales, han jugado -y siguen jugando- un papel muy relevante en el crecimiento de las regiones donde se encuentran. Sin embargo, en los últimos años la rápida transformación del escenario competitivo -debida principalmente fenómenos como la globalización- ha sometido a estas agrupaciones empresariales a una serie de retos que, en cierto modo, han amenazado su supervivencia. Ante esta situación, los clústeres industriales se ven obligados a idear nuevas formas de recuperar su competitividad, las cuales -en algunas ocasiones- pueden llegar incluso cuestionar el modo en que tradicionalmente estas aglomeraciones se han concebido.

Esta tesis doctoral se centra en el análisis de cómo los clústeres industriales pueden favorecer su regeneración y abrir nuevas oportunidades de desarrollo a partir de una de estas alternativas: las innovaciones disruptivas.

El objetivo principal de nuestra investigación consiste, por tanto, en analizar la respuesta desarrollada por los clústeres industriales ante la aparición de una innovación tecnológica disruptiva, identificando así sus patrones de generación y de difusión, sus determinantes $\mathrm{y}$, finalmente, sus efectos. Para llevar a cabo esta tarea, el trabajo empírico ha tenido como objeto principal de estudio el clúster industrial cerámico ubicado en la provincia de Castellón. En este contexto hemos investigado no sólo este 
clúster como entidad, sino también a las empresas que lo integran, mediante el análisis de una muestra representativa de las mismas.

Nuestro trabajo ha sido planteado a través de cuatro estudios específicos: la descripción del proceso innovador disruptivo y su impacto en el clúster industrial cerámico de Castellón; la identificación de unos patrones susceptibles de generalización a partir de un análisis comparativo entre dos casos similares; el análisis de los factores internos que favorecen la adopción temprana de las innovaciones disruptivas por parte de las empresas que integran un clúster; y finalmente, el estudio del efecto que la adopción temprana de una tecnología disruptiva tiene sobre la innovación tecnológica de las empresas individuales de un clúster.

Las principales conclusiones obtenidas de nuestro estudio son las siguientes: (a) En los clústeres industriales se pueden dar procesos de innovación disruptiva y, por tanto, éstas se pueden desarrollar en contextos distintos a los de las empresas individuales. No obstante, la aparición de estos procesos se puede ver inhibida por factores característicos de los clústeres como son la intensidad de las relaciones internas, la densidad de la red que forman los actores que los integran o la existencia de recursos exploratorios conjuntos limitados. Nuestro análisis revela que cuando estas innovaciones se producen, sus efectos son muy positivos, pudiendo incluso favorecer etapas de rejuvenecimiento en clústeres maduros; (b) Nuestra investigación ha identificado unos patrones comunes, y potencialmente generalizables, de los procesos innovadores disruptivos en el contexto de los clústeres industriales, tanto a nivel de determinantes como de consecuencias de los mismos. La determinación del papel desempeñado por elementos clave tales como los agentes visionarios, los gatekeepers tecnológicos, los agentes externos o las empresas especializadas contribuyen a la literatura de innovación en clústeres que identifica los roles que juegan distintos actores en estos procesos; (c) A nivel de empresa individual que integra el clúster, los resultados sugieren que no todas las habilidades internas relacionadas con la capacidad de absorción de conocimiento externo favorecen por igual la adopción temprana de una tecnología disruptiva. En efecto, nuestra investigación revela que el desarrollo de la capacidad de explotación tiene una influencia significativa y positiva en la adopción tecnológica que no tiene el desarrollo de capacidad de exploración; (d) Finalmente, nuestra investigación contribuye a la literatura de innovación, y más concretamente a 
aquella que se centra en la identificación de sus determinantes, puesto que hemos podido identificar distintas combinaciones de factores internos que conducen a las empresas a ser altamente innovadoras. De entre estas combinaciones, nuestro estudio pone de manifiesto que la adopción temprana de una tecnología disruptiva (en combinación con otras habilidades relacionadas con la obtención y explotación de conocimiento procedente de fuentes externas) es un determinante importante y suficiente para que las empresas sean altamente innovadoras.

En definitiva, consideramos que, no exentos de limitaciones y restricciones, los resultados obtenidos en esta tesis doctoral suponen una contribución relevante a diversas líneas de investigación abiertas actualmente. Entendemos que este trabajo supone un avance en la comprensión de los procesos innovadores disruptivos en el contexto del clúster y, especialmente, en el beneficioso papel que estos procesos juegan en la activación de nuevas etapas de desarrollo de los mismos. Por último, pensamos que los resultados pueden tener implicaciones interesantes para el diseño de políticas y de líneas estratégicas tanto a nivel institucional (por ejemplo para organismos encargados de dirigir y diseñar las políticas públicas destinadas a la dinamización del territorio) como a nivel empresarial. 


\section{SUMMARY}

Territorial agglomerations, and more specifically industrial clusters, have played - and are still playing- a very important role in the growth of the regions where they are located. However, in recent years, the rapid transformation of the competitive scenariodue mainly to phenomena such as globalization- has subjected these business contexts to a series of challenges that, in a way, have threatened their survival. Against this background, industrial clusters have been forced to devise new ways of regaining their competitiveness, which -in some cases- can even question the way in which these agglomerations have traditionally been characterised. This research focuses on the analysis of how industrial clusters are able to boost their regeneration and, consequently, open up new development opportunities through one of those alternatives: the disruptive innovations.

The main objective of our research is, therefore, to analyse how industrial clusters have faced the appearance of disruptive technological innovations identifying their patterns of generation and diffusion, their determinants and, finally, their effects.

To carry out this task, the main subject of study in the empirical research has been the ceramic tile industrial cluster which is located in the province of Castellón. We have investigated not only this cluster as an independent entity, but also the companies comprising it, as we analysed a representative sample of them.

Our work has been proposed through four specific studies: the description of the disruptive innovative process and its impact on the ceramic tile industrial cluster of 
Castellón; the identification -from a comparative analysis between two similar cases- of patterns for generalization; the analysis of the clustered firm's internal attributes that favour the early adoption of disruptive innovations; and finally, the study of how the early adoption of a disruptive technology influences on the technological innovation performance of clustered firms.

The main conclusions obtained from our study are the following: (a) Disruptive innovation processes can take place in industrial clusters and, therefore, these processes can be developed in contexts different from those related to individual companies. However, the generation, development and diffusion of these phenomena are conditioned by some cluster peculiarities, such as the intensity of internal relationships, the density of the cluster network or the existence of limited common exploratory resources. Our analysis uncovers the positive effects of these innovations over industrial clusters; specifically, if clusters are in a mature phase, they are able to favour rejuvenation stages; (b) Our research has identified common, and potentially generalizable, patterns of disruptive innovative processes in the context of industrial clusters. The observed patterns are referred not only to the determinants but also to the consequences of these innovative processes. The determination of the role played by key agents such as visionary agents, technological gatekeepers, external agents or specialized companies contributes to the innovation literature in clusters that identifies the roles played by different actors in these processes; (c) At clustered firm level, our results suggest that not all internal skills related to absorptive capacity contribute in the same proportion to favour the early adoption of a disruptive technology. Indeed, our research reveals how exploitation capacity has a significant positive influence whereas the development of exploration capacity doesn't have a significant impact when it comes to early adoption of a disruptive innovation; (d) Finally, our research contributes to the innovation literature, in particular, to literature regarding the identification of determinants of innovation. We have identified different combinations of internal attributes leading to be a highly innovative firm. Among these recipes of attributes, our study demonstrates that being early adopter of a disruptive technology (in combination with the fact of having skills related to exploration and exploitation of external knowledge) is an important and sufficient condition to be a strong innovator in a cluster context. 
In conclusion, notwithstanding limitations and restrictions, the results obtained in this research can be considered as relevant because, in our opinion, we make a relevant contribution to various opened lines of research. We think that this work represents a step forward towards the better understanding of the innovative disruptive processes in a cluster context as we have observed the positive effect that these innovative processes may produce in clusters by opening new stages of development. Finally, we think that the results obtained may lead to interesting implications for the design of policies and strategic lines not only at an institutional level (for instance for those government agencies in charge of designing and managing public policies for territorial revitalization) but also at a firm level. 


\section{ÍNDICE GENERAL:}

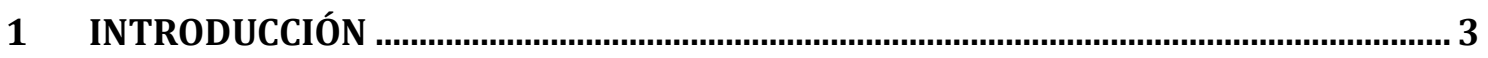

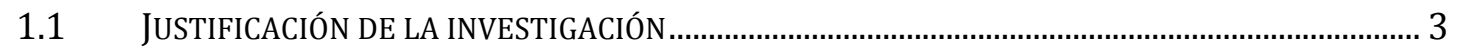

1.2 OBJETIVOS DE LA INVESTIGACIÓN...................................................................................... 9

1.3 CONTRIBUCIONES POTENCIALES DE LA INVESTIGACIÓN …………………………...................12

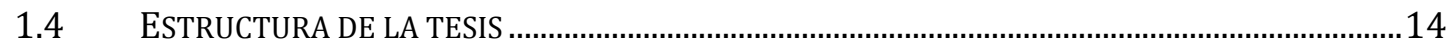

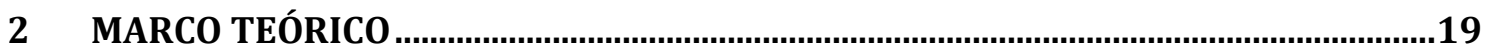

2.1 LAS AGLOMERACIONES TERRITORIALES DE EMPRESAS.......................................................19

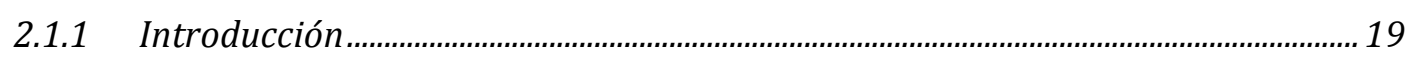

2.1.2 Origen del concepto y evolución en su estudio .............................................................21

2.1.3 Los tipos de aglomeraciones territoriales de empresas..............................................25

2.1.4 Los distritos industriales y los clústeres .......................................................................29

2.1.5 Los componentes de las aglomeraciones territoriales ................................................ 38

2.1.6 Las ventajas de los distritos y clústeres industriales y su presencia en la economía mundial.

2.1.7 Las principales amenazas de los clústeres industriales. La resiliencia como

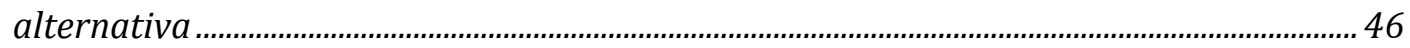

2.2 LA INNOVACIÓN Y LAS INNOVACIONES DISRUPTIVAS...........................................................5

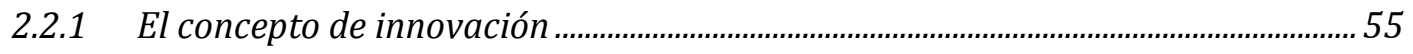

2.2.2 Clasificaciones según el objeto de la innovación........................................................... 62

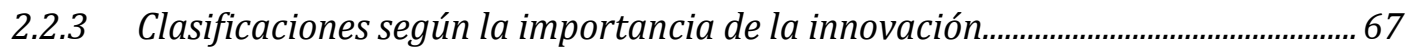

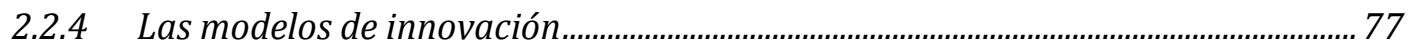

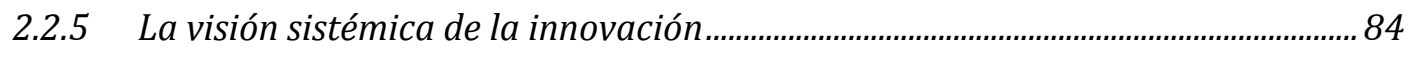

2.2.6 Las innovaciones disruptivas.................................................................................... 96

2.3 LOS FACTORES INTERNOS DE LA INNOVACIÓN. LA CAPACIDAD DE ABSORCIÓN......................111

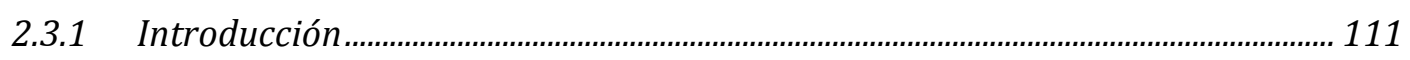

2.3.2 La innovación desde la perspectiva de la Teoría de los Recursos y las

Capacidades ..................................................................................................................................... 112

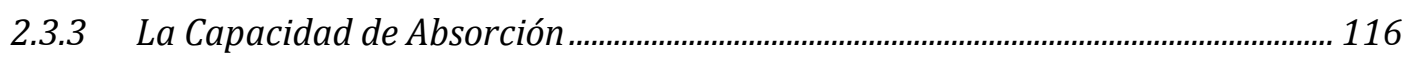

\section{CARACTERIZACIÓN DEL OBJETO PRINCIPAL DE ESTUDIO: EL CLÚSTER}

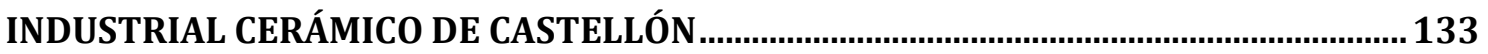

3.1 DESCRIPCIÓN GENERAL DE LA INDUSTRIA CERÁMICA MUNDIAL …………………...............134

3.1.1 Caracterización de la industria desde la perspectiva de la producción............... 134

3.1.2 Caracterización de la industria desde la perspectiva del consumo....................... 138 
3.1.3 Caracterización de la industria desde la perspectiva de las exportaciones y las

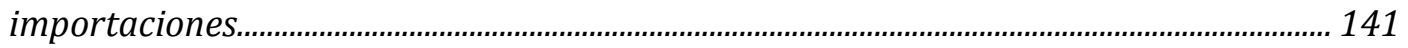

3.2 DESCRIPCIÓN DE LA INDUSTRIA CERÁMICA EN CASTELLÓN..................................................... 146

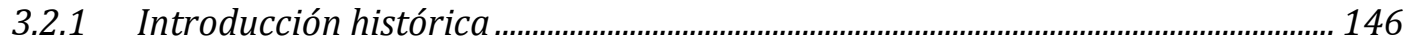

3.2.2 La industria cerámica castellonense en la actualidad ........................................... 149

3.3 PRINCIPALES ACTORES DEL CLÚSTER INDUSTRIAL CERÁMICO DE CASTELLÓN......................152

3.3.1 Los distintos entornos presentes en el clúster cerámico de Castellón.................. 152

3.3.2 El entorno productivo ...................................................................................................... 153

3.3.3 El entorno tecnológico y de servicios avanzados ..................................................... 155

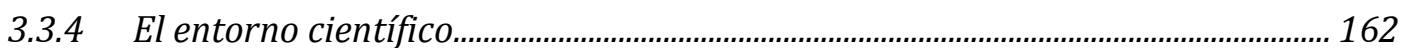

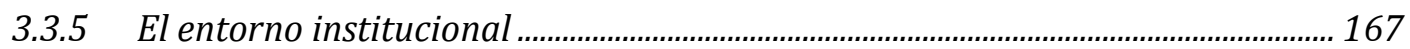

3.4 LA IMPRESIÓN DIGITAL CERÁMICA COMO INNOVACIÓN TECNOLÓGICA DISRUPTIVA DESARROLLADA EN EL CLÚSTER CERÁMICO DE CASTELLÓN .................................................................. 180

4 DISEÑO DE LA INVESTIGACIÓN EMPÍRICA Y LA METODOLOGÍA UTILIZADA... 187

4.1 ESTRUCTURA DE TRABAJO EMPÍRICO ……………………………………………..............187

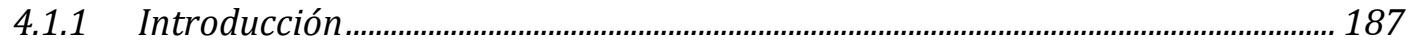

4.1.2 Fases de la investigación: fase descriptiva-cualitativa y fase cuantitativa....... 188

4.2 FUENTES DE INFORMACIÓN Y RECOLECCIÓN DE DATOS........................................................193

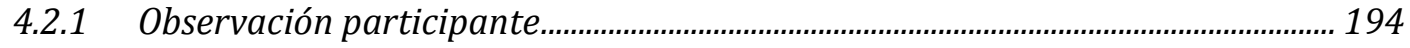

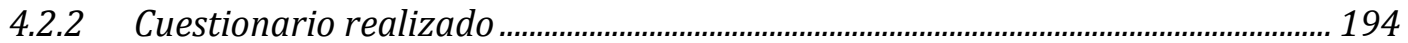

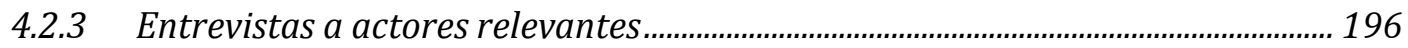

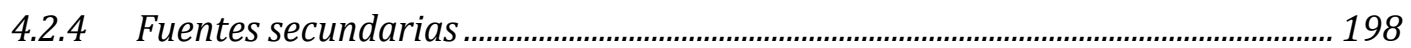

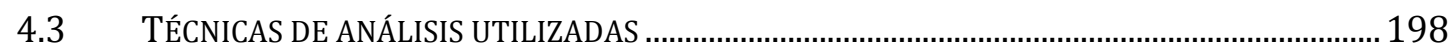

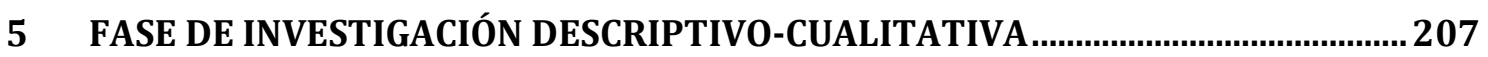

5.1 EMPIRICAL STUDY I: DETERMINANTS AND IMPACT OF DISRUPTIVE TECHNOLOGICAL INNOVATIONS IN INDUSTRIAL CLUSTERS. THE CASE OF THE DIGITAL PRINTING DISRUPTIVE INNOVATION IN THE SPANISH CERAMIC TILE CLUSTER ………........................................................... 208

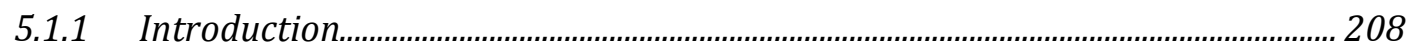

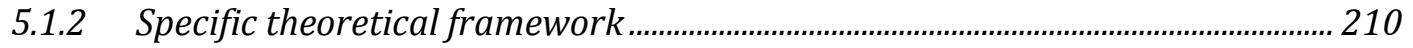

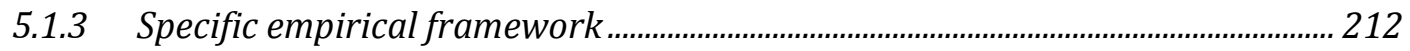

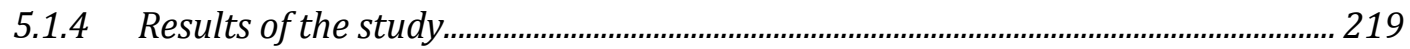

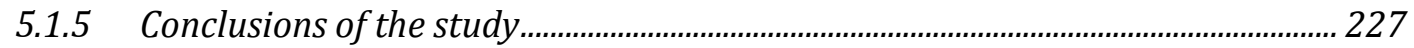

5.2 EMPIRICAL STUDY II: DETERMINANTS AND IMPACT OF DISRUPTIVE TECHNOLOGICAL INNOVATIONS IN INDUSTRIAL CLUSTERS. INSIGHTS FROM A COMPARATIVE CASE STUDY ...................230

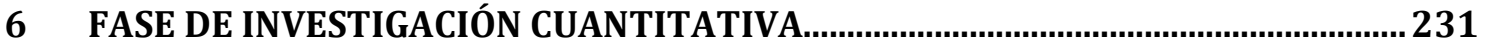


6.1 EMPIRICAL STUDY III: EARLY ADOPTION OF A DISRUPTIVE TECHNOLOGICAL INNOVATION BY CLUSTERED FIRMS. THE ROLE OF THE ABSORPTIVE CAPACITY ……………….................................... 232

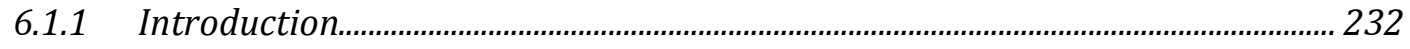

6.1.2 Specific theoretical framework and hypotheses..................................................... 235

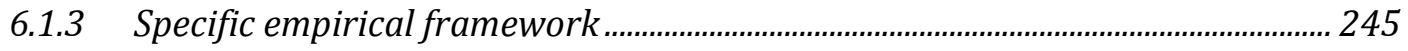

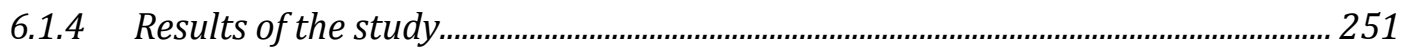

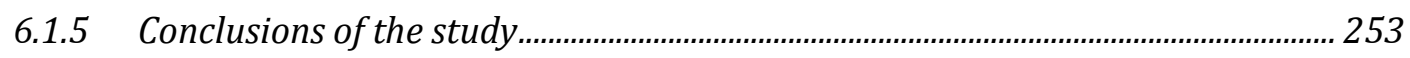

6.2 EMPIRICAL STUDY IV: EARLY ADOPTION OF A DISRUPTIVE TECHNOLOGICAL INNOVATION BY CLUSTERED FIRMS. ITS PARTICIPATION ON DIFFERENT PATHS TO HIGH INNOVATION PERFORMANCE. 257

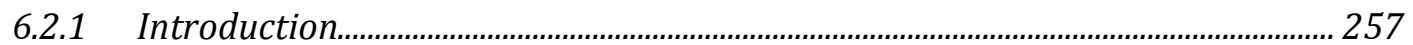

6.2.2 Specific theoretical framework and propositions................................................... 259

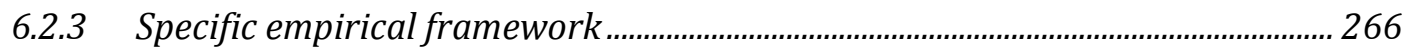

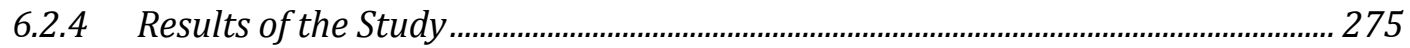

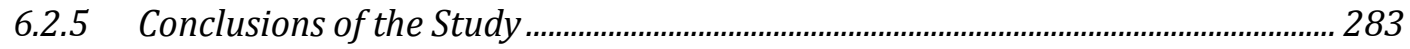

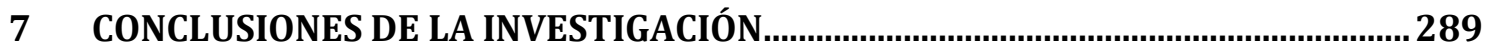

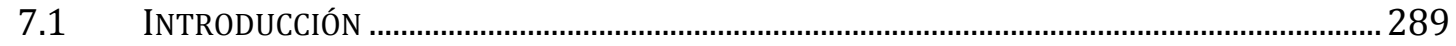

7.2 PRINCIPALES CONCLUSIONES DE LOS ESTUDIOS EMPÍRICOS ................................................290

7.2.1 Las conclusiones del primer estudio empírico.............................................................. 290

7.2.2 Las conclusiones del segundo trabajo empírico ……................................................ 292

7.2.3 Las conclusiones del tercer trabajo empírico ........................................................... 294

7.2.4 Las conclusiones del cuarto trabajo empírico............................................................. 296

7.3 LAS IMPLICACIONES DE LOS RESULTADOS DE LA INVESTIGACIÓN ............................................297

$7.4 \quad$ LIMITACIONES Y FUTURAS LÍNEAS DE INVESTIGACIÓN …………………………………….... 301

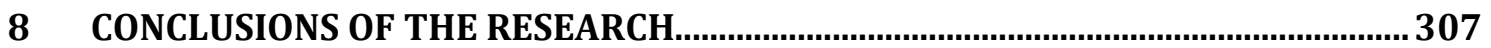

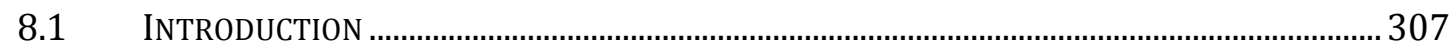

$8.2 \quad$ MAIN CONCLUSIONS OF THE EMPIRICAL STUDIES .................................................................. 308

8.2.1 The conclusions of the first empirical study ............................................................ 308

8.2.2 The conclusions of the second empirical study …..................................................... 310

8.2.3 The conclusions of the third empirical study ............................................................. 311

8.2.4 The conclusions of the fourth empirical study........................................................... 313

8.3 THE IMPLICATIONS OF THE RESULTS OF THE RESEARCH ....................................................... 314

$8.4 \quad$ LIMITATIONS AND FUTURE RESEARCH LINES ……................................................................ 317

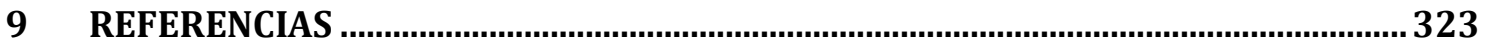

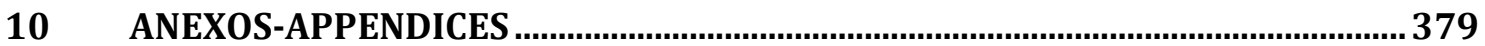




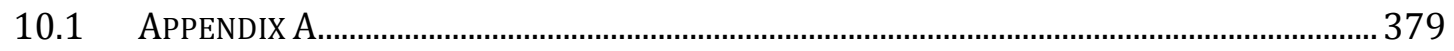

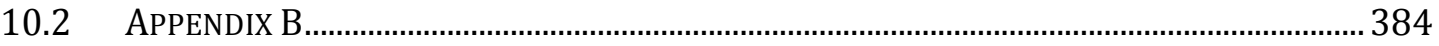




\section{ÍNDICE DE TABLAS:}

Tabla 1: Distintas perspectivas abordadas en relación con las aglomeraciones territoriales a lo largo de las últimas décadas ...................................................... 24

Tabla 2: Tipos de empresas que integran el clúster cerámico español ........................... 39

Tabla 3: Estudios empíricos dedicados a la identificación de ventajas en los clústeres o

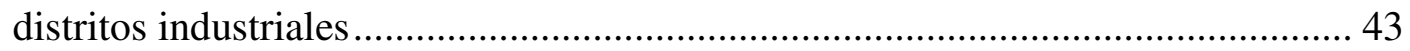

Tabla 4: Principales líneas de definición e interpretación de la resiliencia...................... 51

Tabla 5: Características de la resiliencia de un sistema................................................... 53

Tabla 6: Relación de definiciones de Innovación encontradas en la literatura desde 1966

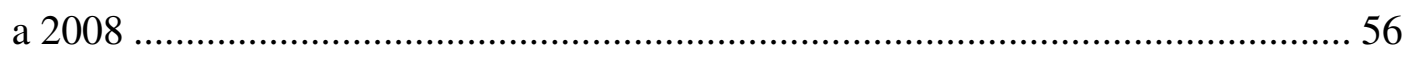

Tabla 7: Principales aspectos considerados como innovación por Schumpeter (1934) . 58

Tabla 8: Distintas definiciones de innovación................................................................. 59

Tabla 9: Clasificación de la innovación según Edquist et al. (2001) .............................. 63

Tabla 10: Fuentes de discontinuidad y sus consecuencias .......................................... 70

Tabla 11: Distintos aspectos de las innovaciones radicales y disruptivas ...................... 72

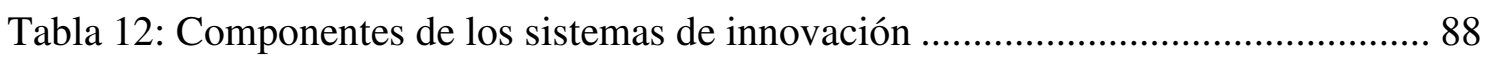

Tabla 13: Fuentes para la transferencia de conocimiento y tecnología.......................... 90

Tabla 14: Cooperación en innovación de las empresas EIN según tipo de agente ........ 91

Tabla 15: Diferentes fenómenos innovadores disruptivos ........................................... 98

Tabla 16: Descripción de los tres artículos seminales de la teoría disruptiva ............... 100

Tabla 17: Algunos estudios dedicados al análisis de fenómenos disruptivos ............... 103

Tabla 18: Estudios relacionados con los factores de asimilación de las innovaciones disruptivas bajo una perspectiva de la industria 108

Tabla 19: Estudios relacionados factores de asimilación de las innovaciones disruptivas bajo una perspectiva de las características de la empresa 109

Tabla 20: Estudios relacionados con los factores de asimilación de las innovaciones disruptivas bajo una perspectiva del fenómeno innovador................................. 110

Tabla 21: Rutinas para la adquisición de conocimiento ............................................. 121

Tabla 22: Temáticas analizadas con relación a la capacidad de absorción con la empresa como unidad de análisis. 126 
Tabla 23: Distribución de la producción mundial de pavimentos y revestimientos en 2016 por área geográfica.

Tabla 24: Producción mundial de pavimentos y revestimientos cerámicos en el periodo (2012-2016) en Mill. $\mathrm{m}^{2}$

Tabla 25: Distribución del consumo mundial de pavimentos y revestimientos en 2016 por área geográfica en Mill. $\mathrm{m}^{2}$

Tabla 26: Consumo mundial de pavimentos y revestimientos cerámicos en el periodo (2012-2016) en Mill. $\mathrm{m}^{2}$ 140

Tabla 27: Exportación mundial de pavimentos y revestimientos por áreas geográficas en 2016 en Mill. $\mathrm{m}^{2}$

Tabla 28: Exportación de pavimentos y revestimientos cerámicos por países en el periodo (2013-2016) en Mill. $\mathrm{m}^{2}$.

Tabla 29: Importación de pavimentos y revestimientos cerámicos por países en el periodo (2013-2016) en Mill. $\mathrm{m}^{2}$.

Tabla 30: Evolución de la cifra de negocio de la industria cerámica española en el periodo (2012-2017) en Mill. $\mathrm{m}^{2}$.

Tabla 31: Evolución de las ventas totales de pavimentos y revestimientos cerámicos en el periodo (2013-2017) en Mill. €

Tabla 32: Principales cifras de negocio de los fabricantes de fritas, esmaltes y colores cerámicos en 2017 159

Tabla 33: Principales actividades de la asociación ASCER. 169

Tabla 34: Principales actividades de la asociación ANFFECC. 171

Tabla 35: Principales líneas de actuación de la Cámara de Comercio de Castellón .... 178

Tabla 36: Descripción de las fases de investigación ..... 188

Tabla 37: Esquema general de la estructura del trabajo empírico correspondiente a la presente tesis. 192

Tabla 38: Identificación de las fuentes de datos utilizadas en cada uno de los estudios empíricos realizados

Tabla 39: Número de empresas integrantes del clúster de Castellón en el momento de la realización de la investigación según datos de las tres principales asociaciones empresariales

Tabla 40: Perfil de los entrevistados 196

Tabla 41: Perfil de las principales empresas y respondientes para la realización de la presente investigación. 197 
Tabla 42: Evolution of sales of ceramic tiles manufacturers and frits, enamels and

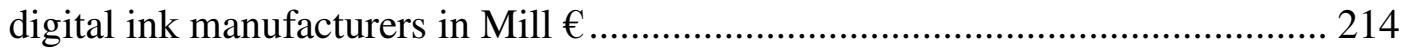

Tabla 43: Evolution of decorative lines conversion rate to digital technology. Number of digital printers installed over the last five years .............................................. 222

Tabla 50: Profiles of the actors comprising the Spanish ceramic tile cluster............... 246

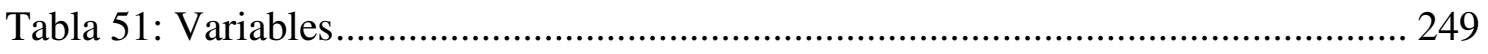

Tabla 52: Descriptive statistics of the dependent variable ......................................... 250

Tabla 53: Descriptive statistics of the control and independent variables ....................2250

Tabla 54: The observed and predicted frequencies for Early Adoption in the Logistic

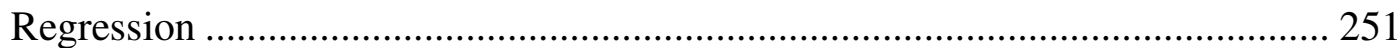

Tabla 55: General significance of the Binomial Logistic Regression (LOGIT) .......... 251

Tabla 56: Binomial Logistic Regression results (LOGIT) ......................................... 252

Tabla 57: Outcome scope, variables and associated conditions .................................. 272

Tabla 58: Outcome and conditions: description and codifications ............................ 273

Tabla 59: Descriptive statistics and calibration points ................................................... 274

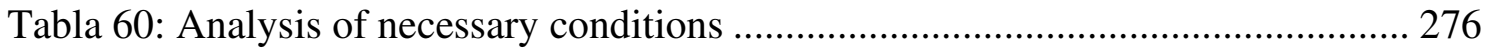

Tabla 61: Results of the intermediate solution ............................................................. 282 


\section{ÍNDICE DE FIGURAS:}

Figura 1: Distintos niveles de análisis económico...................................................... 21

Figura 2: Mapa de los distritos industriales en España en 2001 ................................... 45

Figura 3: Mapa de los distritos industriales en España en 2011 ................................... 46

Figura 4: Resiliencia económica regional como proceso ........................................... 52

Figura 5: Espacio innovador basado en sus dos dimensiones ..................................... 74

Figura 6: Los cuatro tipos de innovación en función de la transilencia comercial y la

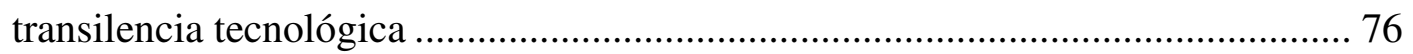

Figura 7: Modelo de empuje de la tecnología ............................................................ 78

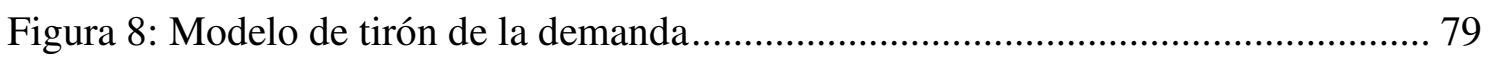

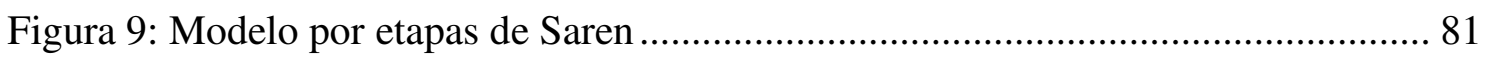

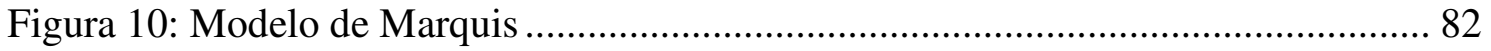

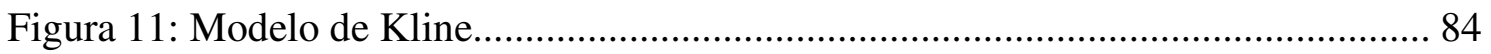

Figura 12: Clasificación de los recursos de una empresa........................................... 115

Figura 13: Modelo de la capacidad de absorción ............................................................ 119

Figura 14: Mapa temático de la investigación de la capacidad de absorción............... 127

Figura 15: Modelo de Zahra y George de Capacidad de absorción .............................. 130

Figura 16: Evolución de la producción mundial de pavimentos y revestimientos cerámicos en el periodo (2000-2016)

Figura 17: Evolución de la producción de los seis principales países productores de pavimentos y revestimientos cerámicos en el periodo (2000-2016) 138

Figura 18: Relación entre el peso del comercio internacional y el doméstico en 2016141

Figura 19: Evolución de la producción cerámica del sector español desde el año 2000

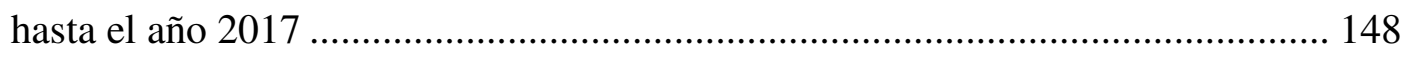

Figura 20: Evolución histórica de la Industria Cerámica de Castellón ......................... 149

Figura 21: Ubicación del clúster cerámico de Castellón ............................................... 150

Figura 22: Los actores del clúster cerámico de Castellón agrupados por entornos....... 153

Figura 23: Esquema general del proceso de fabricación de productos cerámicos ........ 154

Figura 24: Evolución de las ventas nacional / exportación de los fabricantes de fritas, esmaltes y colores cerámicos en el periodo (1995-2017) en Mill. m²................ 158

Figura 25: Cabezal de impresión de la marca Xaar que integra la impresora digital cerámica 180 
Figura 26: Modelo 1400 de la impresora digital cerámica de la marca Kerajet. 181

Figura 27: Máquina rotocolor de la marca System para la impresión tradicional de azulejos

Figura 28: Descripción esquemática del proceso de fabricación cerámica 183

Figura 29: Número de publicaciones en las que se utiliza el estudio del caso en el ámbito del estudio del clúster 200

Figura 30: Número de publicaciones en las que se utiliza la regresión logística binomial en el ámbito de las ciencias sociales. 201

Figura 31: Número de publicaciones en las que se utiliza la regresión logística binomial en el ámbito de las ciencias sociales. 204

Figura 32: Consolidated sales of ceramic tiles manufacturers and frits, enamels and digital ink manufacturers 215

Figura 33: Ceramic tile manufacturing process 216

Figura 34: Conversion rate of decorative lines to digital in 2015. Level of digital printing penetration by country 226

Figura 36: Analytical framework of the study 244 
CAPÍTULO 1 INTRODUCCIÓN 


\section{INTRODUCCIÓN1}

La presente tesis doctoral ha sido diseñada a partir de una serie de consideraciones generales previas. En primer lugar, hemos decidido situar nuestro estudio en un marco conceptual relevante en el ámbito de la administración y dirección de empresas intentando profundizar así, en el análisis de determinados fenómenos de innovación empresarial y mejorar nuestra comprensión de los mismos. En segundo lugar, pretendíamos obtener unas conclusiones relevantes y novedosas que, a nuestro juicio, podrían suponer una contribución en el estudio de las dinámicas empresariales. Finalmente, siendo conscientes del marco institucional al que pertenecemos (el grupo de investigación AERT adscrito al departamento de Administración y Dirección de Empresas de la Universitat Jaume I), hemos pretendido priorizar aquellos temas y cuestiones de investigación que fueran particularmente relevantes para esta institución, así como para su entorno socioeconómico.

\subsection{Justificación de la investigación}

Esta investigación tiene como objeto de estudio las aglomeraciones territoriales de empresas. La justificación de la elección de este tema se basa en el hecho de que esta forma de organización territorial de empresas, por un lado, ha adquirido una

\footnotetext{
${ }^{1}$ Con el objetivo de cumplir los requisitos para la obtención del doctorado con mención internacional, hemos realizado parte de este tesis en inglés. En concreto, presentamos en este idioma el resumen, los cuatro estudios empíricos de los que se compone y las conclusiones.
} 
importancia creciente en el ámbito de los estudios económicos y empresariales y, por otro, es particularmente relevante para nuestro entorno cercano. Además, desde un punto de vista académico, existen todavía una serie de gaps o vacíos en la investigación que, en nuestra opinión, están aún pendientes ser convenientemente cubiertos.

En los últimos años las aglomeraciones territoriales de empresas han captado el interés no sólo de la comunidad académica (desde diversas disciplinas tales como las económicas, empresariales o geográficas) sino también de los ámbitos políticos y sociales. De hecho, en la actualidad, el fomento de aglomeraciones territoriales de empresas forma parte de la mayoría de las políticas públicas relacionadas con el desarrollo económico y abarca el nivel local, regional, nacional y transnacional.

Este creciente interés es debido a la actualidad, utilidad e importancia de esta forma de organización territorial de las empresas. Las empresas, hoy en día, siguen organizándose en forma de aglomeraciones territoriales puesto que les proporciona una serie de ventajas que les permite mejorar sus resultados a través de las denominadas economías externas (Marshall, 1920; Storper, 1992, 1997; Storper \& Harrison, 1991). Estas ventajas han sido ampliamente justificadas por estudios de disciplinas tan diversas como la Geografía (Krugman, 1991), la Política Económica (Mistri, 1999; M Piore \& Sabel, 1984), la Sociología (Lazerson, 1995; AnnaLee Saxenian, 1996) o la Administración de Empresas (Bell, Tracey, \& Heide, 2009; Enright, 1995, 2003; Maskell, 2001; Porter, 1990). El fenómeno de la aglomeración territorial es además, en palabras de Porter, sorprendentemente común a nivel mundial (Porter, 1990:120). De hecho, son muchos los estudios llevados a cabo en países tan diversos como Japón (por ejemplo los estudios de Friedman (1988) o Yamawaki (2002)), Estados Unidos (como por ejemplo, Buenstorf \& Klepper (2009), Klepper (2010) o Saxenian (1991)) o China (por ejemplo, Sonobe, Hu, \& Otsuka (2002)). También en nuestro entorno más cercano, el ámbito europeo, las aglomeraciones territoriales han sido ampliamente estudiadas; en Italia, entre otros muchos, podemos citar a autores como Becattini (1990), Bellandi (1986) o Sforzi (1989); en España, podemos poner como ejemplo a investigadores como Molina-Morales \& Martínez-Fernández (2009) o Ybarra (1991).

Resulta interesante destacar que esta configuración interempresarial no es exclusiva de unos sectores específicos sino que podemos encontrarla tanto sectores tradicionales -o 
considerados de un nivel tecnológico medio-bajo- como en sectores intensivos en conocimiento (como ejemplo de ambos casos podemos destacar los estudios de BelsoMartínez (2006); Aydalot \& Keeble (1988); Belussi (1993); Dalum, Pedersen, \& Villumsen (2005) o Staber (2001; 2011)).

En el entorno de la economía valenciana en el que nuestro grupo de investigación y la Universitat Jaume I se enmarcan, este fenómeno empresarial se encuentra muy arraigado. De hecho, en esta comunidad, se han identificado 54 clústeres o distritos industriales $^{2}$ de los 237 identificados en el conjunto del estado español (Boix \& Galletto, 2006).

Más concretamente esta tesis se ha centrado en uno de los clústeres industriales más importantes a nivel nacional: el clúster cerámico de Castellón. Abarcando un área de unos $20 \mathrm{Km}^{2}$ dentro de los límites de las comarcas de 1'Alcalatén, La Plana Alta y La Plana Baixa (Tomás \& Monzon, 1998), este clúster es la principal fuente de riqueza para estas comarcas y que genera una gran cantidad de puestos de trabajos (tanto directos como indirectos). Como consecuencia de esta importancia económica y social que para la provincia de Castellón tiene el clúster cerámico, así como por la accesibilidad a la información necesaria para realizar una investigación hemos establecido este contexto como el marco principal de nuestro análisis. Este clúster ha recibido anteriormente una gran atención por parte de un número importante de investigadores, no sólo adscritos a la Universitat Jaume I sino también a otras instituciones universitarias. Como ejemplo, podemos destacar las investigaciones llevadas a cabo por Albors (2002); Hervás-Oliver \& Albors-Garrigos (2008); MolinaMorales (2002, 2005); Russo (2004).

\footnotetext{
${ }^{2}$ A una aglomeración de empresas localizada en un área geográfica perfectamente delimitada se le suele catalogar de forma genérica como clúster o distrito industrial. A pesar de que pueden haber ciertas diferencias concretas entre ambos términos, estos pueden ser utilizados de forma indistinta si se estudian de un modo amplio y genérico desde la perspectiva de los modelos de organización empresarial (P. McCann \& Gordon, 2000). En la presente tesis vamos a seguir esta recomendación de uso indistinto puesto que adoptamos una perspectiva genérica. Sin embargo, nos decantaremos por la expresión de origen anglosajón clúster.
} 
En conclusión, justificamos nuestro estudio en base a la importancia del clúster como modelo de organización territorial. No obstante, a pesar de esta importancia, su investigación presenta una serie de gaps o vacíos en la investigación que la presente tesis pretende cubrir y que pasamos a describir a continuación.

En la actualidad, este modelo organizativo se encuentra sometido a una serie de presiones y retos debido a una serie de fenómenos como son los flujos migratorios, los cambios tecnológicos, el desarrollo de las cadenas globales de valor o la maduración de sus ciclos de vida. No obstante, de entre todos estos retos planteados, posiblemente la globalización sea el más relevante. La globalización -como fenómeno que altera la competencia y el acceso no sólo a los mercados sino también al conocimiento a nivel global- está forzando a los clústeres a modificar su propia estructura interna y a alterar sus límites tradicionales; unos límites que no son exclusivamente geográficos sino también cognitivos, organizacionales e institucionales. Esta situación plantea el dilema de cómo este modelo de organización territorial va a cambiar en un futuro cercano y de qué forma puede adaptarse a los retos actuales. Existe en la literatura una corriente importante que, de una forma $\mathrm{u}$ otra, defiende la necesidad de desarrollar nuevos vínculos más globales con nuevos actores. Como ejemplo podemos citar a autores como De Marchi, Gereffi, \& Grandinetti (2018) que abogan por una apertura internacional a través de la integración en cadenas globales de producción, Zucchella (2006) que plantea el desarrollo de arraigo múltiple en los clústeres maduros para evitar su desaparición o Todtling \& Trippl (2004), que identifican como factores clave de renovación del clúster el desarrollo de un sistema regional de innovación y el establecimiento de nuevas redes de innovación.

Por otro lado, existe también un amplio consenso en la literatura en otorgar a la innovación un papel muy importante en los procesos de mejora y regeneración de las oportunidades de las empresas y, también, de los clústeres. La innovación, en definitiva, se considera una de las formas a través de las cuales el clúster puede enfrentar los retos a los que se encuentran sometidos. Diversos autores han argumentado que la habilidad para innovar es uno de los factores clave para la creación de valor en las empresas; de hecho, la medida de la innovación es considerada por una gran cantidad de autores como uno de los mejores indicadores de valor de las mismas (por ejemplo: Anderson, De Dreu, \& Nijstad (2004); Ghoshal \& Bartlett (1990); Hitt, Ireland, \& Hoskisson (2012) o Teece (1998)). 
En un contexto de clúster, podemos encontrar numerosos estudios centrados en la innovación y su impacto positivo en los resultados de estas aglomeraciones de empresas. A este respecto, podemos citar los trabajos de autores como Asheim \& Coenen (2005); Baptista (2000); Cooke (2001); Dandi, Sammarra, Muzzi, \& Biggiero (2006); Giuliani \& Bell (2005); Mattsson (2009); Molina-morales \& Mas-Verdú (2010); Mytelka \& Farinelli (2000); Tomás-Miquel, Molina-Morales, \& Expósito-Langa (2015) o Ughetto (2009). La mayor parte de estos estudios han puesto de manifiesto como la innovación se relaciona con un proceso incremental que se encuentra enfocado a la reducción de costes y la mejora de la productividad. Como ejemplo, podemos destacar los trabajos de desarrollados por Bellandi (1996); Elche-Hortelano, Martínez-Pérez, \& García-Villaverde (2015) o Molina-Morales (2002). Las dinámicas propias de los clústeres tales como la predominancia de relaciones densas e intensas, el flujo de un conocimiento tácito o la dificultad de acceso a conocimiento realmente novedoso, favorecen este tipo de procesos incrementales. Las innovaciones incrementales se suelen generar, por tanto, a partir de un conocimiento que se va agregando de forma gradual y se centran en la extensión menor de las propiedades de los productos existentes o a mejoras relativamente lógicas de los productos o procesos ya realizados.

Este hecho supone, en cierto modo, una limitación puesto que dificulta la generación de las innovaciones de tipo radical o disruptivo ${ }^{3}$ las cuales son capaces de generar un valor mucho mayor, modificando normalmente las reglas del juego de las industrias o contextos donde éstas se generan (Leifer et al., 2000). Las innovaciones disruptivas son capaces de reconfigurar las industrias y son cruciales para la evolución de las empresas

\footnotetext{
${ }^{3}$ Somos conscientes de que existe una cierta discrepancia con relación al uso de los términos radical y disruptivo. En cualquier caso, podemos considerar que estos conceptos no se refieren a pequeñas mejoras o cambios menores en los productos o tecnologías actuales; por el contrario, se refieren a la sustitución de productos o tecnologías existentes por otros nuevos y radicalmente distintos. En esta tesis seguimos el enfoque realizado por Markides (2006) quien ha distinguido entre innovación radical para productos e innovación disruptiva para tecnologías. Por tanto, en esta tesis utilizaremos el término innovaciones disruptivas por estar analizando un fenómeno de introducción tecnológica. En el apartado teórico dedicado a estas innovaciones se detalla con mayor profundidad la clasificación propuesta por Markides (2006).
} 
y el crecimiento económico (Abernathy \& Clark, 1985; Tellis, Prabhu, \& Chandy, 2009; Tushman \& Anderson, 1986).

La presente tesis se centra en el estudio de este tipo de innovaciones disruptivas tan valiosas como difíciles de llevar a cabo en el contexto del clúster. De hecho, éste sería el objeto de estudio específico de nuestra investigación. La innovación disruptiva es aquella que irrumpe y redefine las trayectorias de los productos, procesos o servicios. Este tipo de innovaciones generan nuevas categorías en los mercados en los que se introducen, rompiendo el statu quo y abriendo una gran número de oportunidades para las empresas que las desarrollan (Adner, 2002; Bower \& Christensen, 1995; Christensen, 1997; Christensen \& Raynor, 2003; Danneels, 2004; Markides, 2006). Las innovaciones radicales son consideradas como fenómenos que fundamentan subsiguientes avances tecnológicos (Datta \& Jessup, 2013).

La literatura empresarial ha tratado ampliamente los fenómenos de generación y difusión de las innovaciones radicales o disruptivas, así como sus efectos y factores inhibidores (podemos destacar, por ejemplo, los trabajos de Assink (2006); Bergek, Berggren, Magnusson, \& Hobday (2013); Nagy, Schuessler, \& Dubinsky (2016); Wan, Williamson, \& Yin (2015) o Weeks (2015)). Sin embargo, bajo nuestro punto de vista, este mismo análisis no se ha realizado con el mismo nivel de profundidad en el ámbito de las aglomeraciones territoriales. El estudio de la generación, difusión e impacto de este tipo de fenómenos disruptivos en un contexto de clúster industrial ha sido pocas veces analizado pudiendo destacar los estudios llevados a cabo por autores como Hervás-Oliver \& Albors-Garrigos (2014); Hervás-Oliver, Albors-Garrigos, EstellesMiguel, \& Boronat-Moll (2017); Østergaard \& Park (2013, 2015) o Reig-Otero, Edwards-Schachter, Feliú-Mingarro, \& Fernández-de-Lucio (2014). En nuestra opinión, existe un vacío en la investigación o gap en este punto ya que no se corresponde la importancia de este tipo de fenómenos con la escasa atención que se le ha prestado en la literatura centrada en el estudio de clústeres. Consideramos que la generación y difusión de innovaciones disruptivas en los clústeres industriales puede ser una forma importante de enfrentar los cambios que hechos como la globalización o los cambios tecnológicos están realizando en estos aglomerados territoriales. 
En concreto, en este trabajo hemos pretendido analizar los determinantes de la generación, desarrollo y difusión de las innovaciones disruptivas en el seno de los clústeres industriales y su impacto a nivel de las empresas que los forman y a nivel de clúster como entidad o sistema.

\subsection{Objetivos de la investigación}

El propósito general de nuestra investigación consiste en el análisis de los clústeres en relación con la generación, difusión e impacto de las innovaciones tecnológicas disruptivas. Hemos investigado, en definitiva, cómo los clústeres industriales responden, se transforman y evolucionan a través de la introducción de este tipo innovaciones.

Con este propósito u objetivo general, en primer lugar, nos centramos en analizar la capacidad de los clústeres para generar, desarrollar y difundir innovaciones disruptivas, y el impacto que éstas producen sobre los mismos. En un segundo lugar, hemos analizado cuáles son los determinantes que explican la adopción de este tipo de innovaciones por parte de las empresas que conforman los clústeres, así como la influencia sobre su propia capacidad innovadora.

Para alcanzar estos objetivos nos hemos centrado en el clúster industrial cerámico de Castellón, el cual ha experimentado un proceso de desarrollo y difusión de una innovación tecnológica disruptiva en la primera década de este siglo. Nos referimos a la introducción de la impresión digital de azulejos como alternativa a la impresión tradicional. Esta innovación impactó de manera muy importante en la cadena de valor de la industria cerámica puesto que supuso el primer paso hacia una digitalización de la línea de fabricación de los pavimentos cerámicos. La elección de este caso viene justificada principalmente por dos motivos: la proximidad a nuestra Universidad, y el conocimiento y vinculación que nuestro grupo de investigación tiene del mismo.

El desarrollo de nuestro trabajo empírico se ha fundamentado principalmente en el estudio de una muestra representativa de empresas pertenecientes a este clúster 
cerámico. También hemos accedido a otras fuentes de datos primarias y secundarias que han venido a complementar la información requerida en la investigación.

Con el fin de abordar el objetivo anteriormente planteado, hemos establecido cuatro objetivos específicos que, a su vez, se corresponden con los cuatro estudios empíricos que componen esta tesis. Pasamos a detallar, a continuación, estos cuatro objetivos específicos.

El primer objetivo específico surge de la constatación de que en el clúster de Castellón se había producido un fenómeno de innovación disruptiva. Este hecho es considerado como muy relevante ya que los clústeres son especialmente poco susceptibles a cambios externos y radicales (Glasmeier, 1991; Harrison, 1994). La literatura explica este hecho principalmente, a la falta de capacidades de exploración, así como a la prevalencia de vínculos fuertes y estructuras relacionales cerradas. Siendo, en consecuencia, conscientes de la importancia del caso y de su importante impacto, hemos planteado en primer lugar el estudio en profundidad del fenómeno en cuestión. Hemos analizado, por tanto, cómo se ha generado la innovación, qué actores han intervenido y qué factores han favorecido su difusión dentro del clúster. Además, hemos evaluado el impacto que este fenómeno ha tenido, no sólo sobre las empresas sino también sobre el conjunto del clúster.

El segundo objetivo surge de la necesidad de comprobar si el caso de Castellón estudiado se trataba de un caso aislado o si, por el contrario, las dinámicas innovadoras identificadas y las consecuencias analizadas podían ser observadas en otros casos. En consecuencia, planteamos como segundo objetivo el análisis comparativo con otro clúster que también ha experimentado un fenómeno similar de innovación disruptiva. Más concretamente nos referimos al clúster industrial de calzado deportivo situado en Montebelluna, Italia; este clúster experimentó una evolución de producto, más concretamente las botas de esquí de cuero y cordones fueron sustituidas por botas de esquí de plástico rígido y fijaciones. Esto fue posible gracias a un proceso innovador disruptivo centrado en el uso de nuevos materiales y la utilización de una tecnología de fabricación complemente distintos a los tradicionales. El resultado fue un aumento en la producción de botas de esquí más de 20 veces en 5 años (Codara \& Morato, 2002). En este punto, cabe destacar que si bien el caso italiano plantea ciertas diferencias con 
respecto al español (como puede ser el hecho de que el primero data de los años 60-70 del siglo XX, mientras que el segundo se produjo a principios de la década de los años 2000; o también el distinto momento en relación a la etapa de ciclo de vida en la que ambos clústeres se encontraban), éstas no han sido consideradas lo suficientemente importantes como para invalidar las posibles conclusiones que se pudieran inferir de la rigurosa comparación de los dos procesos innovadores.

A través de este estudio comparativo, pretendíamos, por un lado, conocer si es posible obtener unos patrones comunes de generación, desarrollo y difusión de innovaciones disruptivas aplicables de forma genérica. Por otro lado, nos interesaba determinar en qué grado este modelo de innovación disruptiva es generalizable a otros casos. Este segundo punto lo planteamos a través del uso del concepto de resiliencia que se define como la capacidad de adaptación y respuesta a cambios bruscos externos. Un gran número de autores han aportado evidencia de como el desarrollo de la resiliencia es una alternativa al declive de los clústeres (Elola, Parrilli, \& Rabellotti, 2013; Østergaard \& Park, 2013). Es por ello por lo que consideramos relevante analizar en qué medida los clústeres son capaces de desarrollar resiliencia a través de las innovaciones tecnológicas disruptivas.

El tercer y cuarto objetivo analizan los determinantes y las consecuencias de las innovaciones disruptivas a nivel de empresa. Cambiamos, por tanto, la unidad de análisis utilizada en los dos estudios anteriores para centrarnos en la empresa. Para ello, nos basamos en el concepto de capacidad de absorción que se define como la capacidad de las empresas para detectar y asimilar conocimiento proveniente del exterior (Cohen \& Levinthal, 1990). Este concepto ha sido utilizado por otros autores en el estudio de los clústeres como por ejemplo, Expósito-Langa, Molina-Morales, \& Capo-Vicedo (2011) o Giuliani (2005). También estudiamos el proceso de adopción temprana de las innovaciones por parte de las empresas que integran un clúster. A este respecto, cabe mencionar que la literatura de clústeres atribuye a la adopción temprana de una tecnología un valor diferencial muy importante para las empresas, puesto que éstas se sitúan en un contexto en el que existe un intercambio intenso de conocimiento y un flujo fluido de información e ideas que cataliza los mecanismos de emulación entre empresas (Hervás-Oliver, Lleo, \& Cervello, 2017; Molina-Morales, 2002). 
En concreto el tercer objetivo específico consiste en analizar qué atributos de las empresas favorecen la adopción de la innovación tecnológica disruptiva. En definitiva, nos planteamos estudiar si aquellas empresas con una alta capacidad de absorción son más proclives a la adopción temprana de una innovación disruptiva. Este estudio, se enmarca en la dirección de otros estudios como los realizados por autores como Leonard-Barton (1995) o Tripsas (1997). Sin embargo, en nuestro caso hemos abordado el estudio en un contexto específico como son los clústeres donde las empresas presentan una serie de peculiaridades.

Finalmente, el cuarto objetivo específico se centra en determinar si la adopción temprana de una innovación disruptiva por parte de las empresas que forman el clúster favorece sus resultados de innovación, más allá de la propia adopción de la innovación disruptiva. Para ello, adoptamos la noción de equifinalidad (De Meur \& Rihoux, 2002), es decir, asumimos que la diversidad de empresas existentes en un clúster (Morrison \& Rabellotti, 2005) nos puede conducir a distintos modos o caminos en los que éstas son capaces de obtener mejores resultados de innovación. Hemos tratado de determinar asumiendo la causalidad compleja (Meyer, Tsui, \& Hinings, 1993)- qué caminos conducen a las empresas a ser altamente innovadoras y si éstos se ven condicionados por el hecho de adoptar una novedad antes que el resto o por otros atributos internos de las mismas. Esta investigación puede ser enmarcada en la línea de investigación abierta por autores como Yli-Renko, Autio, \& Sapienza (2001) quienes abordan qué factores favorecen la innovación en las empresas que se encuentra co-localizadas en un mismo territorio.

\subsection{Contribuciones potenciales de la investigación}

La principal contribución que pretendemos realizar en esta investigación es mostrar cómo -contrariamente a lo que se ha venido afirmando hasta el momento- los clústeres son modelos de organización territorial susceptibles de desarrollar innovaciones disruptivas a través de una serie de mecanismos específicos. De este modo, pensamos que es posible extender a nivel de clúster las consideraciones que ha demostrado la literatura a nivel de empresa: el hecho de que las innovaciones disruptivas tienen unos 
importantes y beneficiosos efectos para las organizaciones (Bergek et al., 2013; Roy \& Cohen, 2015); en este caso, para los clústeres industriales.

El desarrollo de nuestra investigación puede presentar, por tanto, una serie de contribuciones potenciales a la literatura de diversas líneas de investigación. Nuestra investigación forma parte de la literatura de clústeres y distritos industriales. En línea con otros estudios recientes en la materia, este trabajo arroja cierta luz sobre cómo las aglomeraciones territoriales, a través de las innovaciones disruptivas, pueden abrir nuevas trayectorias frente a situaciones o fases de maduración o declive (Menzel \& Fornahl, 2009; Zucchella, 2006).

Por otro lado, las conclusiones que se obtengan con relación a cómo conseguir unos mejores resultados de innovación a través de las innovaciones disruptivas pueden contribuir al cuerpo de literatura desarrollado por autores como Albors-Garrigós \& Hervás-Oliver (2013); Leifer et al. (2000) o Markides (2006) que se han centrado en este tipo de innovaciones como factor clave de creación de valor.

Finalmente, consideramos que nuestro trabajo podría contribuir, también, a la literatura de resiliencia territorial. A través del estudio de las consecuencias del fenómeno innovador disruptivo estudiado, podríamos contribuir en la línea de aquellos investigadores centrados en el desarrollo de indicadores de resiliencia para las regiones (Foster, 2007; Sensier, Bristow, \& Healy, 2016).

De este modo, los resultados y conclusiones de nuestra investigación pueden sugerir una serie de prescripciones e implicaciones en el ámbito empresarial y en el político. En el ámbito empresarial, nuestra investigación puede ayudar a las empresas que integran los clústeres a entender y valorar los procesos de innovación disruptivos y cómo estos pueden mejorar sus resultados generales de innovación. En consecuencia, esta tesis puede incentivarlas a invertir en la generación o adopción de conocimiento realmente novedoso procedente del exterior del clúster, más allá de desarrollar o adquirir conocimiento a través de las redes densas de relaciones intensas de conocimiento tecnológico y de información de negocio existentes en el mismo.

En lo referente al ámbito político, nuestro estudio podría contribuir al diseño de aquellas políticas públicas destinadas a la mejora y desarrollo de los clústeres, así como de los 
programas de fomento de la innovación en los mismos. En definitiva, la importancia de las innovaciones radicales o disruptivas puesta de manifiesto en la presente tesis podría orientar a las administraciones competentes cuando se enfrentan al diseño de políticas destinadas a arraigar una industria a un territorio.

\subsection{Estructura de la tesis}

La presente tesis se estructura de la forma que se detalla a continuación: en primer lugar, en el capítulo 2 realizamos una revisión de la literatura de todos aquellos conceptos que intervienen en la parte empírica, en concreto, revisamos la literatura existente acerca de las aglomeraciones territoriales, la innovación (y las innovaciones disruptivas) y por último los factores internos de la innovación (centrándonos en la capacidad de absorción).

A continuación, abordamos la parte empírica. Esta parte se inicia en el capítulo 3 con la descripción del objeto de estudio. Después, en el capítulo 4, hemos explicado el marco empírico, realizando una presentación de la estructura del trabajo, así como de las fuentes de información utilizadas.

Esta tesis se encuentra dividida en dos fases de investigación: la fase descriptivocualitativa (que corresponde al capítulo 5) y la fase cuantitativa (que corresponde al capítulo 6). Cada una de estas dos partes consta de dos estudios empíricos por lo que, en total, la tesis está compuesta de cuatro estudios diferenciados. Cada uno de estos estudios tiene la estructura de artículo científico por lo que las conclusiones específicas de cada uno de ellos se exponen en los respectivos capítulos. Los cuatro estudios se encuentran en los capítulos 5 y 6.

En el capítulo 5 se aborda, en primer lugar, un proceso de innovación disruptiva de tipo tecnológico que se desarrolló en el clúster cerámico de Castellón en la década de los 2000`s (Estudio empírico I). Posteriormente realizamos un análisis comparativo con otro proceso de innovación similar producido en un clúster industrial italiano (Estudio empírico II). 
Una vez estudiado en profundidad el proceso de desarrollo de esta innovación a nivel de clúster, en el capítulo 6 hemos analizado cuáles han sido los determinantes de su adopción por parte de las empresas que lo conforman (Estudio empírico III) y también la influencia que la adopción de estas innovaciones ha tenido sobre los resultados de innovación de las empresas que conforman el clúster (Estudio empírico IV). Para ello, hemos relacionado el hecho de que una empresa adopte una tecnología disruptiva de forma temprana con otros factores internos. Estos atributos o condiciones han sido utilizadas para explicar cómo las empresas pueden obtener altos niveles de innovación a través de la adopción de innovaciones disruptivas.

Finalmente, en los capítulos 7 y 8 se recogen, en castellano e inglés respectivamente, las conclusiones generales de la tesis, así como las recomendaciones para las empresas y las administraciones públicas. Estos capítulos finalizan con la exposición de los límites del estudio y las futuras líneas de trabajo que el mismo ha generado. 


\section{CAPÍTULO 2 MARCO TEÓRICO}




\section{MARCO TEÓRICO}

\subsection{Las aglomeraciones territoriales de empresas}

\subsubsection{Introducción}

El factor geográfico y su influencia ha sido ampliamente estudiado en la literatura debido a su importancia en el ámbito económico. El presente capitulo pretende realizar un análisis de la misma y desarrollar la perspectiva económica del territorio a través del concepto de aglomeración territorial. La configuración espacial de las empresas y su pertenencia a un ámbito territorial determinado ha sido analizada desde perspectivas muy variadas. Lazzeretti et al. (2013) identifican una serie de contribuciones seminales desde distintas vertientes tan variadas como: (a) geografía económica (Hoover, 1948; Krugman, 1991; Lundvall, 1992; Working \& Hotelling, 1929); (b) estrategias organizativas (Chandler, 1962); (c) política económica (Piore \& Sabel, 1984); (d) procesos de innovación (Dosi, 1988; Hippel, 1988); (e) causas y consecuencias de la aglomeración (Audretsch \& Feldman, 1996; Cohen \& Levinthal, 1990; Jaffe et al., 1993); (f) procesos de aprendizaje (Arrow, 1962); (g) costes de transacción y redes sociales (Granovetter, 1973; North, 1991; Williamson, 1975); (h) teoría evolutiva (Nelson \& Winter, 1982); (i) desarrollo local (Aydalot \& Keeble, 1988; Brusco, 1982; Scott, 1988). 
Como consecuencia de esta gran variedad de contribuciones y perspectivas, se han desarrollado una gran cantidad de términos que intentar identificar el concepto de aglomeración industrial. Los milieux innovateurs (Aydalot, 1986), la especialización flexible (Michael Piore \& Sabel, 1984), el sistema de producción (Storper \& Harrison, 1991), los distritos tecnológicos (Storper, 1992; Dalum, 1995), el sistema de innovación -inicialmente concebido a nivel nacional, y luego desarrollado a nivel regional, sectorial o incluso distritual- (Cooke et al., 1997; Edquist, 1997; Lundvall, 1992), los clústeres (Enright, 1995; Porter, 1990), los distritos industriales (Becattini, 1979; 1990), o los hot spots (Pouder \& St. John, 1996) dan buena muestra de ello. No obstante, existe un amplio consenso en la literatura en relación con el hecho de considerar el término clúster como el concepto "paraguas" más representativo de la idea de la aglomeración territorial. Bajo esta denominación coexisten numerosas definiciones las cuales reflejan distintas realidades socioeconómicas. Por lo tanto, éste puede ser considerado como un puzzle formado por distintas piezas que han sido originalmente desarrolladas por la literatura de clúster o tomadas prestadas de otros ámbitos de estudio. Después de un estudio pormenorizado de la evolución de estos conceptos, Lazzeretti et al., (2013) llegan a la conclusión de que el concepto de clúster es: multidisciplinar, transdisciplinar y global.

A pesar de toda esta variedad conceptual, la mayoría de los autores de estas disciplinas coinciden en la consideración de que las aglomeraciones territoriales constituyen una alternativa interesante a las multinacionales. Las empresas que integran estas entidades disfrutan de una serie de beneficios que mejoran su desempeño y su competitividad (Asheim et al., 2011; Becchetti \& Rossi, 2000; Karlsson \& Klaesson, 2000).

En el presente capítulo, realizaremos una revisión teórica del concepto de aglomeración territorial, describiremos los distintos tipos que podemos encontrar en la literatura y nos centraremos en los más utilizados, el distrito industrial y el clúster. Finalmente, analizaremos las principales amenazas y retos a los que los clústeres deben hacer frente y describiremos cómo el desarrollo de resiliencia puede ser una forma de superarlos. 


\subsubsection{Origen del concepto y evolución en su estudio}

El origen del estudio de las aglomeraciones territoriales como concepto se debe al economista y profesor inglés Alfred Marshall (Marshall, 1920) quien, a principios del siglo XX, con el objetivo de estudiar la organización empresarial desde un punto de vista geográfico, identificó las ventajas que para las pequeñas empresas suponía pertenecer a lo que él mismo denominó el distrito industrial. Su propuesta consistía en considerar que las empresas integrantes de estas entidades eran capaces de alcanzar niveles de eficiencia similares a las grandes (que los conseguían gracias a las economías de escala) como consecuencia de las denominadas economías externas, es decir, aquellas que surgen del hecho de formar parte de un aglomerado territorial productivo. Estas economías externas se sustentan en las ventajas generadas por los intercambios económicos y de conocimiento, así como por las relaciones que se generan entre los miembros que integran un territorio. Marshall (1920) identifica una triada de estas economías externas como las causantes de la organización de la actividad económica en distritos locales: la agrupación del mercado laboral, los spillovers tecnológicos y los lazos entre la demanda y el suministro de productos intermedios. El autor introduce, de este modo, un nuevo e interesante nivel de análisis como marco de estudio de las aglomeraciones territoriales de empresas. El nivel meso (como se muestra en la Figura 1) se sitúa en el plano intermedio entre los niveles micro y macro.

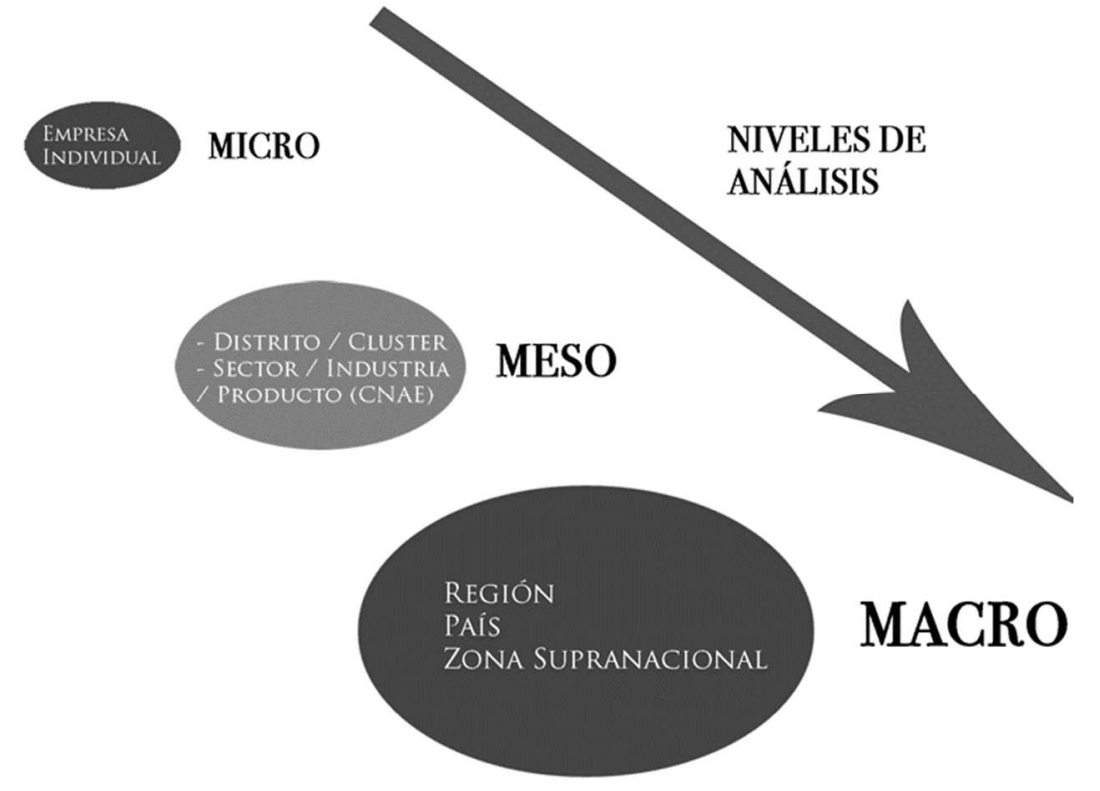

Figura 1: Distintos niveles de análisis económico

Fuente: elaboración propia 
Durante la primera mitad del siglo XX este concepto no fue excesivamente desarrollado en el ámbito de la geografía económica. Fueron algunos autores, principalmente de origen alemán, quienes abordaron esta disciplina desde distintos enfoques. Lösch (1940), por ejemplo, la aborda desde una perspectiva de los recursos económicos, llegando a la conclusión de que la disponibilidad de los mismos limita los lugares en los que una determinada actividad económica puede ser llevada a cabo. Por su parte, Christaller (1966) encontró en Alemania distintos lugares con una elevada concentración económica en contraposición a sus alrededores donde la actividad económica era muy escasa. Concluyó, en consecuencia, que los efectos de estos lugares centrales disminuyen con la distancia.

La dimensión social de las economías de aglomeración territorial, resurgió gracias a las reflexiones llevadas a cabo por Becattini (1979, 1987, 1986, 1990) quien en 1979 publicó un nuevo paradigma en una revista italiana de economía y política dando lugar al redescubrimiento del distrito industrial. Este autor adaptó el concepto anteriormente desarrollado por Marshall a la realidad italiana de las agrupaciones territoriales y definió el término distrito industrial. Éste se caracteriza por la coexistencia de una gran cantidad de pequeñas empresas especializadas en distintas partes de un único proceso productivo y que se nutren de mano de obra local. Sus estudios estaban principalmente centrados en la denominada Terza Italia, una región del noroeste de Italia destacada por su superior desarrollo económico con relación al resto del país. Los trabajos de Becattini fueron más allá del análisis económico realizado por Marshall poniendo de relieve la necesidad de realizar un acercamiento al concepto de distrito industrial desde un punto de vista multidisciplinar (Lazzeretti et al., 2013). Posteriormente, el campo de investigación abierto por Becattini ha sido continuado, y lo sigue siendo hoy en día, por una gran cantidad de autores (vease, Bellandi (1986, 1993); Bellandi \& Russo (1994); Belussi et al. (2000); Belussi (1993, 1996); Brusco (1990); Sforzi \& Lorenzini (2002); Sforzi (1987, 1999) ; Trigilia (1986) o Triglia (1993)).

Paralelamente, en la década de los noventa, se desarrolla una nueva corriente de investigación centrada en la explicación de las aglomeraciones territoriales y su impacto económico. Esta nueva corriente académica se encuentra estrechamente relacionada con el trabajo llevado a cabo por Krugman (1991), así como por los exponentes de la Nueva Geografía Economía (NEG). En este contexto, Porter (1990) desarrolla el concepto de clúster fundamentado en la idea de que se trata de un grupo de empresas agrupadas en 
un espacio geográfico determinado que establecen relaciones entre ellas. De este modo, se desarrolla una cadena de valor interempresarial que permite obtener ventajas competitivas a todos los miembros integrantes, y participantes de la relación.

A partir de estos trabajos desarrollados por Porter, un gran número de autores han investigado la configuración espacial empresarial desde distintos enfoques. En efecto, durante las décadas posteriores, las investigaciones se han centrado en temas tan diversos como la identificación de los clústeres y sus beneficios o la perspectiva relacional a través del capital social y el análisis de redes sociales. La Tabla 1 muestra algunas de las investigaciones llevadas a cabo en los distintos campos investigados en las últimas décadas. 
Tabla 1: Distintas perspectivas abordadas en relación con las aglomeraciones territoriales a lo largo de las últimas décadas

\begin{tabular}{|c|c|}
\hline Perspectivas abordadas & Estudios relevantes \\
\hline $\begin{array}{l}\text { Formación y factores de éxito } \\
\text { de los clústeres }\end{array}$ & $\begin{array}{l}\text { Doeringer \& Terkla (1995); Lee et al. (2000); } \\
\text { Rosenfeld (1997) }\end{array}$ \\
\hline $\begin{array}{l}\text { Identificación de clústeres y } \\
\text { las empresas que los integran }\end{array}$ & $\begin{array}{l}\text { Boix \& Galletto (2006); Boix, (2009); Sforzi (1990); } \\
\text { (Molina-Morales \& Martínez-Fernández (2004) }\end{array}$ \\
\hline $\begin{array}{l}\text { Efecto distrito a través de los } \\
\text { resultados empresariales }\end{array}$ & $\begin{array}{l}\text { Molina-Morales (2001); Paniccia (1998); Signorini } \\
\text { (1994); Ybarra (1991) }\end{array}$ \\
\hline $\begin{array}{l}\text { Intercambio de conocimiento } \\
\text { y aprendizaje }\end{array}$ & $\begin{array}{l}\text { Breschi \& Lissoni (2001); Cooke (2002); Maskell \& } \\
\text { Malmberg (1999); Bathelt et. al (2004); Saxenian } \\
\text { (1991); Belussi \& Sedita (2012) }\end{array}$ \\
\hline $\begin{array}{l}\text { Proximidad geográfica e } \\
\text { Innovación }\end{array}$ & $\begin{array}{l}\text { Boschma \& Frenken (2006); Boschma (2005); } \\
\text { Moodysson et al. (2008); Lissoni (2001) }\end{array}$ \\
\hline $\begin{array}{l}\text { Heterogeneidad de las } \\
\text { empresas y el efecto clúster }\end{array}$ & $\begin{array}{l}\text { Boschma \& Ter Wal (2007); Giuliani \& Bell (2005); } \\
\text { Giuliani (2011); Hervás-Oliver et al. (2012); Munari et } \\
\text { al. (2012); Morrison (2008) }\end{array}$ \\
\hline $\begin{array}{l}\text { Clúster bajo la perspectiva del } \\
\text { capital social }\end{array}$ & $\begin{array}{l}\text { McEvily \& Zaheer (1999); Molina-Morales \& } \\
\text { Martínez-Fernández (2009); Molina-Morales et al. } \\
\text { (2010). }\end{array}$ \\
\hline $\begin{array}{l}\text { Relaciones en los clústeres a } \\
\text { través del Análisis de redes } \\
\text { Sociales }\end{array}$ & $\begin{array}{l}\text { Boari et al. (2017); Giuliani (2013); Giuliani (2007); } \\
\text { Lee et al. (2000) }\end{array}$ \\
\hline $\begin{array}{l}\text { Nuevas trayectorias y } \\
\text { evolución de los clústeres }\end{array}$ & $\begin{array}{l}\text { Zucchella (2006); Sammarra \& Belussi (2006); Belussi } \\
\text { et al. (2012); De Marchi et al. (2018); De Marchi \& } \\
\text { Grandinetti (2014) }\end{array}$ \\
\hline
\end{tabular}

Fuente: elaboración propia 


\subsubsection{Los tipos de aglomeraciones territoriales de empresas}

Las aglomeraciones territoriales de empresas, como hemos descrito en el apartado anterior, han sido analizadas a través de distintas perspectivas a lo largo de las últimas décadas. Una revisión a estos enfoques nos permitirá obtener una comprensión global acerca de este fenómeno y de cómo las distintas corrientes académicas han abordado la innovación y la producción en las concentraciones empresariales.

En este apartado definiremos y revisaremos brevemente los tipos de aglomeraciones de empresas más relevantes. No obstante, debido a su especial importancia, decidimos abordar en el siguiente capítulo el estudio en profundidad de los clústeres y de los distritos industriales.

Los milieux innovateurs: Este tipo de aglomeración territorial fue desarrollado a partir de 1984 por el Groupe de Recherche Européen sur les Milieux Innovateurs (GREMI). Este grupo de investigación, fundado en 1984 por Philippe Aydalot y dedicado principalmente al estudio de la innovación desde un punto de vista territorial, analizan y revisan los conceptos de distrito Marshalliano (Marshall, 1920) y growth poles de Perroux (1955). Con una perspectiva más dinámica, esta corriente defiende la existencia de un milieu (Aydalot, 1986) caracterizado por un conocimiento común basado en un aprendizaje colectivo que ha rebasado los límites de la empresa (Capello, 1999). El aprendizaje y la innovación se consideran acciones colectivas (no exclusivamente individuales de las empresas), en las que participan los distintos agentes que integran la red. En estos lugares innovadores, confluyen, por tanto, el capital relacional, la interacción espacial y el proceso de aprendizaje. Autores como Amara et al. (2005), basándose en determinantes externos del ambiente innovador, han identificado distintos tipologías de milieux a partir de las distintas formas de interacción (débiles y fuertes) y la intensidad en el aprendizaje (alta o baja).

La especialización flexible: Este concepto se desarrolla en EEUU por Piore \& Sabel (1984), en un momento histórico en el que la gran empresa (Ford como paradigma), empieza a perder relevancia en favor de las pequeñas y medianas empresas que son capaces de ofrecer un producto más artesanal y realizado por trabajadores con un alto 
grado de especialización. Debido a su alta especialización, estas empresas (que normalmente se agrupan en un mismo territorio) son capaces de encontrar una oportunidad competitiva en aquellos productos en los que no es posible realizar grandes lotes de producción. En definitiva, son competitivas gracias a su alta especialización y flexibilidad. Nos encontramos ante un concepto muy parecido, en su origen, al de distrito industrial. Sin embargo, la evolución de ambos ha sido distinta. Como el propio Becattini expone (Becattini 2006), el distrito industrial se basa en la comunidad de productores como la principal cualidad por encima del número y la flexibilidad de las empresas que es la principal característica de la especialización flexible.

El sistema de producción: Este concepto se desarrolla por Storper \& Harrison (1991). Bajo esta perspectiva, los sistemas de producción se basan en: (a) unidades de producción, que pueden ser de diversos tamaños y estar vinculadas entre sí; (b) una estructura de gobierno, que ostenta la autoridad y el poder, (c) un territorio, que puede ser disperso o concentrado. En estos sistemas, la interrelación entre economías internas y externas es considerada como un factor que fundamenta la forma y la dinámica de los sistemas productivos. Combinando la intensidad (alta/baja) de estas dos economías (internas/externas) se pueden obtener cuatro alternativas del sistema productivo; éstas son: (a) los talleres aislados; (b) la industria de proceso; (c) la producción en red desintegrada (existe una división del trabajo así como unas intensas relaciones de transacción); (d) sistema de cadenas de montaje a gran escala (existen altos niveles de integración vertical y gran cantidad de proveedores directos e indirectos) (Garofoli, 1995). Mientras que las dos primeras alternativas corresponden a patrones geográficos que presentan dispersión, las dos últimas corresponden a modelos más concentrados tipo clúster.

Del mismo modo, podemos determinar diferentes alternativas de sistemas productivos en base a la organización territorial de la producción (producción aglomerada o producción dispersa) y las formas de relaciones entre empresas (redes jerárquicas o uniones cooperativas). Esto conduce a otras cuatro nuevas alternativas que son: (a) el sistema de pequeñas empresas, donde se enmarcarían los distritos industriales; (b) el sistema de cadenas de montaje a gran escala, representado, por ejemplo, por Fiat en Italia (especialmente durante los años cincuenta y sesenta); (c) la alta descentralización de la producción; (d) los acuerdos de colaboración estratégico (Garofoli, 1995). 
Los distritos tecnológicos: Este tipo aglomeraciones territoriales ha sido identificado por autores como Storper (1992) o Dalum (1995) en países como Francia, Italia, EEUU o Dinamarca. Se consideran distritos tecnológicos a aquellas aglomeraciones en las que, al igual que los milieux innovateurs, la actividad innovadora continua y el aprendizaje son los elementos principales. Estos elementos vertebradores pueden ser llevados al extremo de forma que la mayoría de empresas que forman el distrito no dispusieran de procesos productivos, sino que su actividad se centrara en la investigación y el desarrollo (Dalum, 1995). Este tipo de configuración únicamente es posible cuando existe una fuerte base laboral altamente cualificada que fluye principalmente entre las empresas de la misma región y no hacia otras regiones.

El sistema nacional de innovación: Este tipo de aglomeración centra su enfoque en la capacidad innovadora de las agrupaciones empresariales. El término fue inicialmente acuñado por Freeman (1987), e intensamente desarrollado, posteriormente, por otros autores como Lundvall (1992) o Nelson (1993). En concreto, Lundvall (1992) basa su enfoque en el hecho de que el flujo de conocimiento tecnológico sucede de forma más frecuente en el interior de los países y no trascendiendo a estos. De ahí se justifica el nacimiento del término sistema nacional de innovación que autores como Niosi et al. (1993), definen como:

"El sistema de interacción formado por empresas públicas y privadas (tanto grandes como pequeñas), universidades y agencias gubernamentales cuyo objetivo es producir ciencia y tecnología dentro de los límites fronterizos nacionales. La interacción entre dichas unidades puede ser técnica, comercial, legal, social y financiera ya que el objetivo de la interacción es el desarrollo, protección, financiación o regulación de nuevas tecnologías y avances científicos”. (Niosi et al., 1993, p. 212)

Como se describe en mayor profundidad en el apartado siguiente -que analiza la Innovación- estos modelos de agrupación, que inicialmente se centraron en el ámbito nacional, pronto se desarrollaron para otras unidades de análisis de menor tamaño. De este modo, bajo la visión sistémica de una agrupación de empresas en relación a la innovación, autores como Buesa-Blanco (2002) definen el sistema de innovación como: 
"El conjunto de organizaciones institucionales y empresariales que, dentro de un determinado ámbito geográfico, interactúan entre sí con la finalidad de asignar recursos a la realización de actividades orientadas a la generación y difusión de conocimientos sobre los que se soportan las innovaciones que están en la base del desarrollo económico” (Buesa-Blanco, 2002, p. 2).

En los últimos tiempos -y principalmente a causa de la globalización- el planteamiento inicial de un sistema de innovación cuyos límites se reducen al ámbito nacional ha sido cuestionado como señala, junto a otros autores, el propio Lundall (2002). En consecuencia, se han propuesto como más relevantes otros sistemas de innovación a otros niveles como el sectorial, el regional, o incluso el distritual (Breschi \& Malerba, 1997; Cooke, 2001; Malerba, 2002; Molina-Morales et al., 2012). Sin embargo, otros autores consideran que el nivel nacional sigue siendo importante para determinadas actividades innovadoras, por ejemplo Archibugi \& Michie (1995), Ostry \& Nelson (2000) o Patel \& Pavitt (1997).

Los hot spots fueron inicialmente descritos por Pouder \& St. John (1996). Éstos enfocaron el estudio de las aglomeraciones territoriales desde la perspectiva de su formación y desarrollo y en base a distintas teorías tales como: la teoría de recursos y capacidades, la teoría institucional o la geografía económica. De este modo, un hot spot es definido como una agrupación de empresas que se caracterizan por (Pouder \& St. John, 1996):

- Competir en la misma industria.

- El grupo crece de forma más acelerada que cualquier otro participante en la misma industria fuera del mismo.

- Tienen las mismas o muy similares necesidades de recursos a largo plazo.

En cambio, es importante resaltar que el simple hecho de que una empresa o empresas decidan instalarse en una zona determinada con el objetivo de capturar una oportunidad de negocio o satisfacer una demanda del mercado, no es suficiente para ser considerado como el origen de un hot spot. Según estos autores, este peculiar tipo de aglomeración 
debe cumplir las siguientes etapas durante su génesis y desarrollo: (a) la creación: fase en la que se establece la identidad de esta agrupación; (b) la convergencia: fase en la que la aglomeración se dirige hacia un objetivo común; (d) la reorientación: periodo caracterizado por el deterioro del desempeño del hot spot. Bajo esta perspectiva, casos como los estudiados por autores como Gripsrud \& Gronhaug (1985), en referencia a la competencia entre tiendas de comestibles, o por Baum \& Mezias (1992), en referencia a los hoteles en Manhattan, no pueden ser considerados como hot spots.

\subsubsection{Los distritos industriales y los clústeres}

Como hemos mencionado anteriormente, debido a su importancia para el desarrollo de esta tesis, en este apartado abordamos el estudio de los conceptos de distrito y clúster industrial. También realizaremos una breve comparación de ambos términos y justificaremos el uso indistinto que realizamos de ellos en la presente tesis.

\subsubsection{Los distritos industriales}

Como se ha mencionado anteriormente, el concepto de distrito industrial es desarrollado inicialmente por Becattini $(1979 ; 1987$; 1990; 1989; 2006) a partir de una revisión de los trabajos de Marshall (1920) y complementado por otros economistas y sociólogos tales como, Bellandi (1986, 1989); Brusco (1982, 1990); Sforzi (1990, 2002) o Trigilia $(1986,1993)$.

Inicialmente Marshall (1920), propone una alternativa a la economía de escala obtenida por las grandes empresas: la economía de aglomeración alcanzada en el distrito industrial. En definitiva, el distrito industrial para este autor supone una concentración de pequeñas empresas ubicadas en un área geográfica concreta, especializadas en diferentes fases de un único proceso productivo y que se nutren y benefician de mano de obra local especializada.

Posteriormente, Becattini (1990) amplia esta perspectiva y define el distrito industrial como: 
“Una entidad socioeconómica que se caracteriza por la presencia activa de una comunidad de personas y una población de empresas en un área natural e históricamente limitada” (Becattini, 1990, p. 111).

Este autor pone especial énfasis en el aspecto social y de comunidad en su concepción de distrito industrial. Por tanto, introduce en la definición inicial de Marshall (1920) (población de empresas y atmosfera industrial) un tercer elemento, el sentimiento de pertenencia y las características de la comunidad que lo integran. Los distritos industriales son el producto de espacio (geografía) y tiempo (historia) los cuales transforman un territorio unido geográficamente en un espacio social arraigado a una comunidad socio-económica con unos valores compartidos una identidad y unas instituciones (Zucchella, 2006). A continuación, pasaremos a describir en detalle cada uno de estos tres elementos que conforman la concepción Becattiniana de distrito industrial:

- Comunidad de personas. Este hecho diferencial con respecto a la concepción Marshalliana es considerado como la aportación más interesante realizada por Becattini (Harrison, 1992). Como el propio Becattini argumenta:

"Cualquier subdivisión del campo productivo que no tenga en cuenta esto y que encima del conjunto de las relaciones sociales ponga una red clasificatoria construida según unos modelos geométricos de hombre, familia, empresa, concebidos casi como sólidos geométricos regulares, inevitablemente ve como por las fisuras del análisis se le escapan toda la complejidad y la riqueza de los comportamientos específicos” (Becattini, 1986, p. 6).

El sentimiento de comunidad, la percepción colectiva de que se pertenece a un territorio común que contiene una serie de valores en la esfera familiar y laboral, es capaz de restringir y homogeneizar las conductas individuales. Estas conductas arraigadas en la comunidad, bajo la perspectiva del autor, favorecen el desarrollo de una comunidad empresarial competitiva (Becattini, 1990). Varios autores han destacado la importancia que tiene el sentimiento de pertenencia en 
el concepto Becattiniano de distrito industrial; entre ellos Crewe (1996), Paniccia (1998) o Russo (1997). En concreto, Sforzi (2008) interpreta la propuesta de Becattini como un camino de sentido opuesto al establecido hasta entonces en relación a localización e industria; en este caso se parte de la última (una comunidad localizada en un territorio) para llegar a la primera (industrialización).

La existencia de este sentimiento de pertenencia a una comunidad está estrechamente relacionada con el concepto de arraigo (embeddedness) (Granovetter, 1985). Este concepto, lejos de ser perfectamente observable y medible, representa un elemento constitutivo fundamental en la formación y estructuración de un distrito industrial. A través del arraigo, la mera colocalización de personas, organizaciones e instituciones (proximidad geográfica) se convierte en otros tipos de proximidad tales como la cognitiva, la organizacional, la institucional o la social. El arraigo es un elemento clave para entender el desarrollo y el éxito de los distritos industriales en las últimas décadas (Zucchella, 2006). Este tipo de aglomeración se conforma a través de un arraigo no sólo entendido en su dimensión relacional sino también estructural (Granovetter, 1992). Como consecuencia de este arraigo, se produce una de las paradojas más interesantes de los distritos industriales: las empresas combinan la colaboración y la competición (Harrison, 1992). El arraigo no sólo refuerza los mecanismos que conducen a los procesos de path dependency sino que también altera distintas lógicas del mercado (Zucchella, 2006) como son: (a) la lógica del intercambio, que se convierte en un compromiso a largo plazo donde predomina el intercambio de conocimiento y la resolución conjunta de problemas; (b) la lógica de la competencia, que se desplaza desde un nivel de empresa a un nivel de red de empresas.

- Población de empresas. Por población de empresas, se entiende no únicamente las empresas productoras que definen la actividad principal del distrito, sino también aquellas que se dedican a servicios auxiliares, así como las instituciones. Las empresas en un distrito industrial se caracterizan por una alta especialización en una determinada actividad. Además, puesto que existe una alta división del trabajo, éstas están altamente conectadas entre sí a través de una alta complementariedad (Ottati, 1994; Zucchella, 2006). En los distritos 
industriales se combina una división vertical (en forma de cooperación y complementariedad) y una división horizontal (en forma de competencia entre un número considerable de empresas que se especializan en cada una de las etapas del proceso productivo). Estas entidades suelen configurarse en forma de sistemas cerrados con la excepción de los extremos de la cadena de valor (el suministro de materias primas y la venta de productos finales) (Corò \& Grandinetti, 1999). Se puede hablar, en definitiva, de que existe un efecto homogeneizador en términos de recursos, estructuras de costes e incluso modelos mentales y comportamientos competitivos (Becattini, 1990; Brusco, 1990). En consecuencia, como ya hemos mencionado anteriormente, algunos autores, como Zucchella (2006), argumentan que la lógica de la competición normalmente se traslada desde un nivel inter-empresa a un nivel inter-red de empresas. Las relaciones de cooperación entre las empresas están basadas en la reciprocidad y en un clima de confianza. Dentro de un distrito industrial, la competición suele ocurrir más bien entre diferentes subredes. En una escala de mercado global, las redes locales del distrito están llamadas a competir con otras redes análogas, así como con las multinacionales (Zucchella, 2006). De este modo, al igual que entre las personas, las empresas conforman una comunidad social que se rige por normas análogas a las que rigen a las primeras (MolinaMorales \& Mas-Verdú, 2008). En esta línea, podemos destacar una amplia variedad de trabajos empíricos dedicados a relacionar el desarrollo y éxito de los distritos industriales con el clima de confianza y reciprocidad existente entre las empresas (Biggiero, 1999, 2001; Lazerson \& Lorenzoni, 1999b; Ivana Paniccia, 2002).

Por último, cabe destacar que como hemos introducido anteriormente, en los distritos industriales no sólo existen empresas sino también instituciones. Estos organismos pueden ser tanto de carácter público como privado e incluyen: centros de investigación, agencias de política industrial, instituciones académicas y asociaciones empresariales y profesionales. Esta red ofrece una serie de servicios reales como explica Brusco (1990).

- Atmosfera industrial. Mediante este concepto, Marshall (1920) hace referencia a la circulación de conocimiento, información y experiencias compartidas que se 
producen dentro del distrito industrial. Favorecida por la proximidad geográfica y cognitiva, la atmosfera industrial disemina ideas y know-how originando un valioso activo intangible, el conocimiento tácito. Este conocimiento, que no se puede codificar de forma explícita, es específico y característico de las comunidades de personas y empresas que integran el distrito industrial (Porter \& Sölvell, 1998).

Este modelo de aglomeración territorial ha sido muy útil para explicar la realidad empresarial de muchos territorios a lo largo de las últimas décadas. Sin embargo, algunos autores como Paniccia (1998) han resaltado el hecho de que la visión más restrictiva del mismo impide hacer extensiva su aplicación más allá de las experiencias italianas que lo originaron. En consecuencia, varios autores decidieron evolucionar el concepto hacia un enfoque menos restrictivo estableciendo orígenes y trayectorias de desarrollo alternativas (Amin \& Robins, 1990; Lazerson \& Lorenzoni, 1999a; Spender, 1998; Staber, 1998). El modelo de distrito industrial inicialmente descrito adquiere, por tanto, otras estructuras y patrones de funcionamiento sin que por ello pierda relevancia o interés. Podemos destacar el modelo de distrito abierto propuesto por Zeitlin (1992), las nuevas trayectorias de distritos con arraigo múltiple frente a la globalización desarrollada de forma teórica por Zucchella (2006) o las estructuras globales de los distritos, bajo de denominación de Global Value Chain, como reacción a globalización y la deslocalización de algunas etapas productivas a otros países (De Marchi, Gereffi, et al., 2018). En definitiva -incluso asumiendo las variaciones al modelo originalmente propuesto- podemos considerar que son cuatro los elementos fundamentales que caracterizan a los distritos industriales: la concentración geográfica, la alta especialización de empresas junto a unas elevadas complementariedades productivas, el sistema de valores homogéneo y la fuerte influencia de la dimensión social.

\subsubsection{Los clústeres industriales}

El concepto de clúster es uno de los más utilizados en la literatura económica en la actualidad pudiendo comprender expresiones como clúster regional, clúster industrial, 
clúster innovador, etc. A pesar de que en ocasiones ha sido considerado como una denominación un poco difusa o ambigua (Lazzeretti et al., 2013), el clúster se ha consolidado como un concepto internacional y con aplicación interdisciplinar. Lazzeretti et al. (2013) otorgan a este concepto tres principales características que catalizan su uso y lo convierten en un modelo perdurable a lo largo de las últimas décadas: (a) multi-disciplinaridad: este concepto ha sido analizado por distintas disciplinas tan diferentes como la geografía económica, el management, la innovación o la sociología económica; (b) trans-disciplinaridad: este concepto se ha ido conformando y definiendo a partir de aportaciones de distintas disciplinas las cuales han ido intercambiando sus marcos teóricos y sus metodologías analíticas (Hirschman, 1958; Ottati, 2003); (c) dimensión global: este concepto tiene una extensión geográfica la cual puede ser observada a partir de la afiliación académica de los autores que publican sobre él.

En definitiva, existe un consenso general en considerar un clúster a la aglomeración de empresas de una industria específica y sus actividades relacionadas que tienen una interconexión y donde existe una competitividad cooperativa entre los distintos actores de la misma (Simmie, 2004).

A pesar de que el concepto de aglomeración de empresa, como hemos descrito en el apartado anterior ya se describe por autores como Marshall en los años 20 del siglo pasado (Marshall, 1920), el desarrollo global del clúster como concepto explota en la década de 90s del pasado siglo gracias a la contribución seminal de Porter $(1990,1998)$.

En el artículo más citado por la academia en términos absolutos (Lazzeretti et al., 2013): “Clusters and the New Economics of Competition” de Porter (Porter, 1998), este autor, considerado con el padre de este concepto, define el clúster como:

“Concentraciones geográficas de empresas e instituciones interconectadas que pertenecen a un determinado campo de actividad. Estos clústeres abarcan una amplia gama de sectores vinculados entre sí y otras entidades que son importantes para la competitividad. Éstos incluyen, proveedores especializados de componentes, maquinaria, servicios e infraestructura" (Porter, 1998, p. 78). 
Este autor considera que, a pesar de estar incluidos en una era de competencia global, los clústeres alcanzan grandes niveles de productividad e innovación. Esto significa que, como estamos repasando en este capítulo, la localización es un elemento fundamental en el desarrollo económico. También basa una de las principales ventajas del clúster en el hecho de que son capaces de responder rápidamente a los cambios del entorno. En efecto, mientras que las empresas que se encuentran integradas verticalmente tienen una capacidad de reacción limitada, los clústeres son más ágiles al estar conformados por un gran número de empresas de menor tamaño, que se han especializado en distintas fases del proceso productivo. En 2000, Porter publica otro interesante artículo en el que expone las ventajas competitivas de los clústeres. La competitividad de un clúster se ve favorecida por el fácil acceso a mano de obra cualificada y experimentada que reduce los costes relacionados con la búsqueda y contratación de dichos recursos. En este artículo también analiza el papel que deberían tomar las instituciones gubernamentales con respecto al mantenimiento y desarrollo de los mismos (Porter, 2000).

Otros autores como Martin \& Sunley (2003) trataron de hacer una definición más precisa del concepto de clúster y de sus implicaciones a nivel de políticas institucionales ya que consideran la aproximación de Porter altamente genérica e insuficientemente determinante.

No obstante, a pesar de las controversias, existe un consenso generalizado en el hecho de que la conformación de un grupo de empresas en un clúster presenta ciertas ventajas como son:

- Favorecimiento de la innovación. Para autores como Cooke (2001), el intercambio de información tecnológica y de mercado que se genera dentro del clúster son elementos fundamentales en el desarrollo de innovación. De hecho, este autor es considerado como uno de los pioneros en establecer una conexión entre el concepto de clúster y el amplio concepto de sistema regional de innovación; un concepto que ha ido ganando popularidad no sólo entre la comunidad científica sino también entre los ámbitos de decisión política. Bajo esta perspectiva, los actores económicos presentes en un clúster generan redes de intercambio muy intensas y con alta proximidad geográfica favoreciendo el proceso innovador (Cooke, 2001). Los actores de estas redes de intercambio no son únicamente a los productores finales y los proveedores de sus 
correspondientes materias primas sino también: otro tipo empresas manufactureras auxiliares, otros proveedores, instituciones financieras, universidades y centros de formación especializada, institutos de investigación, administraciones a distintos niveles, asociaciones empresariales, agencias de transferencia tecnológica, etc.

- Generación de externalidades. El hecho de pertenecer a un clúster y, por tanto, tener de la proximidad física y cognitiva con el resto de las empresas, así como el disponer de una intensa red de relaciones, genera una serie de externalidades muy beneficiosas. Principalmente podemos destacar: (a): mejora del rendimiento en el trabajo (Fingleton et al., 2005; Glaeser et al., 1992); (b) mayor productividad y mejores resultados (Henderson, 1986; Porter, 1997); (c) mayor transferencia de conocimiento e innovación (Baptista, 2000; Cooke, 2002; Porter, 1990); (d) mayor acceso a recursos financieros, debido a que tanto las instituciones como los inversores potenciales se encuentran familiarizados con el riesgo asociado a la actividad realizada en el clúster.

Sin embargo, a pesar de las ventajas que este tipo de aglomeración territorial puede presentar, no está exenta de riesgos, entre los que cabría destacar el denominado riesgo de lock-in (Grabher, 1993; Liebowitz \& Margolis, 1995). Este fenómeno conduce, en opinión de muchos autores como Zucchella (2006), a una gradual esterilización del clúster. Más en detalle, el concepto de lock-in se puede considerar como la falta de habilidad para encontrar y modificar a conveniencia el compromiso entre: (a) uso del conocimiento interno que existe y fluye en el clúster; (b) ampliación del ámbito tecnológico a través de la incorporación de nuevo conocimiento externo para el que es necesario una complementariedad cognitiva. En efecto, la red de actores que compone el clúster debe encontrar el compromiso entre la necesaria estabilidad y ventaja que ofrece el flujo de información y la inestabilidad que supone introducir conocimiento realmente novedoso proveniente de fuentes externas. Otros riesgos a los que los clústeres se ven expuestos pueden ser: la aparición de una discontinuidad tecnológica, la rigidez en las relaciones, las regulaciones excesivas, la endogamia, la falta de vigilancia externa, la dificultad de establecer una línea de actuación común o la deficiencia de las instituciones. Todos estos factores pueden acabar reduciendo la competitividad del clúster o incluso generar un ciclo de maduración o declive. 


\subsubsection{Similitudes y diferencias de los términos clúster y distrito industrial}

El interés que han despertado las redes locales ya sean considerados clústeres o distritos industriales, ha favorecido el desarrollo de muchos estudios a lo largo de las últimas décadas (como por ejemplo los llevados a cabo por Garofoli (1992); Nooteboom \& Woolthius (2005); Dei Ottati (1994) o Pyke et al. (1990)). De acuerdo con esta corriente, Zucchella (2006) identifica cuatro elementos básicos presentes en la caracterización de cualquier clúster o distrito industrial; de éstos, los dos primeros son característicos de los clústeres en general, mientras que los dos últimos son considerados como específicos de los distritos industriales. Se trata de: (a) concentración geográfica; (b) alta especialización de las empresas, acompañada de unas fuertes complementariedades productivas; (c) un sistema homogéneo de valores; (d) una fuerte influencia de la dimensión social.

Cabe destacar que si bien ambas concepciones reconocen el papel fundamental de la localización y las relaciones entre los actores integrantes, sus respectivas aproximaciones son distintas; el clúster, desde una perspectiva más global, condiciona la elección de la localización a las condiciones del entorno en busca de ventajas competitivas; por el contrario, el distrito industrial, desde una perspectiva más local, se fundamenta en las comunidades de empresas y personas como incentivo de su desarrollo (Lazzeretti, 2006). El propio Becattini señala las diferencias:

"Superficialmente, un clúster en expansión y un distrito industrial de éxito pueden parecer similares. En ambos casos, en efecto, se tiene una ampliación sistemática del aparato productivo y un aumento de la ocupación y la renta media per cápita. Pero si se profundiza en el análisis, se observa que los dos fenómenos son sensiblemente diferentes: el primero, siendo sólo la manifestación localizada del proceso mundial de acumulación y redistribución territorial del capital es, por definición, precario (incluso si se mide la precariedad en décadas); el segundo, en cuanto resultado del esfuerzo semiconsciente de una comunidad, de hacerse un sitio en la división internacional del trabajo que le permita el desarrollo gradual de su estilo de vida, es, por definición, estable (incluso si se mide la estabilidad en décadas)" (Becattini, 2006, p. 24). 
Otras diferencias las podemos encontrar en el tipo de empresas que los componen (pequeñas y medianas en el caso del distrito; pequeñas, medianas y grandes en el caso del clúster) o su propia génesis, entendida como la posibilidad de ser generados o no por acción deliberada de las políticas económicas (los distritos requieren de un entorno social y un contexto institucional que los clústeres no necesitan para su formación).

Con todo, podemos considerar que el distrito industrial no es una alternativa al clúster, sino que es una forma específica del mismo, un tipo particular de clúster en el que se da especial relevancia a la comunidad de personas y empresas, así como al territorio en su vertiente cultural. Por tanto, podemos concluir que mientras que los distritos industriales pueden ser considerados como clústeres, no todos los clústeres pueden ser considerados distritos industriales. En base a esto, muchos autores, como McCann \& Gordon (2000), sugieren centrarse en el estudio de las aglomeraciones desde un punto de vista más global, en base a su modelo de organización y a los determinantes de su competitividad. Bajo esta perspectiva, podemos utilizar indistintamente ambos términos. En la presente tesis, decidimos seguir esta corriente académica principal y haremos uso de ambos términos de forma intercambiable.

\subsubsection{Los componentes de las aglomeraciones territoriales}

En este apartado vamos a exponer los diferentes elementos que constituyen los clústeres o los distritos industriales a partir de la clasificación realizada por Brenner (2000).

\section{Empresas}

Son los componentes principales y la primordial fuente de actividad económica. Éstas pueden, bien dedicarse a la actividad principal (aquella que define y le da nombre al clúster), o bien realizar actividades relacionadas con la actividad principal, o incluso desempeñar una parte de la misma. Puesto que, en todos los casos, dependen las unas de las otras no se puede realizar una aproximación diferenciada de las mismas.

Brusco (1990), por su parte, clasifica y da nombre a los distintos tipos de empresas presentes en los distritos. Bajo esta perspectiva, las empresas pueden ser: 
1. Empresas finales, aquellas que pertenecen a la actividad que define al clúster, ya sea un producto o un servicio.

2. Empresas especializadas, son aquellas que actúan como proveedores de suministros, componentes, inputs, materias primas etc.

3. Empresas integradas, son aquellas que perteneciendo a una industria diferente a la del clúster se integran en el mismo suministrando distintos tipos de servicios tales como servicios de transporte, financieros, etc.

Con el objetivo de clarificar este punto, la Tabla 2 muestra el cada una de las categorías de empresa correspondiente a un clúster industrial importante, el clúster cerámico de Castellón.

Tabla 2: Tipos de empresas que integran el clúster cerámico español

\begin{tabular}{ll}
\hline Tipo de empresa & Actividad que realizan \\
\hline Empresas finales & Fabricantes de pavimentos y revestimientos cerámicos \\
\hline & Fabricantes de fritas, colores, esmaltes y tintas. \\
& Fabricantes de maquinaria \\
Empresas especializadas & Proveedores de aditivos \\
& Proveedores de diseños cerámicos \\
& Fabricantes de polvo cerámico atomizado \\
& Agencias de publicidad y marketing \\
& Empresas de transporte \\
& Gestores de residuos industriales \\
Empresas integradas & Asesorías jurídicas \\
& Banca \\
& Asesorías técnicas \\
\hline
\end{tabular}

Fuente: elaboración propia

\section{Mercado de trabajo}

Los clústeres disponen de una comunidad de recursos humanos especializados la cual es crucial para el desarrollo competitivo de los mismos. Ésta se caracteriza por presentar una gran estabilidad en comparación con otros recursos presentes en el clúster. La mano 
de obra suele tener baja movilidad y tiene un papel muy relevante en el sistema industrial local (Bramanti \& Senn, 1990; Ottati, 1994; Pietrobelli, 1998)

\section{Mercado de capital}

Con una menor estabilidad que el mercado de trabajo, la existencia de una oferta financiera local es muy importante en los distritos industriales, principalmente en el caso de creación de nuevas empresas (Audretsch \& Frisch, 1999; Russo \& Rossi, 2001; Ughetto, 2009). La disponibilidad de inversores con conocimiento del distrito (y de sus actores), así como de sus riesgos asociados, agiliza la concesión de crédito favoreciendo la creación de nuevas empresas y el funcionamiento operativo de las mismas.

\section{Instituciones políticas}

Se trata de las instituciones que, a un nivel formal, se encuentran presentes en el distrito industrial condicionando sus políticas al resto de elementos que conforman el mismo. Estas instituciones tienen la capacidad de generar sinergias, aglutinar a la comunidad, determinar el desarrollo de infraestructuras y favorecer un clima propicio para la inversión en la región. Además, en muchos casos, son este tipo de instituciones las que toman las decisiones en cuanto al desarrollo de centros formativos e institutos de investigación. A pesar de haber sido centro de numerosas críticas, existe un amplio consenso en relación con el papel que tienen o deberían tener, así como con relación al gran impacto que son capaces de generar en el conjunto del distrito.

\section{Instituciones académicas}

Se trata de aquellas instituciones dedicadas al desarrollo de conocimiento, así como a la introducción de conocimiento procedente de fuentes externas. Principalmente, nos referimos a las universidades y los centros de investigación los cuales son elementos de gran relevancia dentro del distrito (Molina-Morales et al. 2002). Este tipo de instituciones, si bien no tienen por qué circunscribirse al ámbito regional, sí juegan un papel importante en este ámbito a dos niveles: (a) a nivel de formación: éstas son las encargadas de la formación de la comunidad de personas que se convertirá en el capital humano que se incorporará al mercado laboral del distrito; (b) a nivel de transferencia 
de conocimiento: éstas no sólo crean conocimiento junto a otras empresas, sino que también lo transmiten dentro del distrito.

\subsubsection{Las ventajas de los distritos y clústeres industriales y su presencia en la economía mundial}

En este apartado, a partir de una revisión de la literatura, realizamos un análisis de las ventajas que supone la configuración territorial de las empresas en forma de clústeres o distritos industriales. Posteriormente también analizamos la implantación de estas entidades en la economía mundial y comparamos la evolución del número de clústeres en España durante en la última década.

Podemos iniciar este análisis destacando el papel de las economías de escala, las cuales fueron identificadas por Marshall (1920). Este autor identifica una serie de economías externas que obtienen las empresas que se encuentran agrupadas. Se trata de una serie de factores comunes tales como la existencia de recursos humanos cualificados, los proveedores especializados y las escisiones tecnológicas o spillovers (Krugman, 1991). Además, como algo difuso pero real, Marshall identifica lo que denomina atmósfera industrial que es un compendio de recursos intangibles basados en la experiencia, el conocimiento, la información y el know-how comunes a todas las empresas que conforman el distrito. Esta atmosfera industrial, tan beneficiosa para el desarrollo de innovación y mejora de la competitividad, también es identificada posteriormente por Becattini (1989).

Por otro lado, desde la perspectiva de la geografía política, Storper $(1992,1997)$ sugiere que las pertenencia a una aglomeración territorial beneficia a sus integrantes gracias a la aparición de una serie de externalidades o interdependencias que no son susceptibles de ser comercializadas (untraded interdepencies). Este autor sugiere elementos como el mercado de trabajo experimentado y fácilmente disponible, las instituciones públicas y la regulación local o nacional asociada, los valores comunes y el entendimiento particular. Esta idea de interdependencias, las cuales pueden ser consideradas como instituciones ancladas al territorio que pueden incentivar distintas vías de desarrollo en 
el clúster, se encuentra muy relacionada con la idea de arraigo (Granovetter, 1985) anteriormente descrito.

Otros autores (véase por ejemplo Audretsch \& Feldman (1996); Baptista (2000) o Ellison \& Glaeser (1997)) centran el análisis de las ventajas ofrecidas por el clúster en las denominadas difusiones tecnológicas (localized knowledge spillovers). Esta expansión del conocimiento dentro de los límites de la aglomeración es considerada como un bien común y una fuente de conocimiento local de gran valor. La proximidad favorece la generación y transmisión de conocimiento como han demostrado una gran variedad de estudios lo cual, a su vez, incentiva la innovación y, por tanto, la generación de valor dentro del distrito (Amin \& Thrift, 1995; Estornell et al., 2008). Existen una gran cantidad de estudios empíricos, tanto cualitativos como cuantitativos, dedicados a la identificación de las ventajas anteriormente expuestas. Se detectan de este modo, casos de clústeres o distritos distribuidos a lo largo del mundo y pertenecientes a distintos tipos de industria o sectores económicos. En la Tabla 3 se enumeran algunos de estos casos. 
Tabla 3: Estudios empíricos dedicados a la identificación de ventajas en los clústeres o distritos industriales

\section{Localización del \\ clúster estudiado \\ Estudio o investigación}

\begin{tabular}{ll}
\hline Japón & Friedman (1988); Samuels (1987) \\
\hline \multirow{2}{*}{ Estados Unidos } & Saxenian (1994); Saxenian (1991); Scott (1991); Decarolis \& \\
& Deeds (1999); McEvily \& Zaheer (1999) \\
\hline China & Lin, Li, \& Yang, (2011); Sonobe et al. (2002); Wang et al. (2017); \\
& Zhang et al. (2004) \\
\hline Alemania & Herrigel (1996) \\
\hline Chile & Giuliani, (2007b); Giuliani \& Bell(2005); Montero (2004) \\
\hline \multirow{2}{*}{ Italia } & Zeitlin (1992); Rabellotti, (1995); Sammarra \& Belussi (2006); \\
& Boschma \& Ter Wal (2007); Dandi et al. (2006); Sforzi (1990); \\
& Paniccia (1999); Signorini (1994); Becchetti \& Rossi (2000) \\
\hline & Molina-Morales \& Camisón-Zornoza (1998); Contreras Navarro et \\
& al. (2000); Soler i Marco (2000); Molina-Morales \& Martínez- \\
España & Fernández (2004); Hervás-Oliver et al. (2008); Belso-Martínez \\
& (2006); Capó-Vicedo et al. (2008)
\end{tabular}

Fuente: elaboración propia

Los casos expuestos anteriormente pueden presentar algunas limitaciones como son, la especificidad de los casos bajo estudio o su baja posibilidad de generalización. También puede existir un posible sesgo que puede ser introducido por el investigador al realizar la selección de los casos (Paniccia, 1998). Además, desde un punto de vista metodológico, resulta extremadamente difícil delimitar los límites de un clúster o distrito. Incluso Becattini, hace referencia a esta dificultad (Becattini, 1979). La mayor parte de los trabajos realizan, en efecto, una delimitación territorial basada en la densidad de empresas especializadas en un territorio (Becchetti \& Rossi, 2000; Sforzi \& Lorenzini, 2002). No obstante Lazerson \& Lorenzoni (1999b) reconocen que esta limitación podría ser evitada si se tuvieran en cuenta los límites de la homogeneidad cultural (y no exclusivamente territorial) según la propia aproximación distritual de Becattini define. 
No obstante, a pesar de estas limitaciones y siendo muy difícil realizar una generalización, existe un consenso general en relación con el efecto positivo que supone, tanto para las empresas como para los territorios, estar integrados en el nivel meso del clúster. Como indica Harrison (1992), existen incertidumbres acerca de la importancia empírica de un clúster en relación al crecimiento económico y el desarrollo, sus implicaciones distributivas y su estabilidad en el tiempo. Otros autores también muestran un carácter crítico en relación con las ventajas de estos modelos destacando fenómenos como oportunismo dentro del distrito o la existencia de grupos de empresas dominantes que favorecen la asimetría de la demanda y el flujo de información. Bianchi (1998), por ejemplo, pone en duda que los distritos industriales sean configuraciones permanentes y los considera formaciones concretas consecuencia de una situación geopolítica determinada. Muzzi (2004), Glasmeier (1991) o Alberti (2006) manifiestan ciertas reticencias sobre la capacidad de estas entidades para generar avances tecnológicos de importancia. Incluso Micelli \& De Pietro (1997) han considerado a los distritos industriales como redes sin tecnología.

En conclusión, podemos afirmar que las ventajas competitivas a través de las denominadas interdependencias en los clústeres, lejos de ser consideradas condiciones suficientes deberían ser consideradas como condiciones necesarias. En efecto, no podemos afirmar de forma taxativa que el hecho de pertenecer a un clúster sea per se una garantía de obtención de una ventaja superior. Sin embargo, la literatura ha demostrado con una gran cantidad de investigaciones que estas interdependencias sí otorgan cierto potencial para el éxito en términos de probabilidad. Esto se puede conseguir por distintas vías tales como la mejora en la capacidad competitiva de las empresas (Decarolis \& Deeds, 1999; McEvily \& Zaheer, 1999; Paniccia, 1999), la mejora en la performance de las empresas (Signorini, 1994) o el aumento del nivel de exportación (Becchetti \& Rossi, 2000).

Son precisamente las ventajas antes descritas las que han favorecido la aparición de clústeres en todas las regiones del mundo. Estos fenómenos de aglomeración territorial se dan a lo largo de todo el planeta. La literatura sobre este tipo de aglomeraciones industriales ha identificado clústeres en diversas y variadas ubicaciones y sectores. Se han analizado clústeres tanto de países avanzados -véase, por ejemplo, los trabajos de Saxenian (1994); Aydalot et al. (1989) o Schmitz \& Musyck (1994)- como de países en 
vías de desarrollo -véase, por ejemplo, los trabajos de Cassiolato et al. (2003); Nadvi \& Schmitz (1994) o Rabellotti (1995). De igual modo, se han identificado tanto en sectores tecnológicos, intensivos en conocimiento -véase por ejemplo Aydalot \& Keeble, (1988); Breschi \& Lissoni (2009) o Saxenian (1991, 1994)- como en sectores de baja especialización e intensidad tecnológica (medium and low-tech) (véase BelsoMartínez, (2008); Capó-Vicedo et al. (2008); Molina-Morales (2002); Rabellotti (1995) o Staber \& Sautter (2011)). La abundancia de diferentes localizaciones de distritos industriales nos proporciona una idea de la universalidad del fenómeno.

Si centramos el análisis a nivel español (países con una gran tradición de configurar las empresas en distritos), los autores Boix, Sforzi, Galletto, \& Llobet-Domingo (2015) basándose en datos de 2011, realizan una actualización y comparación de su anterior análisis realizado con datos de 2001 (Boix \& Galletto, 2006). En este estudio, los autores calculan la existencia en España de: 215 distritos industriales en el año 2001, y 151 distritos industriales en el año 2011. A pesar de haber sufrido una reducción en el número en términos absolutos, los autores argumentan que éstos no parecen haber perdido importancia en términos puramente geográficos, como demuestra su representación porcentual en los sistemas locales de trabajo españoles (Boix et al., 2015). En la Figura 2 y la Figura 3, podemos observar la comparación entre la situación española en 2001 y 2011 respectivamente, elaborada por estos autores:

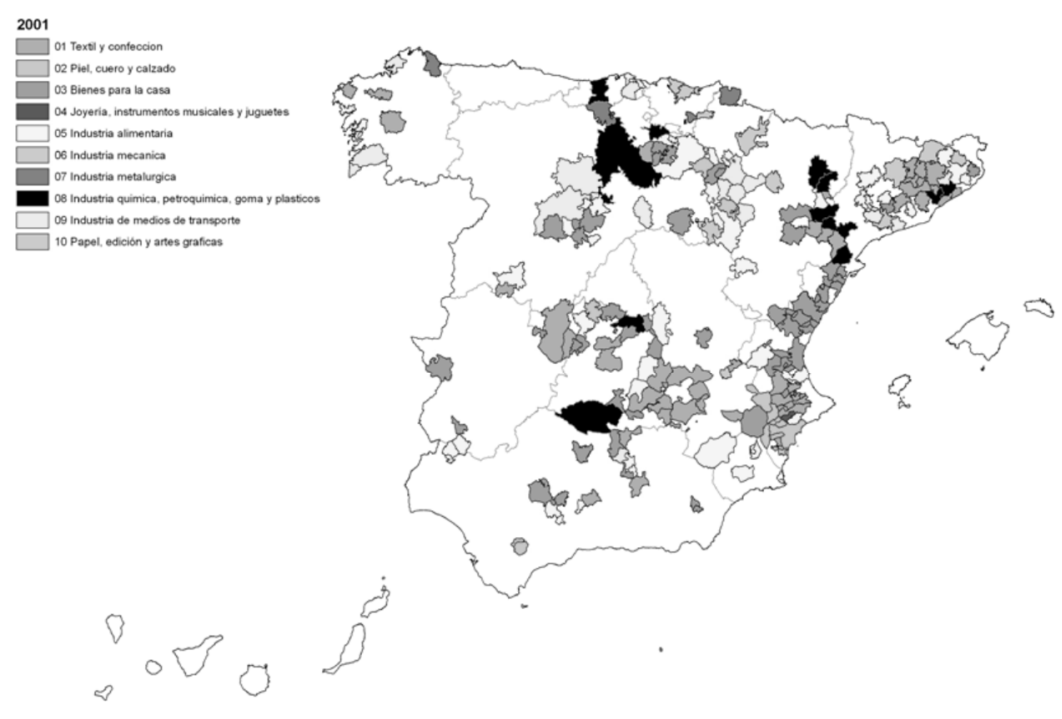

Figura 2: Mapa de los distritos industriales en España en 2001

Fuente: Boix et al. (2015, p. 26) 


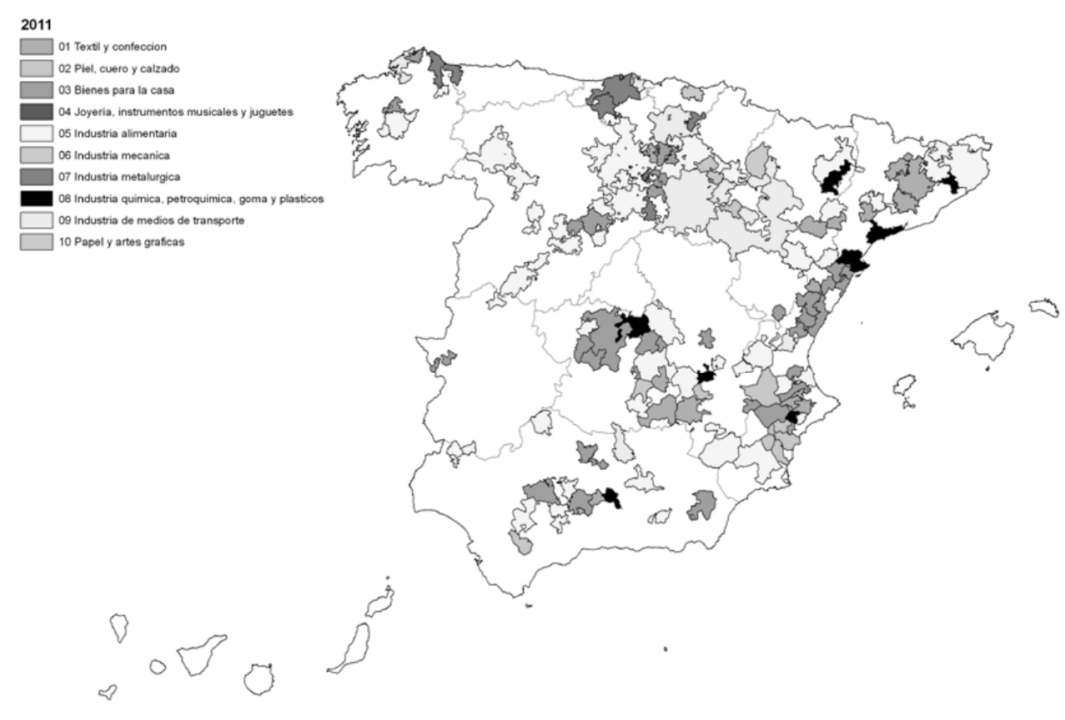

Figura 3: Mapa de los distritos industriales en España en 2011

Fuente: Boix et al. (2015, p. 26)

\subsubsection{Las principales amenazas de los clústeres industriales. La resiliencia como alternativa}

Los clústeres industriales se encuentran sometidos a trayectorias evolutivas como consecuencia de los cambios constantes que se producen en el entorno, en unas ocasiones rápidos o bruscos y en otras ocasiones más graduales. A lo largo de estas trayectorias, estas entidades deben enfrentarse a distintas amenazas las cuales, dependiendo de su magnitud, pueden incluso llegar a desequilibrarlas iniciando así, un camino hacia su desaparición. Los cambios regulatorios, la influencia (o debilidad) de las políticas industriales, las dinámicas de tercerización de algunas de las regiones de los países más industrializados o las crisis económicas son algunas de estas amenazas (Boix et al., 2015). Como muestra, podemos destacar el caso español que, como hemos descrito en el apartado anterior, ha reducido su número de clústeres en los últimos diez años (Boix et al., 2015). En determinadas ocasiones las trayectorias no puede ser simplemente corregidas sin generar un cambio importante en sus rumbos (Zucchella, 2006). Por su impacto, actualidad y relevancia, podemos considerar como las más amenazas más importantes la maduración del ciclo de vida y la globalización. Estos dos 
fenómenos, si bien son de naturalezas intrínsecamente distintas e impactan de formas diferentes, suponen unos retos muy importantes para los clústeres industriales ya que pueden incluso conducir a una trayectoria de declive difícil de corregir.

Desde que a finales de los años 90 del siglo pasado Carminucci \& Casucci (1997) propusieron un modelo de ciclo de vida para los distritos industriales, se ha desarrollado una extensa literatura en relación a la evolución de los mismos bajo esta perspectiva, por ejemplo Fornahl et al. (2010); Menzel \& Fornahl (2009) o Todtling \& Trippl (2004). En esencia, este modelo se centra en establecer un paralelismo con el modelo de ciclo de vida de los productos diferenciando así distintas etapas, desde la génesis hasta la maduración. Incluso en la actualidad, el Observatorio de la Unión Europea para las PYMES (Isaksen \& Hauge, 2002) propone un modelo paradigmático de evolución del clúster industrial formado por seis etapas diferentes.

Sin embargo, la mayoría de los autores se han centrado en el estudio del nacimiento, crecimiento y evolución de los distritos industriales, como por ejemplo Klepper (2010), mientras que pocas contribuciones se han dedicado al análisis de las etapas de declive y posterior crisis o renovación (véase Alberti (2004); Harrison (1994) ; Onida et al. (1992) o Passaro (1994)). De acuerdo con este modelos, la maduración y el declive de un clúster se produce principalmente por su caída en "la trampa de la rígida especialización" (Grabher, 1993), lo que sería comparable con "el diseño dominante" en el ciclo de vida de un producto. En esta etapa existe una falta de renovación tecnológica, institucional, social e incluso cultural. El arraigo, que en otras etapas del ciclo de vida se considera una gran ventaja, se puede convertir, en este momento, en un punto débil (Grabher, 1993; Granovetter, 1985; Uzzi, 1997; Zucchella, 2006). La fórmula basada en la adquisición de la tecnología adecuada y en la obtención de los recursos financieros necesarios (que en otras etapas supone el éxito del distrito industrial) se pone a prueba durante el estado de maduración ya que en la mayor parte de ocasiones se produce un retraso en la introducción de innovaciones verdaderamente novedosas y radicales.

Distintos autores han estudiado como esta falta de novedad conduce a un deterioro comercial y una pérdida de valor añadido (como son por ejemplo Amighini, Rabellotti, Amin, \& Robins (2006); Amin \& Robins (1990); Garofoli \& Mazzoni (1994) o Varaldo \& Ferrucci, (1996)). Como alternativa, autores como Boschma \& Lambooy (2002) o 
Boschma et al. (2002) proponen diferentes trayectorias de evolución para los clústeres industriales maduros. Estas trayectorias renovadoras dependen de especificidades del clúster en cuestión tales como la industria a la que pertenecen o la localización en la que se encuentran (Boschma et al., 2002). A pesar de estas posibles alternativas, resulta evidente que gran parte de los clústeres industriales maduros están enfrentando un periodo de crisis que no solo impacta en sus resultados sino también a su identidad, estructura y cohesión (Zucchella, 2006).

Sin embargo, en la economía global en la que nos encontramos inmersos en la actualidad, el hecho anteriormente descrito contrasta con otro que, en primera aproximación podría, considerarse como contradictorio: se observa una tendencia general de las empresas a agruparse geográficamente en forma de clústeres. La importancia de la localización geográfica en una economía globalizada ha sido considerada como una paradoja por autores como Sölvell \& Zander (1995), mientras que otros, en cambio, han teorizado y encontrado contundentes pruebas empíricas reforzando este hecho (Asheim \& Isaksen, 2002; Markusen, 1996; Storper, 1992). El papel de la globalización como fuerza transformadora ha sido ampliamente reconocida por la literatura (De Marchi, Gereffi, et al., 2018; Nordhaug, 2003). Desde la perspectiva del clúster industrial, este fenómeno consigue desdibujar sus límites naturales (límites geográficos, pero también cognitivos). La economía global ofrece a los miembros de estas redes unos nuevos sistemas relacionales. En este contexto, entender la relación entre los sistemas locales y los mercados globales se convierte en un asunto fundamental para poder establecer trayectorias alternativas de evolución para los distritos industriales (Zucchella, 2006). Desde un punto de vista productivo, los procesos de globalización están generando cambios importantes en los sistemas locales de producción. Este hecho no sólo afecta a los países avanzados sino también a los emergentes (Elola et al., 2013). El desarrollo de las cadenas de valor globales (GVCs) son una prueba de ello; países emergentes, regiones, clústeres y empresas están orientado sus políticas hacía esta nueva estructura de producción global (Cooke, 2013; Ernst, 2009; Yeung, 2009). Por el contrario, los países desarrollados se enfrentan a una crisis de sus sistemas productivos originada por la nueva competencia global y la pérdida de cuota de mercado (como caso paradigmático, podemos destacar el caso de Nokia y el clúster de la tecnología de telefonía móvil (Cooke, 2013)). 
Frente a esta situación de cambio constante originado por las dinámicas descritas, los clústeres industriales se ven obligados desarrollar capacidades de adaptación al entorno para garantizar su supervivencia. La globalización, los cambios tecnológicos o los cambios demográficos obligan a las aglomeraciones a establecer nuevas trayectorias para evitar su desaparición. La resiliencia territorial ha sido considerada como esta capacidad de un territorio para adaptarse y ser flexible a los cambios, tanto internos como externos (Bristow, 2010; Courvisanos et al., 2016; Martin, 2011; Zolli \& Healy, 2012).

El concepto de resiliencia fue originalmente desarrollado en los contextos de la ecología y la psicología, pero pronto fue aplicado a otras disciplinas (como la arquitectura, ingeniería o la respuesta frente a emergencias) para referirse a una cualidad positiva de un objeto, entidad o sistema que debía ser promovida o desarrollada. De forma genérica, la resiliencia se relaciona con la durabilidad, la adaptabilidad o la recuperación (Kaplan, 2002; Luthar, \& Becker, 2000; Wright et al., 2013). En psicología conductual, por ejemplo, la noción de resiliencia describe la capacidad de los individuos de enfrentarse y recuperarse de los traumas o las adversidades. Estableciendo un paralelismo Zolli \& Healy (2012) consideran que en el entorno crecientemente incierto, volátil y propenso al riesgo, el éxito como organización se basa en el nivel de resiliencia que ésta es capaz de alcanzar. En el ámbito de organización de empresas, distintos autores utilizan esta idea en relación a las estrategias que las empresas, u otro tipo de organizaciones, necesitan adoptar si quieren sobrevivir en el incesantemente cambiante mercado global (Denhardt \& Denhardt, 2010; Hamel \& Valikangas, 2003; Starr et al., 2003; Tompkins, 2007).

Las economías siempre han sido propensas a grandes cambios y perturbaciones: recesiones, cambios políticos, crisis de divisas, disrupciones tecnológicas entre otros, son capaces de desestabilizar el patrón de crecimiento económico. Es precisamente en el nivel regional, urbano, local o incluso distritual en el que estas perturbaciones intensifican sus efectos y consecuencias (Martin \& Sunley, 2015). Resulta, por tanto, pertinente considerar la noción de resiliencia a dos niveles de análisis. Por un lado, a nivel de cómo las regiones, las localidades o las aglomeraciones territoriales reaccionan frente a una conmoción o se recuperan de una disrupción (por ejemplo, el cierre o relocalización de una gran empresa, la desaparición de un sector industrial o la 
aparición disruptiva de una nueva tecnología). Por otro lado, desde la perspectiva de la comprensión del papel que estos cambios bruscos pueden tener en relación con la configuración de las dinámicas espaciales de crecimiento económico y desarrollo.

Desde una aproximación más concreta, la definición, la metodología de medida o la interpretación de la resiliencia en el ámbito regional están lejos de conseguir un consenso en la literatura. En la actualidad no existe una metodología general aceptada de cómo el concepto debería ser operacionalizado y medido empíricamente. De igual modo, no existe una teoría de la resiliencia económica regional como tal, sino más bien una discusión de cómo este concepto interacciona con otros, tales como el desarrollo desigual de las regiones, la competitividad regional o la regional path dependence (Bristow, 2010; Hassink, 2010). En la Tabla 4 podemos encontrar las tres principales líneas de definición e interpretación más importantes existentes en la literatura. 
Tabla 4: Principales líneas de definición e interpretación de la resiliencia

\begin{tabular}{|c|c|c|c|c|}
\hline $\begin{array}{l}\text { Línea de } \\
\text { definición }\end{array}$ & Interpretación & $\begin{array}{c}\text { Principal } \\
\text { elemento de } \\
\text { análisis }\end{array}$ & $\begin{array}{c}\text { Principales } \\
\text { ámbitos de uso }\end{array}$ & $\begin{array}{c}\text { Paralelismo con } \\
\text { teorías económicas }\end{array}$ \\
\hline $\begin{array}{l}\text { Resiliencia como } \\
\text { "recuperación" de } \\
\text { una perturbación }\end{array}$ & $\begin{array}{c}\text { El sistema se } \\
\text { recupera y vuelve } \\
\text { al estado anterior a } \\
\text { la perturbación. }\end{array}$ & $\begin{array}{l}\text { Velocidad y } \\
\text { grado de } \\
\text { recuperación }\end{array}$ & $\begin{array}{c}\text { Resiliencia } \\
\text { ingenieril } \\
\text { (ciencias físicas), } \\
\text { ecología }\end{array}$ & $\begin{array}{c}\text { Dinámicas de } \\
\text { equilibrio de } \\
\text { autorrecuperación }\end{array}$ \\
\hline $\begin{array}{l}\text { Resiliencia como } \\
\text { "habilidad de } \\
\text { absorber" una } \\
\text { perturbación }\end{array}$ & $\begin{array}{l}\text { El sistema presenta } \\
\text { una estructura, un } \\
\text { funcionamiento y } \\
\text { una identidad lo } \\
\text { sufrientemente } \\
\text { estables como para } \\
\text { enfrentar las } \\
\text { perturbaciones }\end{array}$ & $\begin{array}{c}\text { Máxima } \\
\text { intensidad de la } \\
\text { perturbación } \\
\text { tolerable por el } \\
\text { sistema antes de } \\
\text { colapsar y } \\
\text { desarrollar un } \\
\text { nuevo estado }\end{array}$ & $\begin{array}{l}\text { Resiliencia } \\
\text { ecológica } \\
\text { extendida } \\
\text { (ecología y } \\
\text { ecología social) }\end{array}$ & $\begin{array}{c}\text { Economía de múltiple } \\
\text { equilibrio }\end{array}$ \\
\hline $\begin{array}{l}\text { Resiliencia como } \\
\text { “capacidad } \\
\text { adaptativa" en } \\
\text { anticipación o } \\
\text { respuesta a una } \\
\text { perturbación }\end{array}$ & $\begin{array}{c}\text { El sistema presenta } \\
\text { la capacidad de } \\
\text { mantener sus } \\
\text { actividades } \\
\text { principales activas } \\
\text { a pesar de las } \\
\text { perturbaciones }\end{array}$ & $\begin{array}{c}\text { Capacidad de } \\
\text { adaptabilidad de } \\
\text { las estructuras, } \\
\text { funciones y } \\
\text { organización del } \\
\text { sistema }\end{array}$ & $\begin{array}{l}\text { Ciencias } \\
\text { psicológicas y } \\
\text { teoría } \\
\text { organizacional }\end{array}$ & $\begin{array}{c}\text { Economía evolutiva; } \\
\text { Teoría de los sistemas } \\
\text { complejos }\end{array}$ \\
\hline
\end{tabular}

Fuente: elaboración propia a partir de Martin \& Sunley (2015)

Existen, por tanto, una amplia variedad de definiciones e interpretaciones de la resiliencia en el ámbito económico regional. De entre todas ellas, una de las definiciones más amplia e inclusiva es la propuesta por Martin \& Sunley (2015), quienes consideran la resiliencia como:

"La capacidad de una región o economía local para resistir o recuperarse de perturbaciones ocasionadas por el mercado, la competencia y el entorno a lo largo de su trayectoria de desarrollo y crecimiento, si es necesario realizando cambios adaptativos en su estructura económica, así como en su configuración social o institucional de forma que ésta región o economía local es capaz de mantener o recuperar su trayectoria de desarrollo previa o transitar hacia nuevos caminos más sostenibles caracterizados por una mayor productividad en 
el uso de los recursos humanos, físicos o medioambientales" (Martin \& Sunley, 2015, p. 13).

Bajo la perspectiva de estos autores, la resiliencia es un proceso adaptativo que comprende una serie de elementos: (a) vulnerabilidad: influencia de las perturbaciones sobre las empresas o trabajadores; (b) perturbación: origen, naturaleza, duración e impacto del cambio; (c) fuerza: magnitud del impacto inicial de la perturbación sobre la región; (d) robustez: mecanismo por el cual todos los actores de adaptan a la perturbación; (e) capacidad de recuperación: intensidad y naturaleza de la trayectoria de recuperación iniciada tras la perturbación (Martin \& Sunley, 2015). La interacción entre todos estos elementos se muestra en la Figura 4

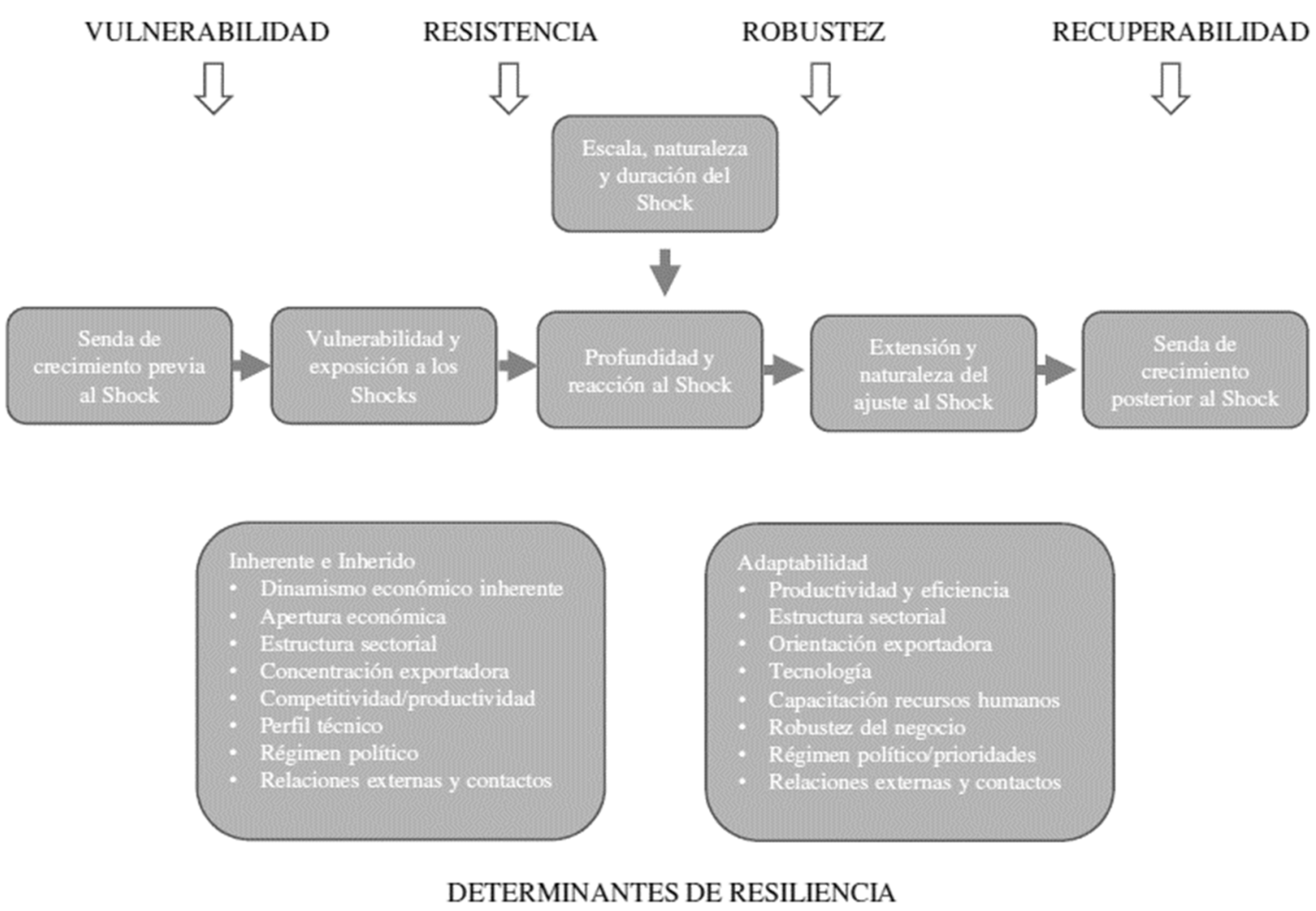

Figura 4: Resiliencia económica regional como proceso

Fuente: elaboración propia a partir de Martin \& Sunley (2015, p. 13)

Desde una perspectiva en la que los sistemas están formados por distintos subsistemas, Walker et al. (2004) consideran cuatro aspectos fundamentales en relación a la resiliencia: latitud, resistencia, precariedad y pananarquía. En la Tabla 5 encontramos 
la definición de estos cuatro conceptos en los que estos autores centran su análisis de la resiliencia.

Tabla 5: Características de la resiliencia de un sistema

\section{Característica}

\section{Descripción}

Máximo cambio soportado por un sistema antes de perder su capacidad de recuperación. Umbral por encima del cual, el sistema tiene dificultades para recuperarse

\begin{tabular}{ll}
\hline Resistencia & $\begin{array}{l}\text { Facilidad o dificultad del sistema a cambiar. Nivel de resistencia al } \\
\text { cambio característico del sistema }\end{array}$ \\
\hline Precariedad & Cercanía del sistema al umbral fijado por la latitud \\
\hline \multirow{2}{*}{ Pananarquía } & $\begin{array}{l}\text { Nivel de interrelación entre los distintos subsistemas que forman el } \\
\text { sistema. Grado de influencia de un subsistema sobre el resto o sobre el } \\
\end{array}$ \\
& sistema global.
\end{tabular}

Fuente: elaboración propia a partir de Walker et al. (2004)

Más allá de definiciones e interpretaciones, otros autores has intentado establecer metodologías de medición de la resiliencia en distintos contextos económicos (véase Briguglio et al. (2006); Courvisanos et al. (2016); Østergaard \& Park (2013) o Sensier et al. (2016)). Como ejemplo, los autores Briguglio et al. (2006) diseñaron un índice a partir de cuatro componentes económicos: (a) macro-estabilidad económica; (b) eficiencia del mercado a nivel microeconómico; (c) nivel de idoneidad en la gobernanza; (d) desarrollo social.

Por otro lado, distintos autores han adaptado la perspectiva regional de la resiliencia al ámbito del clúster industrial (podemos destacar los trabajos de Clark et al. (2010); Elola et al. (2013); Holm \& Østergaard (2011) o Østergaard \& Park (2013)). Estas contribuciones, principalmente, se centran en analizar las trayectorias seguidas por distintos clústeres cuando sufren una perturbación y en describir (normalmente de un modo cualitativo) de qué modo, éstos han mejorado o empeorado su trayectoria. Otros autores como Suire \& Vicente (2014) sugieren tres factores críticos que conducen al desarrollo de resiliencia en los distritos industriales: (a) ubicación de externalidades; (b) enlazamiento de ciclos de vida tecnológicos; (c) propiedades estructurales de las redes de conocimiento. Desde esta aproximación, los autores consideran que los clústeres 
serán resilientes si combinan los efectos beneficiosos de la red local (optimización tecnológica) con los efectos proporcionados por los lazos establecidos con actores externos durante los procesos de co-localización (búsqueda de nuevos mercados o necesidades). Además, proponen una estructura de desarrollo tecnológico basada en una evolución core/periphery en la que el diseño dominante es reforzado y explotado en una estructura cohesiva.

Más allá de estos debates y análisis, la noción económica de resiliencia en el ámbito regional y local está captando el interés de los estratos políticos. La resiliencia está surgiendo como un imperativo "cuyo tiempo ha llegado" en los debates políticos en relación la construcción de habilidades que otorguen a las ciudades, clústeres o regiones de una capacidad desarrollo sostenible a lo largo del tiempo (Martin \& Sunley, 2015). El desarrollo de la resiliencia es vista en todos los niveles políticos (desde la OCDE hasta la Comisión Europea, desde los gobiernos nacionales hasta las agencias de desarrollo local) como una alternativa a las amenazas globales y las trayectorias de estancamiento o declive regional.

\subsection{La innovación y las innovaciones disruptivas}

La literatura se ha centrado durante las últimas décadas en el papel que la innovación ha desempeñado como motor de los cambios económicos y sociales. Como consecuencia de este hecho, el conocimiento que se ha adquirido acerca de las dinámicas innovadoras, así como de sus factores decisivos y su impacto económico y social, ha aumentado enormemente. Tradicionalmente, los enfoques económicos de la innovación trataban el proceso de innovación en sí como una "caja negra” por lo que se centraban, bien en la identificación de sus causas (incluyendo las fuentes de innovación), o bien en la evaluación de sus consecuencias. Desde las últimas décadas del siglo 20, han proliferado una gran cantidad de centros de investigación y departamentos universitarios enfocados en el papel que la innovación juega en el ámbito económico y social. Prueba de ello es la gran cantidad de artículos que se han publicado al respecto. Muchos de éstos tienen una orientación multidisciplinar lo que sugiere la posibilidad de abordar este concepto desde distintas perspectivas (sociología, management, organización empresarial, etc.). 
Debido a que el objetivo de esta tesis es entender cómo los clústeres industriales pueden evolucionar a través de fenómenos de innovación disruptiva, la innovación es uno de los temas centrales de la misma. Resulta conveniente, por tanto, realizar en primer lugar una revisión teórica de este concepto, partiendo de las definiciones más generales y acabando en la descripción de sus concepciones más amplias: los sistemas de innovación.

En la parte final de este apartado profundizaremos en el concepto de innovación disruptiva. De este modo, finalizaremos este apartado con una revisión del tipo de innovación sobre el que se sustenta esta investigación. A través de esta revisión, pondremos de manifiesto cómo la literatura otorga a éstas una importante potencialidad para transformar de forma revolucionaria las trayectorias de las tecnologías, las empresas, las industrias y, consecuentemente, las economías.

\subsubsection{El concepto de innovación}

La innovación es un concepto que representa todas aquellas acciones que conducen a la aparición en el mercado de nuevos productos, servicios o procesos, pero también la mejora sustancial de los existentes.

La innovación hoy en día, se puede considerar como uno de las principales fuentes de valor para las empresas ya que permite obtener y mantener ventajas competitivas (Anderson et al.,2004; Hitt et al.,2012; Teece et al.,1997). A través de la innovación, los productos se hacen más competitivos, se generan nuevas categorías de producto y los mercados evolucionan. El proceso innovador es la respuesta de la empresa a la fuerte y creciente presión del mercado y la consecuente necesidad de no ser alcanzada por la competencia.

La innovación es el modo a través del cual las empresas pueden adaptarse a un mundo altamente cambiante en el que el ciclo de vida de productos y servicios es cada vez más corto debido principalmente a: (a) el desarrollo técnico, que se ha acelerado en los últimos tiempos a medida que lo ha hecho el mundo digital; (b) la internacionalización de la economía, como consecuencia de la tendencia creciente a la eliminación de 
fronteras comerciales y el desarrollo de las nuevas tecnologías de la información; (c) personalización de los mercados, los mercados tienden a desmasificarse ya que el consumidor demanda productos menos genéricos, más personalizados.

La innovación ha sido definida por una gran cantidad de autores pertenecientes a distintas disciplinas muy diversas. Una prueba de ello se muestra en el estudio llevado a cabo por Baregheh et al. (2009). Estos autores realizaron un análisis bibliográfico con relación a la definición de innovación, sus tipos y sus procesos. Después de analizar revistas clave, tales como Management Science, Journal of Management Studies, Organization Science o Administrative Science Quarterly obtuvieron 60 definiciones provenientes de siete disciplinas distintas (Tabla 6)

Tabla 6: Relación de definiciones de Innovación encontradas en la literatura desde 1966 a 2008

\begin{tabular}{ccc}
\hline Disciplina & $\begin{array}{c}\text { Número de definiciones } \\
\text { encontradas }\end{array}$ & $\begin{array}{c}\text { Periodo de } \\
\text { publicación }\end{array}$ \\
\hline Business and management & 18 & $1966-2007$ \\
\hline Economics & 9 & $1934-2004$ \\
\hline Organization studies & 6 & $1953-2008$ \\
\hline $\begin{array}{c}\text { Innovation and } \\
\text { entrepreneurship }\end{array}$ & 9 & $1953-2007$ \\
\hline Technology, science and \\
engineering
\end{tabular}

Fuente: elaboración propia a partir de Baregheh et al. (2009)

Desde una perspectiva un poco más global, la innovación puede ser considerada como un factor clave en el desarrollo tecnológico de las naciones. A partir de la década de los años 60s del pasado siglo, empezaron a aparecer enfoques que trataban de explicar la relación entre el potencial innovador de una nación y su crecimiento económico. 
Fue especialmente relevante la aportación de Posner (1961), quién explicó la diferencia entre el crecimiento económico de dos naciones con diferente nivel económico y desarrollo tecnológico, como el resultado de dos variables: por un lado la innovación, un elemento que genera divergencia puesto que tiende a aumentar la diferencia; y por otro lado, la imitación, un elemento que genera convergencia puesto que tiende a reducirla.

Fagerberg $(1988 ; 1987)$ introduce un tercer factor responsable de estas diferencias, el esfuerzo comercial de explotación de la tecnología. En definitiva, se trata de lo que los académicos han llamado "gap tecnológico" o modelos "norte-sur” (Fagerberg, 1994).

La innovación se ha ido convirtiendo gradualmente en el factor más influyente que explica las diferencias de crecimiento económico entre naciones (Fagerberg \& Verspagen, 2002).

Muchos autores en el ámbito académico han abordado la definición de la innovación. Uno de las primeras fue la desarrollada por Schumpeter (1934) quien de una forma más general, y no exclusivamente en base a la dimensión tecnológica, considera la innovación como la posible introducción en el mercado de cinco aspectos que se muestran en la Tabla 7. 
Tabla 7: Principales aspectos considerados como innovación por Schumpeter (1934)

\begin{tabular}{|c|c|}
\hline $\begin{array}{l}\text { Aspecto } \\
\text { introducido }\end{array}$ & Descripción \\
\hline Un bien & $\begin{array}{l}\text { Aquellos bienes (o nueva clase de bienes) a los que los } \\
\text { consumidores no están familiarizados }\end{array}$ \\
\hline $\begin{array}{l}\text { Un método de } \\
\text { producción }\end{array}$ & $\begin{array}{l}\text { Aquellos métodos no experimentados en el área afectada o } \\
\text { también aquellas nuevas formas de comercializar un producto }\end{array}$ \\
\hline $\begin{array}{l}\text { Un nuevo mercado } \\
\text { en un país }\end{array}$ & $\begin{array}{l}\text { Introducción en un nuevo mercado tanto si éste ya existía como si } \\
\text { no en otro país }\end{array}$ \\
\hline $\begin{array}{l}\text { Una nueva fuente } \\
\text { de suministro }\end{array}$ & $\begin{array}{l}\text { Nuevo acceso a una fuente alternativa de materia prima o } \\
\text { producto semielaborado tanto si la fuente ya existe como si ha de } \\
\text { ser creada de nuevo }\end{array}$ \\
\hline $\begin{array}{l}\text { Una nueva } \\
\text { estructura de } \\
\text { mercado }\end{array}$ & $\begin{array}{l}\text { Nueva reorganización de un mercado que altera los equilibrios de } \\
\text { las empresas que lo integran, como el establecimiento o } \\
\text { destrucción de una situación monopolística. }\end{array}$ \\
\hline
\end{tabular}

Fuente: Elaboración propia a partir de Escorsa \& Valls (2003)

Esta definición clásica ha sido complementada y matizada durante las últimas décadas.

En la Tabla 8, se presentan algunas de las definiciones más relevantes realizadas. 
Tabla 8: Distintas definiciones de innovación

\begin{tabular}{|c|c|}
\hline $\mathbf{p r}$ & Definición \\
\hline $\begin{array}{l}\text { Pavón y Goodman } \\
(1981, \text { p. 19) }\end{array}$ & $\begin{array}{l}\text { La innovación es el conjunto de actividades, inscritas en un determinado periodo } \\
\text { de tiempo y lugar, que conducen a la introducción con éxito en el mercado, por } \\
\text { primera vez, de una idea en forma de nuevos o mejores productos, servicios o } \\
\text { técnicas de gestión y organización. }\end{array}$ \\
\hline $\mathrm{Ge}$ & $\begin{array}{l}\text { La innovación es el proceso en el cual a partir de una idea, invención o } \\
\text { reconocimiento de una necesidad se desarrolla un producto, técnica o servicio útil } \\
\text { hasta que sea comercialmente aceptado. }\end{array}$ \\
\hline $\begin{array}{l}\text { Nelson y Winter } \\
(1982, \text { p. 135) }\end{array}$ & $\begin{array}{l}\text { La innovación es: a) los nuevos productos o servicios, nuevos procesos, y nuevas } \\
\text { estructuras organizacionales que las compañias utilizan para competir entre ellas } \\
\text { y satisfacer la demanda de los clientes; b) la adopción de una nueva idea, proceso } \\
\text { o servicio, desarrollado internamente o adquirido externamente como una función } \\
\text { de las habilidades técnicas, estratégicas y administrativas de una compañía. }\end{array}$ \\
\hline $\begin{array}{l}\text { Pavitt } \\
344)\end{array}$ & $\begin{array}{l}\text { La innovación es un nuevo o mejor producto o proceso de producción } \\
\text { comercializado con éxito. }\end{array}$ \\
\hline $\begin{array}{l}\text { Tushma } \\
(1986,1\end{array}$ & $\begin{array}{l}\text { La innovación es la creación de un producto, servicio o } \\
\text { proceso que es nuevo para una unidad de negocio. }\end{array}$ \\
\hline $\begin{array}{l}\text { nderson } \\
\text { 2) }\end{array}$ & $\begin{array}{l}\text { La innovación ha sido definida como la introducción y aplicación en un grupo, en } \\
\text { una organización o en la sociedad de procesos, productos o procedimientos } \\
\text { nuevos para la unidad de adopción y que intentan beneficiar al grupo, a la } \\
\text { organización o a la sociedad. }\end{array}$ \\
\hline $\begin{array}{l}\text { Damanpour } \\
\text { y Gopalakrishnan } \\
(1998, \text { p. } 3)\end{array}$ & $\begin{array}{l}\text { La innovación puede ser llevada a cabo por las organizaciones por dos vías: pueden } \\
\text { generala o adoptarla. } \\
\text { Las innovaciones que se generan en una organización suelen ser para su propio uso o para } \\
\text { la venta a otras organizaciones. La generación de innovación es un proceso que da un } \\
\text { resultado -un nuevo producto, servicio, programa o tecnología. Si este resultado es } \\
\text { entonces adquirido por otra organización, la segunda organización pasa por otro proceso, } \\
\text { la adopción de la innovación }\end{array}$ \\
\hline $\operatorname{OCDE}(2005$, p. 46$)$ & $\begin{array}{l}\text { Una innovación es la implementación de un nuevo o significativamente mejorado producto } \\
\text { (bien o servicio), o proceso, un nuevo método de comercialización, o de un nuevo método } \\
\text { organizativo, o de las prácticas internas de la empresa, la organización del lugar de } \\
\text { trabajo o de las relaciones exteriores. La empresa innovadora es la que implementa una } \\
\text { innovación durante el periodo de tiempo considerado. }\end{array}$ \\
\hline Plessis $(2007$, p. 3$)$ & $\begin{array}{l}\text { La innovación como la creación de nuevos conocimientos e ideas para facilitar nuevos } \\
\text { resultados empresariales, con el fin de mejorar los procesos y estructuras internas de las } \\
\text { empresas y crear } \\
\text { productos y servicios. La innovación abarca tanto la radical como la incremental. }\end{array}$ \\
\hline
\end{tabular}




\begin{tabular}{ll}
\hline & Innovación: una innovación es un producto nuevo o significativamente mejorado (bueno o \\
& servicio) introducido en el mercado o la introducción dentro de una empresa de un proceso \\
& nuevo o significativamente mejorado. Las innovaciones se basan en los resultados de nuevos \\
& desarrollos tecnológicos, nuevas combinaciones de tecnología existente o la utilización de \\
Departamento de & otros conocimientos adquiridos por la empresa. Las innovaciones pueden ser desarrolladas \\
Comercio e Industria & por la empresa innovadora o por otra empresa. Sin embargo, las innovaciones puramente \\
del Reino Unido ${ }^{4}$ & vendidas totalmente producidas y desarrolladas por otras empresas no se incluyen como \\
& actividad de innovación. Las innovaciones deberian ser nuevas para la empresa afectada. \\
& Para las innovaciones de producto no necesariamente tienen que ser nuevas para el \\
& mercado y para las innovaciones de proceso la empresa no tiene que ser necesariamente la \\
& primera que ha introducido el proceso
\end{tabular}

Fuente: elaboración propia

Al analizar todas estas definiciones podemos observar que, en efecto, existen algunos matices que las diferencian. No obstante, todas ellas coinciden en el hecho de que no existe innovación sin la introducción con éxito en el mercado de la novedad en cuestión. A este respecto, resulta muy interesante la diferenciación clara entre lo que supone una invención y una innovación.

Fagerberg (2004) realiza esta distinción considerando la invención como la primera ocurrencia de una idea para un nuevo producto o proceso, mientras que reserva el termino innovación para la primera comercialización de la idea. El origen de ambos fenómenos suele ser distinto. Mientras que la invención se puede originar en diversos ámbitos (universidades, laboratorios de investigación, iniciativas individuales, etc.), la innovación suele llevarse a cabo en el seno de las empresas como resultado de una estrategia comercial. Por otro lado, la distancia que existe -en términos de tiempo y necesidades para la implementación- entre innovación e invención puede variar según el sector; en campos como la biotecnología o la programación informática, ésta suele ser pequeña por lo que prácticamente ambas pueden solaparse. En otros campos, como el diseño industrial o la ciencia de materiales, la distancia suele ser mayor ya que los recursos necesarios para transformar una invención en una innovación son elevados, así como el desarrollo tecnológico requerido. Esta diferenciación aparece, en consecuencia, entre las figuras del inventor y el innovador (denominado por Schumpeter como

\footnotetext{
${ }^{4}$ Esta definición se ha obtenido de la web https://www.gov.uk/government/publications/business-plan2011-2015-department-for-business-innovation-and-skills-annex-d-technical-definitions-for-bis-inputand-impact-indicators consultada en Marzo de 2015
} 
entrepreneur). Aquel que desarrolla ideas (inventor) sin una implementación y comercialización, no puede ser considerado como un innovador.

De entre todas las definiciones y matices realizados en la literatura, resulta especialmente relevante por su claridad, rigurosidad y amplitud, la propuesta por la OCDE en su Manual de Oslo (2005) que se presenta en la Tabla 8. Esta definición no sólo considera innovación bajo el prisma de los bienes o servicios, sino también en relación con los métodos y procesos necesarios para llevar a cabo una actividad económica en el seno de una compañía.

El enfoque propuesto por la OCDE se radica fundamentalmente en el concepto de la implementación. La innovación debe ser implementada para poder ser considerada como tal. El concepto de implementación es definido como: (a) la introducción en un mercado de un nuevo, o sustancialmente mejorado, producto; (b) el establecimiento real en el ámbito operacional de una empresa de nuevos procesos, métodos de comercialización o métodos organizacionales. En consecuencia, la OCDE (2005, p. 47) define los distintos roles innovadores como:

- “Actividades innovadoras son todas las etapas científicas, tecnológicas, organizacionales, financieras y comerciales que realmente conducen, o intentan conducir, a la implementación de las innovaciones”.

- "Empresa innovadora es aquella que ha implementado una innovación durante el periodo en revisión".

- "Empresa con un producto o proceso innovador es aquella que ha implementado un nuevo, o significativamente mejorado producto o proceso durante el periodo bajo revisión". 


\subsubsection{Clasificaciones según el objeto de la innovación}

Muchos autores han clasificado la innovación en base a aquello en lo que se centra el propio proceso innovador. En base a este criterio, destacamos tres de las clasificaciones más clásicas:

- Innovaciones de producto vs innovaciones de proceso

- Innovaciones tecnológicas vs innovaciones organizativas

- Innovaciones de producto, proceso, marketing y organizativas

A continuación, describimos brevemente cada una de estas clasificaciones:

\subsubsection{Innovaciones de producto e innovaciones de proceso}

Originariamente Schumpeter (1934), basándose en el objeto de innovación, distinguió cinco tipos diferentes de innovación (nuevos productos, nuevos métodos de producción, nuevas fuentes de suministro, nuevos mercados y nuevas formas organizativas). Sin embargo, en un primer momento la literatura se centró fundamentalmente en los dos primeros tipos propuestos: las innovaciones de producto y las innovaciones de proceso.

Schmookler (1966) consideraba crítica la distinción entre tecnología de producto y tecnología de producción para explicar el fenómeno innovador. Mientras que la tecnología de producto era el conocimiento sobre cómo crear o mejorar productos, la tecnología de producción era el conocimiento sobre cómo producirlos.

De forma análoga, Abernathy \& Utterback (1978) distinguen entre innovaciones de producto y proceso. Estos autores consideran que a medida que la empresa evoluciona, también lo hacen, en cierta medida, el tipo de innovaciones que realizan o, dicho de otro modo, que el carácter de la innovación cambia a medida que la empresa que tiene éxito madura. De este modo en etapas tempranas el esfuerzo se sitúa en innovaciones de producto que puedan ser asimiladas por el mercado. Posteriormente, en etapas donde el producto ya tiene una demanda, el objetivo de las innovaciones consiste en mejorar los procesos que consiguen introducirlo de forma masiva en el mercado. La reducción de costes sería un ejemplo en esta segunda etapa. 
Fagerberg (2004) considera que el argumento principal por el que se realiza la distinción entre innovaciones de producto y de proceso se basa en la asunción de que el impacto social y económico que tienen estas innovaciones es diferente. En esta línea Edquist, Hommen \& McKelvey (2001) consideran que mientras que la introducción de un nuevo producto tiene un claro efecto positivo en el crecimiento de los ingresos y el empleo, la innovación de proceso, debido a su carácter fundamentalmente de búsqueda de la eficiencia, puede tener un efecto más ambiguo. En esta misma obra, los autores realizan una distinción a un segundo nivel de manera que las innovaciones de producto a su vez se dividen en innovaciones de bienes y servicios, mientras que las innovaciones de proceso se subdividen en tecnológicas y organizativas (ver Tabla 9).

Tabla 9: Clasificación de la innovación según Edquist et al. (2001)

\begin{tabular}{ll}
\hline \multirow{2}{*}{$\begin{array}{l}\text { Innovaciones de } \\
\text { producto }\end{array}$} & $\begin{array}{l}\text { Innovaciones de bienes: aquellos bienes materiales } \\
\text { manufacturados o producidos en los sectores primarios. }\end{array}$ \\
\cline { 2 - 2 } & $\begin{array}{l}\text { Innovaciones de servicios: aquellos servicios intangibles } \\
\text { normalmente consumidos al ser producidos. }\end{array}$ \\
\hline \multirow{2}{*}{$\begin{array}{l}\text { Innovaciones de } \\
\text { proceso }\end{array}$} & \begin{tabular}{l} 
de producción. \\
\cline { 2 - 2 }
\end{tabular} \\
& $\begin{array}{l}\text { Innovaciones } \text { organizativas: nuevas formas organizativas, nuevas } \\
\text { formas de organizar el trabajo. }\end{array}$ \\
\hline
\end{tabular}

Fuente: Elaboración propia a partir de Edquist et al. (2001).

Por su parte, los autores Damanpour \& Gopalakrishnan (2001) utilizan la misma distinción entre innovaciones de producto y proceso para estudiar los patrones de adopción de ambas en el marco de las empresas individuales. Cabe puntualizar que la mayor parte de la literatura sobre innovación, al hablar de dinámicas innovadoras suele reconocer una similitud entre producto y servicio. En efecto, cuando se analizan factores básicos de las dinámicas innovadoras podemos considerar que los servicios ofrecidos por una empresa pueden ser conceptualizados como productos fabricados por una firma manufacturera puesto que el sector servicios y el manufacturero presentan más similitudes que diferencias (Sirilli \& Evangelista, 1998). En definitiva, ambos tienen la misma punto de referencia objetivo en el proceso innovador, el cliente (Abernathy \& Utterback, 1978). 


\subsubsection{Innovaciones tecnológicas e innovaciones organizativas}

A medida que se van entendiendo los procesos innovadores y éstos van aumentando su complejidad, un número importante de investigadores realizan la distinción entre innovaciones organizativas y tecnológicas.

Las innovaciones tecnológicas son aquellas relacionadas con los procesos productivos y que centran su objeto en las operaciones de la compañía y el desarrollo de nuevos productos. (Daft, 1978; Daft \& Damanpour, 1996; Knight, 1967; Pavitt, 1984; Tushman \& Nadler, 1986). Las innovaciones organizativas, de forma general, se refieren a la creación o adopción de una idea o comportamiento novedoso para la organización. Sin embargo, esta última consideración ha estado sujeta a diferentes interpretaciones en la literatura. Uno de los principales argumentos para clasificar de esta manera las innovaciones radica en la idea de que la capacidad de innovación de una organización es una condición necesaria para la generación e implantación de manera exitosa de nuevas tecnologías (Lam, 2005).

Los autores que han centrado sus trabajos en la relación entre organización e innovación, lo han abordado desde tres puntos de vista diferentes: (a) la relación entre una estructura y su capacidad para innovar (Burns \& Stalker, 1961; Mintzberg, 1979); (b) los procesos cognitivos que conducen a una organización a resolver los retos desarrollando ideas innovadoras (Ikujiro Nonaka \& Takeuchi, 1995); (c) los procesos que subyacen de la introducción de nuevas formas organizativas o cómo las organizaciones se adaptan a un entorno cambiante (Burgleman, 1991; Child, 1997).

\subsubsection{Innovaciones de producto, proceso, marketing y organizativas}

El manual de Oslo (2005) en su tercera edición, atendiendo al criterio de clasificación establecido en este apartado (aquel que se basa en el objeto de la innovación), distingue entre cuatro tipo de innovaciones. Esta edición intenta ampliar, pero también mantener la continuidad con respecto a la anterior donde únicamente diferenciaba entre innovaciones de producto e innovaciones de proceso. 
A continuación, se presenta una descripción más detallada de estos cuatro tipos ofrecida por el manual de Oslo (2005):

- Innovación de producto: consiste en la introducción de un bien o servicio que es nuevo o que se ha mejorado significativamente con respecto a sus características o uso para el que está destinado. Esta innovación incluye mejoras importantes en las especificaciones técnicas, en los componentes, en los materiales, en los softwares incorporados o en otras características funcionales. Por otro lado, se considera nиеvo producto aquel bien o servicio que difiere significativamente en sus características o en los usos para los que está destinado con respecto a los bienes o servicios producidos anteriormente por la compañía. También se considera innovación de producto el nuevo uso de un producto, aunque éste únicamente haya sufrido pequeños cambios en sus especificaciones técnicas.

Se establece que una mejora significativa de un producto puede ocurrir a través de cambios en materiales, componentes y otras características que mejoran su desempeño. También se explicita que la innovación de producto en un servicio puede incluir tanto, mejoras en cómo estos son ofrecidos, en la adición de nuevas funciones o características a los existentes o en la introducción de servicios completamente nuevos. Por último, se destaca que los cambios en el diseño de un producto que no influyen en el funcionamiento del mismo no pueden ser considerados como una innovación de este tipo.

- Innovación de proceso: consiste en la implementación de un nuevo o significativamente mejorado proceso productivo o de distribución. Mientras que los procesos productivos, incluyen las técnicas, los equipos y los sistemas informáticos para producir bienes o servicios, los procesos de distribución comprenden la logística y abarcan el equipamiento, los sistemas informáticos y las técnicas para conseguir materias primas, distribuir suministros dentro de la propia empresa o a otras empresas como producto final. Cabe destacar que las innovaciones de proceso pueden ser realizadas con distintos fines tales como disminuir los costes de fabricación o distribución, aumentar la calidad o producir productos significativamente mejorados. 
Como en el caso anterior, la innovación de proceso también puede llevarse a cabo si hablamos de un servicio. En este caso, este tipo de innovaciones hace referencia a los métodos de creación y prestación de los mismos en la medida en que estos sean nuevos o sensiblemente mejorados. Por último, también son consideradas innovaciones de proceso aquellas técnicas, equipamientos 0 sistemas informáticos nuevos o sensiblemente mejorados que se encuentran orientados a las actividades auxiliares de la empresa tales como compras, contabilidad o mantenimiento.

- Innovación de marketing: consiste en la implementación de un nuevo método de comercialización que implique cambios significativos en el diseño o su envase, así como en su posicionamiento en el mercado, su promoción o su precio. Se hace hincapié en el hecho de las nuevas técnicas utilizadas no pueden formar parte de métodos previamente establecidos en la empresa; tampoco a cambios estacionales o regulares en las técnicas de comercialización ya establecidas en la compañía. El objetivo de estas innovaciones es, en definitiva, incrementar las ventas de la empresa a través de la mejor satisfacción de las necesidades de los clientes, de la apertura de nuevos mercados, o de un nuevo posicionamiento de los productos en el mercado.

Son aceptados como innovaciones de marketing los cambios en la forma o apariencia de los productos (sin alterar las características funcionales o de uso de los mismos) o los nuevos envases (para aquellos productos en los que el envase es el mayor determinante de su apariencia). También nos podemos referir a la creación de nuevos canales de venta (sin incluir a la logística ya que está más relacionada con la eficiencia), al uso de nuevas técnicas de venta de los productos, al diseño de nuevas marcas que posicionen nuestros productos en otros mercados o a la asimilación de nuevas estrategias de precios como el establecimiento de variabilidad de precio en función de la demanda.

- Innovación de organización: consiste en la implementación de nuevos métodos organizativos bien en las prácticas de la empresa, bien en la organización del lugar de trabajo o bien en las prácticas utilizadas en las relaciones externas. El objetivo principal de las mismas es mejorar el resultado de la empresa a través 
de la reducción de costes administrativos o los costes de transacciones, la mejora de la satisfacción en el trabajo (y por lo tanto el aumento de la productividad laboral), el acceso a bienes no comercializables (como el conocimiento tácito) o la reducción de coste de los suministros.

Al igual que en el resto de los tipos de innovación propuestas por el manual de Oslo, se destaca el hecho de que las nuevas técnicas organizativas para ser consideradas innovadoras no pueden haber sido utilizadas con anterioridad en la empresa y deben haber sido fruto de una decisión estratégica tomada por la dirección. Podemos considerar como tales innovaciones los nuevos métodos de organización de laboral (gestión de la información, sistemas de gestión), las nuevas formas de establecer la toma de decisiones dentro y entre las actividades o secciones de la empresa, la distribución de actividades, el establecimiento de nuevas formas de colaborar con centros de investigación o la implementación de nuevos métodos de integración con suministradores (o la inversa de externalizar ciertas actividades).

Puesto que en algunas ocasiones resulta difícil establecer una caracterización clara entre estos tipos de innovaciones, así como categorizar la actividad innovadora de una empresa en un único tipo, el propio manual presenta una serie de directrices para facilitar la distinción y eliminar ambigüedades. También establece qué cambios dentro de una compañía no pueden ser considerados innovación; algunos ejemplos son: el cese del uso de un proceso (aunque suponga un beneficio para la empresa), la actualización de los equipos existentes, un aumento de productividad por el simple cambio de los precios de los factores de producción, etc.

\subsubsection{Clasificaciones según la importancia de la innovación}

Una vez establecidos los objetos sobre los que se puede desarrollar la innovación, resulta necesario poder clasificar las innovaciones según su magnitud. Parece evidente que no todas las innovaciones tienen el mismo alcance ni generan el mismo impacto en las compañías, los mercados o la sociedad. Por tanto, muchos autores han clasificado las 
innovaciones teniendo en cuenta este hecho, según la repercusión, la originalidad o, en definitiva, la magnitud del cambio que éstas han generado.

A continuación, se presentan algunos de los criterios de taxonomía más relevantes:

\subsubsection{La originalidad de la innovación: innovaciones radicales e innovaciones incrementales}

Autores como Daft \& Damanpour (1996), Dewar \& Dutton (1986) o Ettlie et al. (1984) han establecido una diferenciación de las innovaciones en función de su originalidad, distinguiendo así entre innovaciones radicales e incrementales. Mientras que las innovaciones radicales (también llamadas disruptivas) son aquellas que suponen una ruptura con respecto a la situación anterior, las invocaciones incrementales consisten en mejoras de los productos ya existentes o los procesos ya conocidos.

Por otra parte, Tidd \& Bessant (2009) consideran que una parte importante de las innovaciones tienen lugar dentro de un marco de reglas del juego que son claramente conocidas y entendidas por los protagonistas de las mismas. Éstos realizan la actividad innovadora, en consecuencia, utilizando sus herramientas habituales. En este contexto de mejora continua, unos innovadores lo hacen mejor que otros y, por lo tanto, tienen más éxito, pero tienen en común el hecho de que se ciñen a unas mismas reglas del juego que son aceptadas y que no cambian.

Sin embargo, en algunas ocasiones sucede algún hecho que distorsiona el marco establecido y que altera las reglas del juego existentes. Cuando esto sucede, se puede producir una alteración del statu quo de forma que aparecen nuevas oportunidades y nuevos actores que, en cierta medida, pueden forzar a los actores ya existentes a redefinir sus estrategias o actuar de formas distintas a las habituales. Éste es el fundamento de la teoría de innovación definida por Schumpeter en la que define el proceso de destrucción creativa como el eje fundamental de la misma (Foster \& Kaplan, 2011; Schumpeter, 1942). En la misma línea argumental, Fagerberg \& Verspagen (2002) consideran que las innovaciones radicales abren las posibilidades a cambios de gran alcance en la trayectoria y velocidad del crecimiento económico debido a que alteran de manera disruptiva la estructura económica existente y sus 
interrelaciones. Considerando esta alteración (en la que se crean nuevas condiciones de juego en un sector) los actores emergentes tienden a hacerlo mejor puesto que no tienen que luchar contra la inercia establecida ni abandonar su dinámicas habituales para aprender otras y desarrollar nuevas habilidades (Tidd \& Bessant, 2009).

En la Tabla 10 se presentan una serie de fuentes de discontinuidad consideradas por estos autores como orígenes de retos para las organizaciones que las experimentan. La habilidad para detectar y saber responder frente a ellas puede establecer la diferencia entre el éxito o fracaso de una estrategia empresarial. 
Tabla 10: Fuentes de discontinuidad y sus consecuencias

\begin{tabular}{|c|c|c|c|}
\hline $\begin{array}{c}\text { Fuente de } \\
\text { discontinuidad }\end{array}$ & Fundamento & Reto que se plantea & Ejemplo \\
\hline $\begin{array}{l}\text { Nuevo mercado } \\
\text { emergente }\end{array}$ & $\begin{array}{l}\text { Normalmente los mercados } \\
\text { evolucionan de manera } \\
\text { gradual pero en ciertos } \\
\text { momentos pueden aparecer } \\
\text { mercados completamente } \\
\text { nuevos }\end{array}$ & $\begin{array}{l}\text { Los actores establecidos no } \\
\text { detectan estos mercados al } \\
\text { estar enfocados en los } \\
\text { mercados existentes o bien } \\
\text { pueden despreciarlos al } \\
\text { considerarlos pequeños o } \\
\text { fuera de su público objetivo. }\end{array}$ & $\begin{array}{l}\text { Telefonía móvil } \\
\text { Discos duros }\end{array}$ \\
\hline $\begin{array}{l}\text { Nueva tecnología } \\
\text { emergente }\end{array}$ & $\begin{array}{l}\text { Aparición de un salto } \\
\text { tecnológico (producto o } \\
\text { proceso) resultado bien de la } \\
\text { convergencia de varias } \\
\text { corrientes maduras o bien de } \\
\text { una corriente disruptiva }\end{array}$ & $\begin{array}{l}\text { Difícil de detectar puesto } \\
\text { que se puede encontrar más } \\
\text { allá de la periferia } \\
\text { tecnológica establecida, es } \\
\text { decir, más allá de las } \\
\text { corrientes habituales de } \\
\text { extensión tecnológica } \\
\text { propia del mercado. }\end{array}$ & Fotografía digital \\
\hline $\begin{array}{l}\text { Aparición de un } \\
\text { nuevo régimen } \\
\text { político o nuevos } \\
\text { reglamentaciones } \\
\text { públicas }\end{array}$ & $\begin{array}{l}\text { Cambios políticos, así como } \\
\text { cambios en el marco } \\
\text { reglamentario pueden } \\
\text { cambiar la estructura } \\
\text { socioeconómica del mercado } \\
\text { o las reglas del mismo }\end{array}$ & $\begin{array}{l}\text { La mentalidad acerca de } \\
\text { cómo hacer los negocios y } \\
\text { las nuevas reglas del juego } \\
\text { pueden ser difíciles de } \\
\text { asimilar por los actores } \\
\text { presentes. }\end{array}$ & $\begin{array}{l}\text { Desintegración } \\
\text { de la Unión } \\
\text { Soviética }\end{array}$ \\
\hline $\begin{array}{l}\text { Necesidad de cambiar } \\
\text { el rumbo en una } \\
\text { industria madura }\end{array}$ & $\begin{array}{l}\text { Frente a una situación de } \\
\text { mercado en retroceso, las } \\
\text { empresas buscan nuevas } \\
\text { oportunidades a partir de } \\
\text { reorientaciones radicales o } \\
\text { de la salida del mercado } \\
\text { tradicional }\end{array}$ & $\begin{array}{l}\text { El sistema establecido está } \\
\text { construido a partir de una } \\
\text { trayectoria asentada en el } \\
\text { que las rutinas innovadoras } \\
\text { pueden impedir una } \\
\text { innovación radical de alto } \\
\text { riesgo }\end{array}$ & Kodak \\
\hline $\begin{array}{l}\text { Cambio del } \\
\text { comportamiento de un } \\
\text { mercado }\end{array}$ & $\begin{array}{l}\text { La opinión pública o el } \\
\text { comportamiento va } \\
\text { cambiando lentamente hasta } \\
\text { que aparece un nuevo } \\
\text { modelo }\end{array}$ & $\begin{array}{l}\text { Los actores presentes no } \\
\text { perciben el cambio o } \\
\text { persisten en una alternativa } \\
\text { (disonancia cognitiva) hasta } \\
\text { que es muy tarde }\end{array}$ & $\begin{array}{l}\text { Música en } \\
\text { streaming vs } \\
\text { distribución } \\
\text { tradicional }\end{array}$ \\
\hline
\end{tabular}




\begin{tabular}{llll}
\hline & Acontecimientos que de una & La nueva situación puede & World Trade \\
Acontecimientos & manera totalmente inesperada & debilitar a los actores presentes & Center 11 \\
impredecibles & $\begin{array}{l}\text { cambian el mundo y alteran las } \\
\text { reglas del mercado }\end{array}$ & $\begin{array}{l}\text { o convertir algunas de sus } \\
\text { competencias en innecesarias. }\end{array}$ & Septiembre \\
\hline \multirow{2}{*}{$\begin{array}{l}\text { Nuevo modelo de } \\
\text { negocio }\end{array}$} & Entrada de nuevos actores que & $\begin{array}{l}\text { Difícil evaluar la repercusión de } \\
\text { los nuevos modelos. Los actores }\end{array}$ & Amazon \\
& negocio actuales y sus reglas & casos deben ser seguidores de & Banca on-line \\
& & los nuevos. & Revolución \\
Cambios & Cambios a nivel sistémico que & Nuevo paradigma difícil de & industrial \\
sistémicos & condiciona la tecnología y los & percibir hasta que las nuevas & Producción en \\
& mercados & reglas no están establecidas. & masa \\
\hline
\end{tabular}

Fuente: Elaboración propia a partir de Tidd \& Bessant (2009)

Escorsa \& Valls (2003), por su parte, consideran las innovaciones radicales como una forma muy importante de mejorar los resultados de la empresa, sin que la reducción de los costes sea la variable más relevante. En contraposición, estos autores consideran que las innovaciones incrementales se centran más en la reducción de costes. Esta búsqueda constante por la mejora de eficiencia tiene su mayor grado de expresión en el Kaizen, una filosofía defendida por autores japoneses en los años 80 del pasado siglo que sugiere una sucesiva y continua introducción de innovaciones incrementales como forma de generar valor continuado en la empresa.

Por otro lado, ambos tipos de innovación también pueden diferenciarse en base a la fuente que las genera. Por un lado, las innovaciones radicales suelen estar originadas por el progreso de la ciencia y la tecnología, lo que se conoce como technology push. Por otro lado, las innovaciones incrementales suelen estar motivadas por las necesidades del mercado (necesidad de abaratar precio de venta, mejora de la rentabilidad, etc.), lo que se conoce como demand pull (Escorsa \& Valls, 2003).

A modo de resumen, a continuación mostramos un cuadro comparativo desarrollado por Leifer et al. (2000) entre las distintas trayectorias que pueden llevar a cabo en las empresas en relación a ambos tipos de innovaciones Tabla 11 
Tabla 11: Distintos aspectos de las innovaciones radicales y disruptivas

\begin{tabular}{|c|c|c|}
\hline Dimensión & Innovación Incremental & Innovación Radical \\
\hline $\begin{array}{l}\text { Línea temporal del } \\
\text { proyecto }\end{array}$ & $\begin{array}{l}\text { Plazo medio-corto (desde } 6 \\
\text { meses a dos años) }\end{array}$ & Largo plazo (a partir de 10 años) \\
\hline Trayectoria & $\begin{array}{l}\text { Camino lineal y continuo, } \\
\text { desde el concepto a la } \\
\text { comercialización }\end{array}$ & $\begin{array}{l}\text { Camino con abundantes } \\
\text { discontinuidades que deben ser } \\
\text { puenteadas. Discontinuidades, } \\
\text { paradas, bucles. }\end{array}$ \\
\hline $\begin{array}{l}\text { Generación de una } \\
\text { idea y oportunidad } \\
\text { de reconocimiento }\end{array}$ & $\begin{array}{l}\text { La generación de la idea y su } \\
\text { reconocimiento como una } \\
\text { oportunidad se realiza en } \\
\text { etapas muy tempranas }\end{array}$ & $\begin{array}{l}\text { El reconocimiento de la } \\
\text { oportunidad se puede producir } \\
\text { durante todo el camino de } \\
\text { desarrollo del proyecto }\end{array}$ \\
\hline Proceso & Formal y bien trazado & $\begin{array}{l}\text { La incertidumbre es tan alta que } \\
\text { la formalidad del proceso no es } \\
\text { relevante. La formalidad } \\
\text { aumenta a lo largo de la } \\
\text { trayectoria del proyecto }\end{array}$ \\
\hline Modelo de negocio & $\begin{array}{l}\text { Desde una etapa temprana del } \\
\text { desarrollo se puede trazar un } \\
\text { modelo de negocio claro y } \\
\text { detallado por la incertidumbre } \\
\text { suele ser baja }\end{array}$ & $\begin{array}{l}\text { El modelo de negocio en las } \\
\text { etapas tempranas es muy poco } \\
\text { detallado porque muchos de sus } \\
\text { componentes se suelen descubrir } \\
\text { a lo largo del proceso de } \\
\text { desarrollo }\end{array}$ \\
\hline Actores & $\begin{array}{l}\text { Es posible hacer una } \\
\text { distribución de las tareas a un } \\
\text { grupo concreto de } \\
\text { responsables y asignarles } \\
\text { muy bien responsabilidades }\end{array}$ & $\begin{array}{l}\text { Los actores clave no pueden ser } \\
\text { definidos perfectamente y } \\
\text { algunos entran y salen del } \\
\text { proyecto a lo largo del mismo }\end{array}$ \\
\hline
\end{tabular}




\begin{tabular}{lll}
\hline \multirow{2}{*}{$\begin{array}{l}\text { Estructura } \\
\text { organizativa }\end{array}$} & $\begin{array}{l}\text { Normalmente el grupo de } \\
\text { desarrolladores se organizan } \\
\text { dentro de una misma área de } \\
\text { negocio }\end{array}$ & $\begin{array}{l}\text { El proyecto puede ir migrando a } \\
\text { distintas partes de la compañía, por } \\
\text { ejemplo desde I+D a una nueva } \\
\text { unidad de negocio }\end{array}$ \\
\hline \multirow{2}{*}{$\begin{array}{ll}\text { El equipo del proyecto suele } \\
\text { competencias }\end{array}$} & La creatividad y la habilidad de \\
& necesarias para llevar a cabo & crítico para garantizar la \\
& el desarrollo del mismo & supervivencia y éxito del proyecto \\
\hline \multirow{2}{*}{$\begin{array}{l}\text { Protagonismo de } \\
\text { unidades }\end{array}$} & Las unidades operativas & El involucramiento de las unidades \\
operativas & suelen estar involucradas & informal ya que el proyecto no \\
& desde el primer momento & puede ser cautivo de estas unidades \\
& & desde el principio \\
\hline
\end{tabular}

Fuente: elaboración propia a partir de Leifer et al. (2000)

El modo en que las dos clasificaciones más aceptadas por la literatura interaccionan se muestra en la Figura 5: Espacio innovador basado en sus dos dimensiones. En efecto, las innovaciones de producto, proceso, marketing y organizativas por un lado y las innovaciones radicales e incrementales por el otro, pueden ser consideradas como dos dimensiones del mismo proceso innovador, de manera que se genera un espacio innovador marco de cuatro dimensiones en el que la empresa o las organizaciones pueden adentrarse (Tidd \& Bessant, 2009). 


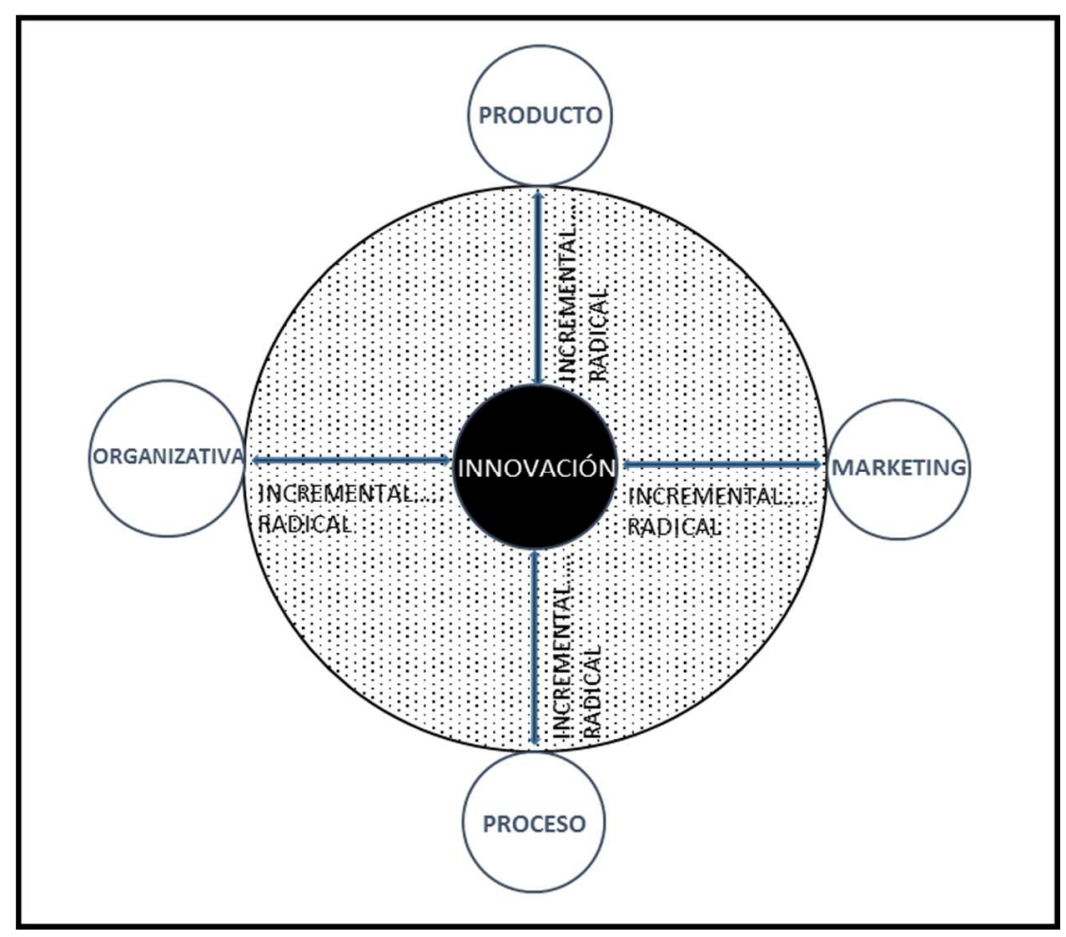

Figura 5: Espacio innovador basado en sus dos dimensiones

Fuente: elaboración propia a partir de Tidd \& Bessant (2009)

\subsubsection{La transilencia de la innovación: innovaciones arquitectónicas, innovaciones de nicho, innovaciones regulares e innovaciones revolucionarias}

En ocasiones, realizar una distinción entre innovaciones radicales e incrementales únicamente en base a la originalidad resulta insuficiente. A lo largo del tiempo se producen innovaciones radicales que dan lugar a sectores enteros o incluso revolucionan la economía mientras que otras tienen menor trascendencia. Unas innovaciones dejan obsoletas a las empresas competidoras existentes en un mercado, mientras que otras refuerzan su posición de predominancia (Escorsa \& Valls, 2003).

En esta línea, los investigadores Abernathy y Clark (1985) desarrollan el concepto de transilencia, considerando que es la capacidad de una innovación para alterar los sistemas existentes de producción y marketing. Estas alteraciones presentan un rango, desde la mejora hasta la destrucción. De este modo, los autores clasifican las innovaciones en función de dos variables: (a) la transilencia comercial o de mercado; (b) la transilencia tecnológica. La Figura 6 muestra las cuatro dimensiones resultantes 
de cruzar estas dos variables en función de si las innovaciones intensifican las dinámicas existentes o las convierten en obsoletas. De este modo, se obtienen cuatro tipos de innovación que definimos a continuación:

- Innovaciones arquitectónicas: son aquellas que suponen un profundo cambio tecnológico y que, a su vez, generan nuevos sectores nuevos en los que se modifican las reglas del mercado existente, así como a las empresas competidoras.

- Innovaciones de nicho: no suponen una transformación tecnológica importante pero sí una apertura de nuevos mercados.

- Innovaciones regulares: son aquellas que se basan en cambios de la tecnología existente para aumentar su competencia y que van dirigidas al mismo mercado. Por tanto, estas innovaciones refuerzan o perpetúan la situación actual del mercado.

- Innovaciones revolucionarias: son aquellas que, suponiendo un cambio importante en la tecnología existente, no modifican los mercados, sino que los conserva y los intensifica. 


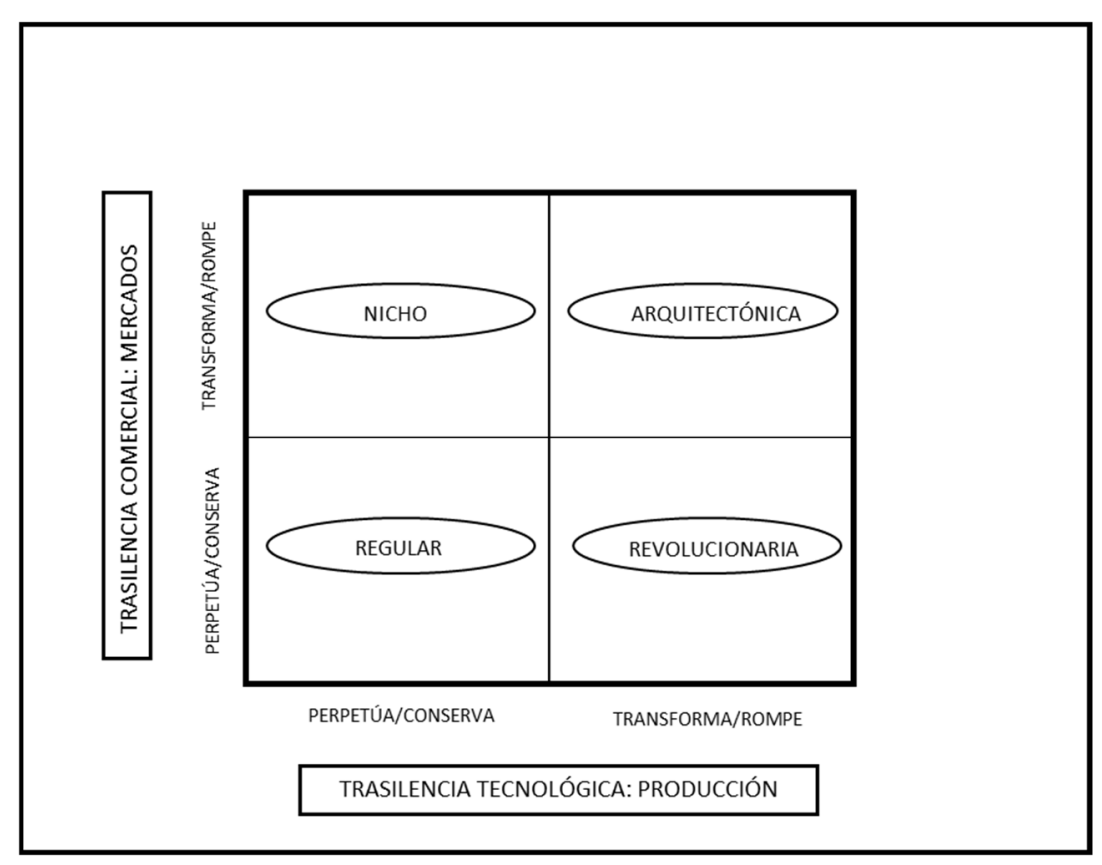

Figura 6: Los cuatro tipos de innovación en función de la transilencia comercial y la transilencia tecnológica

Fuente: elaboración propia de partir de Escorsa \& Valls (2003)

\subsubsection{La originalidad del origen de la innovación: innovaciones radicales $e$ innovaciones de fusión}

En la década de los años 90 del pasado siglo, Kodama (1992) realizó una clasificación de las innovaciones basándose en la consideración de que muchas de éstas se originan a partir de la convergencia de varias tecnologías procedentes de campos distintos. De este modo distingue entre:

- Innovaciones radicales: aquellas en las que se produce una sustitución tecnológica lineal, es decir, una tecnología es sustituida por otra mejor, normalmente basada en otro principio, un nuevo material, etc.

- Innovaciones de fusión: aquellas en las que la sustitución de una tecnología se produce por combinación de una serie de tecnologías ya existentes. 
Este autor considera acertada una estrategia que combine los esfuerzos innovadores de una empresa en dos niveles; por un lado, a nivel de su core competence, es decir, a nivel de su área principal de generación de valor; por el otro, a nivel de otras áreas más periféricas, a través de una labor exploratoria (Escorsa \& Valls, 2003).

\subsubsection{Las modelos de innovación}

Desde mediados del siglo XX, numerosos autores -tanto de la ciencia económica como de la ciencia social- han estudiado desde distintas perspectivas el proceso innovador y los factores que los generan. El proceso por el que una idea conduce a una invención y de ahí al mercado, es una actividad compleja, diversificada, con muchos elementos que interactúan, así como con fuentes de ideas distintas. En primera instancia, se podría considerar que el entorno económico, de por si cambiante, obliga a las empresas a responder a esos cambios para poder sobrevivir. En consecuencia es la propia empresa la única y principal fuente de innovación (Escorsa \& Valls, 2003). De hecho, los modelos que han explicado los procesos innovadores y sus respectivas fuentes han ido evolucionando a lo largo de la historia. Los primeros enfoques lineales y unidireccionales han dado paso al convencimiento actual de que la innovación, y el conocimiento a partir del cual ésta se genera, puede provenir de fuentes muy diversas. También pueden presentar interacciones complejas. En este apartado vamos a analizar con detalle la evolución que las teorías acerca de los procesos innovadores han sufrido a lo largo de las últimas décadas.

\subsubsection{Modelos lineales de innovación}

Los primeros modelos teóricos de innovación aparecen en los años posteriores a la segunda guerra mundial y se desarrollan hasta finales de la década de los setenta. Se trataba de los modelos lineales, los cuales seguían un enfoque simple y lineal en el que se daban unas relaciones secuenciales entre las distintas funciones de las empresas. Estas funciones eran: (a) la investigación básica; (b) la investigación aplicada; (c) el desarrollo tecnológico; (d) el marketing; (e) la introducción en el mercado. 
El proceso innovador bajo esta perspectiva era entendido como una sucesión de etapas unidireccionales (Forrest, 1991; Rothwell, 1994). El elemento que desencadena esa sucesión de etapas (bien la innovación básica o bien las necesidades generadas por el mercado) es lo que da lugar a dos modelos lineales distintos, en primer lugar, el modelo de empuje de la tecnología (technology push) y, posteriormente, el modelo de tirón de la demanda (demand pull) que ya se han comentado con anterioridad.

El modelo de empuje de la tecnología es considerado la primera generación de los modelos de innovación (Rothwell, 1994). Se trata de un modelo lineal que se desarrolló en los años cincuenta del pasado siglo en un contexto económico y social marcado por el crecimiento y la expansión industrial. Se trataba de una época de reconversión industrial y de aparición de una gran cantidad de industrias basadas en las nuevas oportunidades tecnológicas. El consumo aumentaba a medida que lo hacía el empleo. Este modelo se encuentra muy marcado por estas circunstancias ya que -sin considerar un límite en la demanda- asume que a mayor esfuerzo en $\mathrm{I}+\mathrm{D}$, mayor cantidad de productos se lanzarán al mercado. Su planteamiento (ver Figura 7), por tanto, establece un proceso innovador que parte de la ciencia, pasa por el desarrollo tecnológico y acaba en la comercialización de la novedad (Fernández Sánchez, 2005).

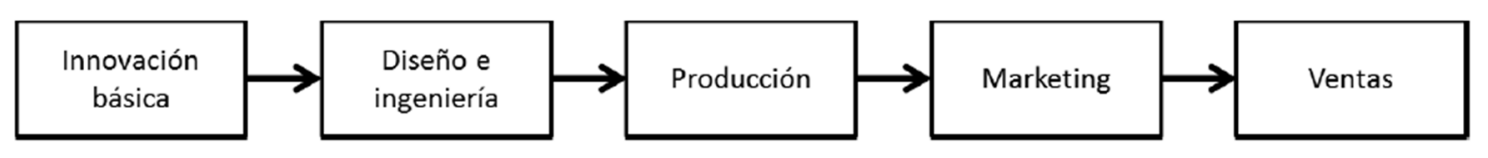

Figura 7: Modelo de empuje de la tecnología

Fuente: adaptación de Rothwell (1994)

La idea que transmite este enfoque es que los avances científicos son considerados la base del proceso innovador por lo que la inversión en I+D, ya fuera pública o privada, acabaría favoreciendo el crecimiento económico. La demanda no forma parte de esta concepción como tampoco lo hacen la relación con proveedores, clientes o competidores. Por otro lado, destaca la relevancia de los descubrimientos científicos como clave competitiva sin considerar la importancia de aspectos como la práctica o la mejora continua (aprendizaje por el uso) defendidos por ciertos autores (Arrow, 1962; Rosenberg, 1982). Sin embargo, este modelo, por su simplicidad resulta útil ya que permite entender de forma simplificada y racional el proceso innovador. 
El modelo de tirón de la demanda supone la evolución del modelo anterior. Se trata de un modelo lineal desarrollado bajo unas circunstancias económicas y sociales distintas a las que originaron el modelo anterior. En efecto, a mediados de los años sesenta del pasado siglo, el empleo en los países industrializados se ha estabilizado o crece a menor ritmo, la industria ha aumentado su productividad y aunque se siguen introduciendo nuevos productos al mercado, estos están basados en la tecnología existente. Además la competencia se intensifica y los esfuerzos de inversión se enfocan hacia la racionalización más que hacia el cambio tecnológico (Rothwell, 1994). En una situación de grandes y eficientes empresas luchando por cuota de mercado, el eje estratégico se centra en la comercialización. En consecuencia, el proceso innovador es enfocado hacia los factores de la demanda, es decir, hacia la mejora de la posición en el mercado. De este modo, al contrario que en el caso anterior, este modelo establece un esquema que parte de las necesidades del mercado. Éstas motivan la investigación que, a su vez, desemboca en una solución la cual, a su vez, es implementada en producción.

Finalmente la solución es comercializada acabando el ciclo innovador (ver Figura 8).

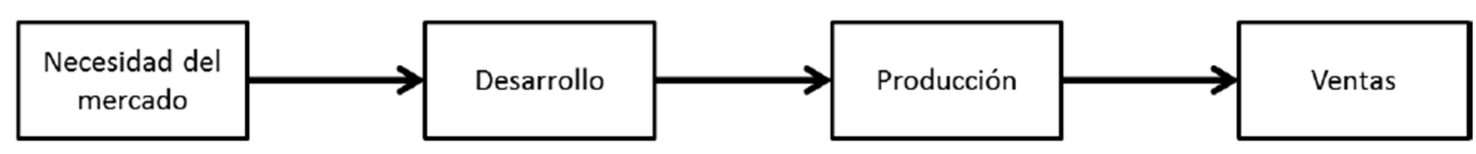

Figura 8: Modelo de tirón de la demanda

Fuente: adaptación de Rothwell (1994)

En definitiva, esta segunda generación del modelo lineal incluye la demanda como elemento fundamental; autores como Schmoockler (1966) realizan una justificación muy exhaustiva de este hecho través de un estudio estadístico de las patentes de Estados Unidos. No obstante, este sigue planteando una limitación por su simplificación debido a que no considera otras fuentes de innovación tales como otras áreas de la empresa o el entorno que rodea a la misma. Este modelo sigue siendo poco realista ya que sigue concibiendo la innovación como un proceso lineal, una sucesión de etapas secuencial y ordenado, desde la detección de una necesidad hasta la comercialización. 
Muchos autores en la década de los setenta centraron sus estudios en la crítica de estos modelos, así como en la propuesta de mejoras a los mismos; unos los criticaban por ser excesivamente simplistas (Langrish et al., 1972), otros por basar el inicio del proceso innovador en un único punto -ya bien fuera el impulso de la tecnología o el tirón de la demanda- estableciendo un flujo simple y unidireccional hacia el resto de etapas sin ningún tipo de retroalimentación (Forrest, 1991; Freeman \& Paredes, 1975). En definitiva, la tesis que subyace en todas estas críticas se basa en considerar los modelos lineales como excesivamente superficiales por plantear un proceso innovador simple y sin interacciones.

\subsubsection{Modelos de innovación por etapas}

Estos modelos, al igual que los anteriores, consideran los procesos innovadores como procesos secuenciales de carácter lineal. En cambio, van más allá caracterizándose por combinar elementos del modelo de empuje de la tecnología y tirón de la demanda y por establecer una serie de etapas, desde la idea hasta la comercialización. El modelo más simple es aquel que establece tan solo dos etapas, la generación de la idea, en primer lugar y la comercialización, en segundo lugar. A partir de éste, distintos autores introducen hasta cinco etapas distintas (Forrest, 1991).

Posteriormente, autores como Saren (1984) desarrollan modelos en los que las etapas equivalen a departamentos a lo largo de los cuales se traslada el esfuerzo innovador hasta conducir a la comercialización de un producto o servicio. La idea es introducida en el departamento de I+D y después pasa a lo largo de los departamentos de diseño, ingeniería, producción y marketing hasta transformarse en un producto que sale al mercado (ver Figura 9) 


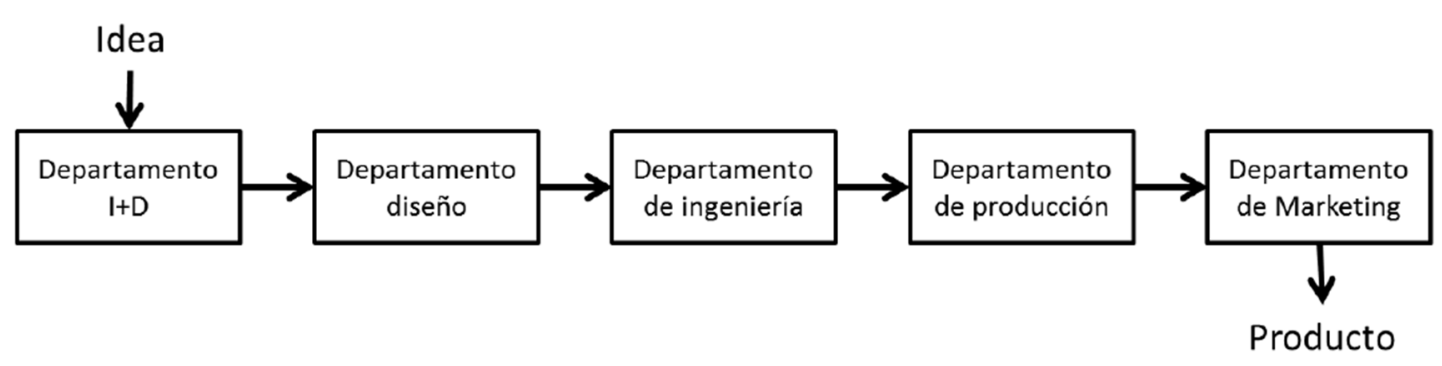

Figura 9: Modelo por etapas de Saren

Fuente: Adaptación de Saren (1984)

De nuevo estos modelos presentan la limitación de considerar las innovaciones como sucesión de etapas individuales y aisladas unas de las otras sin contemplar los solapamientos ni la retroalimentación que se generan entre ellas (Forrest, 1991).

\subsubsection{Modelos interactivos o mixtos}

Estos modelos que aparecen a finales de los años setenta del pasado siglo y continuarán vigentes hasta finales de los años ochenta, se desarrollan en un contexto socioeconómico de inflación, saturación de la demanda y crecimiento de paro estructural. Bajo estas circunstancias, las empresas son conscientes de la necesidad de un control financiero y centran sus esfuerzos en el control y la reducción de costes (Rothwell, 1994).

Con este enfoque, varios autores plantean la innovación como un proceso encaminado a la reducción de los fallos y la optimización de los recursos. La I+D pierde su papel predominante para convertirse en una etapa más del proceso innovador (Castro \& Fernández de Lucio, 2001). Los estudios que se llevan a cabo durante ese periodo, llegan a la conclusión de que los modelos de empuje de la tecnología o tirón de la demanda son casos extremos y atípicos de un proceso general de innovación en el que se produce una interacción entre las capacidades tecnológicas y las necesidades del mercado (Mowery \& Rosenberg, 1979).

Estos modelos -calificados por Rothwell (1994) como modelos de tercera generación o coupling models- contemplan, a su vez, la interacción y retroalimentación entre las 
distintas etapas del proceso innovador. Estas nuevas visiones, en definitiva, no sólo extienden la dinámica innovadora a otras áreas funcionales de la empresa más allá de los departamentos de $\mathrm{I}+\mathrm{D}$, sino que traspasan las fronteras de la misma para integrar a agentes externos tales como el mercado, la investigación científica, la producción o la comercialización.

Destacan el modelo de Marquis (1969) y el modelo de Kline (1985), los cuales describimos a continuación.

El modelo de Marquis (1969), que se puede apreciar en la Figura 10, se basa en la idea principal de que factibilidad técnica y demanda potencial son los elementos imprescindibles de la innovación. De hecho, Schmookler (1966) realiza una analogía entre estos dos elementos y las dos hojas de unas tijeras; si uno de los dos falla, la innovación no es posible (Escorsa \& Valls, 2003). A partir de esta idea, el proceso innovador consiste en evaluar los dos requisitos fundamentales (factibilidad $\mathrm{y}$ demanda), examinar las posibilidades de la tecnología actual, retroceder a la investigación aplicada o la básica si es necesario para, finalmente, encontrar una solución que concluya en una implementación y difusión del producto o servicio.

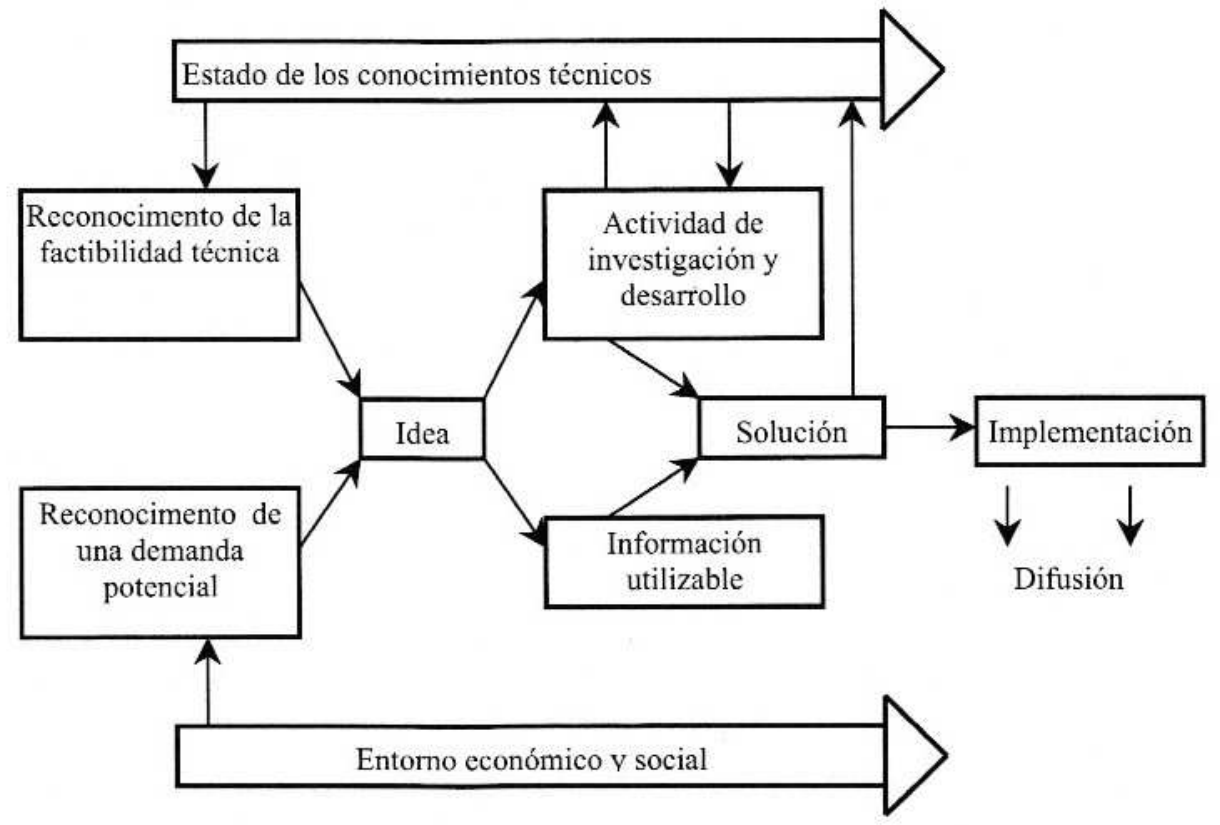

Figura 10: Modelo de Marquis

Fuente: adaptado de Escorsa \& Valls (2003, p. 27) 
El modelo de Kline (1985), que se puede observar en la Figura 11, es uno de los modelos interactivos más conocidos. A partir de una crítica al modelo lineal (Escorsa \& Valls, 2003), el autor propone un modelo que refleje mejor el proceso innovador basado en cinco trayectorias que conducen a la innovación. Estas trayectorias son:

- Camino central de innovación (flechas C en la Figura 11): se trata del procedimiento lineal que empieza en una idea basada en necesidades de mercado y acaba en una comercialización.

- Retroalimentaciones del camino central o feedback links que se producen a tres niveles: (a) entre cada etapa del camino central y la anterior (círculos en la Figura 11); (b) desde el punto final a cada una de las etapas anteriores (flechas $\mathrm{f}$ en la Figura 11); (c) desde el producto final hasta el mercado potencial (flecha $\mathrm{F}$ en la Figura 11).

- Conexión del camino central con la investigación a través de los conocimientos científico-técnicos existentes. La etapas del camino central pueden necesitar de apoyo científico-técnico existente (flechas 1-2 en la Figura 11) así como de una investigación si el conocimiento actual existente no es capaz de satisfacer la necesidad (flechas 3-4 en la Figura 11).

- Conexión entre la investigación y la innovación, puesto que la investigación puede dar lugar a inventos (innovaciones de technology push).

- Conexión directa entre el mercado y la investigación (flecha S en la Figura 11), puesto que los nuevos instrumentos y producto que se lanzan al mercado hacen posible el avance de las investigaciones.

Este modelo, a pesar de suponer un importante avance con respecto a los modelos lineales, presenta ciertas limitaciones como pueden ser las referentes a la falta de interacción con el entorno que incluya la relación con otras empresas, proveedores, clientes, universidades o instituciones (Hobday, 2005). 
Los modelos interactivos o mixtos, sin embargo, no acaban de reflejar con precisión la complejidad de las dinámicas innovadoras puesto que no son capaces de identificar los verdaderos ejes de la innovación o encontrar las causas por las que unas empresas, regiones o países tienen más éxito que otros a la hora de desarrollar la innovación.

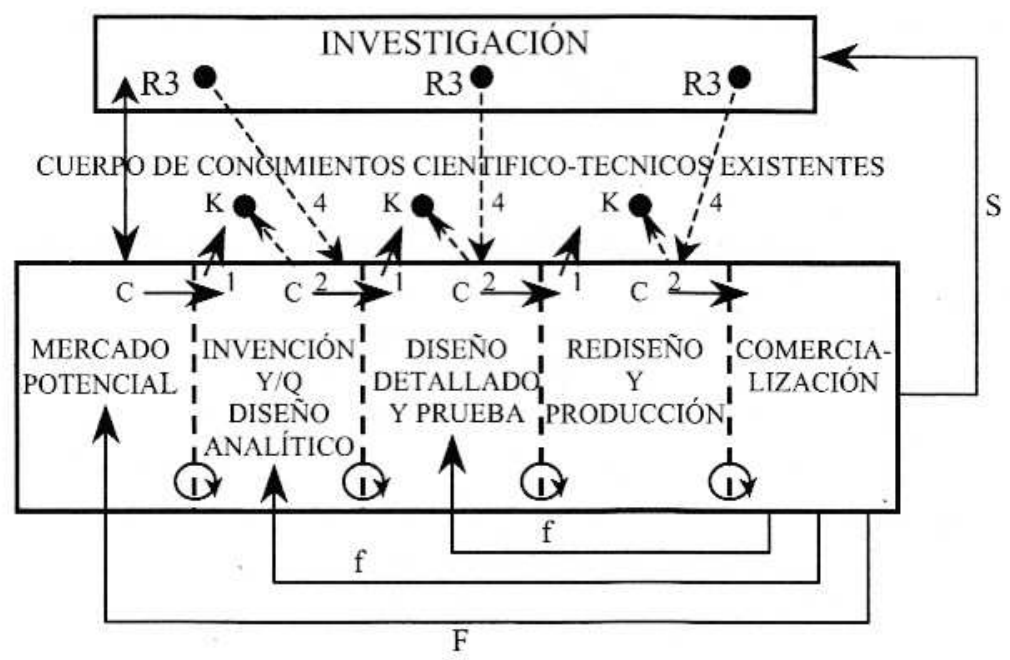

Figura 11: Modelo de Kline

Fuente: Adaptado de Escorsa \& Valls (2003, p. 32)

\subsubsection{La visión sistémica de la innovación}

En la actualidad existe un amplio consenso en torno a la consideración de que la innovación es un proceso interactivo y complejo que depende en gran medida del contexto socioeconómico y cultural en el que las empresas se desenvuelven. Las relaciones y conexiones entre los distintos actores y agentes que componen un determinado entorno son fundamentales en la creación, desarrollo, difusión y explotación del conocimiento. Es por este motivo por el que los modelos actuales que describen el proceso innovador están basados en gran medida en la teoría de redes. Hoy en día se considera a la innovación de naturaleza sistémica porque las empresas normalmente no innovan de forma aislada sino en colaboración e interdependencia con otras organizaciones (Edquist, 2005). Este enfoque, ha ido adquiriendo una relevancia creciente en la última década ya que se ha ido aplicando a diversos ámbitos y se ha 
convertido en una herramienta básica del análisis de las dinámicas innovadoras en los contextos territoriales (Oinas \& Malecki, 2002).

La principal aportación de la visión sistémica de la innovación radica precisamente en que sitúa a ésta como centro del análisis. La innovación es considerada un elemento dinámico y colectivo que, si bien es llevada a cabo por las empresas, se desarrolla fundamentalmente como resultado de interrelaciones entre éstas y las instituciones y organizaciones (científicas o empresariales, industriales o gubernamentales) con las que se relacionan. Otra contribución fundamental de esta visión consiste en que se evalúa la correcta o incorrecta actuación de los agentes e instituciones en el ámbito innovador en base a su contribución a la generación, desarrollo y difusión de las innovaciones generadas por las empresas. En definitiva, su gran mérito, y de ahí su utilidad, consiste en resaltar el valor de las relaciones entre las empresas y las instituciones como eje determinante del proceso innovador.

Este nuevo enfoque del proceso innovador surge en la década de los años ochenta del pasado siglo a partir de las teorías evolucionistas promovidas por autores como Nelson y Winter $(1982,1977)$. En esta línea, otros autores como Freeman y Soete $(1987,1990)$ o Dosit et al., (1990) proponen una interpretación más holística del crecimiento económico. Los factores de los que éste depende no se diferencian entre económicos y no económicos. El sistema social -para estos autores- está formado por distintas esferas interrelacionadas las cuales siguen sus propias dinámicas y procesos. Del mismo modo, la actividad innovadora de las empresas, bajo esta perspectiva, depende estrictamente de fuentes externas (Fagerberg et al., 2005). Estos enfoques se enmarcan en un contexto socioeconómico distinto a las décadas anteriores. La economía mundial se ha debilitado después del fuerte crecimiento experimentado en los años ochenta del pasado siglo, los niveles de desempleo han aumentado, así como también las ratios de proyectos empresariales fallidos. Bajo estas circunstancias, las empresas líderes están comprometidas con la acumulación tecnológica y para ello necesitan crear redes estratégicas puesto que el tiempo que se tarda en llegar al mercado es considerado de vital importancia. Sus esfuerzos son concentrados en integrar las estrategias de producto con las de producción, así como en que la flexibilidad y la adaptación sean sus principales características. La innovación se encuentra marcada, en definitiva, por una 
necesidad de rapidez por lo que muchas empresas centran en la innovación rápida el eje de su competitividad (Rothwell, 1994).

En este contexto se hace necesario un enfoque sistémico de la innovación. Por este motivo durante las últimas décadas se ha desarrollado abundante literatura en la que se aplica el concepto de sistema al estudio de la misma. El análisis de la relación entre las actividades innovadoras en las empresas y el amplio marco en el que éstas se encuentran incluidas ha sido analizado desde distintos enfoques (Edquist, 2005). Las dinámicas innovadoras, sus distintas fases, así como la forma en la que la innovación influencia y es influenciada en los contextos social, institucional y económico, ha centrado la atención de abundantes investigaciones.

Los distintos análisis realizados han tratado de delimitar estos sistemas no sólo en base a características tecnológicas, industriales o sectoriales (proveedores, clientes, ferias sectoriales, consultoría especializada) sino también en base a otros factores relevantes tales como: (a) instituciones (leyes, regulaciones, reglas, hábitos); (b) procesos políticos; (c) infraestructura de investigación pública (universidades, institutos de investigación; (d) fuentes de soporte públicas; (e) instituciones financieras; (f) entorno laboral (Carlsson \& Stankiewicz, 1991; Freeman et al., 1982).

Las implicaciones de aplicar una perspectiva sistémica a la innovación son diversas, Fagerberg (2005) considera que:

- Los sistemas, al igual que las redes, comprenden un conjunto de actividades (o actores) que al estar interrelacionadas deben ser estudiadas desde la perspectiva de las conexiones que se establecen.

- Los sistemas tienen feedback, que va a servir para reforzar o debilitar el funcionamiento de los mismos, conduciéndolos a: (a) una situación de estabilidad (situación lock-in); (b) un cambio de orientación; (c) una disolución.

- Los sistemas, al igual que las empresas, suelen estar centrados en el desarrollo de un campo específico lo que sustenta el desarrollo de ciertas actividades, pero inhibe el desarrollo de otras. Esto puede ser una ventaja (ya que el sistema 
evoluciona en una dirección beneficiosa) pero también una desventaja (al poder ignorar posibles vías de desarrollo futuro).

- Los sistemas presentan una gran complementariedad entre sus componentes (no sólo debemos considerar componentes tecnológicos sino también otros como infraestructura, financiación, etc.) de modo que si uno de los componentes críticos falla esto puede bloquear o dificultar el crecimiento del sistema entero.

En definitiva, un sistema de innovación puede definirse como:

"El conjunto de organizaciones institucionales y empresariales que, dentro de un determinado ámbito geográfico, interactúan entre sí con la finalidad de asignar recursos a la realización de actividades orientadas a la generación y difusión de conocimientos sobre los que se soportan las innovaciones que están en la base del desarrollo económico" (Buesa Blanco, 2002, p. 2).

En cuanto a los diferentes agentes que forman parte de un sistema de innovación, Edquist (2005) considera a las organizaciones y las instituciones como los componentes principales. En la Tabla 12 se definen ambos conceptos y se enumeran algunos de los actores integrantes de ambos componentes, aunque éstos van a variar entre unos sistemas y otros: 
Tabla 12: Componentes de los sistemas de innovación

\begin{tabular}{|c|c|c|}
\hline Componentes & Descripción & Integrantes \\
\hline Organizaciones & $\begin{array}{l}\text { Estructuras formales constituidas de } \\
\text { manera intencionadas con propósito } \\
\text { explícito. }\end{array}$ & $\begin{array}{l}\text { - } \text { Empresas } \\
\text { - } \text { Universidades } \\
\text { - } \text { Centros de investigación } \\
\text { - } \text { Grupos de inversión de } \\
\text { capital riesgo } \\
\text { - } \text { Entidades financieras } \\
\text { - Agencias públicas } \\
\text { responsables de las } \\
\text { políticas de innovación, } \\
\text { competencia, promoción } \\
\text { científica. } \\
\text { Agencias y organismos } \\
\text { responsables del desarrollo } \\
\text { de la legislación }\end{array}$ \\
\hline Instituciones & $\begin{array}{l}\text { Conjunto de costumbres, normas, } \\
\text { rutinas, prácticas establecidas reglas } \\
\text { o leyes que regulan las relaciones e } \\
\text { interacciones entre los individuos, } \\
\text { los grupos o las organizaciones. }\end{array}$ & $\begin{array}{ll}\text { - } & \text { Legislación sobre patentes } \\
\text { - } & \text { Normas que regulan la } \\
\text { relación entre empresas y } \\
\text { universidades } \\
\text { - } \quad \text { Convenios colectivos } \\
\text { - } \quad \text { Leyes laborales } \\
\text { intelectual } \\
\text { Políticas sobre las que se } \\
\text { establece la } \\
\text { responsabilidad del } \\
\text { desarrollo tecnológico y la } \\
\text { investigación. }\end{array}$ \\
\hline
\end{tabular}

Fuente: Elaboración propia a partir de Edquist (2005) y Jasso (2004) 
De forma análoga, la OCDE (2005, p. 76) considera que las actividades innovadoras de una empresa dependen en parte de la variedad y estructura de sus interacciones con distintas fuentes (información, conocimiento, tecnológicas, prácticas, recursos humanos, recursos financieros). Con este enfoque sistémico, la organización establece una clasificación de las diferentes fuentes de innovación y distingue entre: (a) fuentes internas de la empresa; (b) fuentes externas y comerciales; (c) fuentes del sector público y (d) fuentes de información general. Esta clasificación está muy extendida y es utilizada en las encuestas que se realizan sobre innovación en los distintos países de la Unión Europea (Tabla 13). 
Tabla 13: Fuentes para la transferencia de conocimiento y tecnología

\begin{tabular}{|c|c|c|c|}
\hline & $\begin{array}{c}\text { Fuentes de } \\
\text { información de } \\
\text { libre acceso }\end{array}$ & $\begin{array}{l}\text { Fuentes para la } \\
\text { adquisición de } \\
\text { conocimiento y } \\
\text { tecnología }\end{array}$ & $\begin{array}{l}\text { Participantes en } \\
\text { una acción de } \\
\text { cooperación }\end{array}$ \\
\hline \multicolumn{4}{|c|}{ Fuentes internas a la empresa: } \\
\hline $\mathrm{I}+\mathrm{D}$ & $*$ & & \\
\hline Producción & $*$ & & \\
\hline Comercialización & $*$ & & \\
\hline Distribución & $*$ & & \\
\hline $\begin{array}{l}\text { Otras empresas del mismo } \\
\text { grupo }\end{array}$ & $*$ & $*$ & $*$ \\
\hline \multicolumn{4}{|c|}{ Fuentes comerciales y mercados exteriores: } \\
\hline Competidores & $*$ & * & $*$ \\
\hline Otras empresas del sector & $*$ & $*$ & * \\
\hline Clientes o usuarios & $*$ & & $*$ \\
\hline Expertos / Consultoras & & $*$ & * \\
\hline $\begin{array}{l}\text { Proveedores de equipos, } \\
\text { materiales, etc }\end{array}$ & $*$ & $*$ & $*$ \\
\hline Laboratorios comerciales & $*$ & $*$ & $*$ \\
\hline \multicolumn{4}{|c|}{ Fuentes que dependen del sector público: } \\
\hline $\begin{array}{l}\text { Universidades y otra enseñanza } \\
\text { superior }\end{array}$ & $*$ & $*$ & $*$ \\
\hline $\begin{array}{l}\text { Instituciones de investigación } \\
\text { gubernamentales / públicos }\end{array}$ & $*$ & $*$ & $*$ \\
\hline $\begin{array}{l}\text { Institutos de investigación } \\
\text { privados sin ánimo de lucro } \\
\text { Servicios especializados de }\end{array}$ & $*$ & $*$ & $*$ \\
\hline $\begin{array}{c}\text { Servicios especializados de } \\
\text { apoyo a la innovación públicos / } \\
\text { paraestatales }\end{array}$ & $*$ & $*$ & $*$ \\
\hline \multicolumn{4}{|c|}{ Fuentes de información generales: } \\
\hline Difusión de patentes & & $*$ & \\
\hline Conferencias, reuniones, etc & $*$ & & \\
\hline Ferias y exposiciones & & $*$ & \\
\hline $\begin{array}{c}\text { Asociaciones profesionales, } \\
\text { sindicatos }\end{array}$ & & $*$ & \\
\hline Otras asociaciones locales & $*$ & & \\
\hline Contactos o redes informales & $*$ & & \\
\hline $\begin{array}{c}\text { Estándares o agencias de } \\
\text { normalización }\end{array}$ & $*$ & & \\
\hline Normativas públicas & $*$ & & \\
\hline
\end{tabular}

Fuente: elaboración propia a partir de OCDE (2005, p. 81) 
Es importante resaltar que en los últimos años las fuentes de innovación externa han ido teniendo una relevancia creciente. Los indicadores de innovación ofrecidos por el Observatorio Español de $\mathrm{I}+\mathrm{D}+\mathrm{i}$ sitúan la inversión en $\mathrm{I}+\mathrm{D}$ externa realizada por las empresas en un 17,7\% del total en 2014 (ICONO, 2016, p. 69). Por otro lado, las empresas españolas declaran en la encuesta realizada por este organismo su colaboración con distintos agentes externos (ICONO, 2016) como puede observarse en la Tabla 14.

Tabla 14: Cooperación en innovación de las empresas EIN según tipo de agente

\begin{tabular}{lcc}
\hline \multicolumn{1}{c}{ Empresas que han cooperado en innovación } & Total & $\%$ \\
\hline Total empresas con actividad innovadora & 6.132 & $100 \%$ \\
Otras empresas del mismo grupo & 1.780 & $12 \%$ \\
Proveedores de equipos, material, componentes o software & 2.860 & $20 \%$ \\
Clientes del sector privado & 1.767 & $12 \%$ \\
Clientes del sector público & 648 & $5 \%$ \\
Competidores u otras empresas de su rama de actividad & 1.324 & $9 \%$ \\
Consultores, laboratorios comerciales & 1.483 & $10 \%$ \\
Universidades u otros centros de enseñanza superior & 1.977 & $14 \%$ \\
Centros de investigación públicos o privados & 2.463 & $17 \%$ \\
\hline
\end{tabular}

Fuente: elaboración propia a partir de ICONO (2016)

No obstante, focalizarse excesivamente en fuentes externas de innovación puede resultar negativo ya que puede poner en riesgo las competencias núcleo (core competences) que a su vez condicionan y marcan las estrategias de innovación (Coombs, 1996). Existen estudios empíricos que así lo manifiestan como por ejemplo los llevados a cabo por Freel (2003) o Oerlemans, Meeus, \& Boekema (1998).

La innovación se plantea, en definitiva, como un proceso (generalmente y fundamentalmente, distribuido en red) donde el aprendizaje tiene lugar dentro y entre las empresas (Hobday, 2005; Rothwell, 1994). Bajo esta perspectiva de red, el marco teórico del capital social, a través de sus tres dimensiones (relacional, estructural y cognitiva), pone de relevancia la importancia que tienen los vínculos fuertes (Krackhardt, 1992; Molina-Morales \& Martínez-Fernández, 2009a) entre los distintos 
actores en la transferencia de conocimiento y, por tanto, en los procesos innovadores. No obstante, los vínculos débiles son importantes (Brown \& Konrad, 2001; Granovetter, 1973) por lo que es conveniente establecer un equilibrio entre ambos para establecer eficientes dinámicas innovadoras.

Muchos autores han sugerido la dificultad por parte de las empresas de llevar a cabo procesos innovadores de manera individualizada por lo que la habilidad para gestionar las relaciones con el resto de miembros de la red es un factor clave en el éxito de los mismos (Baptista \& Swann, 1998; Laursen \& Salter, 2006; Powell, 1990).

La visión sistémica de la innovación originó el desarrollo del concepto de sistema nacional de innovación (SNI) que fue publicado por primera vez por Freeman (1987) para referirse a la red de instituciones (públicas o privadas) cuyas actividades e interacciones influyen en el inicio, desarrollo y difusión de nuevas tecnologías (Freeman, 1987). Posteriormente, fueron Lundvall (1992) y Nelson (1993) quienes, desde dos enfoques distintos, realizaron una importante aportación en el desarrollo de este concepto. Lundvall (1992), desde una perspectiva teórica, se centró en el desarrollo de una alternativa a la tradición económica neoclásica situando al aprendizaje interactivo, la interacción usuario-productor y la innovación en el centro del análisis. Por el contrario Nelson (1993) plantea un enfoque menos teórico y centra sus estudios, principalmente de casos, en los sistemas nacionales de I+D. En definitiva, ambos autores coinciden en el hecho de definir unos factores determinantes de los sistemas de innovación, aunque sus visiones acerca de cuáles son esos determinantes varía. En consecuencia, sus propuestas de definición varían y de ahí que no se pudiera establecer una definición aceptada de forma general de este término (Edquist, 2005).

Cabe considerar que incluso hoy en día la propia definición es un elemento difuso ya que no todas las aproximaciones comparten la misma visión. A pesar de este hecho, es posible establecer unos puntos comunes que vertebran todas las propuestas. Edquist (1997) destaca los siguientes:

- Situación de la innovación y el aprendizaje en el centro del análisis.

- Enfoque holístico e interdisciplinar. 
- Especial relevancia del factor histórico al considerar el avance tecnológico como un resultado de acumulación de conocimientos (Path dependency).

- No convergencia de los distintos sistemas en uno único y óptimo. Se trata de una visión con múltiples soluciones.

- No linealidad de los sistemas. La interdependencia es una característica fundamental.

- Consideración multidimensional de la innovación. Se incluyen innovaciones tanto tecnológicas como organizativas.

- Valoración de las instituciones como elemento nuclear de la innovación.

- Posicionamiento en el ámbito de desarrollo de un marco conceptual más que en el establecimiento de una teoría propiamente dicha.

Desde sus primeras definiciones, el concepto de sistema nacional de innovación ha sido adaptado por distintos autores en las últimas décadas a otros subniveles más específicos o también a otros contextos tales como el regional o incluso el local. Carlsson (2012), por ejemplo, desarrolló el concepto de sistema tecnológico adaptando la concepción general a los ámbitos tecnológicos (Carlsson, 2012). Malerba $(2002,2004)$ o Breschi \& Malerba (1997) realizan un enfoque sectorial, centrándose en aquellos grupos de empresas que se dedican a producir en un sector determinado haciendo uso de las tecnologías propias de ese sector. También se ha desarrollado el concepto de sistema regional de innovación por autores como Asheim e Isaken (2002), Braczyk et al. (1998), Cooke (2001), Cooke et al. (1997) o Heijs et al. (2002). De igual forma, se ha realizado el análisis a nivel distritual (Molina Morales et al., 2012).

Todas estas adaptaciones podrían ser consideradas como partes integrantes de la concepción genérica de sistemas nacionales de innovación. No obstante, éstas tienen el valor de representar las peculiaridades del contexto al que se circunscriben. En efecto, las industrias tienden a concentrarse en espacios específicos por lo que un espacio político-institucional definido de manera general a un primer nivel nacional no siempre 
coincide con el espacio en el que se producen realmente las relaciones de mayor impacto sobre la innovación. Por otro lado, existen también una serie de políticas nacionales cuyo ámbito de aplicación no es el establecido a ese primer nivel, sino que pueden ser aplicadas de manera descentralizada en los siguientes subniveles.

En definitiva, el resultado de estos nuevos enfoques es la aparición de una serie de adaptaciones de la teoría sistémica inicial en base a unas unidades de análisis más específicas en las que la modelización de las redes relacionales es más fiel a la realidad empresarial.

A continuación, se describen algunas de las características más relevantes de estos sistemas de innovación más específicos:

\section{Sistema Sectorial de innovación (SSI)}

Desarrollado por autores como Breschi \& Malerba (1997), este enfoque se caracteriza por el uso de la noción de sector como unidad de análisis y no por el de territorio o tecnología como lo hacían otras visiones más generales. Bajo esta perspectiva, las empresas, instituciones y organizaciones más relevantes son aquellas que interactúan entorno a una actividad sectorial determinada independientemente de su ubicación o del tipo de tecnología que dominan. La innovación en un sector, en consecuencia, está basada en tres factores principales: (a) conocimiento y tecnología que se utilizan en el mismo; (b) los actores y las redes que lo conforman; (c) las instituciones vinculadas al mismo.

\section{Sistema Regional de Innovación (SRI)}

Poco tiempo después de la definición de los sistemas de innovación a nivel nacional, autores como Cooke et al. (1997), Cooke (2001) o Asheim y Isaksen (2002) aplican el concepto a la dimensión regional. La principal motivación de estos estudios es constatar que en una misma nación conviven varias regiones con patrones de conducta diferenciados en las cuales las estructuras, los recursos y los resultados de la innovación varían de una manera sustancial. Efectivamente, en casi todos los países se pueden establecer regiones con alta concentración de actividad innovadora y otras en las que esta actividad es menor. La contribución al conjunto nacional de las distintas regiones 
puede ser, entonces, asimétrica. Por este motivo, los SNI pueden plantear un sesgo si se basan su análisis en estas regiones más avanzadas. Otro argumento a favor de éstos se basa en el hecho de que, en un mundo cada vez más globalizado donde se desdibujan las fronteras nacionales, puede resultar más adecuado, centrar el análisis de la innovación en un espacio de identidad cultural común socioeconómicamente más homogéneo.

Por estos motivos, los análisis de los sistemas regionales de innovación están centrando el interés de los investigadores. Podemos destacar, entre otros, los trabajos de Saxenian sobre ventajas regionales o los estudios de Jaffe en relación a los efectos de la investigación de la universidad sobre el desarrollo regional y la concentración geográfica de spill overs (Jaffe et al., 1993; Saxenian, 1996). Esta visión regional, en conclusión, se basa en cuatro ejes fundamentales, los cuales, de una manera ponderada, configuran el entorno regional de la innovación. Los cuatro ejes o factores son:

- FACTOR1: entorno productivo de la innovación adscrito a una región.

- FACTOR2: entorno de la administración relacionada con la innovación.

- FACTOR3: entorno universitario relacionado con la generación de conocimiento.

- FACTOR4: empresas beneficiarias de las innovaciones.

\section{Sistema Distritual de Innovación (SDI)}

Con el objetivo de complementar y fortalecer la consistencia del sistema sectorial de innovación, autores como Molina et al. (2012) o Gabaldón-Estevan (2010) integran la visión sistémica con el concepto marshalliano de distrito industrial (Becattini, 1979) planteando así el SDI. Uno de los aspectos más relevantes de esta nueva perspectiva es que, si bien se considera que el concepto de distrito industrial no incluye la innovación como eje central (Pyke et al., 1990), sí introduce su elemento relacional, el cual es, a su vez, distinto a los planteados previamente por otras aproximaciones sistémicas de la innovación. Es precisamente el patrón de relaciones característico sugerido por el distrito el que conduce a la generación de un conocimiento tácito que favorece la generación y transmisión de una innovación de tipo incremental. Este hecho viene a complementar la creación y difusión de la innovación de tipo tecnológico que se genera a partir del conocimiento explícito producido básicamente en universidades y centros de investigación característico de los sistemas de innovación. 
En definitiva, la principal contribución del SDI radica en que combina elementos propios de un distrito, tales como la especialización productiva, el sentido de pertenencia a una comunidad o las relaciones de proximidad, con los aspectos principales de un sistema sectorial, tales como las redes de conocimiento, el marco institucional o la noción de learning by interacting.

\subsubsection{Las innovaciones disruptivas}

\subsubsection{Descripción y definición del fenómeno disruptivo}

Como hemos descrito ampliamente en el apartado correspondiente a la clasificación de las innovaciones según su originalidad, las innovaciones pueden dividirse en radicales (o disruptivas) e incrementales. Para el propósito de la presente tesis, esta distinción es de gran importancia ya que no sólo el impacto que generan es totalmente distinto sino también lo son las competencias y habilidades que son necesarias para desarrollarlas (Story, Daniels, Zolkiewski, \& Dainty, 2014).

La literatura ha reconocido ampliamente la importancia de las innovaciones disruptivas frente a otro tipo de innovaciones más incrementales, así como el impacto positivo que éstas generan tanto para las industrias como para las empresas (Story et al., 2014). Las innovaciones disruptivas pueden transformar los contextos industriales a través de la reconfiguración de las posiciones de liderazgo y son consideradas cruciales para el desarrollo empresarial y económico de las sociedades (Ansari \& Krop, 2012; Markides, 2006; Tellis, Prabhu, \& Chandy, 2009). A través de estas innovaciones, las empresas que suelen operar en una industria (incumbent firms) son retadas y en ocasiones desbancadas de sus posiciones de liderazgo.

Muchos autores han estudiado este fenómeno, por ejemplo (McAdams \& Reavis, 2008) analizaron como la empresa Gemesis retó a la industria tradicional de extracción de diamantes gracias a la producción en laboratorio de estas gemas; o también (Leonhardt, 2006) quien estudió como Netflix retó a las empresas de alquiler de películas 
tradicionales con una oferta on-line generando una experiencia de cliente sin precedentes hasta el momento en ese sector. Glasmeier (1991), por su parte, en un contexto de clúster, analizó ampliamente como la industria suiza de la relojería fue desbancada del liderazgo con la aparición de los relojes digitales japoneses.

Para describir este tipo de fenómenos, muchos autores han utilizado indistintamente los términos radical o disruptivo. Podemos citar como ejemplos a Nagy, Schuessler, \& Dubinsky (2016); Nijssen, Hillebrand, \& Vermeulen (2005); O'Connor \& McDermott, (2004) o Roy \& Cohen (2015). En definitiva, se trata de todas aquellas innovaciones a través de las cuales se consigue lanzar productos o servicios totalmente nuevos o desarrollar tecnologías revolucionarias destruyendo mercados y creando otros nuevos.

Los fenómenos disruptivos han generado una gran corriente de estudios provocando debates muy interesantes en los círculos académicos; no obstante, la investigación empírica rara vez se ha fundamentado en sus argumentos teóricos clave (Christensen, McDonald, Altman, \& Palmer, 2018). En efecto, desde las formulaciones iniciales de la teoría disruptiva, ésta ha sido utilizada para explicar distintos tipos de fenómenos innovadores con características muy diferentes (Markides, 2006).

En este punto, creemos necesario reconocer que existe cierta discrepancia o confusión con relación a la terminología utilizada en la literatura para referirse a estas innovaciones. Somos conscientes de que la aparición de varios conceptos que capturan nociones similares dificulta su identificación y clara delimitación (Gatignon, Tushman, Smith, \& Anderson, 2002). Con el objetivo de clarificar esta situación, Markides (2006) realiza una interesante distinción. El autor argumenta que existen diferentes fenómenos innovadores que tienen en común el hecho de que son disruptivos para las empresas pertenecientes a una industria. Sin embargo, defiende que tratar a todos estos fenómenos por igual puede llevar a confusiones importantes ya que éstos surgen de maneras diferentes, tienen efectos competitivos diversos y requieren respuestas de las empresas existentes distintas. El investigador sugiere, por tanto, distinguir fundamentalmente entre tres tipos distintos de disrupciones que se detallan en la tabla siguiente (Tabla 15). 
Tabla 15: Diferentes fenómenos innovadores disruptivos

\begin{tabular}{|c|c|c|c|}
\hline $\begin{array}{l}\text { Término que } \\
\text { describe el } \\
\text { fenómeno } \\
\text { innovador }\end{array}$ & $\begin{array}{c}\text { Objeto de } \\
\text { la } \\
\text { innovación }\end{array}$ & Características del fenómeno & Ejemplos \\
\hline $\begin{array}{l}\text { Innovación de } \\
\text { Modelo de } \\
\text { negocio }\end{array}$ & $\begin{array}{l}\text { Modelo de } \\
\text { negocio }\end{array}$ & $\begin{array}{l}\text { Descubrimiento de un modelo de } \\
\text { negocio fundamentalmente } \\
\text { diferente a los existentes. } \\
\text { Debe ampliar el mercado } \\
\text { existente, ya sea por atraer } \\
\text { nuevos clientes o alentando a } \\
\text { clientes existentes a consumir } \\
\text { más. }\end{array}$ & $\begin{array}{l}\text { easyJet vs British } \\
\text { Airways; Dell vs } \\
\text { HP (o IBM). }\end{array}$ \\
\hline $\begin{array}{l}\text { Innovación } \\
\text { Tecnológica }\end{array}$ & Tecnología & $\begin{array}{l}\text { Introducción de un cambio } \\
\text { tecnológico revolucionario. } \\
\text { Permite ofrecer el mismo } \\
\text { producto o servicio (o también } \\
\text { mejorado) al mercado pero } \\
\text { obtenido de forma totalmente } \\
\text { distinta. }\end{array}$ & $\begin{array}{l}\text { Relojes digitales; } \\
\text { impresión digital; } \\
\text { copiadoras Canon. }\end{array}$ \\
\hline $\begin{array}{l}\text { Innovación } \\
\text { Radical }\end{array}$ & Producto & $\begin{array}{l}\text { Creación de productos nuevos } \\
\text { para el mundo. } \\
\text { Introducen productos y } \\
\text { propuestas de valor que } \\
\text { modifican los hábitos de } \\
\text { consumo y los comportamientos } \\
\text { existentes de una manera } \\
\text { importante. } \\
\text { Los mercados que crean socavan } \\
\text { las competencias y activos } \\
\text { complementarios en los que las } \\
\text { empresas existentes han } \\
\text { construido su éxito }\end{array}$ & $\begin{array}{l}\text { Aparición del } \\
\text { coche eléctrico, la } \\
\text { televisión, los } \\
\text { teléfonos } \\
\text { inteligentes, etc. }\end{array}$ \\
\hline
\end{tabular}

Fuente: Elaboración propia a partir de Markides (2006) 
En base a esta descripción, cabe destacar que, para el propósito de la presente tesis pretendemos dejar de lado el debate conceptual centrado en la definición de las innovaciones disruptivas llevado a cabo por algunos autores como, por ejemplo, Dahlin \& Behrens (2005;) Govindarajan \& Kopalle (2006); Hang, Chen, \& Yu (2011); Nagy et al. (2016) o Schmidt \& Druehl (2008). Por el contrario, estamos interesados en estudiar los efectos ocasionados por aquellas tecnologías e innovaciones que van más allá de desarrollos incrementales o pequeños cambios. Esto implica la sustitución de productos y tecnologías por otros nuevos que pueden crearse o (en nuestro caso) adoptarse por las empresas. En este sentido, los cambios disruptivos pueden ampliar los mercados existentes, y también romper los vínculos existentes con los mismos generando nuevos (Adner, 2006; Danneels, 2004; Gilbert, 2003).

Por este motivo, y para los fines de esta investigación, nos referimos a la innovación disruptiva como un cambio tecnológico que incorpora nuevos conocimientos, recursos o habilidades que hacen que el valor de los sistemas y tecnologías existentes se vuelvan obsoletos. Pretendemos, en conclusión, captar la naturaleza radical y discontinua de las tecnologías nuevas en la línea de otros estudios como por ejemplo los llevados a cabo por Adner (2002); Charitou \& Markides (2002); Christensen \& Raynor (2003); Danneels (2004); Gilbert (2012) o Markides (2006).

\subsubsection{Orígenes de la teoría disruptiva y su evolución}

La teoría disruptiva tiene su origen en tres estudios seminales publicados a finales de la década de los 90`s. Estos tres artículos son considerados como los pilares fundacionales a partir de los cuales se desarrolla un amplio cuerpo teórico en las décadas sucesivas. Estos tres estudios son los realizados por Bower \& Christensen (1995); Christensen (1997); Christensen \& Bower (1996) y se describen en la Tabla 16: 
Tabla 16: Descripción de los tres artículos seminales de la teoría disruptiva

\begin{tabular}{|c|c|c|c|}
\hline Estudio & Autor/es & $\begin{array}{c}\text { Año de } \\
\text { publicación }\end{array}$ & Descripción \\
\hline $\begin{array}{c}\text { Disruptive technologies: Catching } \\
\text { the wave }\end{array}$ & $\begin{array}{c}\text { Bower \& } \\
\text { Christensen }\end{array}$ & 1995 & $\begin{array}{l}\text { Los autores sugieren que existe un consistente patrón en el mundo empresarial con relación al fracaso de empresas } \\
\text { líderes cuando emergen nuevas tecnologías o mercados. Citan ejemplos de empresas como Goodyear y Firestone } \\
\text { en el mercado de los neumáticos; Xerox, que permitió la entrada y el éxito de Canon; Bucyrus-Erie, que permitió } \\
\text { la entrada de Caterpillar y Deere en el mercado de las excavadoras. } \\
\text { Los autores explican este fenómeno a través de factores como la burocracia, un cuadro ejecutivo cansado, la poca } \\
\text { planificación o la inversión a corto plazo; no obstante asignan la mayor responsabilidad a un dogma empresarial: } \\
\text { Las empresas están cerca de sus clientes. }\end{array}$ \\
\hline $\begin{array}{c}\text { Customer power, strategic } \\
\text { investment, and the failure of } \\
\text { leading firms }\end{array}$ & $\begin{array}{c}\text { Christensen \& } \\
\text { Bower }\end{array}$ & 1996 & $\begin{array}{l}\text { Los autores plantean por qué las empresas que son consideradas como bien dirigidas, en un momento determinado } \\
\text { pierden el liderazgo en la industria al enfrentarse a un cambio tecnológico. } \\
\text { Así se analiza el proceso a través del cual la demanda presente determina la asignación de recursos de innovación } \\
\text { tecnológica en una empresa. } \\
\text { Los autores muestran como las empresas existentes lideraron la industria en el desarrollo de tecnologías de todo } \\
\text { tipo, incluso radicales, siempre que éstas abordaran las necesidades de los clientes existentes. Estas mismas } \\
\text { empresas no desarrollaron tecnologías distintas (aunque más simples) que inicialmente solo eran útiles en } \\
\text { mercados emergentes, porque los esfuerzos se dedicaban a satisfacer a los clientes mayoritarios. } \\
\text { Los autores concluyen que en estas empresa, los proyectos dirigidos al desarrollo de tecnologías incipientes para } \\
\text { satisfacer a clientes aún inexistentes son habitualmente pospuestos. }\end{array}$ \\
\hline $\begin{array}{l}\text { The innovator's dilemma: when } \\
\text { new technologies cause great } \\
\text { firms to fail }\end{array}$ & Christensen & 1997 & $\begin{array}{l}\text { El autor analiza en profundidad el caso de la industria de discos de almacenamiento de memoria en Estados } \\
\text { Unidos. Este sector, de alcance global e integrado verticalmente ha sufrido cambios tecnológicos y de estructura de } \\
\text { mercado muy generalizados, rápidos y de forma implacable. } \\
\text { El autor argumenta que detrás de complejidad de todos estos fenómenos surgen algunos factores increíblemente } \\
\text { simples. Éstos han determinado recurrentemente el éxito y el fracaso de las mejores empresas de la industria. } \\
\text { El autor analiza uno de los dilemas de la empresa innovadora: "Seguir ciegamente la máxima de que los buenos } \\
\text { gerentes deben estar cerca de sus clientes a veces puede ser un error fatal". }\end{array}$ \\
\hline
\end{tabular}

Fuente: elaboración propia a partir de Bower \& Christensen (1995), Christensen (1997), Christensen \& Bower (1996). 
Podemos concluir, por tanto, que al igual que otras teorías, la teoría disruptiva se fundamentó en una observación a partir de la cual se planteó una pregunta de investigación. Estos autores analizaron distintos tipos de industrias, desde la industria informática hasta la distribución del acero, en las que las empresas líderes -a pesar de estar aparentemente bien gestionadas- dejaron de serlo, precipitando su declive o incluso su desaparición. Se generó así un marco explicativo centrado en determinar cómo las empresas líderes se enfrentan a los cambios tecnológicos y el desarrollo de nuevos mercados. De esta forma, la -en esa época- incipiente teoría disruptiva pretendía abordar el fenómeno del declive empresarial de una forma distinta a la utilizada hasta el momento en la literatura. Estas corrientes teóricas se basaban en explicaciones como la complejidad tecnológica, el limitado entendimiento del cuerpo directivo o la inercia organizacional (Henderson, 1993; Henderson \& Clark, 1990; Tushman \& Anderson, 1986).

A partir de estos análisis iniciales, Christensen (1997) sugirió la existencia de tres elementos fundamentales en el proceso disruptivo. Los autores Christensen et al. (2018) los describen como sigue:

- En muchas industrias, el ritmo del progreso tecnológico supera la demanda de nuevas tecnologías por parte de los clientes. Como resultado, las empresas líderes pueden sobre servir al mercado, al producir productos más avanzados y con mejores características de lo que realmente éste demanda. Al hacer esto, las empresas crean un hиесо en la parte inferior del mercado; este hueco es el que aparece entre las necesidades de los clientes y el desempeño proporcionado por las empresas. La brecha abierta proporciona una posibilidad de entrada a nuevas empresas.

- La emergencia de dos tipos fundamentales de innovaciones (innovación tecnológica y de modelo de negocio) supone para las empresas existentes un dilema estratégico crucial. La mayor parte de estas innovaciones son innovaciones menores que sostienen el negocio existente (sustaining innovations) ya que mejoran las propiedades de aquellos productos y servicios que más valoran los principales clientes. En menor medida se producen innovaciones disruptivas. Normalmente, en la primera etapa de su introducción, estas innovaciones suelen ofrecer alternativas 
con propiedades inferiores a los productos existentes por lo que suelen atraer a grupos de clientes marginales (Markman \& Waldron, 2014).

- Los clientes, así como los modelos de generación de beneficios existentes, limitan las inversiones que las empresas presentes pueden hacer en nuevas innovaciones. Estas inversiones sin atractivo para estas empresas pueden suponer oportunidades interesantes para otras empresas nuevas que carecen de una gran cantidad de clientes y disfrutan de menos oportunidades de inversión en tecnologías ya dominantes.

El resultado es, en definitiva, que las empresas que ya operan en un mercado no se encuentran motivadas a desarrollar unas innovaciones disruptivas que generarán menores márgenes (a corto plazo) y que, en la mayoría de los casos, introducirán productos o servicios con unas prestaciones inferiores a las que sus propios clientes están acostumbrados.

Una vez definido este primer modelo, muchos han sido los autores que han tratado de determinar si los patrones establecidos en las industrias inicialmente analizadas podían ser representativos de otras. Así han aparecido una serie de estudios dedicados a someter estas hipótesis a los fenómenos acontecidos en otros sectores. En la Tabla 17 se muestran algunos de ellos. Muchos de estos estudios han reforzado la teoría inicial: ante las innovaciones disruptivas, los empresas presentes suelen mantener sus posiciones dominantes a través de la creación de unidades de negocio autónomas con libertad para adoptar sus propios procesos y nuevas tecnologías (Gilbert, 2006; Gulati \& Garino, 2000; Westerman, McFarlan, \& Iansiti, 2006). 
Tabla 17: Algunos estudios dedicados al análisis de fenómenos disruptivos

\begin{tabular}{|c|c|c|}
\hline Industria & Título de los estudios & Autores \\
\hline Semiconductores & $\begin{array}{l}\text { - Teradyne: Corporate Management of } \\
\text { Disruptive Change } \\
\text { - The Ongoing Process of Building a } \\
\text { Theory of Disruption }\end{array}$ & $\begin{array}{l}\text { d'Arbeloff (1996) } \\
\text { Christensen (2006) }\end{array}$ \\
\hline Distribución & - Patterns of Disruption in Retailing & $\begin{array}{c}\text { Christensen \& Tedlow } \\
\text { (2000) }\end{array}$ \\
\hline $\begin{array}{l}\text { Industria } \\
\text { automovilística }\end{array}$ & $\begin{array}{l}\text { - The Innovator's Solution: Creating } \\
\text { and Sustaining Successful Growth }\end{array}$ & $\begin{array}{c}\text { Christensen \& Raynor } \\
\text { (2003) }\end{array}$ \\
\hline $\begin{array}{l}\text { Administración } \\
\text { educativa }\end{array}$ & - Disruption in Education & $\begin{array}{l}\text { Christensen, Aaron, \& } \\
\text { Clark (2003) }\end{array}$ \\
\hline Imprenta & $\begin{array}{l}\text { - Unbundling the Structure of Inertia: } \\
\text { Resource Versus Routine Rigidity } \\
\text { - Change in the Presence of Residual } \\
\text { Fit: Can Competing Frames Coexist? }\end{array}$ & $\begin{array}{l}\text { Gilbert (2005) } \\
\text { Gilbert (2006) }\end{array}$ \\
\hline $\begin{array}{l}\text { Cirugía } \\
\text { cardiovascular }\end{array}$ & $\begin{array}{l}\text { - The Innovator's Prescription: A } \\
\text { Disruptive Solution for Health Care }\end{array}$ & $\begin{array}{c}\text { Kleinke, Christensen, } \\
\text { Grossman, \& Hwang } \\
\text { (2009) }\end{array}$ \\
\hline Farmacéutica & $\begin{array}{l}\text { Decoding the Adaptability-Rigidity } \\
\text { Puzzle: Evidence from } \\
\text { Pharmaceutical Incumbents' Pursuit } \\
\text { of Gene Therapy and Monoclonal } \\
\text { Antibodies }\end{array}$ & $\begin{array}{l}\text { Kapoor \& Klueter } \\
\qquad(2015)\end{array}$ \\
\hline Electrónica & $\begin{array}{l}\text { - The Disruptor's Dilemma: TiVo and } \\
\text { the U.S. Television Ecosystem, }\end{array}$ & $\begin{array}{c}\text { Ansari, Garud, \& } \\
\text { Kumaraswamy (2016) }\end{array}$ \\
\hline $\begin{array}{l}\text { Servicios } \\
\text { financieros }\end{array}$ & $\begin{array}{l}\text { - Banking on Disruption: Digitization, } \\
\text { FinTech and the Future of Retail } \\
\text { Banking. }\end{array}$ & Das (2017) \\
\hline
\end{tabular}

Fuente: elaboración propia a partir de Christensen et al. (2018) 
Otros trabajos intentaron ampliar el ámbito de estudio analizando no sólo los segmentos más bajos de los mercados desarrollados sino todo tipo de ellos (por ejemplo, Christensen et al., 2018; Govindarajan \& Kopalle, 2006; Markides, 2006). En efecto, el modelo inicial describía disrupciones de gama baja (low-end), en las que las empresas entrantes iniciaban el negocio en la parta baja del mercado para, una vez afianzadas, moverse hacia arriba y empezar a competir con las empresas tradicionalmente presentes (Christensen \& Raynor, 2003). Esto fue observado en industrias como la del acero o los distribuidores de bajo coste (Christensen \& Tedlow, 2000). En contraposición, la literatura ha identificado las disrupciones de nuevo mercado (new-market disruptions); estos fenómenos son aquellos que son capaces de crear nuevas cadenas de valor para las que no existían clientes previamente. Ofrecen, por tanto, las primeras generaciones de productos o servicios. En estos casos, no hay cuota de mercado que ganar puesto que estos clientes no accedían previamente a esos productos o servicios. Es precisamente por este motivo por el que en estos casos, las empresas que operan tienden a ignorar a los nuevos entrantes (Anthony, Johnson, Altman, \& Sinfield, 2008; Charitou \& Markides, 2002).

Otro importante avance en la evolución de la teoría disruptiva ha consistido en definir la disrupción como un fenómeno relativo y no absoluto. Esto significa que una misma innovación puede ser disruptiva para una empresa, mientras que para otra simplemente refuerza su mercado. Christensen et al. (2018) ponen como ejemplo internet: mientras que para los distribuidores que operaban por correo tradicional esta innovación tan sólo reforzó sus mercados, para otros distribuidores centrados en las tiendas físicas supuso una verdadera disrupción al no poder aprovecharse de este avance en sus procesos de venta habitual. A este respecto, los autores Kapoor \& Klueter (2015) sugieren que las tecnologías y los modelos de negocio deben analizarse conjuntamente: una empresa debe evaluar el grado de disrupción de una innovación con relación a su modelo de negocio.

En definitiva, podemos concluir que con el paso del tiempo, la teoría disruptiva ha evolucionado desde una perspectiva asociada al cambio tecnológico (esencialmente descriptiva y de alcance relativamente limitado) a una teoría causal más amplia acerca de la innovación y la respuesta competitiva que desarrollan las empresas (Christensen et al., 2018). Esta evaluación revela que nuestra comprensión del fenómeno de la disrupción ha cambiado a medida que la teoría se ha desarrollado, dando lugar a un apasionante debate en relación a los conceptos teóricos subyacentes (Christensen, 2006; Gans, 2016; Sood \& 
Tellis, 2011; Utterback \& Acee, 2005), así como a temas tan diversos como la teoría de organización empresarial, los fenómenos innovadores o la estrategia tecnológica (Di Stefano, Gambardella, \& Verona, 2012).

\subsubsection{Determinantes de adopción de las innovaciones disruptivas}

A pesar de todos los beneficios que estas innovaciones generan, su tasa de fracaso durante su desarrollo es significativamente más alta en comparación a otras formas de innovación como, por ejemplo, las innovaciones incrementales. Este hecho no solo se debe a elementos como la alta incertidumbre o la complejidad (tanto técnica como de mercado) que las rodea (Leifer et al., 2000). Las empresas se enfrentan también a una gran cantidad de desafíos y factores (tanto internos como externos) los cuales suelen inhibir los esfuerzos destinados desarrollarlas. Por otro lado, el impacto de las innovaciones disruptivas no es el mismo para las empresas que entran en una industria existente (retándola de algún modo), como para las empresas que previamente operaban en la misma (incumbents). La literatura ha demostrado cómo mayoritariamente y de forma general, las empresas presentes en un sector bien desaparecen (al no ser capaces de adaptarse al cambio tecnológico), bien adoptan la innovación tarde y pierden su ventaja competitiva (King \& Tucci, 2002).

Todas las habilidades desarrolladas durante los periodos de crecimiento, estabilidad o liderazgo de mercado suelen llevar a muchas empresas a ser menos receptivas al cambio (Benner \& Tushman, 2003). El cambio tecnológico suele forzarlas a desarrollar una nueva forma de competencia a la que en muchas ocasiones no consiguen adaptarse. Distintos autores han explicado este hecho a través de factores tan diversos como los sesgos cognitivos o el establecimiento de una política errónea de incentivos a los directivos (Christensen \& Bower, 1996; Tripsas \& Gavetti, 2000). En efecto, estas innovaciones no sólo impactan en las tecnologías como se podría suponer en primera aproximación; más bien plantean otras implicaciones de mayor profundidad que las empresas deben entender. La creación de nuevos segmentos de mercado con preferencias distintas (Tripsas, 2008); la necesidad de desarrollar activos complementarios (Tripsas, 1997); el desarrollo de nuevas arquitecturas de la industria (Baldwin, 2007); la aparición de nuevas redes de alianzas (Rosenkopf \& Nerkar, 2001) o el nacimiento de nuevos modelos de negocio (Baden-Fuller \& Morgan, 2010) son consecuencias que plantean la necesidad de analizar los impactos de 
estas innovaciones de una forma muy profunda. A pesar de esta dificultad de adaptación planteada de forma general, la literatura también ha encontrado importantes excepciones de empresas capaces de mantener el liderazgo tras un cambio tecnológico disruptivo. Por ejemplo, (Klepper \& Simons, 2000) estudiaron el fenómeno de la introducción de la televisión en Estados Unidos después de la segunda guerra mundial y demostraron cómo las empresas que ya operaban en esta industria fueron capaces de hacer frente con éxito a la disrupción.

Como consecuencia de su importancia, la literatura ha analizado ampliamente durante las últimas décadas los motivos por los cuales las empresas presentes en una industria son capaces, o no, de mantener el liderazgo después de un cambio tecnológico disruptivo. La mayor parte de estos estudios han abordado esta cuestión desde un único nivel de análisis tal como la industria, la empresa, el marco institucional o la propia innovación. Se han sugerido así interesantes conclusiones como por ejemplo las obtenidas en los trabajos realizados por Argote, Beckman, \& Epple (1990); Chesbrough (1999); Danneels, 2004; Rafii \& Kampas (2002) o Tripsas (1997). Algunas de las aportaciones más interesantes se muestran a continuación en la Tabla 18, Tabla 19 y Tabla 20 para tres niveles distintos de análisis: la industria, la empresa existente y el reto innovador respectivamente.

Sin embargo, son menos los estudios que tratan de analizar de una forma concurrente todos estos factores, así como las conexiones existentes entre ellos. Ahuja et al., (2008), por ejemplo, proporcionan una revisión muy exhaustiva acerca de las distintas aportaciones que diversos autores han realizado sobre la innovación disruptiva. No obstante, su enfoque se centra exclusivamente en los determinantes de la innovación tecnológica. Así, a pesar de décadas de interés en desarrollar y aplicar modelos muy razonados (por ejemplo los estudios de Cattani (2005;) Lavie (2006); Murmann \& Frenken (2006) o Nijssen et al. (2005)) pocos estudios han acabado de reflejar la vasta complejidad del fenómeno disruptivo. Entre estos, podemos destacar el realizado por los investigadores Ansari y Krop (2012). A través del análisis de cuatro innovaciones acontecidas en la industria de fabricación de televisiones en Alemania, estos autores han aplicado una perspectiva holística. Pretenden así incluir cada una de las dimensiones anteriormente estudiadas en un único análisis: el contexto de la industria, las características de la empresa que afronta el cambio de paradigma tecnológico y las características del fenómeno disruptivo en sí mismo. Este tipo de estudios suponen un punto de inflexión en la literatura ya que ponen 
de manifiesto la necesidad de establecer puentes e interacciones entre los distintos niveles (industria, intra-empresa e inter-empresa) que intervienen en estos complejos fenómenos. 
Tabla 18: Estudios relacionados con los factores de asimilación de las innovaciones disruptivas bajo una perspectiva de la industria

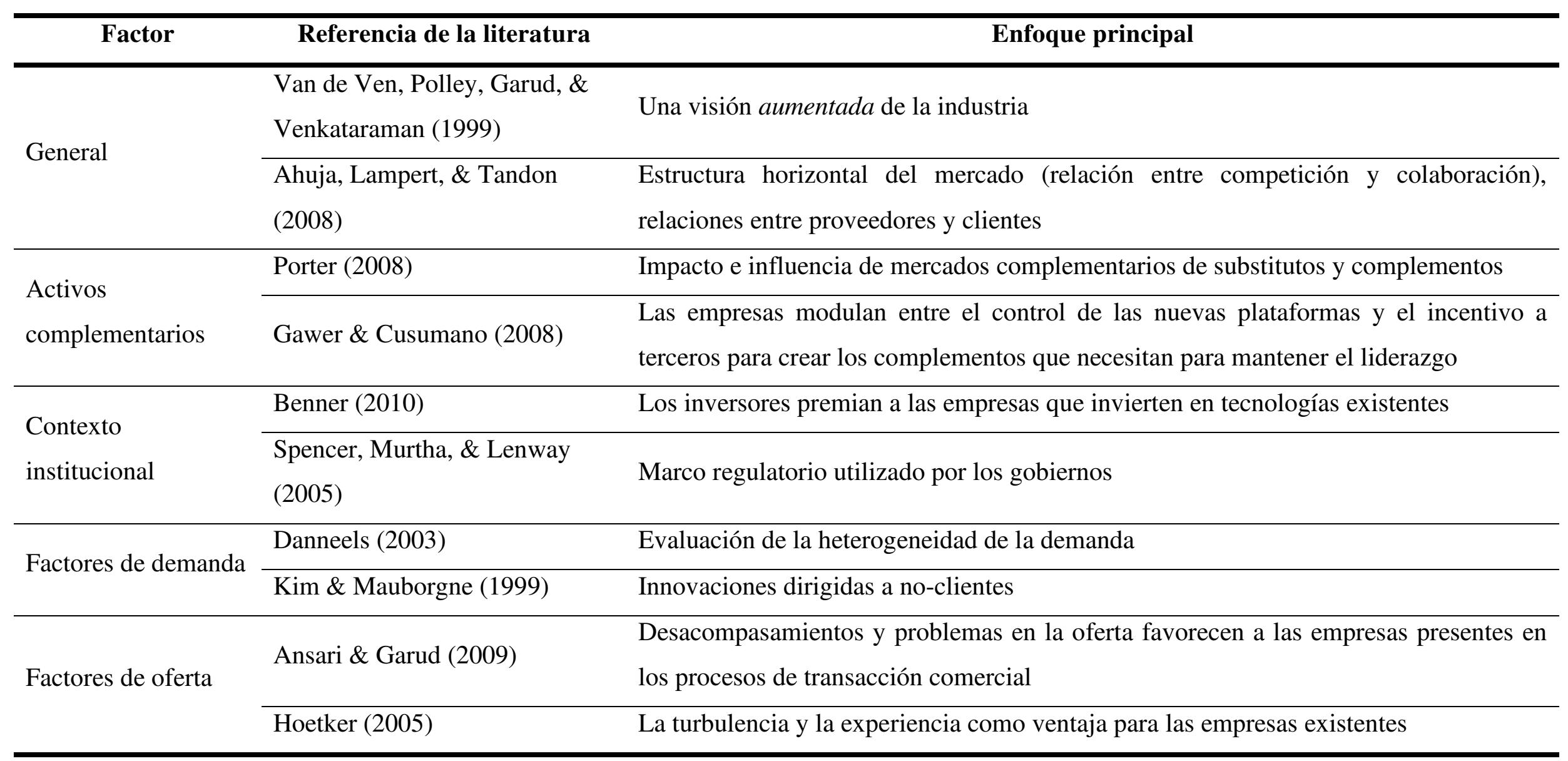

Fuente: elaboración propia a partir de Ansari \& Krop (2012) 
Tabla 19: Estudios relacionados factores de asimilación de las innovaciones disruptivas bajo una perspectiva de las características de la empresa

\begin{tabular}{|c|c|c|}
\hline Factor & Referencia de la literatura & Enfoque principal \\
\hline General & Volberda \& Elfring (2001) & Configuración de las capacidades complementarias \\
\hline \multirow[t]{2}{*}{ Gestión de los límites } & Rothaermel (2001) & $\begin{array}{l}\text { Alineación con start-ups y suministro de capacidades } \\
\text { complementarias }\end{array}$ \\
\hline & Macher \& Richman (2004) & Estrategias de joint-venture o adquisición de empresas \\
\hline \multirow{2}{*}{ Organización empresarial } & Eisenmann, Parker, \& Van Alstyne (2006) & Control de la infraestructura asociada a una nueva tecnología \\
\hline & Smith, Collins, \& Clark (2005) & Influencia del clima organizacional \\
\hline \multirow{2}{*}{$\begin{array}{l}\text { Desarrollo de capacidades } \\
\text { complementarias }\end{array}$} & Sosa $(2011)$ & (Posibilidad de acceso a nuevas competencias \\
\hline & Taylor \& Helfat (2009) & $\begin{array}{l}\text { Desarrollo de lazos entre las distintas unidades de la empresa } \\
\text { envueltas en el desarrollo de una tecnología }\end{array}$ \\
\hline
\end{tabular}

Fuente: elaboración propia a partir de Ansari \& Krop (2012) 
Tabla 20: Estudios relacionados con los factores de asimilación de las innovaciones disruptivas bajo una perspectiva del fenómeno innovador

\begin{tabular}{|c|c|c|}
\hline Factor & Referencia de la literatura & Enfoque principal \\
\hline \multirow[t]{2}{*}{ Tipo de innovación } & Tushman \& Anderson (1986) & $\begin{array}{l}\text { Innovaciones que desarrollan competencias vs innovaciones que destruyen } \\
\text { competencias }\end{array}$ \\
\hline & Tripsas (2008) & Innovaciones que desafían la identidad \\
\hline \multirow{2}{*}{$\begin{array}{l}\text { Requerimientos de } \\
\text { comercialización }\end{array}$} & Rothaermel \& Hill (2005) & $\begin{array}{l}\text { Balance entre activos complementarios genéricos y específicos durante la } \\
\text { comercialización de una innovación }\end{array}$ \\
\hline & Hill \& Rothaermel (2003) & Requerimientos de comercialización de una innovación \\
\hline \multirow{2}{*}{$\begin{array}{l}\text { Perspectiva de tiempo de } \\
\text { incubación }\end{array}$} & Klepper \& Simons (2000) & Tiempos largos de incubación favorece a las empresas existentes \\
\hline & Rosenbloom (2000) & Una rápida transición de las empresas existentes favorece a éstas \\
\hline
\end{tabular}

Fuente: elaboración propia a partir de Ansari \& Krop (2012) 


\subsection{Los factores internos de la Innovación. La capacidad de absorción}

\subsubsection{Introducción}

En los apartados anteriores de este capítulo hemos descrito los distintos beneficios que para las empresas supone, por un lado, formar parte de una aglomeración territorial, y por el otro lado, realizar un esfuerzo en el desarrollo de innovaciones disruptivas (en términos, por ejemplo, de mejora de la competitividad, creación de nuevas oportunidades, acceso a nuevos mercados). Podemos aceptar, por tanto, que el hecho de pertenecer a un clúster puede facilitar a las empresas el acceso a un conocimiento compartido que les permita desarrollar, implementar o asimilar innovaciones, con un mayor o menor grado de radicalidad o disrupción. Se trata de las denominadas capacidades de orden superior (Foss, 1996).

No obstante, este efecto clúster debe ser integrado dentro de un marco más general explicativo de la capacidad innovadora de las empresas como entidades individuales. Todas las empresas que forman parte de un clúster no disponen de los mismos recursos ni tienen las mismas capacidades de innovación. Por lo tanto, debemos considerar la existencia de unos factores internos característicos que dirigen, condicionan y explican los procesos innovadores de cada una de las empresas que integran la aglomeración territorial. Se trata de lo que podríamos considerar el efecto empresa sobre la innovación.

En este apartado vamos a analizar la innovación desde la perspectiva de la empresa, dejando de lado el enfoque centrado en el clúster. El conjunto de teorías y desarrollos teóricos que se han identificado en la literatura bajo el epígrafe de la Teoría de la Ventaja Competitiva basada en los Recursos y las Capacidades (Barney, 1991; Grant, 1999; Mahoney \& Pandian, 1992; Peteraf, 1993; Prahalad, 1990) pueden ser un instrumento de análisis válido para explicar el proceso innovador con este enfoque. Esta teoría, en el plano más general, se fundamenta en la consideración de que son los 
recursos y capacidades de la empresa los que explican su competitividad y, por tanto, también su capacidad innovadora. Esto se debe principalmente a que, como distintos autores han sugerido, el conocimiento es el recurso estratégico de mayor importancia (Grant, 1996; Hill \& Deeds, 1996). En este sentido, la creación y mejora del stock de estos recursos y capacidades se convierte en el eje central de la estrategia empresarial ya que condiciona la capacidad de absorber el stock de conocimiento en circulación (LealRodríguez et al., 2014). La capacidad de absorción, como característica interna distintiva entre las empresas que integran las aglomeraciones territoriales, se convierte así en una pieza fundamental de esta tesis puesto que, en gran medida, puede determinar la capacidad de las mismas de adquirir un conocimiento tan novedoso como son las innovaciones radicales o disruptivas.

En definitiva, este apartado se dedica principalmente a una revisión teórica de este concepto. Vamos a realizar, en primer lugar, un análisis de la innovación a partir de la Teoría de Recursos y Capacidades; posteriormente nos centraremos en la revisión conceptual de la capacidad de absorción (Cohen \& Levinthal, 1989) como elemento interno más relevante en relación a la habilidad de una empresa de absorber y obtener fruto del conocimiento externo que circula en su entorno. Por último, repasaremos las revisiones que ciertos autores realizan de la teoría originalmente propuesta.

\subsubsection{La innovación desde la perspectiva de la Teoría de los Recursos y las Capacidades}

La Teoría de los Recursos y las Capacidades (Resource-Based View) se origina formalmente en 1984, con la publicación del artículo The Resource Base-View of the Firm por parte de Wernerfelt (1984). Sin embargo, anteriormente, Penrose (1959) había teorizado sobre cómo los recursos influyen en el crecimiento de las empresas. Y posteriormente, Barney (1991) realizó la conexión entre los recursos estratégicos de una empresa y su ventaja competitiva.

Esta teoría se fundamenta en el hecho de que la heterogeneidad de los recursos y capacidades que tienen las empresas de una determinada industria o sector es la fuente de su ventaja competitiva ya que éstas se encuentran desarrollando su actividad en el 
mismo entorno y, a priori, estarían sujetas a los mismos factores de éxito propios del mismo. En otras palabras, los recursos y capacidades de una empresa explican la forma en la que una empresa desarrolla su ventaja competitiva frente a otras que se encuentran en el mismo sector económico (Barney, 1991). En consecuencia, la estrategia empresarial debería estar orientada hacia la creación y mejora constante de estos recursos y capacidades estratégicamente más valiosos. Bajo esta perspectiva, una ventaja competitiva sostenible en el tiempo se fundamenta en unos recursos y unas capacidades caracterizados por: (a) ser duraderos; (b) ser difíciles de identificar y entender; (c) ser imperfectamente intransferibles; (d) ser difícilmente replicables; (e) ser perfectamente controlados a través de una propiedad clara (Barney, 1991; Grant, 1999; Peteraf, 1993).

Esta teoría se centra, en definitiva, en la relación entre la estrategia de una compañía y sus recursos internos a través del denominado marco VRIO. Éste consiste en valor (V), es decir, si los recursos producen ventaja competitiva; rareza (R), es decir, si éstos son poseídos también por los competidores; imitabilidad (I), es decir, si éstos son difíciles de imitar por los competidores y organización (O), es decir, si la empresa está dotada de una estructura que le permite la explotación de los mismos (Barney, 1991). El gran reto para los directivos de las empresas será, en consecuencia, la identificación, el desarrollo, la protección de recursos y capacidades de modo que conceda a la empresa una ventaja competitiva sostenible y por lo tanto, un retorno de capital superior (Amit \& Schoemaker, 1993). La principal novedad introducida por esta corriente teórica radica en la consideración de la empresa no como una cartera de negocios sino como un conjunto único de recursos tangibles o intangibles que se vinculan a la empresa de forma semipermanente (Navas López \& Ortiz de Urbina Criado, 2001; Wernerfelt, 1984). Su capacidad competitiva se focaliza en su stock de recursos valiosos y escasos, la diferenciación de los mismos, así como su difícil obtención o sustitución (Barney, 1991; López et al., 2004).

Distintos autores han comprobado como en los sectores industriales, el desarrollo de ventaja competitiva se puede producir, fundamentalmente, bien a través del desarrollo de nuevos productos diferenciados (Damanpour, 1992; Fuchs et al., 2000), bien a través de obtención de una eficiencia de costes (Benner \& Tushman, 2003; Bessant \& Tidd, 2007; Porter, 1990). En todos los casos, estas estrategias necesitan del desarrollo de 
procesos innovadores. La innovación se convierte así en el principal método de creación de valor en una empresa, llegándose a convertir, incluso, en uno de los mejores indicadores de creación de valor de la misma (Tsai \& Ghoshal, 1998). De este modo, los recursos y capacidades de una organización, en la medida en la que condicionan el proceso innovador de la misma, pueden ser utilizados para desarrollar la capacidad innovadora de una empresa (Dosi, 1988). En conclusión, la construcción y el desarrollo de las fuentes de innovación en las empresas a partir de sus recursos y capacidades determinará en gran medida el valor competitivo y, en consecuencia, la supervivencia de las mismas (Leonard-Barton, 1995).

La innovación bajo la perspectiva de la Teoría de Recursos y Capacidades se basa en conclusión, en la identificación del potencial de los recursos y capacidades de la empresa para establecer, identificar y desarrollar fuentes externas de innovación a través de las cuales poder introducir nuevo conocimiento en la misma. Desde este punto de vista se trata de un enfoque interno más que externo de la innovación. De otro modo, puesto que las empresas difieren en su dotación de recursos y capacidades, los procesos de innovación y desarrollo de nuevos productos serán distintos (López, et al., 2004). En este punto, creemos interesante diferenciar entre dos conceptos clave, los recursos y las capacidades, puesto que siguiendo a otros autores (Grant et al., 2006; López et al., 2004), consideramos que ambos términos se encuentran en dos niveles de agregación distintos. Los recursos son considerados como activos individuales situados en un primer nivel, mientras que las capacidades son considerados competencias o habilidades colectivas de la organización situados en un segundo nivel (López-Sintas, 1996). López et al., (2004) basan esta distinción en el hecho de que mientras los recursos son elementos que tienen una relativa independencia de su uso concreto, las capacidades representan precisamente las formas en las que los primeros son utilizados. Estos autores también destacan el carácter colectivo de las capacidades frente al individual de los recursos (López et al., 2004). De acuerdo con lo anterior, adoptamos la definición propuesta por Wernerfelt (1984) del concepto de recursos los cuales son definidos como:

“Aquellos activos (tangibles e intangibles) que se vinculan a la empresa de forma semipermanente como las marcas, el conocimiento tecnológico propio, el 
empleo de habilidades personales, los contactos comerciales, los procedimientos eficientes, el capital, etc.” (Wernerfelt, 1984, p. 172).

En esta misma línea, los autores Navas \& Guerras (2002) clasifican los recursos tal como se describe en la Figura 12.

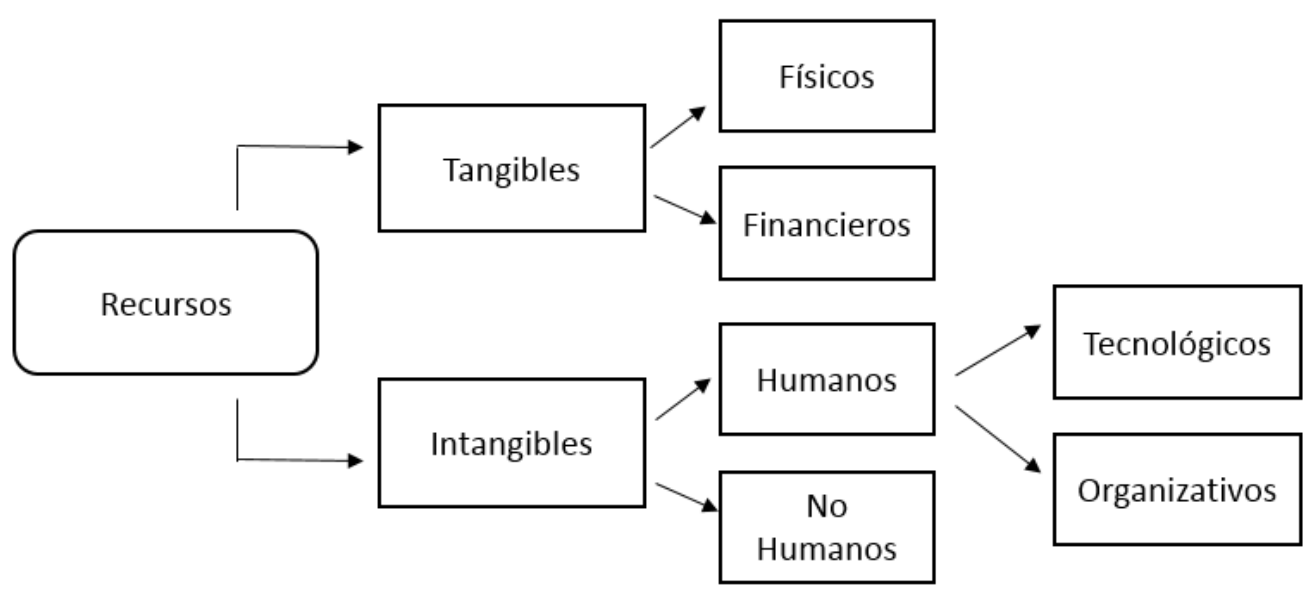

Figura 12: Clasificación de los recursos de una empresa

Fuente: elaboración propia a partir de Navas \& Guerras (2002)

No obstante, los recursos considerados de forma aislada sólo permiten desarrollar determinadas actividades en la empresa. Para obtener verdaderas habilidades o competencias se necesita una correcta gestión de los mismos, lo que da lugar a las capacidades (López et al., 2004). Las capacidades son definidas por Grant et al., (2006) como:

"Una capacidad organizativa es la habilidad de una empresa para llevar a cabo una actividad concreta" (Grant et al., 2006, p. 165).

Hall (1993) propone una clasificación basada en cuatro tipos diferentes de capacidades: (a) capacidades basadas en los activos regulatorios (derechos de propiedad, contratos, etc.); (b) capacidades basadas en activos posicionales (reputación, posición dominante en la cadena de valor, etc.); (c) capacidades basadas en las competencias funcionales (resultado de habilidades, conocimiento, experiencia, etc.); (d) capacidades basadas en las competencias culturales (hábitos, actitudes, creencias y valores de los trabajadores). 
En cualquier caso, como proponen Fernández \& Suárez (1996), las capacidades se encuentran organizadas en forma de una estructura jerárquica. De este modo, a partir de recursos individuales se empiezan a construir unas capacidades determinadas y éstas, a su vez, se van integrando en capacidades más complejas o de mayor nivel. (López et al., 2004).

\subsubsection{La Capacidad de Absorción}

Desde la perspectiva del conocimiento, la justificación básica de la existencia de la empresa -así como de la fuente principal de ventaja competitiva sostenible- es la creación, acumulación y aplicación del conocimiento (Grant, 1996; Nonaka, 1994; Spender, 1996). En este contexto, la innovación -entendida como un proceso continuo en el que se acumula conocimiento a través de las actividades propias de I+D y de la interacción con el entorno (Vega et al., 2005)- puede ser considerada como una de los principales ejes de creación de valor de las empresas.

Así, de entre todas las capacidades que una empresa puede construir para mejorar sus procesos innovadores, la capacidad de absorción es, sin lugar a duda, una de las más relevantes. Gracias a ésta, la empresa es capaz de identificar, asimilar y explotar el conocimiento del entorno. El desarrollo de este factor interno supone uno de los procesos de aprendizaje fundamentales en una empresa (Lane, Koka, \& Pathak, 2006). El desarrollo de nuevos productos y procesos, necesarios para obtener y mantener una ventaja competitiva, requiere de nuevas competencias o, al menos, de una recombinación de las existentes. Estas nuevas habilidades y capacidades son, en gran parte, resultado de la adquisición, asimilación y explotación de nuevo conocimiento de su entorno (Leal-Rodríguez et al., 2014).

A través de la capacidad de absorción se refleja en qué medida una organización es capaz de aprender, absorber, trasmitir internamente y obtener rendimiento de todo el desarrollo tecnológico que se genera y construye más allá de sus propios límites. Desarrollar y mantener esta capacidad resulta crítico para la supervivencia a largo plazo de una organización porque refuerza, complementa o reorienta la base de conocimientos de la empresa (Peris et al., 2011). Bajo esta perspectiva consideramos que la capacidad 
de absorción es un elemento fundamental a través del cual las empresas pueden favorecer la generación o adopción de innovaciones disruptivas. Por este motivo, a continuación, realizamos una revisión teórica de este concepto.

El modelo de capacidad de absorción, se basa en la propuesta original realizada por los investigadores Cohen \& Levinthal (1989). Estos autores expusieron cómo, hasta ese momento, los economistas convencionalmente habían considerado el esfuerzo en I+D de las empresas como el único proceso de generación de nueva información. En contraposición, éstos sugieren que el esfuerzo innovador no sólo es capaz de generar nueva información útil para el desarrollo de productos o la mejora de los procesos, sino que también mejora la capacidad de asimilación y explotación de la información ya existente. El concepto de capacidad de absorción se origina, en consecuencia, a partir de una consideración dual del papel que el I+D tiene en las empresas.

En este trabajo seminal, Cohen \& Levinthal (1989) se apoyan en trabajos anteriores como los desarrollados por Allen (1977), Allen \& Mowery (1983) o Tilton (1971). Por ejemplo, Tilton (1971), realiza un análisis de la industria de los materiales semiconductores en EEUU y comprueba como uno de los motivos más importantes que llevan a éstas a invertir en I+D es el desarrollo de capacidades técnicas internas que les permitan estar al corriente y asimilar los desarrollos tecnológicos que se originan fuera de las mismas. En base a estas contribuciones, estos autores concluyen que mientras que el esfuerzo en I+D obviamente genera innovación, también desarrolla la capacidad de identificar, asimilar y explotar conocimiento del entorno, en definitiva, capacidad de aprendizaje o absorción. En este sentido, el nuevo concepto difiere de otro desarrollado anteriormente: el aprendizaje basado en la propia experiencia o learning by doing (Lieberman, 1984; Spence, 1981). Este término hace referencia a aquel tipo de aprendizaje que se basa en la práctica y que conduce a una mejora continua y una mayor eficiencia en aquello que ya está realizando. Mediante la capacidad de absorción una empresa adquiriere conocimiento externo que le permite implementar nuevos procesos o productos.

Otra aportación importante realizada por Cohen \& Levinthal (1989) se centra en las fuentes de conocimiento tecnológico de las que dispone una empresa. Según la nueva visión, las principales fuentes de conocimiento tecnológico no son exclusivamente el propio departamento de I+D sino también: (a) el conocimiento de acceso público 
originado por la I+D de los competidores; (b) el conocimiento generado fuera de la industria. En la literatura económica, autores como Arrow (1962) o Nelson (1959) habían asumido que dicho conocimiento, al ser de dominio público, puede ser considerado también como un bien público. Estos autores asumían que el coste de asimilación de un bien público no era significativo, como por ejemplo no lo es el coste de recibir una señal de radio (Cohen \& Levinthal, 1989). Frente a esta consideración, Cohen \& Levinthal (1989) argumentan si el coste de adquisición en estos casos era pequeño, se debía al hecho de que la empresa tenía desarrolladas unas habilidades que se podían asimilar a aquellas definidas en la capacidad de absorción. Siguiendo con el ejemplo, defendían que, si el coste de recepción de la señal de radio es bajo, era porque se había realizado previamente un esfuerzo de $\mathrm{I}+\mathrm{D}$ alrededor de esa emisión. La capacidad de absorción, por tanto, juega un papel fundamental en el proceso de adquisición de conocimiento externo y, por lo tanto, se convierte en un activo fundamental en el proceso innovador de las empresas.

Una vez planteado el concepto, los autores Cohen y Levinthal (1989) determinan aquellos factores externos a la empresa que pueden incentivar el desarrollo la capacidad de absorción. Estos factores son: (a) la oportunidad tecnológica, es decir, coste para una empresa de obtención de un avance técnico en su sector; (b) la capacidad de apropiación, es decir, la facilidad que tiene una empresa de obtener un beneficio a partir de la innovación; (c) la demanda del mercado (elasticidad), que condiciona la intensidad con la que una empresa se ve incentivada en la adquisición y asimilación de nuevo conocimiento.

En la Figura 13 se muestra el modelo de capacidad de absorción desarrollado por Cohen \& Levinthal (1989). 


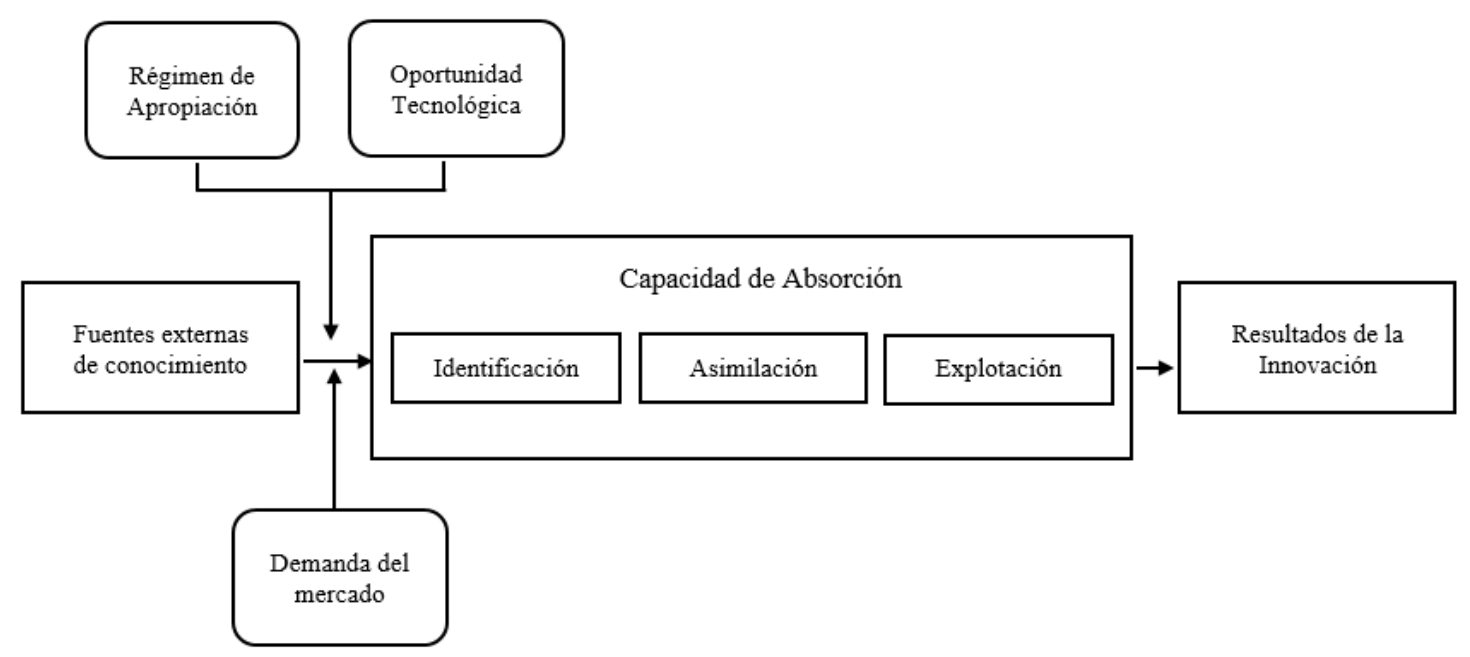

Figura 13: Modelo de la capacidad de absorción

Fuente: elaboración propia a partir de Cohen \& Levinthal (1989)

El desarrollo de la capacidad de absorción implicará el desarrollo de habilidades para identificar, asimilar y explotar el conocimiento procedente de fuentes externas. Esta nueva capacidad, por tanto, impactará en los resultados de innovación de la empresa. Cohen \& Levinthal, un año más tarde, en 1990, publicaron otro trabajo (Cohen \& Levinthal, 1990) en el que ampliaron el concepto original y lo completaron con una perspectiva comercial y de explotación del conocimiento adquirido. También se centran en dos factores que influyen en el desarrollo de la capacidad de absorción a nivel de empresa: (a) diferencia entre la capacidad de absorción de la organización con respecto a la propia de los individuos que la integran; (b) la diversidad de conocimiento y experiencia en la organización. Introducen, por tanto, la dualidad empresa-individuo señalando que la capacidad de absorción es el resultado de la interrelación de capacidades individuales más que de la acumulación de conocimiento por parte de individuos aislados. De esta forma, los autores se centraron más en los aspectos cognitivos del proceso de aprendizaje, enfatizando de nuevo el hecho de que el conocimiento y la inversión en I+D suponen elementos determinantes de la innovación. Concluyen sugiriendo que la innovación es path-dependent y, por tanto, la falta de investigación en esta área acabaría por anular el futuro desarrollo de capacidades técnicas en la empresa. 
Por último, en un tercer trabajo publicado en 1994, Cohen y Levinthal (1994) profundizaron de nuevo en el concepto añadiendo que éste también permite predecir el avance tecnológico futuro, aspecto que para los autores es de especial relevancia puesto que permite a la organización aprovechar nuevas oportunidades potenciales antes que sus competidores. Los autores aportaron evidencias empíricas sobre la relación existente entre la inversión destinada a mejorar la capacidad de absorción y el aumento de la capacidad para prever nuevas tendencias tecnológicas. En consecuencia, demostraron empíricamente cómo la inversión en capacidad de absorción permitía obtener una ventaja competitiva. Cohen \& Levinthal (1994) también concluyen que aquellas empresas con mayores niveles de capacidad de absorción son más capaces de anticiparse a los cambios del mercado gracias a su mayor habilidad para realizar nuevos desarrollos. Por el contrario, aquellas con menor capacidad de absorción tienen un perfil más reactivo hacia la exploración de nuevas tecnologías y oportunidades.

Como hemos podido comprobar, el modelo de capacidad de absorción inicialmente propuesto en 1989 fue consolidado y mejorado a través de las distintas aportaciones posteriores de los autores. En definitiva, la capacidad de absorción se podría considerar como la habilidad -desarrollada mediante el esfuerzo en I+D- para identificar, asimilar y aplicar el conocimiento proveniente de fuentes externas a la empresa con el objetivo de obtener una renta en el mercado.

\section{Las distintas dimensiones de la capacidad de absorción}

A continuación, analizaremos en profundidad el concepto de capacidad de absorción a través de la definición de sus distintas dimensiones (identificación, asimilación y explotación). Lane et al. (2006) consideran esta tarea fundamental ya que cada una de estas dimensiones requiere desarrollar e implementar diferentes procesos en la organización los cuales, al ser de distinta naturaleza, establecen interesantes interrelaciones. Estas tres dimensiones originales favorecen, no sólo la capacidad de una empresa de imitar otros productos o procesos de otras firmas, sino también la de explotar conocimiento más alejado del plano comercial como, por ejemplo, el originado en el proceso de investigación científica (Lane et al., 2006). 


\section{Identificación}

La identificación consiste en aquella capacidad de detectar, localizar y adquirir un conocimiento externo que, a su vez, puede ser crítico para el desarrollo de la actividad. De una empresa. Otros autores como McEvily \& Zaheer (1999), han denominado a esta primera dimensión como competitive scanning, término que generalmente se ha asociado a la capacidad innovadora de la empresa. Desde un punto de vista estratégico, la empresa debe realizar un control y un análisis continuo del entorno para detectar así oportunidades y amenazas. La identificación es la primera dimensión gracias a la cual podemos evitar perder la oportunidad de explotar prematuramente los cambios tecnológicos.

La capacidad de identificación se puede desarrollar a través de, por ejemplo, el desarrollo de lo que Zahra \& George (2002) denominan rutinas para la adquisición de conocimiento. Estas rutinas constan, a su vez, de tres dimensiones que inciden de manera diferencial en la capacidad de identificación y son: (a) la intensidad; (b) la velocidad; (c) la dirección. En la Tabla 21 puede observarse el impacto de estas tres dimensiones sobre la capacidad de identificación de una empresa.

Tabla 21: Rutinas para la adquisición de conocimiento

\begin{tabular}{ll}
\hline Rutina de adquisición & Impacto sobre la capacidad de Identificación \\
\hline Intensidad & Calidad \\
Velocidad & Vías. Líneas de búsqueda de conocimiento \\
Dirección & \\
\hline
\end{tabular}

Fuente: elaboración propia a partir de Zahra \& George (2002)

Además, estas actividades de identificación, por ser distintas y variadas en cuanto a riqueza y complejidad, necesitan tener varias áreas de experiencia para poder importar las tecnologías externas con éxito (Rocha, 1999). El conocimiento previo de la organización es considerado también como un factor de influencia en el desarrollo de esta capacidad, es lo que se considera asset stock accumulation (Dierickx \& Cool, 1989). 


\section{Asimilación}

La asimilación del conocimiento se refiere a aquellas rutinas y procesos que favorecen el análisis, procesado, interpretación y entendimiento de la información obtenida de fuentes externas (Szulanski, 1996). Esta habilidad es muy importante cuando la empresa necesita introducir ideas y descubrimientos que no pueden ser comprendidos fácilmente porque caen más allá de la zona tradicional de búsqueda de la misma (Peris et al., 2011). En otras palabras, la asimilación del conocimiento refleja la capacidad de una organización para interpretar y comprender el conocimiento externo con las estructuras de conocimiento existentes (Todorova \& Durisin, 2007). En la mayor parte de ocasiones el conocimiento externo suele estar próximo al existente por lo que, normalmente, las habilidades propias de una empresa para analizar y obtener la información relevante cercana (aquella que proviene de competidores, proveedores, clientes $\mathrm{u}$ otras instituciones de la industria) son suficientes para relacionar de manera sencilla este conocimiento nuevo con el que ya se posee (Peris et al., 2011). Sin embargo, en otras ocasiones el conocimiento externo no es tan fácilmente entendible y asimilable puesto que se encuentra en contextos específicos difícilmente descifrables para aquellos que no han participado en su desarrollo. En estos casos, la asimilación se ve dificultada por la inexistencia de activos cualificados que le permitan su comprensión (Teece, 1981).

En definitiva, independientemente de la distancia entre ambos conocimientos, la habilidad para ser integrados en una organización se ha convertido en un asunto capital para un desarrollo eficiente, sostenible y duradero de cualquier organización. Esta tarea se basa, principalmente, en una actualización permanente de la base de conocimiento de una empresa. A este respecto, varios autores han identificado distintos factores internos que influyen ésta; para Nelson y Winter (1982), por ejemplo, el conocimiento tácito de la empresa juega un papel fundamental; Child (1984) sugiere otros elementos tales como la estructura organizativa, el grado de centralización de la misma y el nivel de formalización en la distribución de tareas y responsabilidades, la existencia y características de las figuras de autoridad o la rigidez de los procesos relacionados con la toma de decisiones. 


\section{Explotación}

La explotación del conocimiento se refiere a las rutinas que encaminadas a perfeccionar, aprovechar y ampliar las competencias existentes, o crear nuevas, mediante la incorporación en sus operaciones del conocimiento previamente adquirido y asimilado (Tiemessen et al., 1997). Como señalan Lane et al. (2006), una vez asimilado el conocimiento externo, su combinación con el existente posibilita que este sea utilizado de nuevas maneras. Este proceso de interiorización de conocimiento externo dará como resultado la creación de nuevos productos, procesos, conocimientos o nuevas formas organizativas (Spender, 1996). El desarrollo de esta dimensión en el seno de una organización requiere un intercambio permanente de recursos y una recombinación de los mismos a través de las distintas unidades que la conforman. Esto implica la necesidad no sólo de una información de alta calidad, sino también de una capacidad por parte de las distintas unidades para compartir y cooperar; en definitiva, una transformación del esquema colectivo de las diferentes unidades organizativas (Lane et al., 2006).

La explotación permite concluir el proceso de absorción de conocimiento externo a partir del que las empresas podrán obtener una ventaja competitiva. Una explotación del conocimiento de forma estructurada y sistémica a lo largo del tiempo y no mediante el azar, obtiene mejoras en los beneficios, los procesos o las formas organizativas (Spender, 1996).

\section{Distintas revisiones del modelo original de Cohen \& Levinthal (1989)}

Desde que Cohen \& Levinthal (1989) introdujeran el concepto seminal de la capacidad de absorción, se ha desarrollado un extenso cuerpo teórico alrededor de éste; la capacidad de absorción ha sido un constructo ampliamente revisado, interpretado y utilizado. Los autores Lewin et al., (2011) han llegado a contabilizar la existencia de alrededor de unas 10.000 publicaciones, ya sean artículos en revistas, capítulos o libros relacionados con ésta. Lane et al., (2006), por su parte, han registrado unos 900 artículos académicos relacionados con peer-review. 
Este rápido desarrollo de la literatura relacionada se debe en parte, en opinión de Lane et al., (2006), a la perspectiva única que este constructo proporciona. Estos autores también consideran que otro motivo importante es su solapamiento con otras disciplinas que estaban siendo desarrolladas en ese mismo periodo de tiempo como, por ejemplo, el aprendizaje organizacional, la estrategia de las alianzas, la gestión del conocimiento, la Teoría de Recursos y Capacidades o la gestión estratégica (Lane \& Lubatkin, 1998; Lane et al., 2006; Mowery \& Oxley, 1995; Van den Bosch et al., 1999). No obstante, este hecho no resta a la capacidad de absorción del valor e importancia que sin duda tiene. Este concepto ha evolucionado desde una concepción basada en los factores moderadores de la empresa para desarrollar y adoptar innovaciones tecnológicas hasta convertirse en un marco teórico en relación a la capacidad de las empresas a la adaptación y el cambio de un modo más general (Meyer, 1991).

Los autores Hirsh and Levin (1999) han identificado un modelo de evolución y desarrollo en la literatura basado en tres etapas. La primera, la considerada por estos autores como énfasis emergente, se inicia inmediatamente después de la articulación original del concepto y se caracteriza por el hecho de atribuir a la capacidad de absorción de una compañía, de forma eminentemente teórica, sus resultados de innovación. La segunda etapa, la denominada reto de la validación focaliza la investigación en operacionalizar o crear medidas directas de la capacidad de absorción, así como validarla empíricamente. Sin embargo, después de una etapa sin obtener verdaderas medidas directas, se entra en la tercera etapa, la denominada construcción de tipologías en la cual se pueden enmarcar las importantes aportaciones realizadas por autores como Lane et al., (2006), Todorova y Durisin (2007) o Zahra \& George (2002) que analizaremos a continuación. En opinión de Hirsh \& Levin (1999), la ausencia de un progreso en la operacionalización del constructo puede desembocar en tres alternativas: (a) emergencia de constructos alternativos; (b) estancamiento como un problema no resulto; o (c) colapso y desuso del mismo.

En resumen, distintos trabajos han tratado más de adaptarse a las propias necesidades de las realidades en estudio que de realizar una revisión teórica del concepto. En la mayor parte de estos trabajos, la unidad de análisis ha sido la empresa; tan sólo en algunos casos se examinaron las actividades interorganizativas -como, por ejemplo, el realizado por Lane \& Lubatkin (1998)-, las distintas unidades de negocio que conforman una 
empresa -como, por ejemplo, los realizados por Jansen et al. (2005); Tsai (2001)- o los sistemas nacionales de innovación, como por ejemplo, los realizados por Liu \& White (1997). En la Tabla 22 se muestran algunos de los trabajos realizados en los que se ha utilizado la empresa como unidad de análisis. Por otro lado, en la Figura 14 se establecen los temas centrales de análisis en relación a la capacidad de absorción propuestos por (Lane et al., 2006).

No queda duda de que existe un claro consenso en la comunidad científica acerca de la importancia de este concepto. Sin embargo, a pesar de esta amplia corriente de investigación originada en torno al mismo, no son muchos los trabajos que aportan alguna revisión teórica o ampliación del mismo (Lane et al., 2006). Sin pretender realizar una revisión exhaustiva, a continuación, analizaremos aquellas aportaciones o revisiones que consideramos más relevantes. 
Tabla 22: Temáticas analizadas con relación a la capacidad de absorción con la empresa como unidad de análisis

\section{Temática}

Efecto de la capacidad de absorción sobre la actividad innovadora de la empresa
Trabajos realizados

Becker \& Peters (2000); Nieto \&

Quevedo (2005); Veugelers

Stock et al. (2001)

Mowery, Oxley, \& Silverman

(1996); Negassi (2004); Newey \&

Shulman (2004)

Lenox \& King (2004)

Barkema \& Nadolska (2003);

Kumar \& Seth (2001)

Mangematin \& Mandran (2001)

asimilación del conocimiento público en las

industrias de baja intensidad tecnológica

Diferentes categorías de conocimiento a las que

puede acceder la organización en función del tipo

Mangematin \& Nesta (1999)

de capacidad de absorción

Relación entre la estrategia empresarial y la

capacidad de absorción

Peris et al. (2011)

Capacidad de absorción en los clústeres

Expósito-Langa et al. (2011);

Giuliani (2005); Hassink (2005)

Fuente: elaboración propia 


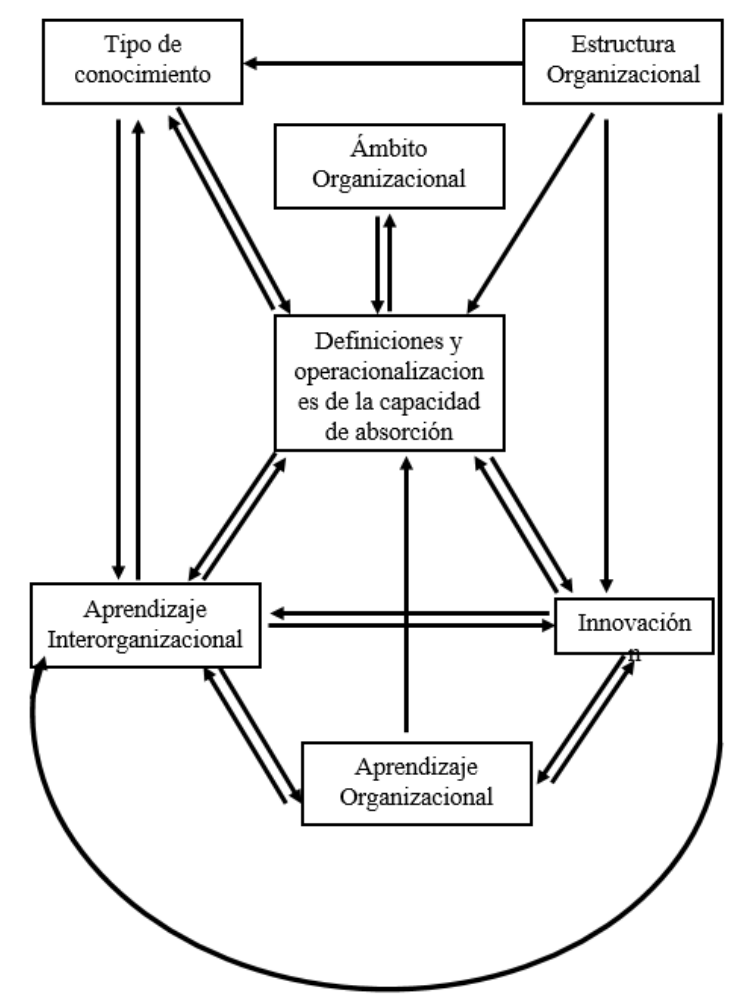

Figura 14: Mapa temático de la investigación de la capacidad de absorción

Fuente: elaboración propia a partir de Lane et al., (2006, p. 843)

\section{Revisión de Lane \& Lubatkin (1998)}

La consideramos relevante por el hecho de que fue la primera en enfocar el concepto en un nuevo contexto, el marco interorganizacional. De forma análoga a la realizada por Cohen \& Levinthal (1989), estos autores aplicaron las tres dimensiones de la capacidad de absorción (identificación, asimilación y explotación del conocimiento) en el marco de las empresas que establecen alianzas. Definieron así, los roles de empresa profesor y empresa alumno para describir cómo una empresa absorbe el conocimiento que otra ofrece. También identificaron los factores de los que depende el éxito en la transferencia de este conocimiento: (a) conocimiento suministrado por la empresa profesor; (b) prácticas de compensación para la empresa profesor (incentivos); (c) estructuras organizativas de ambas empresas; y (c) similitud entre los problemas organizacionales de la empresa alumno con los de la empresa profesor. Estos autores concluyeron que, cuando se produce una alianza entre empresas, la capacidad que tienen para aprender entre ellas estará determinada tanto por sus características y por la relación de sus dinámicas de generación de conocimiento. 
Revisión de Van den Bosch et al. (1999).

La consideramos relevante por el hecho de que fue la primera en analizar los determinantes que afectan al desarrollo de la capacidad de absorción introduciendo la influencia del entorno en este proceso. De este modo, introducen al ciclo de aprendizaje inicialmente propuesto por Cohen \& Levinthal (1989) la variable del entorno y la capacidad de respuesta al cambio de la organización. Estos autores sugirieron dos posibles escenarios en cuanto a entorno se refiere: (a) entorno estable, propio de las industrias maduras, y en el que las empresas focalizan sus esfuerzos en la explotación de conocimiento, no tanto en la identificación ni la asimilación; (b) entorno turbulento, propio de las industrias en desarrollo, y en el que el esfuerzo deberá estar más orientado a las habilidades de exploración y no tanto en la explotación. En definitiva, estos autores consideran que la capacidad de absorción co-evoluciona a medida que también lo hace el entorno del conocimiento. En cuanto a la influencia sobre la capacidad de absorción de la capacidad de respuesta al cambio de la organización, los autores proponen como determinantes, la forma organizativa y la capacidad de combinación de conocimiento que ésta posee (Capó-Vicedo; Exposito-Langa; Molina-Morales, 2008).

Revisión de Zahra \& George (2002).

Es, sin lugar a duda, la revisión del concepto original de mayor repercusión a nivel académico. Ésta se enfoca en la adaptación de las compañías a la generación de conocimiento a partir del entorno. Estos autores, partiendo de la aportación realizada por Teece et al., (1997) que estaba basada en las capacidades dinámicas de una organización, profundizan en el concepto de capacidad de absorción y lo redefinen como un conjunto de rutinas y procesos a través de los cuales la empresa adquiere, asimila, transforma y explota conocimiento para generar unas capacidades dinámicas organizacionales orientadas a obtener ventajas competitivas (Capó-Vicedo; ExpositoLanga; Molina-Morales, 2008). Estos autores, reformulan el modelo original, estableciendo cuatro dimensiones ( $\mathrm{y}$ no tres dimensiones como se planteaba inicialmente) que son agrupadas en dos categorías, la capacidad de absorción potencial (PACAP) y la capacidad de absorción realizada (RACAP). La PACAP -expresada a través de la adquisición y asimilación del conocimiento externo- representa aquellas capacidades que facilitan la búsqueda de conocimiento externo. Este conocimiento 
podría ser utilizado o no para producir innovaciones. La RACAP -expresada a través de la transformación y explotación del conocimiento externo- representa aquellas capacidades que favorecen el desarrollo productos y servicios a partir de ese stock de conocimiento obtenido en la categoría anterior.

Los autores decidieron introducir la nueva dimensión de transformación, como respuesta a la constatación de que el conocimiento externo se encuentra normalmente en contextos específicos que dificultan su comprensión si no se está estrechamente relacionado con dichos contextos (Szulanski, 1996) y que se requieren, por tanto, de recursos complementarios que, normalmente, no están al alcance de las empresas de una forma directa y evidente (Teece, 1981). De este modo, definieron la trasformación como la capacidad de desarrollar rutinas que favorecen la unión del nuevo conocimiento con el ya existente, para de esta forma poder generar nuevos cuerpos de conocimiento (Zahra \& George, 2002). Bajo esta nueva perspectiva desarrollada por estos autores, una vez definidas y caracterizadas estas dos nuevas categorías, es tarea principal de la empresa, realizar una correcta gestión de las mismas para tener un resultado superior (Jansen et al., 2005).

Estos autores también definen una ratio de eficiencia (y), resultado del cociente entre RACAP y PACAP y sugieren que esta ratio refleja en nivel de eficiencia de las empresas en el desarrollo de capacidad de absorción. Defienden la existencia de mecanismos de integración social que, acortando la distancia entre ambas dimensiones, permiten mejorar dicha ratio. Los propios autores describen cómo la dimensión potencial de la capacidad de absorción ha recibido un menor interés por parte de la comunidad científica. Sin embargo, defienden su utilidad ya que ésta permite aumentar la flexibilidad, favoreciendo así, una mejor adaptación a los cambios del entorno.

Los mecanismos de integración social permiten compartir conocimiento relevante entre los miembros de la empresa con el objeto de promover el mutuo entendimiento y comprensión (Garwin, 1993; Spender, 1996).

De forma breve, podemos definir cuatro dimensiones que propusieron estos autores de la forma siguiente:

- Adquisición: capacidad para identificar y adquirir conocimiento externo crítico para la empresa. 
- Asimilación: rutinas y procesos que permiten analizar, procesar, interpretar y entender la información.

- Transformación: capacidad de desarrollar rutinas que facilitan la combinación del nuevo conocimiento con el ya existente.

- Explotación: rutinas que permiten a la empresa refinar, extender y apalancar las competencias existentes, así como crear nuevas, mediante la incorporación del nuevo conocimiento adquirido y transformado (Capó-Vicedo; Exposito-Langa; Molina-Morales, 2008).

Finalmente, estos autores establecieron la existencia de una serie de mecanismos de activación (triggers) favorecen la respuesta de las empresas frente a estímulos (internos o externos) (Walsh \& Ungson, 1991; Winter, 2000). Un ejemplo de estímulo interno podría ser una crisis o una fusión empresarial; ante estas situaciones una empresa puede optar por una reformulación de la estrategia corporativa, o por una intensificación los esfuerzos para conseguir nuevas cuotas. Por el contrario, ejemplos de estímulos externos podrían ser las innovaciones radicales, los cambios tecnológicos emergentes, los nuevos diseños emergentes o incluso los cambios políticos. De este modo, cuanta más intensidad tengan estos estímulos más invertirá la empresa en obtener recursos adicionales potenciando así las dimensiones de adquisición y asimilación de conocimiento de fuentes externas; desarrollando, en consecuencia, nuevo y valiosos conocimiento y estimulando el aprendizaje para permitir incrementar su capacidad de absorción (Kim, 1998). A continuación, en la Figura 15 se muestra un esquema del modelo completo del modelo propuesto por Zahra \& George (2002)

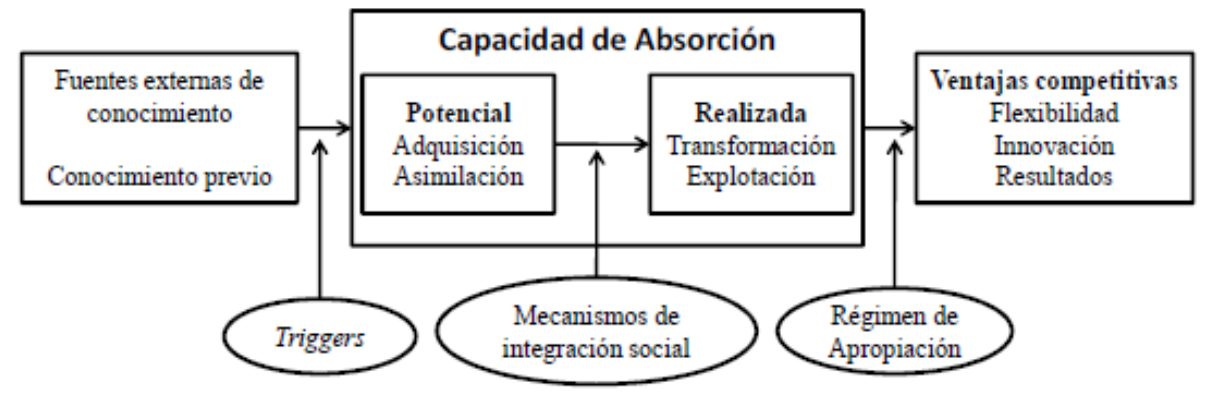

Figura 15: Modelo de Zahra y George de Capacidad de absorción

Fuente: Zahra \& George (2002) 


\section{CAPÍTULO 3 \\ CARACTERIZACIÓN DEL OBJETO \\ PRINCIPAL DEL ESTUDIO: EL CLÚSTER \\ INDUSTRIAL CERÁMICO DE CASTELLÓN}




\section{CARACTERIZACIÓN DEL OBJETO PRINCIPAL DE ESTUDIO: EL CLÚSTER INDUSTRIAL CERÁMICO DE CASTELLÓN}

De forma general, como se ha explicado en la introducción, esta investigación se centra en el análisis de los clústeres en relación con la generación, difusión e impacto de las innovaciones tecnológicas disruptivas.

Para alcanzar este objetivo, nos hemos centrado en el análisis del clúster industrial cerámico de Castellón. Este clúster no sólo se encuentra en el mismo territorio que la Universidad Jaume I (a la que nuestro grupo de investigación se encuentra adscrita) sino que también ha experimentado una transformación profunda como consecuencia del desarrollo de una innovación tecnológica disruptiva. Nos referimos a la introducción de la impresión digital de azulejos como alternativa a la impresión tradicional. Esta innovación impactó de manera muy importante en la cadena de valor de la industria cerámica puesto que supuso el primer paso hacia una digitalización de la línea de fabricación de azulejos. Además, hemos podido observar cómo, gracias a este hecho, el clúster cerámico de Castellón se posicionó en la vanguardia tecnológica de la industria cerámica mundial, alcanzando, por primera vez, un liderazgo tecnológico que históricamente había ejercido el clúster italiano de Sassuolo.

En conclusión, para la realización de esta investigación hemos considerado como principal objeto de estudio el clúster cerámico de Castellón el cual vamos a describir en los próximos tres apartados partiendo, en primer lugar, de una descripción general de la 
industria cerámica a nivel mundial. Por último, en el apartado final de este capítulo describiremos en qué consiste la innovación tecnológica disruptiva que se llevó a cabo: la impresión digital de azulejos por tecnología inkjet. De hecho, este fenómeno innovador puede ser considerado el objeto específico de estudio de la presente tesis.

\subsection{Descripción general de la industria cerámica mundial}

La industria cerámica mundial puede ser considerada como un paradigma de sector industrial de media-baja tecnología configurado entorno a aglomeraciones territoriales. Desde un punto de vista académico, esta industria resulta una opción excelente para el estudio de las dinámicas que rigen estas aglomeraciones.

En este apartado procederemos a realizar una caracterización de la industria cerámica a nivel mundial con el fin de poder enmarcar convenientemente la industria cerámica del clúster de Castellón. Para ello a continuación se describirá la industria cerámica global desde tres perspectivas diferentes: la producción, el consumo y las exportacionesimportaciones.

\subsubsection{Caracterización de la industria desde la perspectiva de la producción}

La producción mundial en el año 2016 sobrepasó los 13 billones de metros cuadrados de pavimentos y revestimientos cerámicos. En cuanto a su distribución geográfica, en la Tabla 23, podemos observar cómo la principal área de producción es Asia (siendo China el mayor país productor en esta región) seguida por Europa, que sigue manteniendo el liderazgo desde un punto de vista de valor añadido del producto. 
Tabla 23: Distribución de la producción mundial de pavimentos y revestimientos en 2016 por área geográfica.

\begin{tabular}{cccc}
\hline Posición & Área geográfica & $\begin{array}{c}\text { Producción total (en } \\
\left.\text { millones de } \mathbf{~ m}^{\mathbf{2}}\right)\end{array}$ & $\begin{array}{c}\text { \% producción } \\
\text { mundial }\end{array}$ \\
\hline$\# 1$ & Asia & 9.331 & 71,5 \\
\hline$\# 2$ & $\begin{array}{c}\text { Unión Europea (28 } \\
\text { países) }\end{array}$ & 1.304 & 10,0 \\
\hline$\# 3$ & $\begin{array}{c}\text { Suramérica-América } \\
\text { Central }\end{array}$ & 1.086 & 8,3 \\
\hline & Resto del mundo & 1.335 & 10,2 \\
\hline PRODUCTION TOTAL & 13.056 & 100 \\
\hline
\end{tabular}

Fuente: elaboración propia a partir de Baraldi (2017)

De forma más específica, en la Tabla 24, se analiza la producción cerámica por países desde 2012 a 2016, observando cómo en 2016, el 83,7\% de la producción mundial se realiza tan sólo en 10 países. La tabla muestra también que la producción mundial de pavimentos y revestimientos cerámicos no ha dejado de crecer en los últimos años. Se ha crecido desde unos niveles de unos 9.200 millones de metros cuadrados en 2012 hasta alrededor de 13.000 millones de metros cuadrados en el año 2016. Esto supone un aumento en la producción mundial de entorno al $15 \%$ en los últimos 5 años. Además, teniendo en cuenta que la producción mundial en 2006 alcanzó los 7.760 millones de metros (Tile Today ${ }^{5}$ ), el aumento de producción mundial en los últimos diez años se sitúa en el $70 \%$.

Esta producción se encuentra distribuida, salvo excepciones, en núcleos productivos situados en gran cantidad de países a lo largo de todo el mundo. En general, cada país presenta uno o varios clústeres en los que se produce prácticamente la totalidad de la correspondiente cerámica nacional. Son núcleos productivos tradicionales de la industria cerámica, por ejemplo, los de Castellón en España, Sassuolo en Italia, Aveiro en Portugal, Santa Catarina en Brasil o Foshan en China.

\footnotetext{
5 Datos obtenidos a través de la información disponible en su sitio Web: http://www.infotile.com/publications/ consultado en febrero de 2017.
} 
Tabla 24: Producción mundial de pavimentos y revestimientos cerámicos en el periodo (2012-2016) en Mill. $\mathrm{m}^{2}$

\begin{tabular}{lcccccc}
\hline \multicolumn{1}{c}{ País } & $\mathbf{2 0 1 2}$ & $\mathbf{2 0 1 3}$ & $\mathbf{2 0 1 4}$ & $\mathbf{2 0 1 5}$ & $\mathbf{2 0 1 6}$ & $\begin{array}{c}\text { \% producción } \\
\text { mundial 2016 }\end{array}$ \\
\hline China & 5.200 & 5.700 & 6.000 & 5.970 & 6.495 & $49,7 \%$ \\
India & 691 & 750 & 825 & 850 & 955 & $7,3 \%$ \\
Brasil & 866 & 871 & 903 & 899 & 792 & $6,1 \%$ \\
España & 404 & 420 & 425 & 440 & 492 & $3,8 \%$ \\
Vietnam & 290 & 300 & 360 & 440 & 485 & $3,7 \%$ \\
Italia & 367 & 363 & 382 & 395 & 416 & $3,2 \%$ \\
Indonesia & 360 & 390 & 420 & 370 & 360 & $2,8 \%$ \\
Irán & 500 & 500 & 410 & 300 & 340 & $2,6 \%$ \\
Turquía & 280 & 340 & 315 & 320 & 330 & $2,5 \%$ \\
Méjico & 231 & 230 & 230 & 245 & 267 & $2,0 \%$ \\
TOTAL & 9.189 & 9.864 & 10.270 & 10.229 & 10.932 & $83,7 \%$ \\
TOTAL & 11.226 & 11.961 & 12.377 & 12.357 & 13.056 & $100,0 \%$ \\
MUNDIAL & & & & & &
\end{tabular}

Fuente: elaboración propia a partir de Baraldi (2017)

España se sitúa en el año 2016, según los últimos datos disponibles, como el cuarto país productor de pavimentos y revestimientos cerámicos con una producción total de 492 millones de metros cuadrados. Nuestro país tan sólo es superado por China, India y Brasil. Italia, un gran referente en la producción y venta de producto cerámico, se sitúa en el sexto puesto detrás de Vietnam. De forma gráfica, la Figura 16 y Figura 17 muestran la evolución de la producción a nivel mundial y también de los principales países productores del mundo desde el año 2000. En ella podemos observar, de forma agregada y a nivel mundial, que la producción no ha dejado de crecer en los últimos 16 años. Sin embargo, el comportamiento en España e Italia es ligeramente diferente a la tendencia mundial. Estos dos países, referentes mundiales de tecnología, innovación y diseño, iniciaron una tendencia bajista a inicios de la década del 2000 (en el caso de Italia en 2001 y en el caso de España en 2005). Esta tendencia, se agravó con la crisis económica mundial. El caso español fue especialmente alarmante ya que la producción se redujo prácticamente a la mitad en el período que transcurre desde 2005 a 2009 pasando de 610 millones de metros cuadrados a 324 millones. Sin embargo, a partir de 
2010 se observa una recuperación continuada que se mantiene hasta 2016. Italia, por su parte, inició la tendencia bajista en 2001, la cual continuó hasta 2009. En este periodo, su producción se redujo un 42\%. Al igual que España. Italia inició una recuperación en 2010 que, de forma análoga, se ha mantenido hasta 2016.

En la otra cara de la moneda se sitúan los países que han experimentado un fuerte crecimiento en todo este periodo. Brasil, India, Irán y China no dejaron de crecer en el periodo 2000-2013. Bajo la influencia China y la emergencia de Irán e India (ésta última sobrepasó a Brasil en cuanto a producción se refiere en 2016) se puede concluir que la producción mundial presenta un claro dominio asiático con el 71,5\% de cuota de producción (ver Tabla 24). De ésta, China es responsable en un 70\%. En cambio, Europa, con una cuota de producción del 10\% y a pesar de su recuperación, se sitúa muy lejos del mercado asiático aunque supera, por poco, a la producción suramericana.

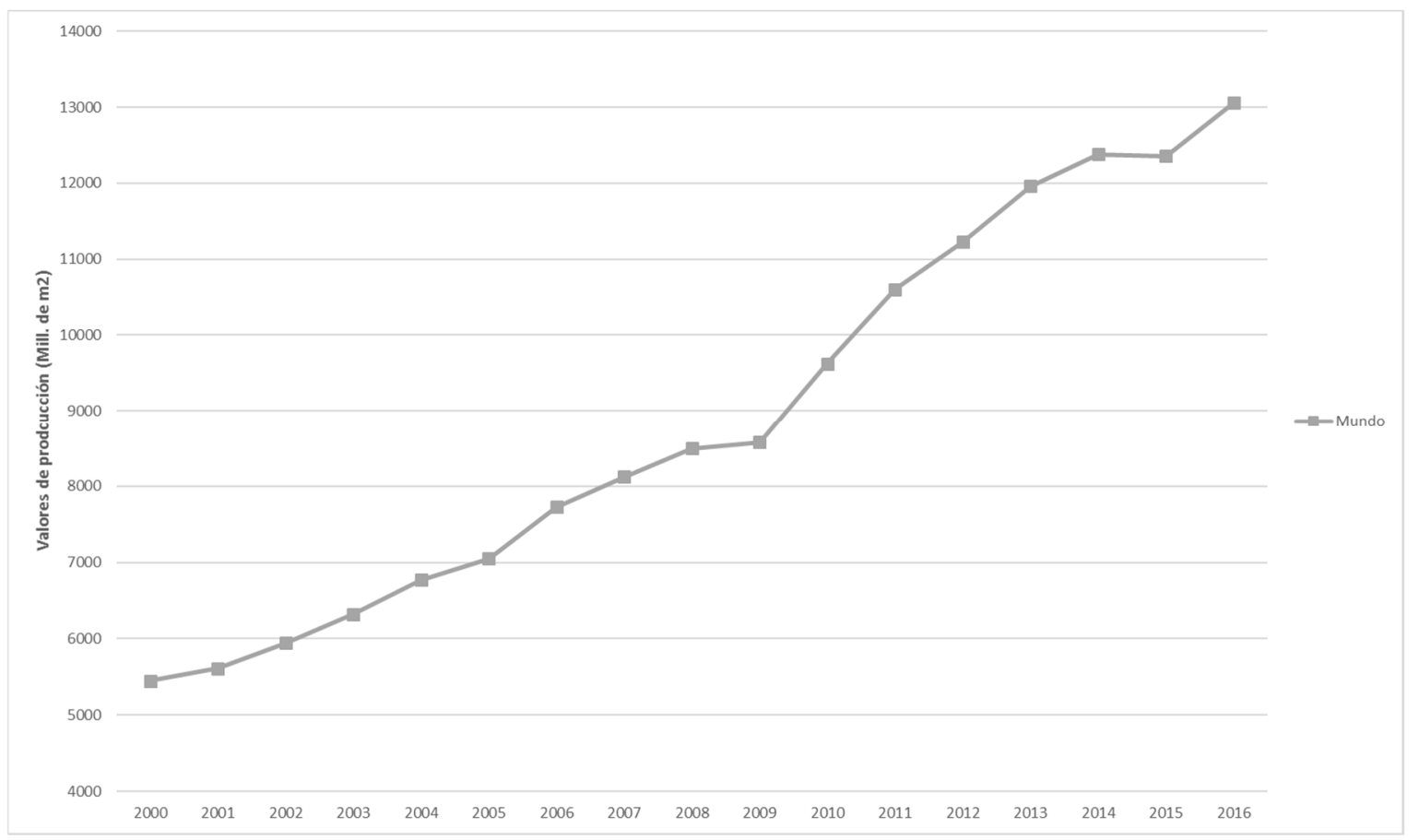

Figura 16: Evolución de la producción mundial de pavimentos y revestimientos cerámicos en el periodo (2000-2016)

Fuente: Elaboración propia a partir de ASCER ${ }^{6}$, Baraldi (2017) y Tile Today ${ }^{7}$.

\footnotetext{
${ }^{6}$ Datos obtenidos a través de la información disponible en su sitio Web: http://www.ascer.es en Julio de 2018.
} 


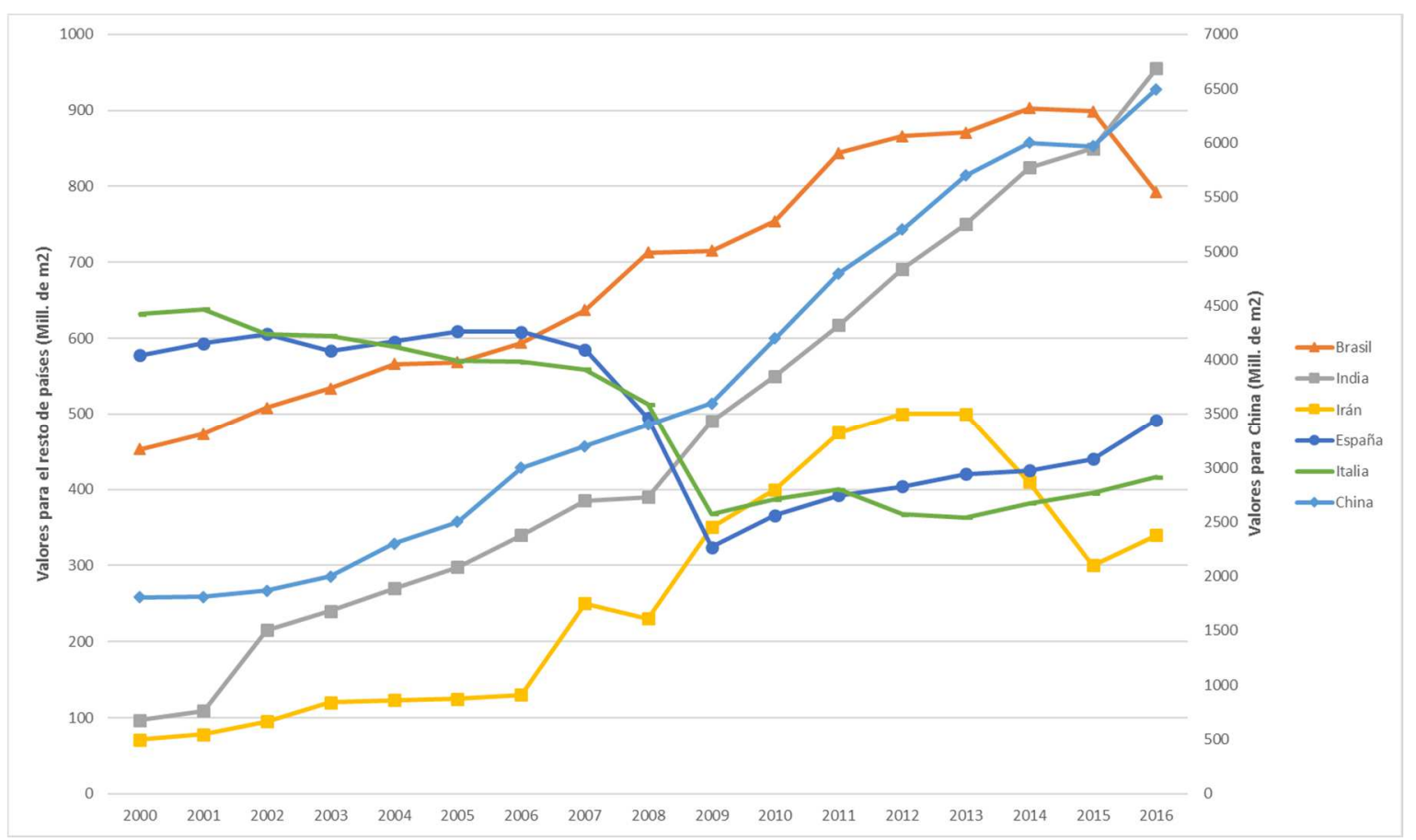

Figura 17: Evolución de la producción de los seis principales países productores de pavimentos y revestimientos cerámicos en el periodo (2000-2016)

Fuente: Elaboración propia a partir de $\operatorname{ASCER}^{8}$, Baraldi (2017) y Tile Today9

\subsubsection{Caracterización de la industria desde la perspectiva del consumo}

El consumo total de pavimentos y revestimientos cerámicos en todo el mundo durante el año 2016 alcanzó los 12.783 millones de metros cuadrados. El consumo total de pavimentos y revestimientos cerámicos en ese año, distribuido por áreas geográficas, se muestra en la Tabla 25. Como podemos observar, Asia se sitúa de nuevo en primera posición, consumiendo un $69 \%$ del total mundial. Esta región no sólo es la que más cerámica fabrica del mundo sino también la que mayor cantidad consume. De hecho, su

7 Datos obtenidos a través de la información disponible en su sitio Web: http://www.infotile.com/publications/ consultado en febrero de 2017.

${ }^{8}$ Datos obtenidos a través de la información disponible en su sitio Web: http://www.ascer.es en Julio de 2018.

9 Datos obtenidos a través de la información disponible en su sitio Web: http://www.infotile.com/publications/ consultado en febrero de 2017. 
balanza entre consumo y exportación se encuentra equilibrada: como muestran las Tabla 23 y Tabla 25, la diferencia entre los metros cuadrados que produce y los que consume es tan sólo de un punto y medio porcentual. No ocurre lo mismo en la Unión Europea la cual ocupa el segundo puesto como productor (1.304 millones de $\left.\mathrm{m}^{2}\right)$, pero el tercer puesto como exportador (964 millones de $\mathrm{m}^{2}$ ). De hecho, produce un 2,5\% más de lo que consume (Ver Tabla 23 y Tabla 25). El análisis de estos datos confirma que, en cuota mundial, la producción y el consumo tiende a ser similar en cada continente. En resumen, las balanzas entre producción y consumo son las siguientes: Asia produce el $71.5 \%$ del total mundial mientras que consume el 69\%; Europa (que incluye los 28 países) el $10.0 \%$ y el $7.5 \%$ respectivamente; América el 11\% y el 13.5\% y África el 3.1 y el 5.4\%. Esto demuestra que, como es bien sabido en el sector, los azulejos se consumen principalmente allí donde se producen (desde un punto de vista de grandes áreas geográficas, no tanto desde una perspectiva de país).

Tabla 25: Distribución del consumo mundial de pavimentos y revestimientos en 2016 por área geográfica en Mill. $\mathrm{m}^{2}$

\begin{tabular}{cccc}
\hline Posición & Área geográfica & $\begin{array}{c}\text { \% sobre consumo } \\
\text { mundial }\end{array}$ & Consumo total \\
\hline$\# 1$ & Asia & $69,0 \%$ & 8.818 \\
\hline$\# 2$ & Suramérica/América & $9,2 \%$ & 1.180 \\
\hline$\# 3$ & Central & $7,5 \%$ & 964 \\
\hline & Unión Europea (28 países) & $14,3 \%$ & 1.821 \\
\hline & Rosto del mundo & $100,0 \%$ & 12.783
\end{tabular}

Fuente: elaboración propia a partir de Baraldi (2017)

De forma análoga a la tabla mostrada para la producción, la Tabla 26 nos muestra la distribución de consumo de 2012 a 2016 para los diez principales países consumidores. En primer lugar, cabe destacar que el consumo mundial, al igual que sucedía con la producción, ha sufrido un incremento continuado durante los últimos años. Si comparamos la cifra de 2012 (10.964 millones de m2) con la de 2016 (12.783 millones de $\mathrm{m} 2$ ) el crecimiento ha sido de un 16,5\%. Los mayores consumos, al igual que sucedía con la producción, se producen en el continente asiático, con China, India, 
Vietnam e Indonesia ocupando cuatro puestos de entre los cinco primeros. Tan sólo el mercado chino, con un consumo de 5.475 millones de metros cuadrados durante 2016, representa en torno a un $40 \%$ del consumo mundial total. El país que se encuentra en segunda posición en consumo, Brasil, está muy alejado de esos niveles, suponiendo un $6,1 \%$ sobre el total del consumo mundial.

Tabla 26: Consumo mundial de pavimentos y revestimientos cerámicos en el periodo (2012-2016) en Mill. $\mathrm{m}^{2}$

\begin{tabular}{lcccccc}
\hline \multicolumn{1}{c}{ País } & $\mathbf{2 0 1 2}$ & $\mathbf{2 0 1 3}$ & $\mathbf{2 0 1 4}$ & $\mathbf{2 0 1 5}$ & $\mathbf{2 0 1 6}$ & $\begin{array}{c}\text { \% consumo } \\
\text { mundial } \\
\mathbf{2 0 1 6}\end{array}$ \\
\hline China & 4.250 & 4.556 & 4.894 & 4.885 & 5.475 & $42,8 \%$ \\
India & 681 & 718 & 756 & 763 & 785 & $6,1 \%$ \\
Brasil & 803 & 837 & 853 & 816 & 706 & $5,5 \%$ \\
Vietnam & 254 & 251 & 310 & 400 & 412 & $3,2 \%$ \\
Indonesia & 340 & 360 & 407 & 357 & 369 & $2,9 \%$ \\
EE. UU. & 204 & 230 & 231 & 254 & 274 & $2,1 \%$ \\
Arabia Saudí & 230 & 235 & 244 & 263 & 248 & $1,9 \%$ \\
Turquía & 184 & 226 & 215 & 234 & 241 & $1,9 \%$ \\
Méjico & 187 & 187 & 197 & 218 & 235 & $1,8 \%$ \\
Tailandia & 160 & 180 & 175 & 192 & 189 & $1,5 \%$ \\
TOTAL & 7.293 & 7.780 & 8.282 & 8.382 & 8.934 & $69,9 \%$ \\
TOTAL & & & & & & \\
MUNDIAL & $\mathbf{1 0 . 9 6 4}$ & $\mathbf{1 1 . 5 8 2}$ & $\mathbf{1 2 . 0 8 1}$ & $\mathbf{1 2 . 1 7 7}$ & $\mathbf{1 2 . 7 8 3}$ & $\mathbf{1 0 0 , 0 \%}$ \\
\hline
\end{tabular}

Fuente: elaboración propia a partir de Baraldi (2017)

Es muy interesante observar cómo ningún país de la Unión Europea se encuentra entre los diez principales consumidores mundiales, ni siquiera España o Italia que, en cambio, si se encuentran entre los diez principales países productores. 


\subsubsection{Caracterización de la industria desde la perspectiva de las exportaciones y las importaciones}

El análisis de las cifras de importación y exportación de la industria cerámica a nivel mundial confirman lo que ya hemos descrito anteriormente: esta industria está enfocada a un mercado eminente de consumo interno. En efecto, si analizamos el volumen total consumido en el año 2016 en base al consumo interno o destinado a importación/exportación (véase Figura 18) se observa que un 78,1\% del comercio total internacional en 2016 se formaba por ventas a nivel doméstico.

\section{Comercio internacional en 2016 (en relación al consumo total mundial)}

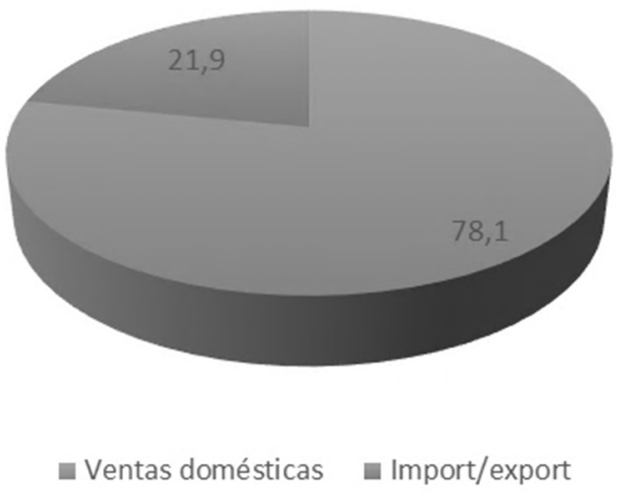

Figura 18: Relación entre el peso del comercio internacional y el doméstico en 2016 Fuente: Elaboración propia a partir de Baraldi (2017)

Por otro lado, en las Tabla 27 y Tabla 28 se muestran, respectivamente, las exportaciones en 2016 por áreas geográficas, así como la evolución de los últimos cuatro años de los diez principales países exportadores (que suponen 85,5\% del volumen total de exportaciones). En ese año, las exportaciones mundiales se incrementaron en 48 millones de metros cuadrados en relación con 2015 hasta alcanzar la cifra de 2.794 millones de metros cuadrados $(+1.7 \%)$. Se mantiene, por tanto, la tendencia de crecimiento moderado de los últimos años. Es interesante destacar que el incremento es atribuible casi en su totalidad a la Unión Europea, la cual aumentó sus exportaciones en un 5,5\% con respecto a 2015 (Baraldi, 2017), alcanzando la cifra de 
los 903 millones de metros cuadrados. Esto supone un tercio del total de exportaciones mundial. Por otro lado, las exportaciones en América Central y Suramérica también aumentaron (de 126 a 141 millones de $\mathrm{m}^{2}$, +11.9\%). En contraposición, Asia experimentó una ligera caída en la exportación hasta los 1.513 millones de metros cuadrados $(-0.8 \%)$. No obstante, esta área geográfica sigue siendo por volumen, la más importante en cuanto a exportación se refiere (54,2\% de las exportaciones mundiales) si bien cabe destacar que únicamente China representa alrededor del 37\% de las mismas (Tabla 27 y Tabla 28).

Tabla 27: Exportación mundial de pavimentos y revestimientos por áreas geográficas en 2016 en Mill. $\mathrm{m}^{2}$

\begin{tabular}{cccc}
\hline Posición & Área geográfica & $\begin{array}{c}\text { \% sobre } \\
\text { exportación } \\
\text { mundial }\end{array}$ & $\begin{array}{c}\text { Exportaciones totales } \\
\text { en 2016 }\end{array}$ \\
\hline$\# 1$ & Asia & $54,2 \%$ & 1.513 \\
\hline$\# 2$ & Unión Europea (28 países) & $32,3 \%$ & 903 \\
\hline$\# 3$ & $\begin{array}{c}\text { Resto Europa (incluyendo } \\
\text { a Turquía) }\end{array}$ & $5,3 \%$ & 147 \\
\hline$\# 4$ & $\begin{array}{c}\text { Suramérica/América } \\
\text { Central }\end{array}$ & $5,0 \%$ & 141 \\
\hline & Resto del mundo & $3,2 \%$ & 90 \\
\hline EXPORTACIÓN TOTAL & $\mathbf{1 0 0 \%}$ & $\mathbf{2 . 7 9 4}$ \\
\hline
\end{tabular}

Fuente: elaboración propia a partir de Baraldi (2017). 
Tabla 28: Exportación de pavimentos y revestimientos cerámicos por países en el periodo (2013-2016) en Mill. $\mathrm{m}^{2}$

\begin{tabular}{|c|c|c|c|c|c|c|c|}
\hline País & 2013 & 2014 & 2015 & 2016 & $\begin{array}{c}\text { \% sobre } \\
\text { producción } \\
\text { nacional } \\
2016\end{array}$ & $\begin{array}{c}\text { \% sobre } \\
\text { exportación } \\
\text { mundial } \\
2016\end{array}$ & $\begin{array}{c}\text { Precio } \\
\text { medio de } \\
\text { exportación } \\
\left(€ / \mathbf{m}^{2}\right)\end{array}$ \\
\hline China & 1.148 & 1.110 & 1.089 & 1.025 & $15,8 \%$ & $36,7 \%$ & 4,9 \\
\hline España & 318 & 339 & 378 & 395 & $80,3 \%$ & $14,1 \%$ & 6,5 \\
\hline Italia & 303 & 314 & 316 & 332 & $79,8 \%$ & $11,9 \%$ & 13,8 \\
\hline India & 55 & 102 & 134 & 186 & $19,5 \%$ & $6,7 \%$ & 3,2 \\
\hline Irán & 114 & 109 & 112 & 126 & $37,1 \%$ & $4,5 \%$ & 2,6 \\
\hline Brasil & 63 & 69 & 77 & 94 & $11,9 \%$ & $3,4 \%$ & 3,1 \\
\hline Turquía & 88 & 85 & 77 & 81 & $24,5 \%$ & $2,9 \%$ & 5,7 \\
\hline Méjico & 64 & 62 & 61 & 56 & $21,0 \%$ & $2,0 \%$ & 5,2 \\
\hline E.A.U. & 58 & 55 & 54 & 48 & $66,7 \%$ & $1,7 \%$ & 5,8 \\
\hline Polonia & 48 & 42 & 42 & 46 & $32,4 \%$ & $1,6 \%$ & 5,3 \\
\hline TOTAL & 2.259 & 2.287 & 2.340 & 2.389 & $23,2 \%$ & $85,5 \%$ & -- \\
\hline $\begin{array}{l}\text { TOTAL } \\
\text { MUNDIAL }\end{array}$ & 2.670 & 2.705 & 2.746 & 2.794 & $100,0 \%$ & $100,0 \%$ & -- \\
\hline
\end{tabular}

Fuente: elaboración propia a partir de Baraldi (2017).

Por países, resulta interesante destacar cómo España e Italia se posicionan como industrias principalmente exportadoras (exportando entorno al $80 \%$ de todo lo que producen y prácticamente casi un tercio de todo lo que se exporta a nivel mundial) y con los niveles de precio de venta mayores (el precio medio de venta español para la exportación se ha situado en 2016 en $6,5 € / \mathrm{m}^{2}$, mientras que el italiano se ha situado en $13,8 € / \mathrm{m}^{2}$ ). Además, estos dos países, motores de la industria cerámica de la Unión Europea, han revertido la tendencia de la década anterior y han conseguido aumentar sus exportaciones en los últimos cuatro años (en un 24\% España y en un 9,5\% Italia). También es interesante observar el importante crecimiento que ha tenido India en los últimos años; desde el año 2013 hasta 2016, este país ha incrementado sus exportaciones en un $238 \%$ pasando de exportar 55 a 186 millones de metros cuadrados (Ver Tabla 28) 
Finalmente, en el capítulo de las importaciones, en la Tabla 29 se muestra, de forma análoga a las exportaciones, el ranking de los diez países con mayor volumen de negocio, así como su evolución en los últimos cuatro años. En general, podemos destacar que los países importadores suelen ser países en los que no se produce cerámica de forma significativa. Cuando se observa en el peso de la importación sobre la producción nacional, estos porcentajes oscilan entre el $60 \%$ y $98 \%$ para 9 de los 10 principales países importadores.

Podemos destacar, por volumen, el papel de Estados Unidos. Este país es el primer importador mundial (importando el $71 \%$ de su volumen producido) y sus importaciones han aumentado en un 18\% durante los últimos cuatro años. También es interesante resaltar el papel de Arabia Saudí, Irak y los Emiratos Árabes. Arabia Saudí se encuentra ya desde hace más de una década entre los primeros puestos de los países importadores. Sin embargo, en Iraq, el crecimiento en los últimos años le ha permitido pasar de importar unos 2 millones de metros cuadrados en 2005 (Baraldi, 2017) a los 112 millones de metros cuadrados y ocupar la tercera plaza a un nivel de negocio con un volumen similar a Alemania.

Por lo que respecta a la Unión Europea, únicamente Alemania y Francia aparecen en esta clasificación. Después de unos años de reducción de sus importaciones, estos países han invertido la tendencia pasando a importar un $19 \%$ y un $8,3 \%$ en los últimos cuatro años respectivamente. 
Tabla 29: Importación de pavimentos y revestimientos cerámicos por países en el periodo (2013-2016) en Mill. $\mathrm{m}^{2}$

\begin{tabular}{lcccccc}
\hline \multicolumn{1}{c}{ País } & $\mathbf{2 0 1 3}$ & $\mathbf{2 0 1 4}$ & $\mathbf{2 0 1 5}$ & $\mathbf{2 0 1 6}$ & $\begin{array}{c}\text { \% sobre } \\
\text { producción } \\
\text { nacional 2016 }\end{array}$ & $\begin{array}{c}\text { \% sobre } \\
\text { importación } \\
\text { mundial 2016 }\end{array}$ \\
\hline EE. UU. & 165 & 164 & 179 & 194 & $70,8 \%$ & $6,9 \%$ \\
Arabia Saudí & 170 & 156 & 188 & 167 & $67,3 \%$ & $6,0 \%$ \\
Alemania & 89 & 95 & 100 & 115 & $91,3 \%$ & $4,1 \%$ \\
Iraq & 121 & 102 & 106 & 112 & $98,2 \%$ & $4,0 \%$ \\
Francia & 96 & 99 & 99 & 104 & $87,4 \%$ & $3,7 \%$ \\
Corea del Sur & 65 & 76 & 72 & 75 & $60,0 \%$ & $2,7 \%$ \\
Filipinas & 46 & 53 & 60 & 75 & $65,2 \%$ & $2,7 \%$ \\
E.A.U. & 53 & 54 & 64 & 59 & $71,1 \%$ & $2,1 \%$ \\
Indonesia & 36 & 46 & 45 & 57 & $15,4 \%$ & $2,0 \%$ \\
Israel & 48 & 44 & 52 & 57 & $91,9 \%$ & $2,0 \%$ \\
TOTAL & 889 & 889 & 965 & 1.015 & $62,1 \%$ & $36,3 \%$ \\
TOTAL & $\mathbf{2 . 5 2 4}$ & $\mathbf{2 . 6 7 0}$ & $\mathbf{2 . 7 0 5}$ & $\mathbf{2 . 7 4 6}$ & $\mathbf{1 0 0 , 0 \%}$ & $\mathbf{1 0 0 , 0 \%}$ \\
MUNDIAL & & & & & & \\
\hline Fut & & & & &
\end{tabular}

Fuente: elaboración propia a partir de Baraldi (2017) 


\subsection{Descripción de la industria cerámica en Castellón}

Una vez caracterizada la industria cerámica mundial, en este apartado procederemos a la descripción de la industria cerámica en el clúster de Castellón. Para ello, en primer lugar, realizaremos una descripción histórica acerca de cómo esta industria se creó y se asentó en la provincia de Castellón. Posteriormente, caracterizaremos la industria y lo que supone en la actualidad.

\subsubsection{Introducción histórica}

Si bien la producción cerámica en la Comunidad Valenciana se remonta al siglo XIV con el desarrollo de Manises como centro fabricación nacional, es en el siglo XVIII el momento en el que podemos fijar la aparición de la cerámica en la provincia de Castellón.

En efecto, fue la fundación, por parte del Conde de Aranda, de la Real Fábrica de Loza en Alcora (Castellón) en el año 1727 lo que podemos considerar el inicio de la industria cerámica de Castellón. El conde de Aranda ubicó esta fábrica de porcelana y loza fina en un territorio donde abundaban los recursos necesarios para esta actividad (arcilla, agua y leña). Por otro lado, en ese territorio existía, además, una larga tradición alfarera, así como un puerto a través el cual poder enviar los productos fabricados. Los nuevos métodos de fabricación introducidos en esta fábrica, con relación a los artesanales de la época, hicieron posible el inicio de una fabricación a gran escala. Pronto surgen otras iniciativas similares a la desarrollada en Alcora; las conocidas como fabriquetes, son fundadas en pueblos cercanos como Ribesalbes u Onda para imitar la nueva técnica de fabricación cerámica (pudiéndolo considerar como un proceso de knowledge spillover).

Un poco más tarde, en la segunda mitad del siglo XIX, la población de Onda empieza a especializarse en la producción de pavimentos y revestimientos cerámicos. Aparecen así, una cantidad considerable de fábricas, iniciándose de este modo la aglomeración territorial. Además, como respuesta a la creciente demanda nacional y a las nuevas técnicas desarrolladas, se comienza a reducir el tamaño de las piezas y a homogeneizar sus formatos entre los distintos fabricantes, lo cual supuso un importante avance en el desarrollo del sector. 
Otros hitos importantes en el desarrollo de la industria castellonense fueron la introducción de la energía eléctrica, el desarrollo de la conexión ferroviaria con el puerto de Castellón, el desarrollo del prensado por fricción o la mejora del proceso de depuración y preparación de los materiales arcillosos. Estos avances permitieron no sólo seguir mejorando la producción (en términos de calidad y cantidad) sino además, reducir los costes de fabricación. No obstante, distintos acontecimientos históricos acaecidos en los años posteriores tales como la crisis del 29, la Guerra Civil Española y la Segunda Guerra Mundial frenarán el crecimiento de este sector hasta mediados de los años 60 del siglo XX.

A partir de este momento, las condiciones económicas nacionales empezaron a mejorar y se produce un boom migratorio nacional desde las zonas interiores rurales a las costeras (como por ejemplo a Cataluña o Comunidad Valenciana). Estos factores condujeron al desarrollo de la construcción y con ella al consumo del azulejo como revestimiento para los hogares. De hecho, la producción de azulejos pasó de 1,6 millones de metros cuadrados en 1930 a 25,2 millones de metros cuadrados en 1969. En esta época, el sector estaba apoyado prácticamente en la totalidad por la demanda interna. A este aumento del volumen de negocio le acompañaron también una serie de mejoras tecnológicas que permitieron seguir mejorando la eficiencia del sector. Innovaciones como la llevada a cabo en el proceso de preparación de la pasta cerámica o la introducción del horno túnel (el cual transformó el sistema producción discontinuo en semicontinuo) seguían mejorando la calidad y rentabilidad del producto.

Durante los años 70, a pesar de la crisis del petróleo, el sector continuó su desarrollo y como resultado, se pasó de una producción de 36,2 millones de metros cuadrados de pavimentos y revestimientos en 1970 a 90 millones de metros cuadrados en 1979. Es precisamente a partir de ese momento, y durante la década de los años 80 del siglo XX, cuando se produce la expansión internacional de las empresas gracias también al desarrollo de una nueva técnica de fabricación (la monococción) que supondría una revolución en el sector. España se convierte así, en el segundo país exportador detrás de Italia a pesar de que la calidad era inferior a la italiana. En los años 90, el clúster cerámico de Castellón se convierte en el primer productor de cerámica mundial. España compite, en ese momento, en un mercado en el que empiezan a aparecer nuevas potencias productoras tales como China, Turquía, México o Indonesia. Por primera vez 
la producción de cerámica en España intentará mejorar los estándares de calidad de su producto, con el objetivo de incrementar el valor añadido e intentar así acercarse a los niveles de calidad italianos, su principal referencia competitiva. Otros avances tecnológicos como los sistemas de cogeneración desarrollados en estos años permitieron seguir aumentando la eficiencia de esta industria. De este modo, se pasa de unas cifras de producción a inicios de los años 90 de aproximadamente 220 millones de metros cuadrados de azulejos, a unos valores cercanos a los 600 millones de metros cuadrados a finales de la década. Sin embargo, después de disfrutar de este importante crecimiento en los años 90, la industria cerámica experimenta la década posterior una estabilización hasta alcanzar su máximo de producción histórico en 2005 con 609 millones de metros cuadrados. Esto suponía un 8\% de la producción cerámica total mundial (ver Figura 19). Posteriormente la crisis del sector financiero y de la construcción entre el año 2008 y el 2009 acaba con esta tendencia y hace desplomar la producción nacional en 2009 a la mitad de lo que había sido su máximo histórico en 2005. A partir de ese momento, el sector empieza a experimentar una sucesiva recuperación que, permite vislumbrar la salida de la crisis. No obstante, las condiciones internacionales han cambiado y la industria cerámica castellonense se está viendo obligada a competir con nuevos modelos de negocio y frente a nuevos competidores emergentes con relación a los favorables años 80 y 90 del pasado siglo.

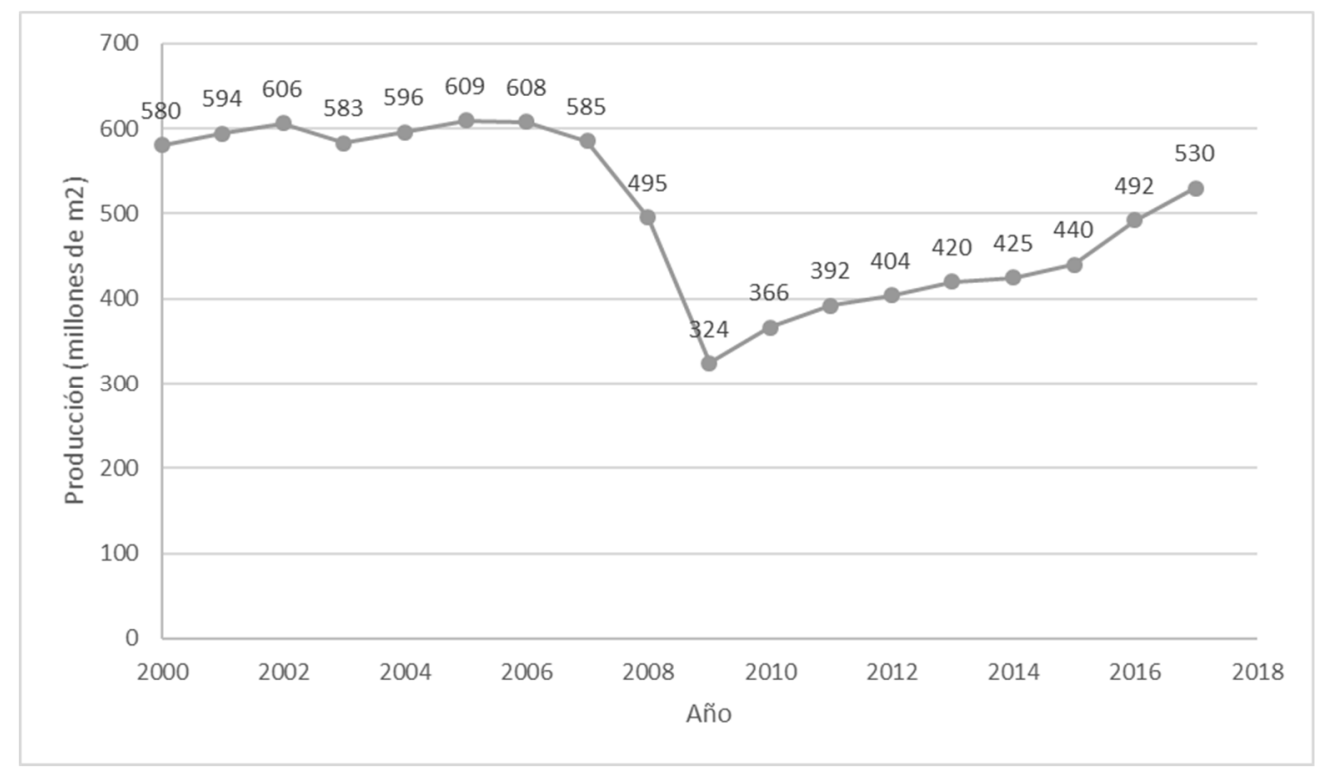

Figura 19: Evolución de la producción cerámica del sector español desde el año 2000 hasta el año 2017 
Fuente: elaboración propia a partir de $\mathrm{ASCER}^{10}$

A modo de resumen, en la Figura 20 se muestra cómo, en opinión de (Molina-Morales, Martínez-Fernández, Ares-Vázquez, \& Hoffmann, 2008) la industria cerámica ha evolucionado en Castellón a partir de sus principales avances.

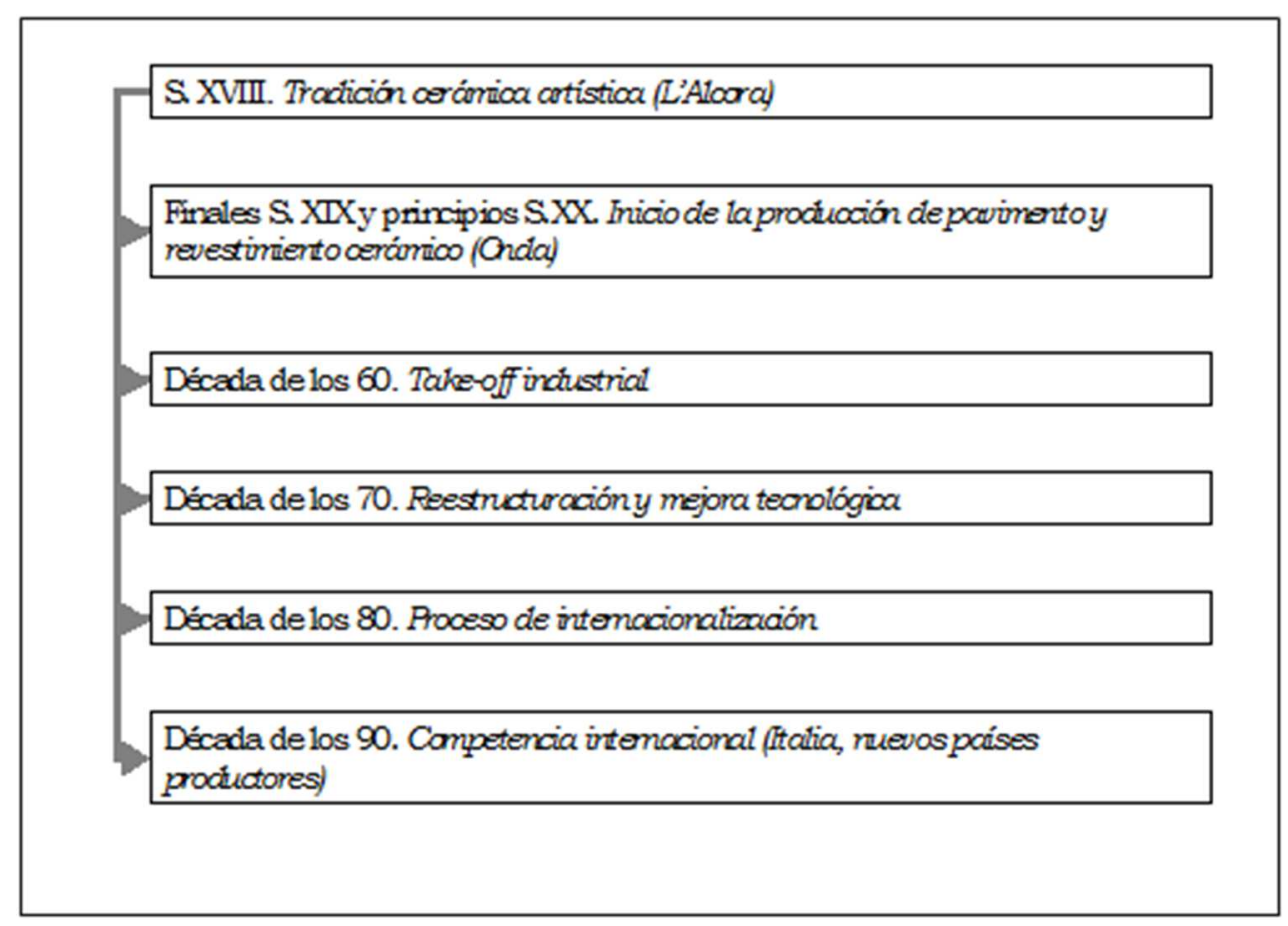

Figura 20: Evolución histórica de la Industria Cerámica de Castellón Fuente: Molina-Morales et al. (2008, p. 72)

\subsubsection{La industria cerámica castellonense en la actualidad}

En la actualidad, cómo ya hemos descrito, la industria cerámica de Castellón constituye el paradigma de lo que podría ser considerado como una organización de actividad productiva en forma de clúster industrial. Este clúster se encuentra situado entre las comarcas de l'Alcatalen, la Plana Baja y la Plana Alta (véase Figura 21); en especial en un área delimitada: al norte por Alcora y Borriol, al oeste por Onda, al sur por Nules y al este por Castellón de la Plana. En esta área (de en torno a $30 \mathrm{~km}$ de radio) se

\footnotetext{
${ }^{10}$ Los datos están obtenidos de ASCER (Asociación Española de Fabricantes de Azulejos y Pavimentos Cerámicos). Los datos han sido consultados en su página Web: http://www.ascer.es/ en Julio de 2018.
} 
concentra prácticamente la totalidad de la fabricación de pavimentos y revestimientos de España (Budí-Orduña, 2008). En porcentaje, la producción en este territorio supone el $90 \%$ de la industria cerámica de toda España, cerca del 40\% de la producción europea y entorno al 4\% de la producción mundial (Baraldi, 2016).

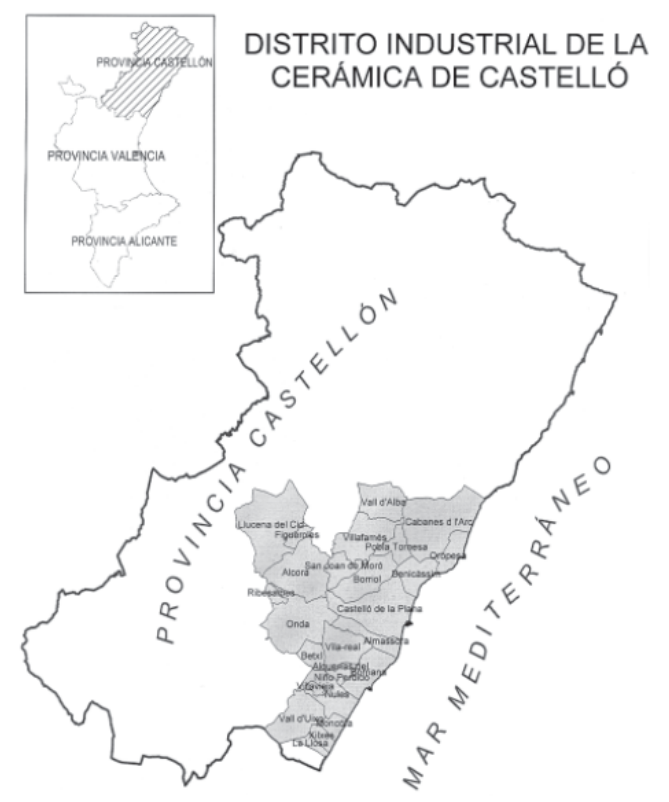

Figura 21: Ubicación del clúster cerámico de Castellón

Fuente: adaptación de Budí-Orduña (2008)

Según las últimas cifras publicadas correspondientes al año 2107 por la Asociación Española de Fabricantes de Azulejos y Pavimentos Cerámicos (ASCER) ${ }^{11}$ : la producción en el clúster alcanzó los 530 millones de metros cuadrados (lo que supone un incremento del 8\% con respecto a la producción del año 2016), el volumen de ventas total fue de 3.520 millones de euros (un 7\% más que en 2016) y se alcanzó una cifra récord de ventas en exportación; un 75\% de las ventas se realiza al exterior (lo que supone un valor de 2.700 millones de euros).

Este clúster es capaz de exportar a 187 países distintos, destacando el hecho de que, por ejemplo, las ventas a EE. UU. han aumentado en 2017 un 25,5\% con respecto a 2016. Estas cifras demuestran el buen estado en el que se encuentra el sector industrial cerámico de Castellón el cual se estima que es el tercer sector industrial que más

\footnotetext{
11 Los datos están basados en estimaciones de ASCER consultadas en su página Web: http://www.ascer.es/ consultada en Julio de 2018.
} 
superávit comercial aporta a la economía española. La industria de fabricantes de baldosas cerámicas en España se caracteriza por ser altamente innovadora. En el contexto internacional ocupa una posición de liderazgo tanto en el desarrollo tecnológico (principalmente de desarrollo de materiales cerámicos) como en el diseño de producto. En la actualidad, esta industria es la primera productora de cerámica a nivel europeo y la segunda exportadora mundial en volumen. En la Tabla 30 podemos observar en términos de volumen de venta, la evolución de la industria cerámica española de los últimos años.

Tabla 30: Evolución de la cifra de negocio de la industria cerámica española en el periodo (2012-2017) en Mill. $\mathrm{m}^{2}$

\begin{tabular}{lcccccc}
\hline & $\mathbf{2 0 1 2}$ & $\mathbf{2 0 1 3}$ & $\mathbf{2 0 1 4}$ & $\mathbf{2 0 1 5}$ & $\mathbf{2 0 1 6}$ & $\mathbf{2 0 1 7}$ \\
\hline Volumen de exportación & 2.082 & 2.240 & 2.328 & 2.452 & 2.570 & 2.700 \\
Volumen de venta nacional & 575 & 557 & 574 & 647 & 746 & 820 \\
Volumen total de ventas & 2.657 & 2.797 & 2.902 & 3.100 & 3.316 & 3.520 \\
\hline
\end{tabular}

Fuente: elaboración propia a partir de $\mathrm{ASCER}^{12}$

En total, se estima que el sector cerámico español ha sido capaz de generar un empleo directo de alrededor de 15.600 trabajadores (en 2017). Este empleo se ha creado principalmente en empresas de tamaño pequeño y mediano. Se calcula que la industria ha generado además alrededor de los 7.000 empleos indirectos ${ }^{13}$.

\footnotetext{
12 Datos obtenidos del "Balance económico del sector cerámico español en 2016” publicado por ASCER en su sitio web: http//www.ascer.es//

13 Los datos están basados en estimaciones de ASCER consultadas en su página Web: http://www.ascer.es/ consultada en Julio de 2018.
} 


\subsection{Principales actores del clúster industrial cerámico de Castellón}

\subsubsection{Los distintos entornos presentes en el clúster cerámico de Castellón}

La fabricación de baldosas cerámicas es un proceso continuo como consecuencia, principalmente, de que una de las etapas que lo conforman incluye una cocción a altas temperaturas (entre $1000^{\mathrm{a}} \mathrm{C}$ y $1250^{\mathrm{a}} \mathrm{C}$ ). Esta cocción se realiza en unos hornos de rodillos cuya eficiencia se obtiene cuando trabajan de forma continua 24/24 los 365 días del año. Por otro lado este proceso de fabricación es difícilmente divisible debido a que únicamente en su última etapa (la cocción) las piezas dejan de ser extremadamente frágiles para obtener la típica consistencia cerámica. Por todo ello, la fabricación de azulejos se realiza de forma continua en instalaciones que cubren todas las etapas del proceso productivo. Las empresas que realizan esta actividad son consideradas como las principales en el clúster cerámico. Sin embargo, éstas no son las únicas que generan actividad en el clúster; están rodeadas por una serie de otras empresas que realizan una gran cantidad de actividades complementarias a la actividad principal. Nos referimos a fabricantes de fritas, esmaltes y colores cerámicos, así como a fabricantes de maquinaria, de piezas especiales, de polvo atomizado y proveedores de aditivos cerámicos. También a una serie empresas dedicadas a la prestación de servicios auxiliares como son el embalaje, la logística, etc. Además, encontramos una serie de actores que tienen una especial relevancia en labores tales como el apoyo técnico y comercial, la representación institucional o la formación entre otras; nos referimos a las instituciones. Son precisamente las estrechas interrelaciones que se establecen entre instituciones y empresas las consideradas como los motores principales en los procesos de innovación (INGENIO, 2004).

En este apartado realizaremos un análisis de la estructura del clúster cerámico de Castellón que nos permitirá obtener un mapa de los agentes involucrados y de las relaciones que se establecen entre ellos. Iniciamos este análisis estableciendo cuatro entornos o marcos distintos dentro de los cuales podemos ubicar a todos los actores; nos 
referimos a los entornos: (a) productivo, (b) científico, (c) institucional y, (d) tecnológico y de servicios avanzados. En la Figura 22 se muestra la forma en que estos cuatro entornos interactúan entre ellos. A continuación, en los siguientes apartados de esta sección, procedemos a la descripción en detalle de cada uno de ellos.

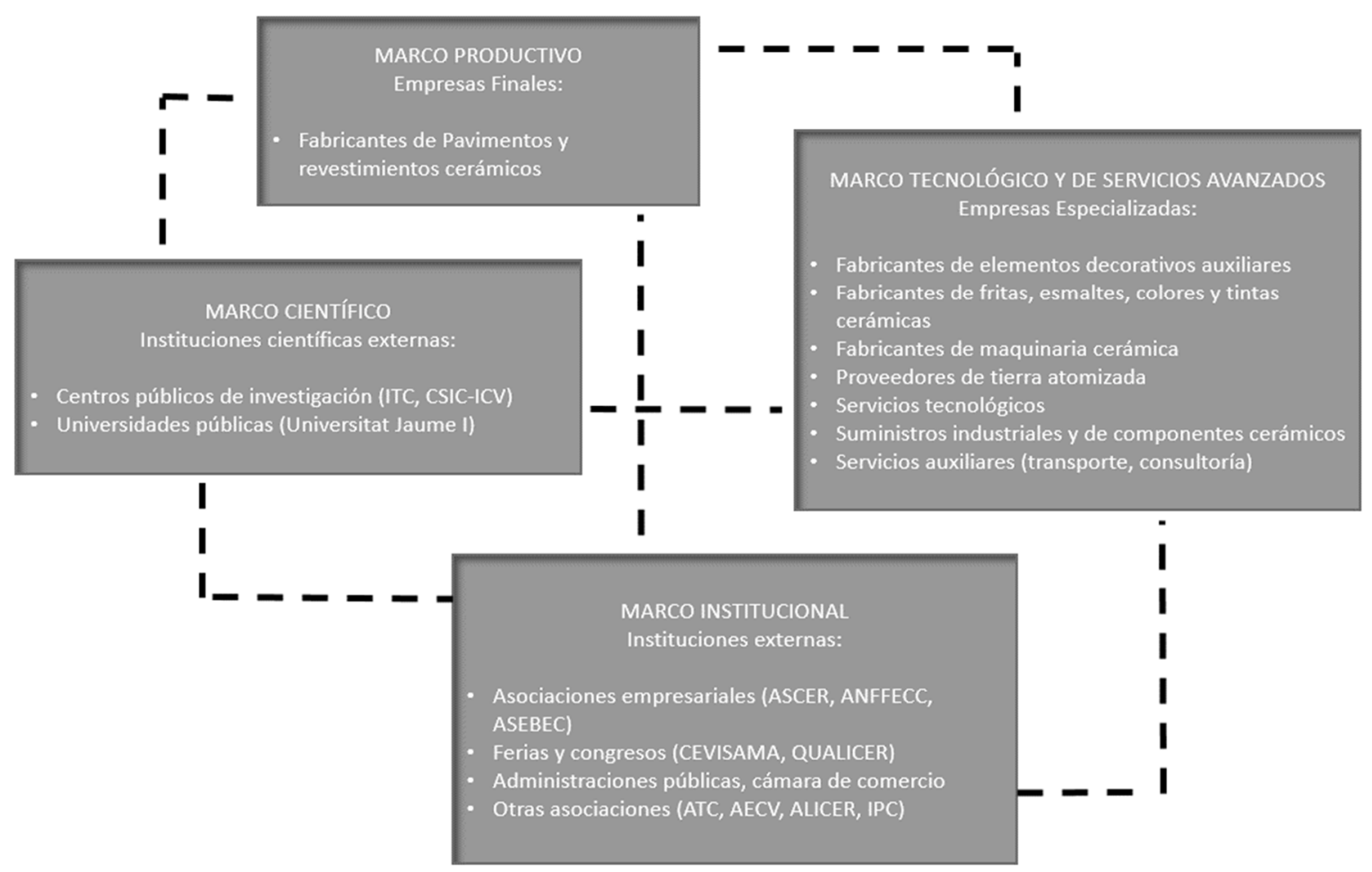

Figura 22: Los actores del clúster cerámico de Castellón agrupados por entornos

Fuente: elaboración propia a partir de Molina-Morales et al. (2008)

\subsubsection{El entorno productivo}

El entorno productivo está formado por aquellas empresas que realizan la actividad principal del clúster, que es la fabricación de pavimentos y revestimientos cerámicos. Siguiendo la terminología propuesta por Brusco (1990), estas empresas se denominan empresas finales ya que realizan las últimas fases del proceso productivo y están en contacto directo con el mercado externo. Continuando con esta consideración, en el caso del clúster cerámico de Castellón podemos considerar como empresas finales a aquéllas que, al menos, llevan a cabo las etapas centrales del proceso de fabricación: conformado, decoración y cocción de los productos cerámicos. No obstante, como podemos observar en la Figura 23, el proceso de fabricación de pavimentos y 
revestimientos es más complejo, por lo que el número de etapas realizadas por cada empresa puede ser mayor a las tres centrales dependiendo de las características de la misma (principalmente su tamaño).

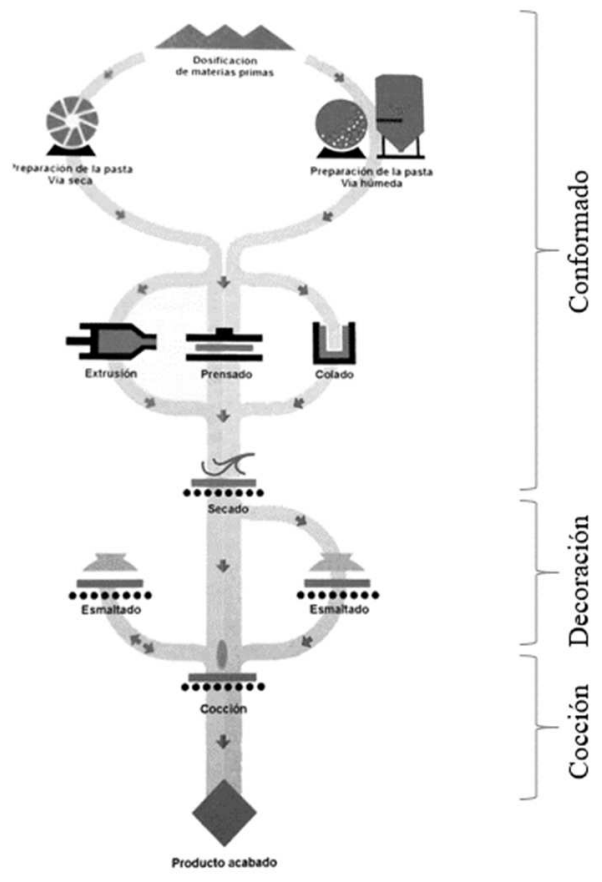

Figura 23: Esquema general del proceso de fabricación de productos cerámicos

Fuente: adaptación de Martinez-Chafer \& Molina-Morales (2012)

Las empresas finales constituyen el grupo más importante dentro del clúster cerámico, tanto por número, como por facturación y número de empleados. En el año 2018, según la base de datos de $\mathrm{ASCER}^{14}$, en la provincia de Castellón existían 107 empresas productoras finales. Según esta misma asociación empresarial, las ventas totales en 2017 crecieron un 6\% con respecto al año anterior alcanzando los 3.510 millones de euros. El número total de trabajadores directos en el sector cerámico ascendió en 2017 a 15.600, lo que supone un aumento de 1.300 trabajadores si lo comparamos con los datos de cuatro años atrás, en 2013, cuando había 14.300 empleados. Sin embargo, aún no se han alcanzado las cifras de empleo del año 2008, cuando se llegó a la cifra récord de 22.300 empleados. Desde una perspectiva un poco más general, la evolución de las

\footnotetext{
${ }^{14}$ Datos obtenidos a través de la información disponible en su sitio Web: http://www.ascer.es en Diciembre de 2018.
} 
ventas en los últimos 5 años ha sido muy positiva. En efecto, como se observa en la Tabla 31, desde 2013 a 2017, las ventas totales de productos cerámicos en el clúster de Castellón han ido aumentando progresivamente alejándose así de los peores resultados obtenidos inmediatamente después del año 2009 a causa de la gran recesión que sufrió el sector de la construcción.

Tabla 31: Evolución de las ventas totales de pavimentos y revestimientos cerámicos en el periodo (2013-2017) en Mill. €

\begin{tabular}{llllll}
\hline & $\mathbf{2 0 1 3}$ & $\mathbf{2 0 1 4}$ & $\mathbf{2 0 1 5}$ & $\mathbf{2 0 1 6}$ & $\mathbf{2 0 1 7}$ \\
\hline Ventas totales & 2.793 & 2.902 & 3.095 & 3.316 & 3.510 \\
\hline
\end{tabular}

Fuente: elaboración propia a partir de $\mathrm{ASCER}^{15}$

\subsubsection{El entorno tecnológico y de servicios avanzados}

El entorno tecnológico y de servicios avanzados engloba a aquellas empresas que asumen algunas actividades secundarias del proceso de fabricación de pavimentos y revestimientos cerámicos. Dentro de este marco podemos encontrar una gran variedad de empresas; desde aquellas que se dedican a actividades con nivel tecnológico mediobajo (como los proveedores de tierra atomizada o los proveedores de suministros industriales) hasta a aquellas cuyas actividades necesitan de una alta capacitación tecnológica (como los fabricantes de fritas, esmaltes y colores cerámicos o los fabricantes de maquinaria). No obstante, todas ellas se caracterizan porque, en menor o mayor medida, son capaces de ofrecer y transmitir conocimientos técnicos a las empresas finales que pueden ser utilizados por éstas en procesos de innovación. Entre estos conocimientos se encuentra, por ejemplo, la optimización del uso la maquinaria, el uso de nuevos materiales, el know-how químico y cerámico, etc. Este tipo de actores también realizan una función de intermediación muy importante dentro del sector que consiste en conectar al entorno científico con el entorno productivo.

A este grupo de empresas se les denomina empresas especializadas ya que, sin dedicarse a la actividad principal que define el clúster, tienen un alto grado de

15 Datos obtenidos a través de la información disponible en su sitio Web: http://www.ascer.es en Diciembre de 2018. 
especialización en sus actividades complementarias las cuales son muy necesarias para el desarrollo de la actividad principal.

A continuación, describiremos a los agentes más relevantes que forman este entorno.

\section{Fabricantes de fritas, esmaltes y colores cerámicos}

Las fritas, los esmaltes y los colores cerámicos son los materiales necesarios para decorar y proporcionar a los pavimentos y revestimientos cerámicos sus propiedades finales tales como el aspecto y las propiedades mecánicas. Se trata, por tanto, de materiales muy técnicos y con un grado de personalización muy importante.

Las empresas que se dedican a esta actividad dentro del clúster industrial cerámico son, por lo general, de mayor tamaño que las empresas finales. En 2018, el número de empresas de este tipo ascendieron a 21, según la Asociación Nacional de Fabricantes de Fritas y Esmaltes Cerámicos (ANFFECC) $)^{16}$. Sin embargo, mientras que las empresas finales son en su mayoría de capital español, una parte de las especializadas no tienen capital nacional siendo muchas de ellas de origen extranjero. Otra diferencia estriba en el tamaño; se trata, de forma general, de empresas de mucho mayor tamaño, situándose la media de trabajadores por encima de 130 empleados. Algunas de ellas llegan a superar los 500 puestos de trabajo en una sola planta. En 2017 la cifra de trabajadores alcanzó los 3.861 según los datos proporcionados por su asociación nacional.

El clúster castellonense, desde hace algunos años, ocupa la posición de liderazgo mundial en la fabricación y comercialización de fritas, esmaltes y colores cerámicos, sobrepasando a Italia, el segundo productor de estos productos. La razón de su éxito reside en la apuesta permanente por la $\mathrm{I}+\mathrm{D}+\mathrm{i}$ y en la forma que ha sabido obtener un grado de personalización de los productos capaces de hacerlos aptos en todos los mercados mundiales. I+D e internacionalización son, en definitiva, los dos pilares de desarrollo para estas empresas. Así lo muestra su cifra de exportación que alcanzaba en 2017 los 937 millones de euros. De éstos el 71\% son obtenidos en países como China,

\footnotetext{
${ }^{16}$ Datos obtenidos a través de la información disponible en su sitio Web: http://www.anffecc.com en Diciembre de 2018.
} 
Italia, Egipto, Argelia, Rusia, Marruecos, India, Turquía, Emiratos Árabes, Alemania, Polonia, Rusia, Indonesia, Emiratos Árabes Unidos, Arabia Saudí o Brasil. La internacionalización de estas empresas no se basa únicamente en la comercialización en terceros países a través de delegados o traders; esta estrategia se ha complementado con el establecimiento de empresas o filiales en numerosas zonas geográficas. De este modo, son capaces de adaptar y personalizar los productos a las peculiaridades de los mercados locales. Además, este sector empresarial ha apostado reducir en la medida de lo posible su impacto ambiental, eliminando el uso de materias primas extremadamente tóxicas (como el plomo) y mejorando la eficiencia energética de sus intalaciones.

Pero, sin duda, la estrategia fundamental en la que se han basado estas empresas ha sido la gran apuesta por la $\mathrm{I}+\mathrm{D}+\mathrm{i}$. El gran tamaño de estas empresas les ha permitido integrar dentro de sus estructuras grandes departamentos dedicados a la investigación y el desarrollo que trabajan, en muchas ocasiones, de forma muy estrecha con los departamentos de desarrollo de las empresas fabricantes de pavimentos o revestimientos. Más aún, en otras muchas ocasiones, incluso llegan a sustituirlos. En efecto, el pequeño tamaño de una parte de las industrias finales ha favorecido que los fabricantes de fritas y esmaltes acaben asumiendo las labores de investigación y desarrollo de producto de éstas a cambio de la compra y uso de sus materiales en sus respectivos procesos productivos. De esta forma, una pequeña empresa final puede eliminar parte de su estructura a costa de subcontratar esa tarea a las grandes empresas suministradoras de fritas y esmaltes. Este fenómeno ha dado lugar a una dependencia de los pequeños fabricantes de pavimentos y revestimientos frente a estas grandes empresas; un hecho que se observa desde los años 80 y 90 del siglo pasado, cuando los fabricantes de fritas y colores cerámicos basan su estrategia de venta en ofrecer investigación y desarrollo en compensación a la compra de sus productos. Así se establece un vínculo muy fuerte ya que el fabricante de pavimentos o revestimientos deja en manos de los fabricantes de fritas no sólo sus materias primas, sino también su estrategia de diferenciación de producto.

Las cifras de negocio de este subsector de empresas especializadas demuestran que esta estrategia ha sido acertada. Desde el año 1982 a 2017, la facturación se ha incrementado considerablemente llegando a un máximo de 1.322 millones de euros en 2017 (Figura 24). Podemos resaltar cómo después de la pérdida de ventas como consecuencia de la 
crisis económica global en 2008, un enfoque hacia la exportación ha dado unos resultados excelente, volviendo a sendas alcistas de crecimiento. Finalmente, con el objetivo de mostrar la situación de este subsector en la actualidad, en la Tabla 32 resumimos las principales cifras del año 2017.

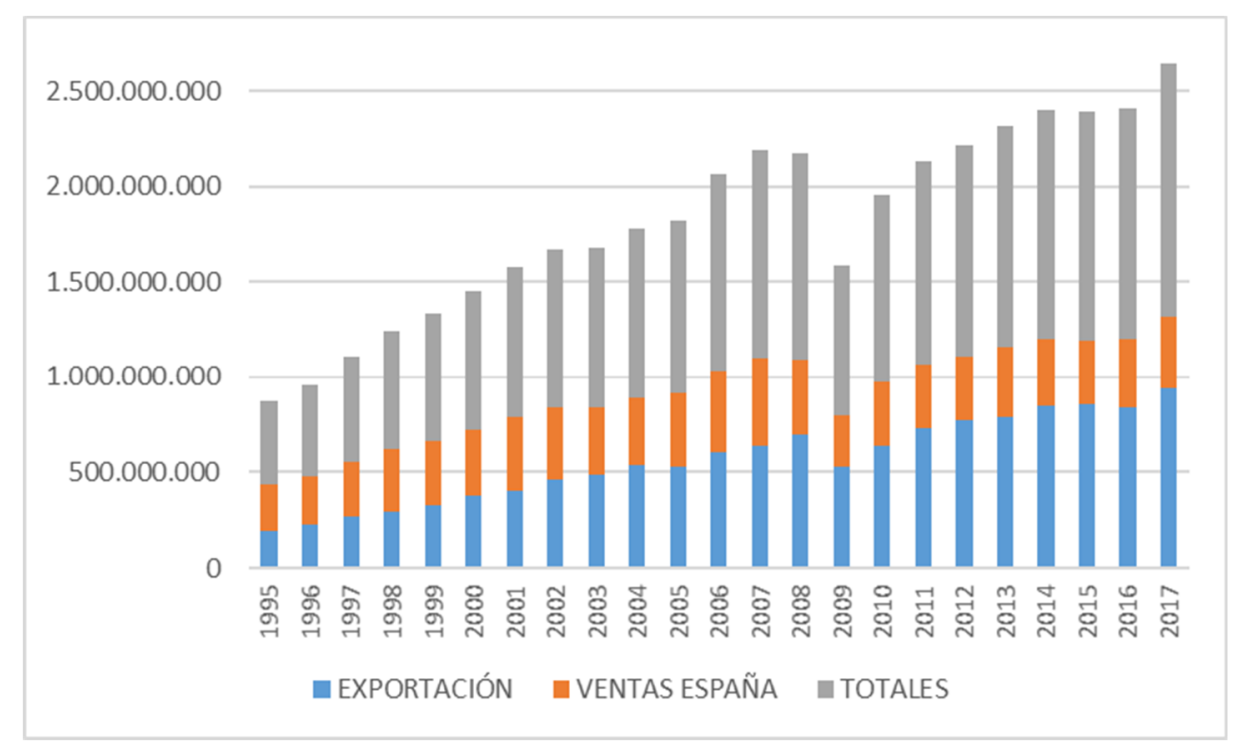

Figura 24: Evolución de las ventas nacional / exportación de los fabricantes de fritas, esmaltes y colores cerámicos en el periodo (1995-2017) en Mill. m²

Fuente: Elaboración propia a partir de ANFECC $^{17}$

La maquinaria cerámica es todo aquel elemento industrial necesario para llevar a cabo la producción de pavimentos y revestimientos. Dentro de este apartado, incluiríamos una gran variedad de subsectores tales como los fabricantes de hornos cerámicos, de líneas de movimentación, de líneas de esmaltado, de complementos de laboratorio, etc. Históricamente, los fabricantes de maquinaria se han considerado el eslabón más débil del clúster castellonense. La construcción de maquinaria cerámica en España ha sido siempre muy reducida y se ha dependido, en gran parte, de unas tecnologías principalmente desarrolladas en Italia. No obstante, este hecho se ha visto invertido en los últimos años precisamente con el fenómeno innovador examinado en la presente tesis. En efecto, en los últimos años, los fabricantes de maquinaria españoles (encabezados por los fabricantes de equipos de impresión digital) se han posicionado en

\footnotetext{
${ }^{17}$ Gráfico realizado a partir de datos obtenidos a través de la información disponible en su sitio Web: http://www.anffecc.com en Diciembre de 2018.
} 
la vanguardia de la tecnología y la innovación del sector cerámico mundial gracias al liderazgo obtenido en el desarrollo de la impresión digital por tecnología inkjet. Este fenómeno se explica ampliamente en el primer estudio empírico de esta tesis. En cualquier caso, el colectivo de empresas dedicadas a esta actividad, tanto subsidiarias de empresas extranjeras como talleres y empresas locales, están representadas por la Asociación Española de Fabricantes de Maquinaria y Bienes de Equipo para la Industria Cerámica (ASEBEC). Esta asociación está integrada por 44 empresas $^{18}$ de diversa especialización profesional que conforman la práctica totalidad del sector a nivel nacional. Las actividades incluyen: fabricantes de maquinaria, talleres de mantenimiento industrial, asistencia técnica de distinta índole y oficinas de firmas extranjeras.

Tabla 32: Principales cifras de negocio de los fabricantes de fritas, esmaltes y colores cerámicos en 2017

\begin{tabular}{|c|c|}
\hline TOTAL VENTAS SECTOR 2017: & $1.322 .236 .924 €$ \\
\hline TOTAL EXPORTACIONES 2017: & $936.715 .758 €$ \\
\hline PORCENTAJE SOBRE EL TOTAL VENTAS: & $70,8 \%$ \\
\hline TOTAL VENTAS ESPAÑA 2017: & $385.521 .166 €$ \\
\hline PORCENTAJE SOBRE EL TOTAL VENTAS: & $29,2 \%$ \\
\hline TOTAL TRABAJADORES DEL SECTOR 2017: & 3.861 \\
\hline \multicolumn{2}{|l|}{ PORCENTAJES DE VARIACION SOBRE 2016: } \\
\hline VENTAS TOTALES: & $9,9 \%$ \\
\hline EXPORTACIONES: & $11,1 \%$ \\
\hline VENTAS ESPAÑA: & $7,0 \%$ \\
\hline TRABAJADORES: & $4,9 \%$ \\
\hline
\end{tabular}

Fuente: Elaboración propia a partir de ANFECC $^{19}$

18 Dato obtenidos a través de la información disponible en su sitio Web: http://www.asebec.org en Diciembre de 2018.

19 Datos obtenidos a través de la información disponible en su sitio Web: http://www.anffecc.com en Diciembre de 2018. 
En este subsector podemos encontrar dos tipos de empresas muy distintas; por un lado, existen una gran cantidad de pequeños talleres que se encargan del montaje o reparación rutinaria de las máquinas y líneas; por otro lado, cuenta con empresas que son líderes mundiales en tecnología cerámica, en su mayoría italianas. La forma de operar de estas empresas es global ya que abastecen de tecnología a todo el mercado mundial. Esto ha supuesto también la eliminación de las barreras tecnológicas en el sector a nivel general.

\section{Fabricantes de piezas especiales}

Las piezas especiales son productos cerámicos que complementan la oferta de pavimentos y revestimientos cerámicos. Se trata de productos como: cenefas, listelos, molduras, cubrecantos, piezas decoradas a mano, etc. El objetivo de este subsector es poder ofrecer al mercado una solución global cerámica en la decoración de espacios complementado a los fabricantes de los pavimentos y revestimientos.

Este sector se desarrolla con motivo de la evolución y crecimiento de la fabricación de pavimentos y revestimientos cerámicos en los años 80 . La creciente sofisticación de los productos en dicha época desemboca en el desarrollo de complementos. De este modo el cliente se convierte en parte activa del proceso de diseño de la oferta pudiendo elegir entre una amplia gama de elementos decorativos lo que se traduce en un avance importante en la estrategia de venta de los productos cerámicos. No obstante, este avance genera problemas a nivel operativo para las industrias fabricantes de pavimentos y revestimientos ya que su proceso de fabricación continuo es más eficiente cuanto más estandarizado está el producto. Aparecen así una serie de empresas que deciden dedicarse exclusivamente a este tipo de productos complementarios a través del diseño de unas instalaciones productivas que les permiten mantener la competitividad incluso con una gran variabilidad de producto en su catálogo.

Las empresas que se dedican a la fabricación de estas piezas especiales son conocidas comúnmente como empresas de tercer fuego debido a que se precisa de una cocción adicional. Éstas suelen trabajar sobre pedido para empresas productoras de pavimento y revestimiento cerámico las cuales demandan sus servicios buscando complementar su 
catálogo de productos. En 2018 la asociación de fabricantes AVEC $^{20}$ censaba a 47 empresas dedicadas a dicha actividad. La propia asociación declaraba en 2008 el cierre del $20 \%$ de estas firmas motivado por las presiones provenientes de los fabricantes de pavimentos y revestimientos cerámicos.

\section{Fabricantes de polvo atomizado}

El polvo atomizado constituye la base de la mayor parte de los azulejos que se fabrican. A pesar de que existen otras técnicas para conformar una azulejo a partir de una mezcla de materiales arcillosos, el proceso más utilizado consiste en prensar en una prensa hidráulica un polvo que previamente ha sido granulado a través de un proceso denominado atomización.

El proceso de atomización, el cual también es utilizado en otras industrias como la alimentaria, consiste básicamente en un proceso de secado y granulado de una mezcla de las distintas materias primas que conforman el material cerámico. El objetivo de este proceso es doble: secar la mezcla de materias primas que se ha realizado en húmedo y dotarla de una fluidez óptima para poder ser utilizada en la etapa posterior. El resultado es un polvo granulado (esférico y hueco) que presenta aproximadamente entre un $5 \%$ y un $6 \%$ de humedad. Técnicamente consiste en una pulverización del material líquido obtenido de la mezcla y molienda de las materias primas, denominada barbotina. El principal inconveniente de este proceso es su elevado coste energético a pesar de que se intenta mejorar su rentabilidad a través de la implantación de turbinas de cogeneración que aprovechan el calor de los gases para la producción de energía eléctrica. Debido al alto consumo energético de esta industria y a las grandes instalaciones requeridas, es muy común el establecimiento de asociaciones entre empresas productoras de pavimentos y revestimientos cerámicos para la creación de empresas atomizadoras que abastecen de polvo atomizado a todas las asociadas. Estas industrias optimizan su coste en la medida que llevan capacidad productiva al máximo. De esta forma pueden hacer frente a la inversión necesaria y se garantizan el suministro regular y rentable de materia prima. Este hecho es significativo pues es una muestra de la capacidad de colaboración

\footnotetext{
${ }^{20}$ Dato obtenidos a través de la información disponible en su sitio Web: http://www.spainceramics.com/ en Diciembre de 2018.
} 
de empresas competidoras en ciertas fases específicas del proceso de producción. Este tipo de colaboración se ajusta al comportamiento esperado dentro de un clúster industrial como han descrito autores como Bayona Sáez, García Marco, \& Huerta Arribas (2003). Las empresas compiten en los mismos mercados y con la misma gama de productos, pero sin embargo colaboran en aspectos como la investigación básica y el suministro de materias primas.

Sin embargo, las empresas de mayor tamaño no tienen la necesidad de recurrir a este tipo de sociedades y normalmente se fabrican su propio polvo atomizado. Por este motivo, el número de empresas atomizadoras es relativamente bajo. Hasta la llegada de la crisis actual el negocio del atomizado se caracterizaba por la presión de la demanda, no obstante esta tendencia se ha visto invertida y ahora son los propios fabricantes de arcilla atomizada quienes sacrifican el precio y otros servicios para continuar siendo rentables.

\subsubsection{El entorno científico}

Consideraremos entorno científico a aquellas instituciones que ofrecen servicios y apoyo técnico a las empresas dentro del clúster. Este tipo de actores no sólo nutren de conocimiento técnico y de mercado a las empresas, sino que realizan una función muy importante de intermediación dentro del sector (Molina-Morales \& Martínez-Cháfer, 2016).

A continuación, detallaremos a las más importantes.

Instituto de Tecnología Cerámica ${ }^{21}$ (ITC)

Creado en 1969, el ITC es el instituto tecnológico de referencia en el clúster de Castellón y uno de los más importantes a nivel mundial. Se trata de un instituto mixto concertado, formado por el Instituto Universitario de Tecnología Cerámica de la Universitat Jaume I y la Asociación de Investigación de Investigación de las Industrias

21 La información recopilada para describir esta institución proviene de su página Web: http://www.itc.uji.es consultada en Diciembre de 2018. 
Cerámicas (AICE). Su principal función es la de satisfacer las necesidades de cooperación universidad-empresa, investigando sobre aquellos asuntos técnicos requeridos por las empresas del clúster, las cuales, por su tamaño y limitación de recursos, ven de este modo complementadas sus capacidades investigadoras. La misión del ITC pone de manifiesto esta vocación innovadora, ya que como en la propia página web del organismo se enuncia:

"Liderar los procesos de innovación tecnológica y de diseño del sector cerámico español anticipándose a las necesidades del mercado y de los consumidores con respecto a los usos y utilidades de la cerámica, por medio de la gestión profesionalizada de un equipo humano cualificado y comprometido con la excelencia del sector".

El clúster cerámico se dota, a través del ITC, de uno de los principales soportes de la innovación cerámica. Este organismo actúa como socio de las empresas, proporcionándoles acceso a la tecnología necesaria para poder obtener innovaciones que de otra forma no se podrían alcanzar. El ITC considera la investigación como la principal vía de desarrollo sectorial ofreciendo a las empresas herramientas mediante las cuales pueden ayudarles a resolver sus inquietudes de desarrollo tecnológico, con pretensión de impulsar la competitividad de las mismas y su proyección internacional.

El complimiento de su misión se basa en el desarrollo y acumulación de conocimiento, así como en la transmisión del mismo. Por tanto, el capital humano es un elemento clave. La estructura de investigación del ITC cuenta con una plantilla, en datos de Diciembre de 2018, de 100 empleados. Como la propia web describe:

"La relación del personal con la Universidad Jaume I de Castellón es evidente, unas 25 personas mantienen vínculos laborales con la Universidad, lo que garantiza que la titulación de Ingeniería Química de la UJI esté a la vanguardia en cuanto a tecnología cerámica se refiere. En cuanto al nivel de estudios del personal del ITC cabe destacar que un $26 \%$ de la plantilla ostenta el grado de Doctor y 2 de cada 3 empleados poseen al menos una licenciatura universitaria”. 
Las actividades que realiza el ITC son las siguientes:

- Servicios tecnológicos. La labor que realiza el ITC en este campo es la prospección, asimilación e implantación de nuevas tecnologías empleadas en otros procesos de fabricación. Este servicio es fundamental debido a la imposibilidad de una gran parte de las empresas del sector cerámico para generar la totalidad de la tecnología necesaria, dado su tamaño y disposición de recursos financieros. Así, la institución cuneta con un portafolio de más de 475 tipos diferentes de análisis y ensayos que se estructuran en cuatro áreas principales:

- Análisis y ensayos.

- Laboratorio de producto acabado.

- Garantía de calidad.

- Información y documentación.

- Formación. Se trata posiblemente, de la principal actividad del instituto. La formación está orientada a la formación cerámica e industrial tanto a empresas como a estudiantes y desempleados. El ITC tiene estructurada una amplia gama de cursos de formación, abarcando todo el espectro necesario en las empresas del sector cerámico, impartiendo enseñanza en: tecnología cerámica, calidad, innovación, diseño y arquitectura, tendencias de producto, etc. Todo ello organizado en tres áreas diferentes según el colectivo a quienes va dirigido: (a) cursos para estudiantes y desempleados, (b) cursos abiertos de corta duración, (c) formación estructurada según las necesidades de la empresa a través de cursos diseñados en exclusiva según las necesidades manifestadas por la compañía interesada. El ITC mantiene, como ya ha comentado con anterioridad, una estrecha colaboración con la Universidad Jaime I. En 1993 la Universidad de Castellón estableció la titulación de Ingeniería Química con perfil de Tecnología Cerámica. Esta es la primera titulación con estos contenidos que se imparte en España lo que permite generar una cartera de ingenieros con unas habilidades muy específicas en el ámbito cerámico que encuentran fácilmente trabajo al acabar sus estudios superiores. 
La formación reglada en nivel secundario también ha sido objeto de colaboración con el ITC. Destacan por la estrecha vinculación con el sector, dos especialidades: (a) cerámica industrial de formación profesional de $2^{\circ}$ grado (desde 84/85) y, (b) diseño de Revestimientos Cerámicos integrada en la Escuela de Artes Aplicadas y Oficios Artísticos (desde 88/89). Finalmente, el instituto mantiene estrechos contactos con la Cámara de Comercio, Industria y Navegación de Castellón, para ofertar alternativas de formación conjunta, como complemento a la formación específicamente cerámica.

- El Observatorio Cerámico. Se trata de una estructura formada por tres plataformas de investigación de mercados y tecnologías destinada a favorecer la competitividad de la industria cerámica. Estas tres plataformas son:

- El Observatorio de Mercado, es un sistema de inteligencia competitiva. Tiene por objetivo implementar una plataforma que permita a las empresas obtener suficientes datos para poder anticiparse a los cambios que se produzcan en el mercado. Emite anualmente un Informe de posición competitiva en marketing y venta para los fabricantes de baldosas cerámicas.

- El Observatorio de Tendencia del Hábitat, es un sistema consorciado entre ITC, Instituto tecnológico textil (AITEX) y el Instituto Tecnológico de la Madera, Mueble, Embalajes y Afines (AIDIMA) que pretende generar y difundir el conocimiento sobre las tendencias del hábitat. Este proyecto tiene carácter multisectorial y también multidisciplinar. Se preocupa especialmente de las tendencias en las corrientes estéticas y socioculturales, que influyen decisivamente sobre los productos.

○ El Observatorio Tecnológico y Medioambiental, está constituido como un sistema de observación, análisis e información especializado, que trata de identificar los cambios tecnológicos, que afecten especialmente a la industria cerámica. 
- Potenciación de los sistemas de calidad en la empresa. Los requisitos de la norma UNE-EN ISP/IEC170252000, que incluye todas las normas de la ISO 9000:2000, se han continuado aplicando en los sistemas de gestión de calidad del centro. A través de los acuerdos de reconocimiento, el ITC colabora con organismos de acreditación (ENAC) y certificación (CSTB-AFNOR-AENOR), principalmente en labores de auditoría y asesoramiento técnico, fomentado el mantenimiento y desarrollo de los sistemas de certificación de calidad (ISO 9000) y de gestión medioambiental (ISO 14001)

- Información y documentación. El ITC también atiende y gestiona las necesidades de información y documentación que surgen tanto internamente, como con las empresas con las que se relaciona. Tiene estructurada una depurada metodología de localización y relación de los diferentes archivos documentales de los que dispone.

\section{La Universidad Jaume I de Castellón (UJI)}

La Universitat Jaume I destaca por su presencia en el sector cerámico a través de dos vertientes totalmente distintas: el Departamento de Ingeniería Química Inorgánica y Orgánica y los diferentes grupos de investigación de distintos departamentos como el de administración de empresas y marketing. En cuanto al Departamento de Ingeniería Química podemos destacar el elevado grado conexión que tiene con la industria cerámica a través del grado de Ingeniería Química realizado en colaboración con el ITC.

Por otro lado, en cuanto a la actividad de los grupos de investigación adscritos a esta universidad, éstos han tomado de forma recurrente el clúster industrial cerámico como objeto de análisis de sus investigaciones. Y no nos referimos al ámbito técnico exclusivamente, sino también a otros ámbitos como por ejemplo, el empresarial o económico con la presencia de grupos de investigación tales como el grupo Alianzas Estratégicas, Redes y Territorio (AERT) o el grupo Innovación en Marketing (IMK), ambos pertenecientes al departamento de administración de empresas y marketing. 


\subsubsection{El entorno institucional}

De acuerdo con la clasificación realizada previamente, consideraremos entorno institucional al conjunto de organizaciones e instituciones, de ámbito público o privado, que apoyan la actividad del clúster a través de una diversa variedad de actividades.

En el apartado institucional encontramos varias categorías de actores. En primer lugar, existen una serie de asociaciones empresariales, que destacan como agentes de gran relevancia y presencia en este sector. Además, se incluyen en este entorno a las instituciones públicas que, a través de las administraciones a distintos niveles, desarrollan las políticas que pueden influir de forma más o menos intensa a la actividad industrial del sector. Junto con los dos anteriores grupos de instituciones encontramos las ferias y los congresos que son muy importantes como fuentes de conocimiento y como instrumentos de promoción. Finalmente destacamos el papel que realizan ciertos organismos locales como la Cámara de Comercio de Castellón, el CEEI u otros, a través de los servicios de apoyo que prestan a las empresas. A continuación, pasamos a describir brevemente los actores más relevantes de cada una de estas categorías enumeradas:

\section{$\underline{\text { Asociaciones empresariales }}$}

Las descritas a continuación son las tres principales asociaciones de fabricantes del sector cerámico en Castellón.

\section{Asociación Española de Fabricantes de Azulejos y Pavimentos Cerámicos (ASCER) ${ }^{22}$}

La Asociación Española de Fabricantes de Azulejos y Pavimentos Cerámicos (ASCER), es la organización que representa a la práctica totalidad de las empresas productoras de Pavimentos y Revestimientos Cerámicos, en la actualidad tiene 115 empresas asociadas de pleno derecho y 11 asociados afines. Cada empresa está representada en la asamblea general, que es el máximo órgano de gobierno, delegando en el órgano decisorio, que es

22 La información recopilada para describir esta institución proviene de su página Web: http://www.ascer.es/ consultada en Diciembre de 2018. 
la Junta Rectora, compuesta por un presidente, tres vicepresidentes y 13 vocales. Esta asociación se creó en 1977, al amparo de la Ley de 19/1977 de Organizaciones Profesionales, siendo la continuadora de la Agrupación Nacional Sindical de Industriales Azulejeros (ANSIA), que había sido creada en 1959 y que a su vez provenía del reconocimiento oficial de la Agrupación de Fabricantes de Azulejos (fundada en los años cuarenta).

ASCER tiene por objeto desarrollar y promocionar, cualquier tipo de proyecto que pueda tener interés para sus asociados siendo concebida especialmente para el apoyo, defensa y promoción de intereses generales y comunes de la industria cerámica. Es especialmente útil para la resolución de acciones, que tendrían un elevado coste si fuesen atacadas por las empresas individualmente y que son viables en el seno de la asociación. En la Tabla 33 se detallan sus actividades principales: 
Tabla 33: Principales actividades de la asociación ASCER

- Promoción Sectorial a nivel internacional cofinanciado por el Instituto Español de Comercio Exterior (ICEX)

- Su objetivo es la promoción y consolidación de la imagen de la industria, tratando de posicionar la marca de calidad que representa el azulejo español

- Ha definido el concepto Tile of Spain que está registrado en más de 20

Promoción exterior

Promoción nacional países, incluyendo todos los mercados principales.

- Tiene desarrollos específicos para numerosos países como Estados Unidos, Alemania, Reino Unido, Francia y la Federación Rusa.

- Específicamente tiene 4 herramientas:

- Planes País

- Asistencia a ferias

- Seminarios técnicos

○ Campañas de publicidad

- Plan de comunicación creado a nivel nacional, con el objeto de consolidar los azulejos como una opción vanguardista decorativa frente a otras como la madera o el mármol

- Trata de informar a los prescriptores (arquitectos, decoradores, interioristas, etc.) y también a los medios de comunicación, sobre todo a las revistas especializadas, evitando el tecnicismo y dirigiéndose al consumidor final.

- Las acciones pueden agruparse en:

- Participación en Casa Decor

- Realización de talleres formativos para medios de comunicación

- Despliegue de la Red de Cátedras

- Edición de la revista Ceraspaña

○ Lanzamiento de campañas de publicidad

Proyectos Departamento de I+D+i, apoyado por el programa i-creo de la Generalitat
sectoriales de Valenciana que tiene como objetivo desarrollar proyectos de distinta índole innovación siempre relacionados con el ámbito técnico e innovador

Medio ambiente

Labores de asesoramiento, información y cumplimiento de los aspectos medioambientales propios del sector cerámico a nivel internacional.

Servicio informativo para los asociados exclusivamente, donde se analizan

Servicio

estadístico de

datos sectoriales las cifras de exportación por países en unidades y en valor, emitiendo informes con carácter mensual y acumulado. Igualmente se señalan las cifras de producción, venta, importación y exportación agregada y otros datos relacionados con la balanza de pagos

Fuente: elaboración propia 
Asociación Nacional de Fabricantes de Fritas, Esmaltes y Colores Cerámicos $(\text { ANFFECC })^{23}$

Asociación que agrupa prácticamente la totalidad de los productores españoles de fritas, esmaltes y colores cerámicos, subsector que ya hemos descrito anteriormente. La Asociación nació en 1977, a partir de una iniciativa de un conjunto de empresarios (19 en el momento de la fundación) dedicados a la fabricación de fritas, esmaltes y colores cerámicos. Estos empresarios decidieron agruparse y fundar esta entidad, con la intención de defender el interés colectivo de sus asociados. La mayoría de las firmas fundadoras siguen existiendo en la actualidad, aunque algunas de ellas se hayan fusionado.

Debe tenerse en cuenta de que a pesar de que el número de empresas no es muy numeroso, este sector español, desde hace unos años, ocupa la posición de líder mundial en la fabricación de fritas, esmaltes y colores cerámicos, habiendo sobrepasado a Italia, país con más tradición en la fabricación de estos productos. En un principio la asociación se centró en la negociación de los convenios colectivos sectoriales, para pasar a la elaboración de normas para el etiquetado de los productos evitando así las confusiones. También gestiona las relaciones con otras asociaciones afines, para establecer convenios de colaboración.

Desde sus orígenes las empresas que se integran en ANFFECC han estado muy concienciadas en perseverar y respetar el entorno, pero en los últimos años lo consideran de carácter prioritario. Como consecuencia se ha producido la eliminación en el proceso productivo de materias primas que por sus características son contaminantes o nocivas para la salud de los trabajadores. Cobjeto de arbitrar soluciones y proponer pautas de trabajo, existe una comisión técnica, cuya misión es el estudio de aquellos temas que suscitan especial preocupación en los asociados, principalmente en materias de legislación medioambiental, clasificación de productos, determinación de tecnología disponible, y cualquier otro tema que por su carácter vanguardista deba de

23 La información recopilada para describir esta institución proviene de su página Web: http://www.anffecc.com consultada en Diciembre de 2018. 
ser considerado desde el punto de vista de la incorporación en las industrias. En la Tabla 34 se detallan sus actividades principales:

Tabla 34: Principales actividades de la asociación ANFFECC

\begin{tabular}{lll}
\hline & - & Reducción de las emisiones de partículas a la \\
& atmósfera \\
$\begin{array}{l}\text { Prevención, reducción } \\
\text { y control de la } \\
\text { contaminación }\end{array}$ & Reducción de las emisiones de partículas de SO2 a la \\
& atmósfera \\
& - & Reducción del ruido \\
\hline Generación de & Gestión de residuos y reciclaje \\
contenidos útiles & Determinación de, por ejemplo, el manual de \\
& manipulación segura de productos. \\
Colaboración con otras & Colaboración con el Ministerio de Medio Ambiente y \\
instituciones & Fundación Entorno, para el desarrollo en España de \\
& la directiva IPPC. \\
& Colaboración con el Ministerio en materia de \\
& Comercio de Emisiones \\
Estudios técnicos & Estudio y clasificación de las fritas cerámicas \\
\hline & Estudio de las fritas a efectos de su transporte y \\
& etiquetado
\end{tabular}

Fuente: elaboración propia a partir de datos obtenidos de http://www.anffecc.com

Asociación Española de Fabricantes de Maquinaria y Bienes de Equipo (ASEBEC) $)^{24}$

El Sector español de fabricantes de maquinaria y bienes de equipo para la industria cerámica, está representado por ASEBEC, asociación que actúa como patronal y que se encarga de desarrollar líneas de trabajo que ayuden al sector a mantener la línea de crecimiento iniciada hace una década. Se trata de la tercera asociación por importancia del clúster cerámico y está integrada por alrededor de 47 empresas (representa prácticamente a la totalidad del sector a nivel nacional) estructuradas en diversos

24 La información recopilada para describir esta institución proviene de su página Web: http://www.asebec.org/ consultada en Diciembre de 2018. 
subgrupos atendiendo a la especialización profesional. En ella se encuadran diferentes actividades como maquinaria, talleres de mantenimiento y servicios, talleres de asistencia técnica y representantes de firmas extranjeras.

Estas empresas han sido reconocidas tradicionalmente a nivel mundial por la calidad de sus hornos, prensas, secaderos y atomizadores. Sin embargo, sus capacidades se han ampliado en los últimos tiempos hacia el desarrollo de soluciones de impresión y decoración de esmaltes digital. Tradicionalmente el sector de fabricantes de maquinaria y bienes de equipo ha trabajado para la industria azulejera española, sin embargo, en los últimos tiempos, se ha desarrollado de una forma muy intensiva el mercado de exportación, principalmente en países como Turquía, México, Brasil o Egipto. Destaca su merecido prestigio en líneas de esmaltado e impresión digital.

\section{Administraciones públicas}

En el apartado institucional referente a las administraciones públicas encontramos varios actores en distintos marcos de competencia: a) instituciones europeas, b) instituciones nacionales, c) instituciones regionales. A continuación, pasamos a describir brevemente algunas de las instituciones más relevantes de estos ámbitos.

\section{Ayudas y fondos procedentes de la Unión Europea}

Para la Unión Europea (UE) la investigación y la innovación contribuyen de forma muy significativa en la mejora de la calidad de vida. Es por ello por lo que su órgano de gobierno, la Comisión Europea de Empresa e Industria, formula políticas encaminadas a incrementar la innovación en el espacio europeo. Esta labor es llevada a cabo principalmente a través de diferentes programas de los cuales se pueden beneficiar las empresas de los países de la unión. Además, la UE proporciona instrumentos financieros como el Fondo Europeo para el Desarrollo Regional (FEDER) que tiene como objetivo incentivar el desarrollo económico de las regiones que más lo necesitan a nivel europeo. Se trata de subvenciones a fondo perdido que serán gestionadas por las administraciones de cada país miembro a nivel central, autonómico y local según los cupos otorgados para cada una de ellas. Así, las empresas pueden acudir directamente a la UE, para pedir ayudas en la variada oferta de programas destinados a incentivar la 
innovación y la cooperación entre empresas o, indirectamente, a través de las administraciones locales que gestionan los fondos FEDER ya mencionados.

\section{Centro para el Desarrollo Tecnológico Industrial (CDTI $)^{25}$}

Entidad pública empresarial que, dependiendo del ministerio de ciencia y tecnología, promueve la innovación y el desarrollo tecnológico de las empresas españolas. Además, canaliza, desde 2009, las solicitudes de apoyo y financiación a los proyectos $\mathrm{I}+\mathrm{D}+\mathrm{i}$ que realizan las empresas españolas tanto en el ámbito nacional como internacional. El CDTI apoya a las empresas financieramente tanto en la concesión de ayudas propias como en facilitar el acceso a las ayudas de terceros como, por ejemplo, las líneas de financiación bancaria para la innovación establecidas en el Programa Marco de la UE. Además de las ayudas financieras, el CDTI presta apoyo a las empresas que quieren explotar sus tecnologías internacionalmente a través de las oficinas antes comentadas, incluso gestionan y apoyan la obtención, por parte de las empresas españolas, de contratos de contenido tecnológico con organizaciones nacionales e internacionales como la Agencia Espacial Europea (ESA), Hispasat o el Laboratorio Europea para la Física de Partículas (CERN) por citar algunos.

\section{Instituto Valenciano de Competitividad Empresarial $(I V A C E)^{26}$}

Anteriormente conocido como el Instituto de la Pequeña y Mediana Industria de la Generalitat Valenciana (IMPIVA). Esta institución de ámbito regional pertenece a La Conselleria de Economía Sostenible, Sectores Productivos, Comercio y Trabajo de la Generalitat Valenciana. El IVACE tiene como función principal el desarrollo de la política de promoción de la innovación en el País Valenciano así como de promover y apoyar a las PYMES industriales en este territorio. Para realizar esta función, este instituto presenta una variada oferta de programas destinados a las empresas y a las entidades públicas y privadas sin ánimo de lucro. Se trata principalmente de financiación semilla para proyectos muy concretos.

\footnotetext{
${ }^{25}$ Elaborado a partir de la información disponible en http://www.cdti.es consultado en Diciembre de 2018.

${ }^{26}$ Elaborado a partir de la información disponible en http://www.ivace.es/index.php?lang=es consultado en Diciembre de 2018.
} 
Periódicamente el IVACE lanza una línea de actuación que está encuadrada en un sector (o sectores) determinado. De forma general, estas líneas cambian de estructura anualmente, si bien se trata programas con parámetros de funcionamiento muy similares. A estas convocatorias suelen acudir bien empresas de forma independiente, bien consorcios de empresas promovidos por otras organizaciones del clúster como poder ser el ITC o el CEEI.

\section{Instituto Valenciano de Finanzas $(I V F)^{27}$}

Este organismo tiene como finalidad actuar como principal instrumento de la política financiera del Consejo, así como ejercer las competencias de la Generalidad sobre el sistema financiero. Además, desde la publicación del Decreto Ley 5/2015, el IVF ha recuperado las competencias en materia de financiación empresarial y actualmente también desde este organismo se prestan los servicios de certificación de firma electrónica avanzada y servicios relacionados con identificación y firma electrónica. El IVF posee tres grandes líneas principales de actuación financiera: (a) la gestión del endeudamiento de la Generalitat, (b) la supervisión y control de las entidades financieras que están bajo tutela administrativa de la Comunidad Valenciana y (c) el desarrollo de la política de crédito público y apoyo financiero a la inversión productiva.

La financiación que proporciona a las empresas puede consistir en la concesión de préstamos directos o de la utilización de fondos de capital riesgo. En este último tipo de financiación el IVF ha impulsado la creación de dos fondos, Comval Emprende y Tirant, participando a su vez en el fondo Angels Capital para emprendedores.

\section{Instituto Valenciano de la Exportación $(\text { IVEX })^{28}$}

El Instituto Valenciano de la Exportación (IVEX) es un instrumento cuyo propósito es la internacionalización del tejido empresarial de la Comunitat Valenciana. Éste facilita

\footnotetext{
${ }^{27}$ Elaborado a partir de la información disponible en el sitio Web: http://portales.gva/ivf/ consultado en Diciembre de 2018.

28 Elaborado a partir de la información disponible en el sitio Web: https://www.lasnaves.com/miembros/instituto-valenciano-de-la-exportacion-ivex/?lang=es consultado en Diciembre de 2018.
} 
el acceso de las empresas al mercado global. El IVEX pone a disposición de las empresas personal técnico, infraestructura y conocimiento basado en la experiencia. Toda esta atención se complementa con un amplio plan de formación de recursos humanos especializados en internacionalización. Al personal técnico en las oficinas centrales de Valencia se une una extensa red en el exterior formada por 28 delegaciones situadas en los principales mercados internacionales.

\section{$\underline{\text { Ferias y congresos }}$}

En este apartado destacamos dos eventos de máximo interés para el sector que se realizan de forma regular. Pasamos a describirlas a continuación:

Salón Internacional de la Cerámica para Arquitectura, Equipamiento de Baño y Cocina, Piedra Natural, Materias Primas, Fritas, Esmaltes y Maquinaria $(\text { CEVISAMA })^{29}$

Siendo el segundo salón por número de asistentes y fama en la industria cerámica mundial (después de la feria internacional de Italia), Cevisama es una feria que cuenta en la actualidad con treinta y cinco años de trayectoria y se ha consolidado como una importante plataforma de negocio, en constante crecimiento y capaz de atraer a más de 94.000 profesionales de todo el mundo. En este salón, se reúnen los principales productores de pavimentos y revestimientos cerámicos; fritas, esmaltes y colores cerámicos; materias primas y materiales de agarre y utillaje; maquinaria cerámica; equipamiento de baño y piedra natural. Es un encuentro profesional de gran relevancia, y punto de encuentro imprescindible para conocer las últimas tendencias. En su última edición se han congregado un total de 838 empresas de todo el mundo. De hecho, el carácter internacional de este evento es una de sus señas de identidad puesto que el $40 \%$ de los expositores de su edición de 2019 son empresas extranjeras y 17.000 de los 94.000 asistentes fueron de fuera de España. La presencia de empresas de más de 40 países distintos es una buena prueba de este carácter entre los que se encuentran las principales potencias en el mercado de los pavimentos y revestimientos cerámicos

\footnotetext{
29 La información recopilada para describir esta institución proviene de su página Web: http://cevisama.feriavalencia.com consultada en Febrero de 2019.
} 
además de algunas incorporaciones recientes como Japón, Líbano, Lituania, Rumania, Ucrania y Suiza.

Esta feria es, además, un escaparate de la innovación que realizan las empresas del sector. De hecho, este evento premia a las innovaciones más punteras mediante los denominados Alfa de Oro. Desde su creación hace 43 años estos premios son un referente en materia de innovación distinguiendo aquellos productos, procesos, maquinaria y equipamiento del sector de la cerámica y vidrio que destacan por su innovación tanto tecnológica como artística. Mediante los premios Alfa de Oro se estimula la creatividad científica, tecnológica y artística de las empresas que participan en la feria.

\section{Qualicer}

Qualicer es un foro sobre la tecnología cerámica que nace en 1990 cuando la Cámara Oficial de Comercio, Industria y Navegación de Castellón y el Colegio Oficial de Ingenieros Superiores Industriales decidieron realizar un evento dedicado al sector cerámico. Este hecho marcó un antes y un después en la historia del clúster de Castellón. En sus orígenes se trataba de un modesto foro de debate sobre el azulejo; hoy en día se ha convertido en un congreso mundial sobre calidad en la industria cerámica que aborda, además, temas relacionados con la calidad del proceso productivo, de la colocación de las baldosas y, en general, de la calidad de todos los elementos que integran el la cadena de valor de la industria cerámica. Actualmente Qualicer es uno de los eventos más relevantes del mundo de la cerámica a nivel internacional.

\section{Cámara de comercio y otras asociaciones}

Finalmente, existen una serie de asociaciones estrechamente vinculadas al sector cerámico de la provincia de Castellón como son: 
Cámara de Comercio de Castellón ${ }^{30}$

La Cámara de Comercio de Castellón es una entidad destinada a ser un órgano consultivo y de colaboración con las administraciones públicas. Sus principales tareas son la representación, promoción y defensa de los intereses del tejido empresarial, así como la prestación de servicios a las empresas adscritas. Por su importante peso en la economía de la provincia, el clúster cerámico es el principal motor de esta corporación. Los servicios que proporciona a través de una extensa gama de programas se pueden resumir en la Tabla 35.

\section{Asociación Española de Técnicos Cerámicos $(A T C)^{31}$}

Fundada en 1976, tiene como objetivo potenciar la formación e información de los técnicos cerámicos. Se trata de una asociación con una gran trayectoria en Castellón en la que se encuentran inscritos una gran cantidad de profesionales de las distintas industrias del ámbito cerámico. Destacan sus iniciativas de formación, realizando tanto cursos, como mesas redondas, etc.

Cada dos años esta asociación organiza el Congreso del Técnico Cerámico con la colaboración de ATC con organismos oficiales y empresas privadas. Se hace especial énfasis en la comunicación e intercambio de opiniones entre los profesionales asociados. De forma resumida, esta asociación realiza las siguientes actividades:

- Labores de formación para motivar y capacitar a los técnicos del sector cerámico (Intra-emprendedurismo).

- Labores de formación para consolidar y a las empresas del sector cerámico.

- Difusión de conocimientos entre los técnicos del sector.

- Inserción de estudiantes y desempleados.

- Apoyo a la innovación.

\footnotetext{
30 La información recopilada para describir esta institución proviene de su página Web: http://www.camaracastellon.com consultada en Febrero de 2019.

31 La información recopilada para describir esta institución proviene de su página Web: http://www.atece.org/ consultada en Enero de 2019.
} 
Tabla 35: Principales líneas de actuación de la Cámara de Comercio de Castellón

\begin{tabular}{|c|c|}
\hline Comercio Exterior & $\begin{array}{l}\text { - } \quad \text { Iniciación a la exportación } \\
\text { - } \quad \text { Consolidación de la exportación } \\
\text { - Tramitación y legalización de documento } \\
\text { - Formación en comercio exterior }\end{array}$ \\
\hline Formación y Empleo & $\begin{array}{l}\text { - } \quad \text { Gestión de ofertas de trabajo } \\
\text { - } \quad \text { Preselección y selección de personal } \\
\text { - } \quad \text { Planes Integrales de Empleo } \\
\text { - } \quad \text { Contratos a alumnos de Formación Profesional } \\
\text { - Formación presencial, on-line y mixta } \\
\text { - Formación empresarial subvencionada } \\
\text { - Formación a medida para la empresa } \\
\text { - } \quad \text { Planes de Formación para las empresas } \\
\text { - Fundión de las bonificacion Tripartita } \\
\text { - Prácticas de alumnos da } \\
\text { - } \quad \text { Profesional Inicial y para el Empleo } \\
\text { - Apoyo en proyectos de recursos humanos } \\
\end{array}$ \\
\hline Estudios Económicos & $\begin{array}{l}\text { - Informes } \\
\text { - Estadísticas mensuales } \\
\text { - Castellón en cifras } \\
\text { - Anuario Económico } \\
\text { - Datos e indicadores socioeconómicos municipales } \\
\end{array}$ \\
\hline $\begin{array}{l}\text { Desarrollo } \\
\text { Empresarial }\end{array}$ & 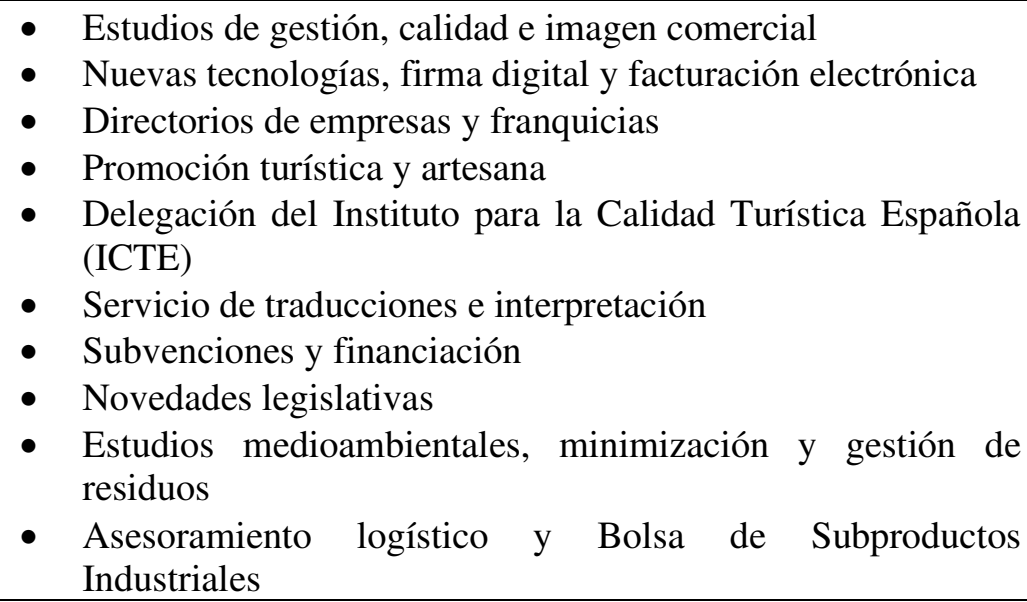 \\
\hline Creación de Empresas & $\begin{array}{l}\text { - } \text { Información personalizada } \\
\text { - Tramitación ante las Administraciones Públicas } \\
\text { - Formación a medida } \\
\text { - } \quad \text { Viveros de Empresas }\end{array}$ \\
\hline Otros Servicios & $\begin{array}{l}\text { - Asesoría Jurídica } \\
\text { - Biblioteca y Archivo Histórico } \\
\text { - Calidad y Protección de Datos } \\
\text { - Corte de Arbitraje } \\
\text { - Servicios informáticos } \\
\text { - Unidad de Promoción y Desarrollo (UPD Castellón) }\end{array}$ \\
\hline
\end{tabular}

Fuente: elaboración propia. 
Centro Europeo de Empresas Innovadoras de Castellón (CEEI) ${ }^{32}$

El CEEI Castellón es una asociación privada cuyo principal objetivo es el apoyo a PYMEs y emprendedores a través de la innovación. La asociación está integrada por entidades y organismos públicos y privados. Impulsado por éstas y el Instituto Valenciano de la Mediana y Pequeña Industria (IMPIVA), este centro es un motor de apoyo a emprendedores y a PYME innovadoras en fase de desarrollo y consolidación. Los servicios que ofrece este organismo se resumen a continuación:

- Vivero de Empresas

- Servicios de apoyo a la innovación y a la creación de empresas

- Apoyo en la elaboración de planes de empresa

- Asesoramiento personalizado al emprendedor

- Seminarios: Formación.

- Actividades de networking, capital relacional: Oportunidades del negocio

- Servicios de apoyo a la innovación y a la mejora competitiva para empresas

- Planificación económico-financiera

○ Planificación estratégica

- Búsqueda de financiación para proyectos innovadores

- Asesoramiento para el desarrollo de las áreas del Marketing

○ Sistemas de gestión de $\mathrm{I}+\mathrm{D}+\mathrm{i}$

- Valorización de las actividades de I+D+i

○ Generación, gestión y maduración de ideas (Idealab)Diagnóstico del departamento comercial (Comerzialab)

- Diagnóstico de innovación (Chekinlab)

○ Diagnóstico de la propiedad intelectual e industrial (Securitylab)

32 La información recopilada para describir esta institución proviene de su página web: http://ceeicastellon.emprenemjunts.es/ consultada en Febrero de 2019. 


\subsection{La impresión digital cerámica como innovación tecnológica disruptiva desarrollada en el clúster cerámico de Castellón}

Como hemos introducido en la introducción de este capítulo, el desarrollo de la impresión digital cerámica llevado a cabo en el clúster de Castellón ha supuesto fenómeno innovador que hemos considerado como el objeto específico de estudio de la presente tesis. Procedemos a continuación, en consecuencia, a describir brevemente los fundamentos de la impresión digital, así como a la justificación de por qué puede ser considerada como una innovación disruptiva de tipo tecnológico ${ }^{33}$.

El fundamento de la impresión digital cerámica consiste en un novedoso sistema de impresión basado en una tecnología de inyección de tinta similar al que existía previamente para otro tipo de aplicaciones no industriales como las artes gráficas. Este sistema de decoración consiste fundamentalmente, y de forma muy esquemática, en un dispositivo que lanza tinta sobre una superficie (denominado cabezal de impresión) y un software informático que lo dirige. En la Figura 25 se muestra lo que supone en corazón del sistema, el cabezal de impresión. Los autores Nebot \& Dal (2018) han descrito de una forma mucho más extensa los principios técnicos de esta nueva forma de decoración cerámica.

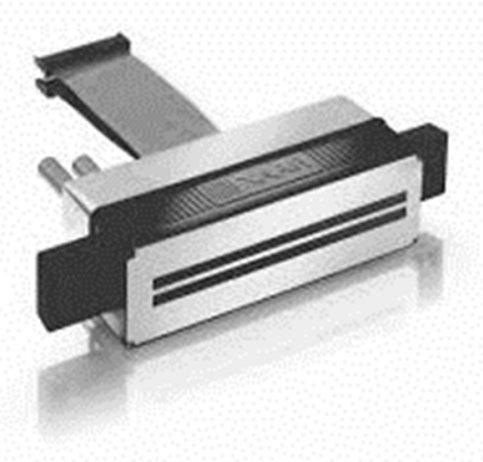

Figura 25: Cabezal de impresión de la marca Xaar que integra la impresora digital cerámica

Fuente: www.xaar.com

\footnotetext{
${ }^{33}$ En este apartado vamos a realizar una breve descripción de este fenómeno puesto que en el primer estudio empírico de esta tesis se analiza y describe de forma exhaustiva.
} 
Los cabezales de impresión se aglutinan en número variable (dependiendo del tamaño de la máquina) en lo que se denomina la impresora digital cerámica. En la Figura 26 se muestra una impresora digital cerámica

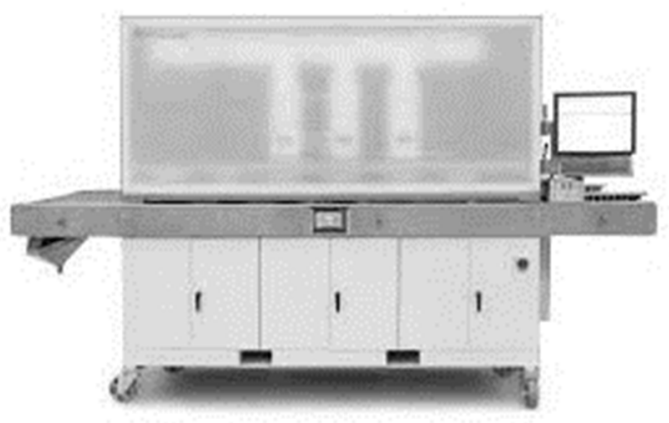

Figura 26: Modelo 1400 de la impresora digital cerámica de la marca Kerajet Fuente: www.kerajet.es

El desarrollo de esta impresora fue iniciado en el año 2000 por una empresa castellonense dedicada a la fabricación de maquinaria para el sector cerámico. Diecinueve años más tarde, en 2019, este sistema digital de impresión cerámica ha sustituido a la gran mayoría de máquinas tradicionales de impresión cerámica en todo mundo, como se describe ampliamente en el primer estudio empírico de la presente tesis.

Las máquinas tradicionales se basaban en una tecnología muy antigua, totalmente analógica, consistente en la deposición por presión de una capa de tinta a través de una tambor semiperforado que contenía el dibujo que se quería imprimir. En la Figura 27 se muestra una máquina tradicional cerámica. 


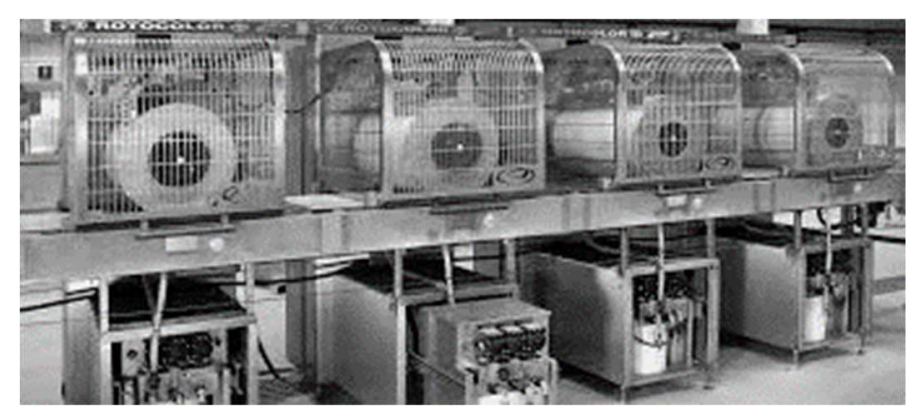

Figura 27: Máquina rotocolor de la marca System para la impresión tradicional de azulejos

Fuente: www.system-ceramics.com

Las diferencias entre ambos sistemas van más allá de la simple sustitución de una tecnología analógica por otra digital. Como se describe ampliamente en el primer estudio empírico de la presente tesis, el sistema tradicional es menos eficiente desde distintos puntos de vista tales como productividad, coste de materiales fungibles, coste de mano de obra, calidad de la impresión obtenida, variabilidad de la calidad de la impresión obtenida, consumo o velocidad. Además, el nuevo sistema no sólo permite el control de todos los parámetros de impresión de forma digital sino que también la dirección de forma remota, permitiendo así un control on-line, incluso desde otro país o ciudad donde, por ejemplo, se encuentre el servicio técnico.

El avance descrito en relación a la impresión cerámica ha sido calificado por una gran variedad de autores como una innovación tecnológica radical o disruptiva ${ }^{34}$ debido principalmente a que el nuevo sistema digital rompe con el sistema anterior generando una nueva categoría de producto y permitiendo un avance sustancial en la mejora del proceso de fabricación cerámica (por ejemplo, Albors-Garrigos \& Hervás-Oliver (2013); Hervás-Oliver, Albors-Garrigos, Estelles-Miguel, \& Boronat-Moll (2017); Reig-Otero at al. (2014). Para poder entender el ámbito de aplicación de la innovación, en la Figura 28 se describe el proceso de fabricación de pavimentos y revestimientos cerámicos.

\footnotetext{
${ }^{34}$ Somos conscientes de la discusión terminológica existente en la academia en relación con el uso de los términos radical y disruptivo. Por lo tanto, adoptamos la propuesta sugerida por Markides (2006), quien, basándose en el trabajo de Christensen (1997), distinguió entre innovación radical para productos e innovación disruptiva para tecnologías.
} 
De forma esquemática -aunque un poco más detallada que en la descripción realizada anteriormente en este mismo apartado- podemos decir que el proceso de fabricación cerámico consta de siete etapas, de ellas, la impresión (en la figura 28 se encuentra rodeada con un círculo) es considerada como una de las más importantes por dos motivos; por un lado, esta etapa incide proporcionalmente en un coste muy alto con respecto al resto; por otro lado, esta etapa dota al producto final de gran parte de su valor añadido puesto que el diseño (la impresión) es lo que es percibido por el cliente medio con mayor claridad.

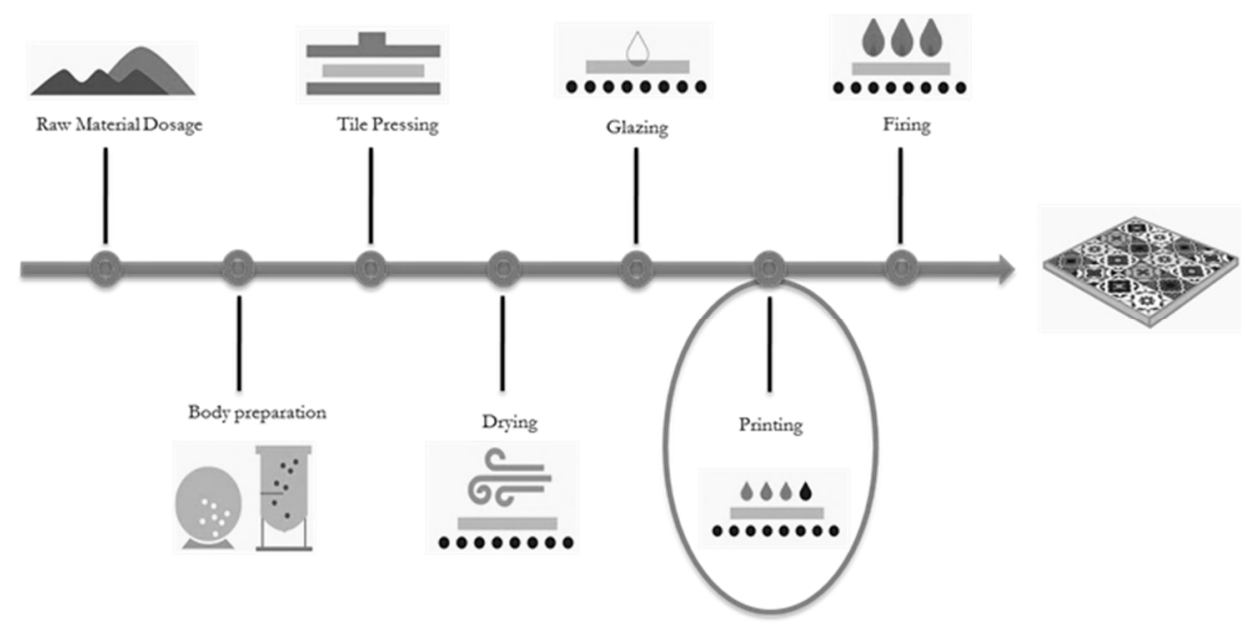

Figura 28: Descripción esquemática del proceso de fabricación cerámica

Fuente: elaboración propia.

En base a lo anterior, podemos concluir que la impresión digital cerámica supuso un cambio radical en la manera de imprimir los pavimentos y revestimientos cerámicos. Además tuvo un gran impacto en la cadena de valor de la industria cerámica. En el siguiente capítulo de esta tesis, más concretamente en el estudio empírico I, se realiza un análisis más profundo de los fundamentos de esta innovación, así como del proceso de generación y difusión en el clúster cerámico de Castellón (donde fue creada). Finalmente se evalúa su impacto no sólo a nivel de cadena de valor sino también a nivel de clúster como entidad. 
CAPÍTULO 4

DISEÑO DE LA INVESTIGACIÓN EMPÍRICA

Y LA METODOLOGÍA UTILIZADA 


\section{DISEÑO DE LA INVESTIGACIÓN EMPÍRICA Y LA METODOLOGÍA UTILIZADA}

\subsection{Estructura de trabajo empírico}

\subsubsection{Introducción}

El trabajo empírico desarrollado en la presente tesis consta de dos etapas perfectamente diferenciables. A pesar de que ambas etapas tienen como objetos de estudio el clúster de Castellón y la innovación disruptiva (impresión digital), anteriormente expuestos, cada una de ellas plantea unidades de análisis y uso de metodologías completamente distintas. En efecto, podemos concluir que el presente trabajo empírico consta de: (a) una fase descriptiva-cualitativa y, (b) una fase cuantitativa. Con el fin de mejorar la claridad expositiva, en la Tabla 36 se muestran de forma resumida las principales características de las dos fases que componen nuestra investigación.

La investigación se ha estructurado de este modo en base a la aproximación que hemos pretendido realizar al fenómeno objeto de estudio. En efecto, nuestra investigación parte de la observación del hecho de que el clúster cerámico de Castellón había experimentado una transformación como consecuencia de la irrupción de una innovación tecnológica disruptiva. A partir de este hecho, nos planteamos poder 
entender cómo los clústeres son capaces de generar y asimilar este tipo de innovaciones tan alejadas de su dinámica innovadora habitual, así como qué consecuencias pueden generar tanto para éstos como para las empresas que los componen.

Tabla 36: Descripción de las fases de investigación

\begin{tabular}{cccc}
\hline Fase & $\begin{array}{c}\text { Unidad de } \\
\text { análisis }\end{array}$ & $\begin{array}{c}\text { Tipo de metodología } \\
\text { utilizada }\end{array}$ & $\begin{array}{c}\text { Estudios empíricos } \\
\text { realizados }\end{array}$ \\
\hline $\begin{array}{c}\text { Descriptiva- } \\
\text { cualitativa }\end{array}$ & Clúster & Cualitativa-exploratoria & $\begin{array}{c}\text { Estudio empírico I } \\
\text { Estudio empírico II }\end{array}$ \\
\hline \multirow{2}{*}{$\begin{array}{c}\text { Cuantitativa } \\
\text { Empresa }\end{array}$} & $\begin{array}{c}\text { Estadística y configuracional- } \\
\text { Estudio empírico III }\end{array}$ & \begin{tabular}{c} 
Estudio empírico VI \\
\hline
\end{tabular} \\
\hline
\end{tabular}

A continuación se describe con mayor profundidad cada una de las dos fases de investigación propuestas.

\subsubsection{Fases de la investigación: fase descriptiva-cualitativa y fase cuantitativa}

\subsubsection{Fase descriptiva-cualitativa}

La primera fase de nuestra investigación tiene como objetivo el entendimiento en profundidad de los fenómenos de innovación disruptiva en el contexto de los clústeres industriales, así como en el análisis cualitativo de consecuencias que tienen sobre ellos. Se trata, en conclusión, de un objetivo doble. En primer lugar, hemos pretendido averiguar cuáles son los determinantes de las innovaciones disruptivas cuando éstas no son desarrolladas por empresas individuales en un contexto de industria general sino más bien, por un conjunto de actores interactuando en el contexto de un clúster industrial. En segundo término, hemos intentado determinar qué impacto -en términos cualitativos- producen estas innovaciones a nivel de clúster, es decir, qué trayectorias de evolución se pueden desarrollar en este contexto como consecuencia de estos fenómenos innovadores tan valiosos como extraños. 
Este objetivo es, en nuestra opinión, de gran importancia ya que, como la literatura ha descrito previamente -por ejemplo, Glasmeier, 1991 o Harrison, 1994-, los clústeres son especialmente poco proclives a experimentar cambios externos y radicales debido principalmente a la falta de capacidades de exploración y de análisis de conocimiento externo, así como a la prevalencia de vínculos fuertes que favorecen el desarrollo de innovaciones incrementales (Bellandi, 1996; Molina-Morales, 2002). En esta fase hemos planteado la realización de dos estudios cualitativos distintos (Estudio empírico I y Estudio empírico II) en ambos estudios nos hemos basado en la metodología del estudio del caso y hemos fijado el clúster como unidad de análisis.

En el primer estudio (Estudio empírico I), hemos realizado un análisis detallado del caso de introducción de un innovación tecnológica disruptiva (la impresión digital cerámica) acontecido en el clúster cerámico de Castellón. Nos proponemos analizar a través del estudio del caso, por tanto, cómo se ha generado esta innovación dentro del clúster, qué actores han intervenido, qué tipo de interacciones ha habido entre ellos y qué factores han favorecido su difusión dentro del mismo. En este mismo estudio, nos hemos planteado la necesidad de evaluar el impacto que este fenómeno ha tenido sobre el clúster como entidad o sistema, partiendo de las consecuencias que ha tenido sobre las distintas categorías de empresas presentes en el mismo.

En el segundo estudio (Estudio empírico II), planteamos la necesidad de determinar si el fenómeno estudiado en Castellón se trata de una caso excepcional y raro o si, por el contrario, las conclusiones obtenidas podrían ser generalizables a otros clústeres, al menos, de tipo industrial. En otras palabras, hemos determinado si es posible generalizar unas dinámicas innovadoras disruptivas características de los clústeres industriales, así como el efecto que éstas producen sobre los mismos. Para ello, hemos realizado un estudio comparativo de dos casos: (a) el caso de Castellón, y (b) otro caso similar experimentado en Italia, más concretamente en el clúster de calzado deportivo de Montebelluna. En este apartado no vamos a entrar en profundidad a describir este último caso ya que esto se realiza de forma extensa en el Estudio empírico II. Tan sólo recordaremos que, como hemos descrito en el capítulo introductorio, este fenómeno innovador disruptivo consistió en la sustitución de las pesadas botas de cuero utilizadas por los esquiadores por unas mucho más ligeras hechas completamente de plástico. Se trató de una innovación radical de producto basada, a su vez, en una innovación 
disruptiva de proceso (introducción de la tecnología de inyección del plástico). En efecto la nueva tecnología desarrollada, necesaria para fabricar las nuevas botas de plástico, estaba muy alejada de la tradicional en términos de uso de nuevos materiales y proceso de fabricación.

\subsubsection{Fase cuantitativa}

La segunda fase de nuestra investigación se ha planteado en base al objetivo de analizar los determinantes y el impacto tienen los fenómenos de innovación disruptiva, ya no a nivel de clúster, sino a nivel de las empresas que lo conforman. Cambiamos, por tanto, la unidad de análisis utilizada en la fase anterior para centrarnos en la empresa. El objetivo de esta fase consiste, de forma análoga al de la fase anterior, en un objetivo doble. En primer lugar, hemos planteado la necesidad de averiguar qué atributos de las empresas que integran un clúster favorecen la adopción temprana de las innovaciones tecnológicas disruptivas. En segundo término, pretendemos determinar si la adopción temprana de una innovación disruptiva favorece la innovación de las empresas del clúster. Trataremos de explorar, por tanto, qué caminos conducen a las empresas a ser altamente innovadoras y si éstos se ven condicionados por el hecho de adoptar una novedad antes que el resto o por otros atributos internos. Con estos objetivos, en esta fase nos planteamos la realización de dos estudios cuantitativos distintos basándonos en dos metodologías distintas (una de ellas cuantitativa y otra semicuantitativa) y fijando como unidad de análisis, la empresa.

Más concretamente, en el primer estudio de esta fase (Estudio empírico III), hemos establecido una correlación estadística entre aquellos atributos de las empresas que están relacionados con el desarrollo de capacidades innovadoras (principalmente las dimensiones de la capacidad de absorción) y su propensión a adoptar innovaciones disruptivas de forma temprana. En otras palabras, hemos determinado cómo influye la capacidad de absorción de las empresas sobre el hecho de que éstas adopten antes o después una innovación tecnológica disruptiva. De este modo, pretendíamos obtener un mejor entendimiento de los factores determinantes de la adopción de una tecnología disruptiva por parte de las empresas que integran un clúster industrial. 
Por último, en el segundo estudio de esta fase (Estudio empírico IV), nos hemos propuesto investigar cómo la adopción temprana de una innovación disruptiva contribuye sobre los resultados de innovación de un empresa cuando esta adopción se combina con otros atributos tales como la capacidad de absorción u otros recursos de innovación disponibles. Hemos tratado, en definitiva, de determinar el peso relativo que tiene, sobre el desarrollo de capacidades innovadoras generales, el hecho de introducir y asimilar una innovación muy alejada de las normalmente desarrolladas en un clúster a través de procesos incrementales. Para ello, hemos aplicado el principio de equifinalidad y un enfoque de análisis basado en la causalidad compleja (Meyer et al., 1993) y utilizaremos una técnica de análisis configuracional comparativa (semicuantitativa): el Análisis Comparativo Cualitativo (comúnmente conocido como QCA) (Eng \& Woodside, 2012; Rihoux \& Ragin, 2009).

Para finalizar este punto, a modo de resumen, en la Tabla 37, se presenta esquemáticamente la estructura del trabajo empírico correspondiente a la presente tesis: 
Tabla 37: Esquema general de la estructura del trabajo empírico correspondiente a la presente tesis

\begin{tabular}{|c|c|c|c|c|}
\hline Fase & $\begin{array}{l}\text { Unidad de } \\
\text { análisis }\end{array}$ & $\begin{array}{l}\text { Estudio } \\
\text { empírico }\end{array}$ & Objetivo específico del estudio & $\begin{array}{l}\text { Metodología } \\
\text { utilizada }\end{array}$ \\
\hline \multirow{2}{*}{$\begin{array}{l}\text { Descriptiva- } \\
\text { cualitativa }\end{array}$} & \multirow[t]{2}{*}{ Clúster } & $\begin{array}{l}\text { Estudio } \\
\text { empírico I }\end{array}$ & $\begin{array}{l}\text { Análisis en profundidad del fenómeno de innovación tecnológica disruptiva } \\
\text { experimentado por el clúster cerámico de Castellón; determinación de cómo se ha } \\
\text { generado, qué actores han intervenido y qué factores han favorecido su difusión; } \\
\text { evaluación de su impacto sobre el clúster como entidad. }\end{array}$ & Estudio del caso \\
\hline & & $\begin{array}{l}\text { Estudio } \\
\text { empírico II }\end{array}$ & $\begin{array}{l}\text { Determinación de la excepcionalidad del fenómeno estudiado en Castellón. Obtención } \\
\text { de unos parámetros generalizables de generación, difusión y efecto que las dinámicas } \\
\text { innovadoras disruptivas tienen en el contexto de los clústeres industriales. }\end{array}$ & $\begin{array}{l}\text { Estudio } \\
\text { comparativo del } \\
\text { caso }\end{array}$ \\
\hline \multirow[t]{2}{*}{ Cuantitativa } & \multirow[t]{2}{*}{ Empresa } & $\begin{array}{l}\text { Estudio } \\
\text { empírico III }\end{array}$ & $\begin{array}{l}\text { Análisis de los determinantes de adopción temprana de una tecnología disruptiva por } \\
\text { parte de las empresas que integran un clúster industrial: correlación entre las } \\
\text { capacidades innovadoras (principalmente las distintas dimensiones de la capacidad de } \\
\text { absorción) y la capacidad específica para adoptar innovaciones disruptivas de forma } \\
\text { temprana. }\end{array}$ & $\begin{array}{l}\text { Regresión logística } \\
\text { Binomial (LOGIT) }\end{array}$ \\
\hline & & $\begin{array}{l}\text { Estudio } \\
\text { empírico VI }\end{array}$ & $\begin{array}{l}\text { Estudio de la contribución que tiene la adopción temprana de una innovación disruptiva } \\
\text { (por ella misma o en combinación con otros atributos) en los resultados de innovación } \\
\text { de las empresas. }\end{array}$ & Fuzzy-sets QCA \\
\hline
\end{tabular}




\subsection{Fuentes de información y recolección de datos}

De forma general, podemos destacar el hecho de que se han utilizado tres fuentes de información primaria (observación participante, cuestionario y entrevistas) además de otras fuentes secundarias (que se describirán en el punto correspondiente). Su pormenorización detallada en relación con el uso en cada uno de los estudios empíricos llevados a cabo será realizada en la correspondiente sección de cada uno de los mismos (capítulos 5 y 6 de la tesis). No obstante, con el fin de favorecer la claridad expositiva, pasamos a resumir en un cuadro las fuentes de datos utilizadas en cada uno de los estudios empíricos (Tabla 38).

Tabla 38: Identificación de las fuentes de datos utilizadas en cada uno de los estudios empíricos realizados

\begin{tabular}{|c|c|c|}
\hline Estudio empírico & Naturaleza del estudio & Fuente de datos utilizadas \\
\hline Estudio empírico I & Cualitativa & $\begin{array}{l}\text { - Observación participante } \\
\text { - Entrevistas a actores relevantes } \\
\text { - Fuentes secundarias }\end{array}$ \\
\hline Estudio empírico II & Cualitativa & $\begin{array}{l}\text { - Observación participante } \\
\text { - Entrevistas a actores relevantes } \\
\text { - Fuentes secundarias }\end{array}$ \\
\hline Estudio empírico III & Cuantitativa & $\begin{array}{ll}\text { - } & \text { Cuestionario } \\
\text { - } & \text { Fuentes secundarias }\end{array}$ \\
\hline Estudio empírico VI & Semicuantitativa & $\begin{array}{ll}\text { - } & \text { Cuestionario } \\
\text { - } & \text { Fuentes secundarias }\end{array}$ \\
\hline
\end{tabular}

A continuación, nos centramos en describir de forma breve las distintas fuentes de datos expuestas. 


\subsubsection{Observación participante}

La observación participante permite a los investigadores obtener datos fiables de los fenómenos bajo estudio donde éstos de producen. Su carácter participativo va más allá de la mera observación por parte del investigador ya que éste también interactúa en las actividades objeto de estudio (Martínez, 2006). En nuestro caso, miembros del grupo de investigación han observado durante un largo periodo de tiempo, y también participado, el proceso de desarrollo y difusión de la innovación tecnológica (la impresión digital cerámica) en el clúster cerámico de Castellón. Hemos podido, por tanto, estar en contacto permanente con los actores más relevantes y protagonistas del cambio tecnológico producido. También hemos podido registrar las opiniones y testimonios de aquellos agentes que estuvieron directamente involucrados en el establecimiento, desarrollo y promoción de la tecnología de impresión digital inkjet, primero en el clúster de Castellón y posteriormente a nivel mundial.

De este modo, se ha podido observar y recopilar datos muy valiosos del fenómeno innovador desde una perspectiva interna (Mayring, 2002) y de acuerdo a lo que establece esta metodología: (a) en su situación natural; (b) en tiempo real; (c) con una situación preferente en el acceso a información relacionada con el fenómeno (Punch, 2013). En el apartado correspondiente de los Estudios empíricos I y II se describe con un mayor nivel de detalle cómo se llevó a cabo esta observación participante.

\subsubsection{Cuestionario realizado}

Esta investigación se ha basado también en otra fuente primaria de información. Datos relevantes sobre las características de las empresas y su relación con la innovación fueron recogidos a través de un cuestionario. Entre Octubre de 2016 y Febrero de 2018, se llevó a cabo una encuesta a través de la plataforma digital de encuestas Surveymonkey (www.surveymonkey.com). La encuesta se dirigió a un universo de 118 empresas finales (fabricantes de pavimentos y revestimientos cerámicos) que componían en ese momento el clúster cerámico de Castellón. Es precisamente este perfil de empresas (y no otro) las únicas susceptibles de adoptar la innovación en estudio. En efecto, a pesar de que el clúster está compuesto por varios tipos de empresas 
-como hemos descrito en el capítulo 3 de la tesis- únicamente las empresas productoras de pavimentos y revestimientos cerámicos pueden introducir la impresión digital en su proceso productivo. Por este motivo el número de empresas objetivo es sustancialmente menor al número de empresas que integran el clúster. En concreto, en el momento de realización del estudio (principalmente en los años 2017 y principios del 2018), las tres principales asociaciones del sector (ASCER, ANFFECC y ASEBEC) ${ }^{35}$ reunían a una población de 214 empresas distribuidas como se muestra en la Tabla 39:

Tabla 39: Número de empresas integrantes del clúster de Castellón en el momento de la realización de la investigación según datos de las tres principales asociaciones empresariales

\begin{tabular}{ccc}
\hline Categoría de empresa & Entorno al que pertenecen & $\begin{array}{c}\text { \# de } \\
\text { empresas }\end{array}$ \\
\hline $\begin{array}{c}\text { Fabricantes de pavimentos y } \\
\text { revestimientos cerámicos }\end{array}$ & Productivo & 118 \\
\hline Fabricantes de fritas, esmaltes, colores y & Tecnológico y de servicios & \multirow{2}{*}{ tintas digitales } \\
Fabricantes de maquinaria cerámica & Tecnológico y de servicios & \multirow{2}{*}{71} \\
\hline
\end{tabular}

Fuente: elaboración propia a partir de ASCER, ANFFECC y ASEBEC

Con el objeto de favorecer la participación de los responsables de las empresas, así como de realizar un seguimiento de su respuesta, se contrató a una empresa de campo especialista en el sector cerámico de Castellón. No obstante, en primer lugar, se envió una carta a través de la cuenta institucional del grupo de investigación AERT presentando el proyecto, garantizando el anonimato y ofreciendo la posibilidad de enviar un informe final de los resultados como agradecimiento de la participación. A partir de ese momento, la empresa de campo se dedicó a realizar el seguimiento de las respuestas obtenidas, así como a fomentar la participación mediante llamadas

\footnotetext{
${ }^{35}$ Datos obtenidos a través de las páginas web de estas asociaciones en una consulta realizada en Febrero de 2018. (www.ascer.es; www.annfecc.es; www.asebec.org)
} 
telefónicas. En todos los casos las respuestas fueron realizadas por miembros de las empresas a través de la plataforma digital en la que encuesta estaba alojada.

Finalmente se obtuvieron 88 cuestionarios completos, lo que representa un $75 \%$ del total. El cuestionario fue contestado, en la mayoría de los de los casos, por directores técnicos y directores de producción que son los que de forma lógica tienden a asumir la responsabilidad de implantación de un nuevo sistema de impresión que viene a sustituir al tradicional. Consideramos que estos perfiles son, por tanto, los más adecuados para contestar a nuestro cuestionario (véase Tabla 40).

Tabla 40: Perfil de los entrevistados

\section{Puesto}

$\%$ de respuestas

Gerente

$2 \%$

Director técnico

$67 \%$

Director de I+D $2 \%$

Director de producción $17 \%$

Director de Marketing y desarrollo de producto $7 \%$ Otros $7 \%$

En el apartado correspondiente de los Estudios empíricos III y VI se describe, con un mayor nivel de detalle, algunos aspectos más relevantes de este cuestionario.

\subsubsection{Entrevistas a actores relevantes}

Con el fin de poder realizar una triangulación de los datos obtenidos, se han llevado a cabo una serie de entrevistas como fuente de información primaria. Se han llevado a cabo alrededor de 50 entrevistas semiestructuradas a personas con distintos perfiles profesionales (directivos, responsables técnicos, responsables comerciales, etc.) los cuales estuvieron en contacto directo con el fenómeno. Además estos profesionales pertenecían a distintas categorías de empresas dentro del clúster; no se trataba únicamente de empresas dedicadas a la fabricación de pavimentos y revestimientos cerámicos. 
Cabe destacar que estas personas pertenecían tanto al clúster cerámico de Castellón (donde la innovación se desarrolló) como a otros clústeres cerámicos de otros lugares del mundo (donde se observaba con interés el fenómeno que se produjo en Castellón) e incluso a otras industrias no relacionadas con la cerámica pero estrechamente vinculadas a la tecnología que se estaba desarrollando (como por ejemplo, las industrias del sector de la inyección de tinta). El tipo de empresas entrevistadas, así como el perfil de los respondientes se puede observar en la Tabla 41:

Tabla 41: Perfil de las principales empresas y respondientes para la realización de la presente investigación

\begin{tabular}{|c|c|c|c|}
\hline & & & Porcentaje de \\
\hline Tipo de empresa & $\begin{array}{l}\text { las entrevistas } \\
\text { realizadas }\end{array}$ & $\begin{array}{l}\text { profesionales de los } \\
\text { respondientes }\end{array}$ & $\begin{array}{l}\text { las entrevistas } \\
\text { realizadas }\end{array}$ \\
\hline \multirow{4}{*}{ Empresas finales } & \multirow{4}{*}{$22 \%$} & $\mathrm{CEO}$ & $12 \%$ \\
\hline & & $\begin{array}{l}\text { Responsable de } \\
\text { Planta }\end{array}$ & $12 \%$ \\
\hline & & $\begin{array}{l}\text { Responsable de } \\
\text { unidad de negocio }\end{array}$ & $38 \%$ \\
\hline & & $\begin{array}{l}\text { Responsable de } \\
\text { desarrollo de } \\
\text { producto }\end{array}$ & $38 \%$ \\
\hline \multirow{4}{*}{$\begin{array}{l}\text { Empresas } \\
\text { especializadas }\end{array}$} & \multirow{4}{*}{$56 \%$} & CEO & $12 \%$ \\
\hline & & Responsable técnico & $31 \%$ \\
\hline & & $\begin{array}{l}\text { Responsable de } \\
\text { unidad de negocio }\end{array}$ & $44 \%$ \\
\hline & & Ingeniería & $13 \%$ \\
\hline \multirow{3}{*}{$\begin{array}{l}\text { Empresas no } \\
\text { pertenecientes a la } \\
\text { industria cerámica }\end{array}$} & \multirow{3}{*}{$22 \%$} & CEO & $20 \%$ \\
\hline & & $\begin{array}{l}\text { Responsable de } \\
\text { proyecto }\end{array}$ & $60 \%$ \\
\hline & & $\begin{array}{l}\text { Responsable de } \\
\text { unidad de negocio }\end{array}$ & $20 \%$ \\
\hline
\end{tabular}


En el apartado correspondiente de los Estudios empíricos I y II se describe con un mayor nivel de detalle las entrevistas llevadas a cabo para la realización de esta tesis.

\subsubsection{Fuentes secundarias}

Las tres fuentes principales de información anteriormente expuestas han sido complementadas con otras fuentes secundarias. Principalmente hemos recurrido a la base de datos SABI (Sistema de Análisis de Balances Ibéricos) la cual contiene información detallada de empresas en España y Portugal y cubre, entre muchos aspectos, la información financiera de empresas, sus indicadores de fortaleza financiera, así como sus estructuras corporativas. La información obtenida ha sido utilizada para caracterizar a las empresas en relación con determinados atributos como activos totales, ingresos totales o número de empleados.

También hemos utilizado otras fuentes secundarias como informes sectoriales llevados a cabo por asociaciones de empresas que pertenecen al clúster cerámico de Castellón (como ANFFECC o ASCER), informes técnicos de la industria digital -como Inkjet Report (2010)- u otros artículos académicos relacionados con el caso en estudio, como por ejemplo los trabajos de Hervás-Oliver \& Albors-Garrigos (2014) o Reig-Otero at al. (2014).

\subsection{Técnicas de análisis utilizadas}

Para la realización de la presente tesis hemos recurrido al uso de distintas técnicas de análisis. La variedad de objetivos planteada, la utilización de dos marcos de análisis distintos así como la distinta naturaleza de los análisis llevados a cabo (cualitativos en primer lugar y cuantitativos en segundo lugar) nos ha llevado a utilizar tres técnicas de análisis diferentes.

A continuación, nos centramos en presentar estas técnicas y resumirlas de forma breve ya que su descripción pormenorizada es realizada en la correspondiente sección de cada uno de los cuatro estudios empíricos. 


\section{Estudio del caso}

La primera técnica utilizada es la del estudio del caso. Se hace uso de ella en los Estudios I y II. Este método nos permite realizar un análisis exploratorio de un fenómeno en su propio contexto haciendo uso de una variedad de fuentes y datos tales como documentación, entrevistas (estructuradas o semiestructuradas), observaciones directas u observaciones participantes (Yin, 1989). Esto asegura que nuestros estudios abordan el fenómeno analizado desde diferentes puntos de vista y nos proporciona una comprensión holística del mismo. Con esta metodología podemos obtener información relevante de los protagonistas del fenómeno (o personas relacionadas) los cuales expresan sus propios puntos de vista. Esto nos permite comprender mejor los actos y las motivaciones de los mismos (Lather, 1992).

De forma más precisa, Yin (2003) clasifica los estudios de caso en explicativos, exploratorios y descriptivos. De acuerdo con esta taxonomía, el enfoque llevado a cabo en nuestros dos estudios empíricos puede considerarse como de carácter descriptivo, ya que describe un fenómeno, así como el contexto real en el que ocurre (Yin, 2011).

El estudio del caso ha sido ampliamente utilizado en la literatura de empresa, geografía economía, clústeres e innovación. Más concretamente, en la Figura 29 se muestra como esta metodología ha ido ganando protagonismo en la literatura de clúster durante los últimos años. 


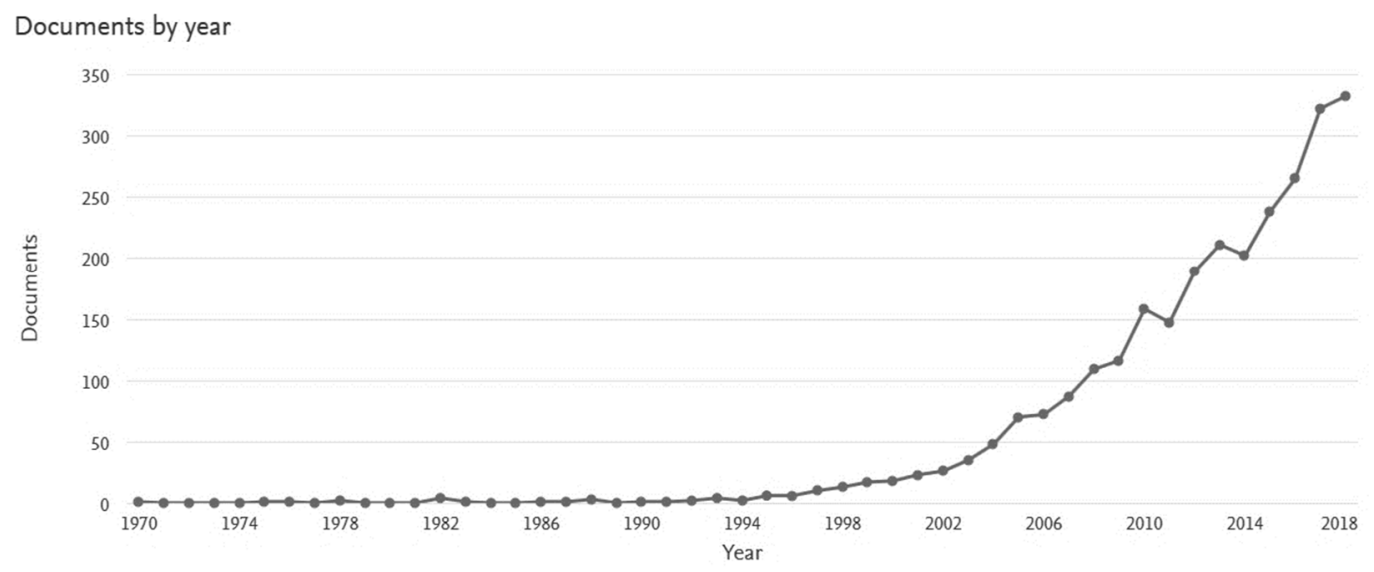

Figura 29: Número de publicaciones en las que se utiliza el estudio del caso en el ámbito del estudio del clúster Fuente: elaboración propia a partir de Scopus ${ }^{36}$

\section{Regresión Logística Binomial}

La técnica utilizada en el tercer estudio (Estudio III) es la Regresión Logística Binomial (LOGIT). Esta técnica es un tipo de regresión logística que tiene como objetivo comprobar hipótesis o relaciones causales cuando la variable dependiente es una variable binaria, es decir, de solo dos categorías (por ejemplo: 1-Sí, 0-No); estas variables también son conocidas como dummies o dicotómicas. Aunque su lectura e interpretación se asemeja a la regresión lineal múltiple (la cual es utilizada cuando la variable dependiente es ordinal o escalar), la regresión logística está basada en principios diferentes: los odd ratio y las probabilidades. De forma muy breve, este ajuste se basa en la idea de que las variables independientes tratan de predecir la probabilidad que ocurra algo sobre la probabilidad que no ocurra.

Aplicando esta idea a nuestra investigación -como se expone ampliamente en el Estudio empírico III- podemos decir que pretendemos analizar la probabilidad de que una empresa del clúster adopte de modo temprano la innovación disruptiva en base a una

\footnotetext{
${ }^{36}$ Estos datos han sido obtenidos en la base de datos Scopus (www.scopus.com) en Enero de 2019 a través de la búsqueda: ( TITLE-ABS-KEY ( case AND study)) AND (industrial AND cluster ) AND ( LIMIT-TO ( SUBJAREA, "SOCI" ) ) AND （ LIMIT-TO ( PUBSTAGE , "final" ) ) AND ( EXCLUDE ( PUBYEAR, 2020 )) AND (EXCLUDE ( PUBYEAR, 2019 ))
} 
serie de atributos. La adopción temprana es, por tanto, nuestra variable dependiente dicotómica mientras que los atributos (por ejemplo, las distintas dimensiones de la capacidad de absorción) son las variables independientes. La regresión logística binomial también ha sido ampliamente utilizada en los últimos años como técnica de análisis en el campo de las ciencias sociales. En la Figura 30 podemos observación la evolución de su uso en los últimos tiempos.

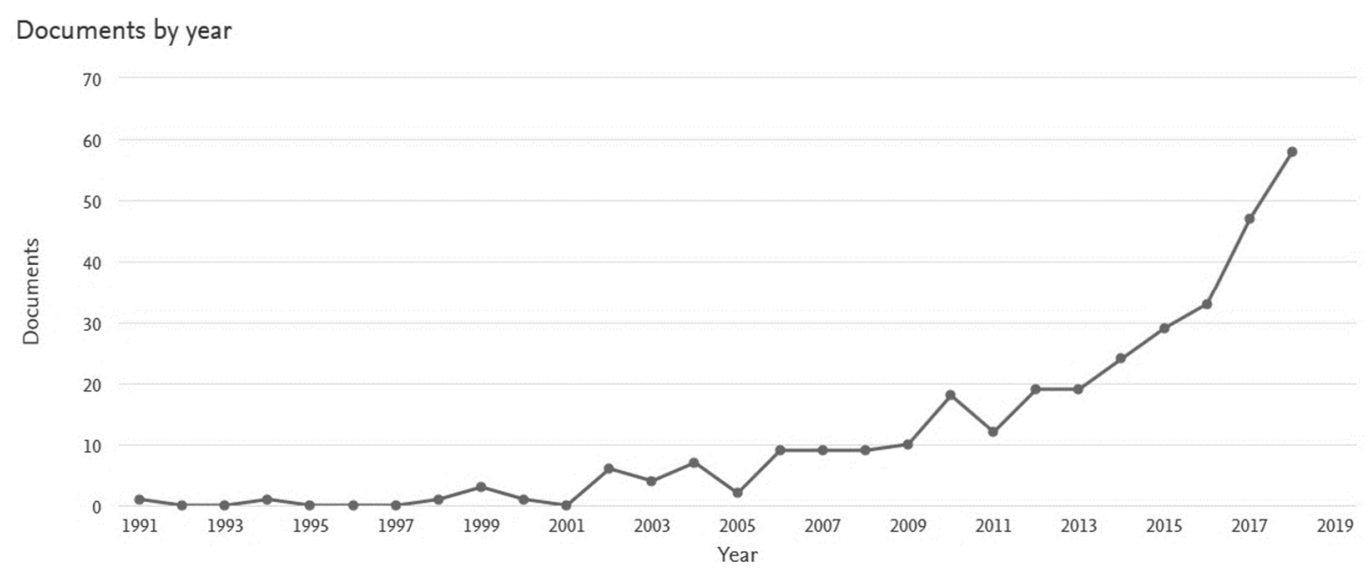

Figura 30: Número de publicaciones en las que se utiliza la regresión logística binomial en el ámbito de las ciencias sociales

Fuente: elaboración propia a partir de Scopus ${ }^{37}$

\section{Análisis Comparativo Cualitativo de Conjuntos Difusos (Fuzzy-sets QCA)}

Por último, la técnica utilizada para la realización del Estudio Empírico IV es el método configuracional comparativo (Fiss, 2007) denominado Análisis Comparativo Cualitativo de Conjuntos Difusos (o como se conoce por sus siglas en inglés Fuzzy-sets QCA). Los Métodos Comparativos Configuracionales son un conjunto de técnicas relativamente novedosas cuyo principio básico y fundamental es la comparación sistemática de casos (Ragin \& Becker, 1992). Bajo esta denominación podemos encontrar cuatro técnicas distintas: (a) Análisis Comparativo Cualitativo de Conjuntos

\footnotetext{
${ }^{37}$ Estos datos han sido obtenidos en la base de datos Scopus (www.scopus.com) en Enero de 2019 a través de la búsqueda: TITLE-ABS-KEY (binomial AND logistic AND regression) AND (EXCLUDE (PUBYEAR, 2019)) AND (LIMIT-TO (PUBSTAGE, "final")) AND (LIMIT-TO (SUBJAREA, "SOCI"))
} 
Definidos (o como se le conoce por sus siglas en inglés Crisp-sets QCA); (b) Análisis Comparativo Cualitativo de Conjuntos Difusos (o como se le conoce por sus siglas en inglés Fuzzy-sets QCA); (c) Análisis Comparativo Cualitativo Multivalor (o como se le conoce por sus siglas en inglés Multi-value QCA); y (d) Análisis Comparativo Cualitativo Más similar diferente resultado/ Más diferente, mismo resultado (o como se le conoce por sus siglas en inglés $M S D O / M D S O Q C A)$.

Como es bien sabido en las ciencias sociales, los casos que se analizan suelen ser intrínsecamente complejos, con múltiples facetas y con límites poco definidos (Rihoux \& Ragin, 2009). De este modo, este conjunto de técnicas ha sido desarrollado con el objetivo de aumentar las limitadas posibilidades de generalización que plantea el estudio del caso, así como de proporcionar a los investigadores una técnica más sistemática y formal con relación al estudio múltiple de casos. Estas metodologías se centran en la descomposición de los casos en configuraciones (combinaciones de factores, a los que se les llama condiciones) las cuales conducen al resultado que se pretende analizar (outcome). Los resultados obtenidos por estas técnicas son planteados en forma de condiciones de necesidad y suficiencia (Rihoux \& Ragin, 2009) como se expone ampliamente en el Estudio empírico IV de esta tesis. En definitiva usando técnicas QCA, el investigador puede combinar datos cualitativos y datos cuantitativos y analizarlos de forma conjunta, sistemática y analítica. Por este motivo, son consideradas como técnicas semicuantitativas o mixtas (Spitzlinger, 2010).

Uno de los conceptos básicos de sobre los que descansan las técnicas QCA, es la equifinalidad o causalidad coyuntural múltiple (Rihoux \& Ragin, 2009), la cual se caracteriza de modo resumido por:

- La causalidad es, en la mayor parte de los casos, una combinación de condiciones relevantes que desembocan en una resultado o outcome $(A B \rightarrow Y)$.

- La causalidad puede ser múltiple, es decir, un mismo resultado puede ser obtenido por una gran cantidad de combinaciones de condiciones $(A B \rightarrow Y$ ó $C D \rightarrow Y$ ).

- La causalidad se puede dar tanto en la presencia como en la ausencia de condiciones, es decir, puede existir un resultado que se produzca a través de una 
combinación de condiciones pero también a través de la ausencia de éstas $(A B \rightarrow Y \text { pero también } \sim A B C \rightarrow Y)^{38}$. En este ejemplo, [A] combinado con [B] conduce a que el resultado ocurra, pero éste también ocurre en ausencia de ambos cuando se combina con [C].

En otras palabras: existen diferentes caminos (o paths) causales -cada camino siendo relevante de forma distinta- que nos pueden conducir al mismo resultado (De Meur \& Rihoux, 2002). Esta consideración se refiere, por tanto, al concepto de equifinalidad.

En definitiva, esta metodología amplía el marco de análisis habitual de la causalidad relajando algunas de las asunciones tradicionales (Rihoux \& Ragin, 2009) como son:

- No se asume aditividad causal: esto significa que la idea de que cada caso tiene un impacto propio, independiente y aislado sobre un resultado es remplazada por la asunción de que se da una causalidad coyuntural, es decir, varias causas pueden estar presentes (solas o en combinación con otras) en la obtención de un determinado resultado. Se obtiene, por tanto, una combinación causal que nos conduce al resultado.

- Una combinación causal determinada puede no ser la única ruta hacia un resultado; se pueden dar otras combinaciones diferentes de causas que nos conduzcan al mismo resultado.

- La uniformidad de los efectos causales no se asume; más al contrario, una condición determinada, combinada con otras diferentes, puede en unas ocasiones favorecer un determinado resultado mientras que en otras, combinada de modo diferente, puede actuar de modo contrario.

- La causalidad no es asumida como simétrica, es decir, se asume la asimetría de la causalidad; esto significa que la presencia y la ausencia de un resultado no tiene por qué explicarse del mismo modo.

\footnotetext{
${ }^{38}$ Con el símbolo “ ” nos referimos a la ausencia de condición.
} 
De forma análoga, a lo realizado en la exposición de las dos técnicas anteriores, en la Figura 31 se muestra cómo la metodología QCA ha sido ampliamente utilizada en los últimos tiempos como técnica de análisis en el campo de las ciencias sociales.

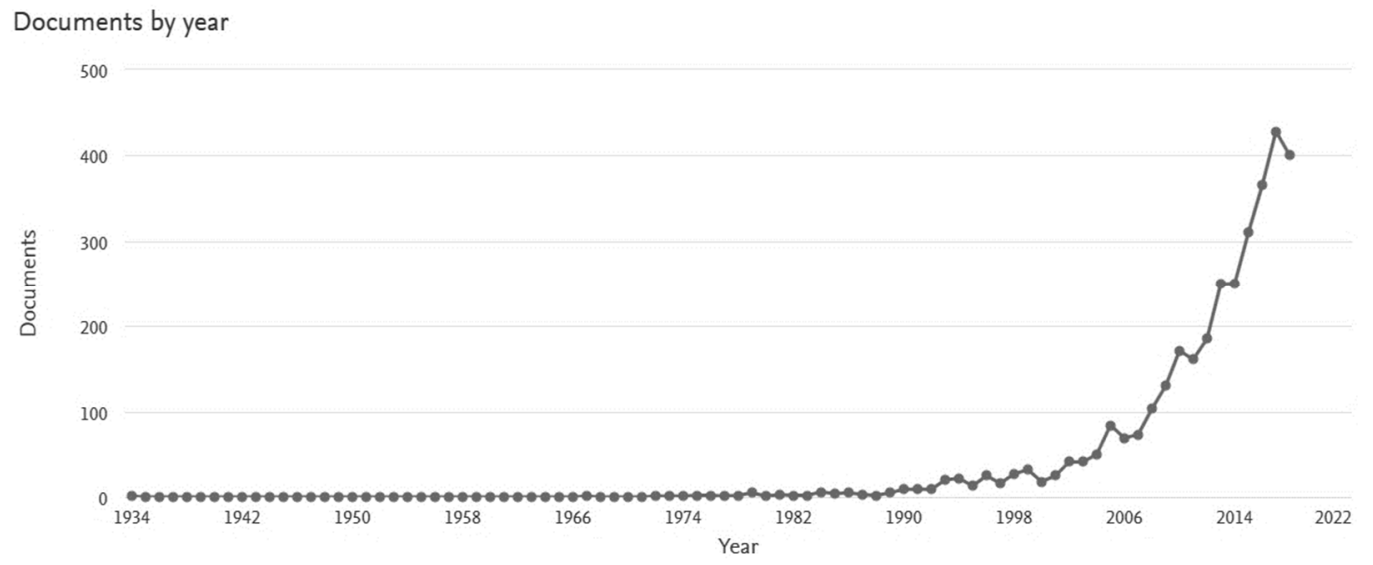

Figura 31: Número de publicaciones en las que se utiliza la regresión logística binomial en el ámbito de las ciencias sociales

Fuente: elaboración propia a partir de Scopus ${ }^{39}$

39 Estos datos han sido obtenidos en la base de datos Scopus (www.scopus.com) en Enero de 2019 a través de la búsqueda: TITLE-ABS-KEY (comparative AND qualitative AND analysis) AND (EXCLUDE (PUBYEAR, 2019)) AND (LIMIT-TO (SUBJAREA, "SOCI")) AND (LIMIT-TO (PUBSTAGE, "final")) 


\section{CAPÍTULO 5 \\ FASE DE INVESTIGACIÓN DESCRIPTIVO- CUALITATIVA}




\section{FASE DE INVESTIGACIÓN DESCRIPTIVO- CUALITATIVA}

Como se ha descrito en el capítulo anterior, esta primera fase de nuestra investigación tiene como objetivo el entendimiento en profundidad de los fenómenos de innovación disruptiva en el contexto de los clústeres industriales, así como en el análisis cualitativo de consecuencias que tienen sobre ellos. A continuación presentamos los dos estudios empíricos que componen esta fase. 


\subsection{Empirical Study I: Determinants and impact of disruptive technological innovations in industrial clusters. The case of the digital printing disruptive innovation in the Spanish ceramic tile cluster ${ }^{40}$}

\subsubsection{Introduction}

In the last decades, radical or disruptive innovations have received increasing attention from various authors (Charitou \& Markides, 2002; Christensen, 1997; Tellis, 2006). Unlike incremental innovations, radical innovations generate important transformations in products, markets or technologies, leading even to the obsolescence of existing ones (Chandy \& Tellis, 2000). In this work, we analyse the territorial dimension of these discontinuities, adopting the concept of cluster as a frame of reference (Becattini, 1979; Porter, 1990). It is important to point out that we consider a cluster as a network within a production context in a geographically defined area (Boschma \& Ter Wal, 2007; Parrilli \& Sacchetti, 2008). Most clusters are characterized by the prevalence of small firms, which have comparatively greater access to external knowledge resources than firms in other contexts. This fact is relevant since it can become an important source of innovation for cluster's firms.

However, the capacity of an agglomeration to create and develop disruptive innovations has been widely questioned for a long time by different authors in cluster literature. The literature developed by these authors argues that the dynamics of clusters seem to be much more appropriate for the generation and development of incremental or contextual innovations, to the detriment of radical or disruptive ones (Maskell, 2001). On the one hand, the proximity between companies, which facilitates the frequency of contacts and,

\footnotetext{
${ }^{40}$ Este estudio corresponde a una versión pre-print de un artículo que ha sido ya publicado en la revista Investigaciones Regionales (ISSN: 1695-7253) cuya cita es: Molina-Morales, Martínez-Cháfer, \& Valiente-Bordanova (2017). Disruptive technological innovations as new opportunities for mature industrial clusters. the case of digital printing innovation in the spanish ceramic tile cluster. $\begin{array}{lllll}\text { Investigaciones } & \text { Regionales, } & \text { (39), } & \text { 39-57. } & \text { Retrieved }\end{array}$ https://search.proquest.com/docview/1980712219?accountid=15297
} 
on the other hand, the proximity between the actors, leads to the formation of a dense network structure, as well as strong relationships among the different actors. These characteristics often hinder the diffusion of new ideas as well as exclusive or more radical innovations (Molina-Morales, 2002).

In order to overcome the aforementioned limitations regarding generation of radical advances, many authors defend the need to open the cluster to external sources of knowledge (Belussi, Sammarra \& Sedita, 2008). In that sense, authors as Sammarra (2005) or Biggiero (2006), proposed a selective relocation of certain activities out from the cluster. Other authors, such as Giuliani (2011), have focused on the role played by technological gatekeepers in providing new ideas, knowledge or technologies which are subsequently developed and disseminated within the cluster.

The foregoing reflections and considerations have motivated our investigation. As far as we know, authors who have focused their approaches in the context of the cluster have rarely analysed the process leading to the generation and diffusion of disruptive innovations. These authors have typically focused on descriptions of the main actors, as well as their connections and other related issues. Our approach tries to go one step further and aims to focus on how clusters can achieve the development and diffusion of disruptive innovations which are able to reshape both the internal and external relationships in them. With this aim, this work focuses on analysing the appearance of disruptive technological innovation (Markides, 2006), in the heart of the Spanish ceramic tile cluster. We refer to the so-called digital printing technology or inkjet technology. We will use this case to illustrate how this cluster has been able to capture a new technology coming from abroad and later, to develop it internally, adapting it to the cluster idiosyncrasy and even spreading the adapted technology successfully beyond its boundaries.

Finally, our study shows how the deep knowledge acquired by key players in the cluster, as well as the new skills they developed, provide them with new competencies that can be used in other industrial sectors. In fact, the new technology has created many diversification opportunities for those companies which realized their potential and successfully transferred this knowledge to other industrial fields similar to the ceramic one. 


\subsubsection{Specific theoretical framework}

\subsubsection{Disruptive innovations}

Nowadays, companies and organizations are constantly struggling to create and introduce product, process and service innovations in the markets (Bayus, Griffin \& Lehmann, 1998). In fact, a company's innovation capacity has probably become one of the best indicators of value creation for the company (Tsai \& Ghoshal, 1998). In the context of our research, we consider the distinction between incremental and disruptive innovations to be particularly relevant.

The first approach to the generic concept of disruptive innovation is due to the Schumpeterian notion of creative destruction (Schumpeter, 1942). Later, the differentiation between the concepts of incremental and disruptive innovation was introduced by Abernathy y Utterback (1978) and by Abernathy \& Clark (1985). Unlike incremental innovations, disruptions produce fundamental changes, revolutions in technology, clearly diverging from existing practices (Ettlie, 1983; Ettlie et al., 1984). These innovations are important ways of expanding and developing new markets, as well as providing new functionalities which, in turn, radically change the existing links of the market. It leads to the obsolescence of not only products but also technological and market capacities (Bower \& Christensen, 1996; Christensen \& Raynor, 2003; Danneels, 2004). As the interest of researchers increased, this concept has widened its scope to encompass different types of innovation. Currently, under the term disruptive innovation we will find business model innovations, radical product innovations or technological ones (Markides, 2006). The concept of disruption in the innovation literature has emerged recently as something strategically important (Assink, 2006; Charitou \& Markides, 2002; Gilbert, 2003; Govindarajan \& Kopalle, 2006; Henderson \& Clark, 1990). 


\subsubsection{Creation and diffusion of innovations in cluster contexts}

Clusters present peculiar dynamics regarding the generation and development of innovations. Most of the literature describes how the fact of belonging to a cluster generates a positive effect that catalyses the innovation of those companies who belong to it (Inkpen \& Tsang, 2005; Tallman, Jenkins, Henry, \& Pinch, 2004). However, as it has been proposed in other different researches, these companies need to combine the close and intense relationships, naturally generated in the cluster, with distant and outof-the-cluster ones in order to access to global sources of knowledge (Corò \& Grandinetti, 1999).

In the attempt of describing the inter-organizational relationships within industrial clusters, the metaphor of the network has been widely used; in this, physical proximity and sense of belonging are key elements that facilitate trust, reciprocity and other common values (Antonelli, 2000). From a relational perspective, the cluster is described as a cohesive and dense network made up of strong contacts. As a result, companies can potentially benefit from a certain efficiency when exploiting the opportunities that have arisen through the exchange of high-quality information, tacit knowledge and cooperative exchange.

On the contrary, following the same logic, the companies in the cluster may have problems to access to new and unique information. For example, Glasmeier (1991) in terms similar to those of Harrison (1994), described how Swiss watchmakers presented weaknesses in responding to disruptive technological changes from outside the district; and thus generated a competitive disadvantage.

In a way, the above argument is controversial, since there are many counterexamples that describe how industrial clusters are able to access new opportunities. In fact, other cases show that the existence of these industrial concentrations benefits the companies that integrate them both in relation to exploitation and exploration advantages. Saxenian (1991), for instance, found out that, in the rapidly changing environment of the information technology industry, especially in Silicon Valley, firms had abandoned the large number of distant relationships with suppliers to establish instead a small and selected number of relationships nearby. 


\subsubsection{Specific empirical framework}

\subsubsection{Context of the research}

The present study focuses its research context in the ceramic industry and more specifically in the Spanish ceramic tile cluster. On the other hand, it is based on the analysis of the digital printing technology introduction in the cluster that could be considered as a disruptive technological innovation as we will expose subsequently.

\section{The ceramic industry and the Spanish ceramic tile cluster}

In general terms, the manufacturing tile companies are grouped worldwide in the form of clusters or industrial districts. The ceramic tile industry is considered as a highly dynamic and competitive industry where technological advances, focused mainly on processes and products, are frequent (Russo, 1985). The result is an agile sector which is continuously moving towards high-technical and aesthetical products, quality excellence, efficiency and processes optimization. The strategy of this industry is mainly based on the reduction of energy consumption and environmental impact, the increase of flexibility and reduction of the productive cycle (Budí-Orduña, 2008). This ceramic sector is also characterized by its intensity in terms of knowledge transmission. Mechanisms such as the constant creation of companies, the mobility of human resources and an informal channel of communication among the members of the cluster community are the basis of this characteristic (Molina-Morales, 2002).

The Spanish ceramic tile cluster is located in the province of Castellón and covers all activities of the ceramic industry value chain. Previous research has identified this territorial grouping as the paradigm of an Marshallian-type industrial cluster (Boix, 2009). This industry includes, on the one hand, the end-product companies - which are engaged in the production of pavements and ceramic tiles - and, on the other hand, a wide range of companies engaged in related secondary activities, such as, distribution of raw materials, manufacturing of frits and enamels, development of chemical additives, manufacturing of machinery, or other services such as, trading services. In addition, this 
cluster includes a number of public and private institutions as well as a set of organizations and associations that provide technical, logistic and knowledge support. Finally, R\&D centres, the local university, local vocational training centres, business associations and trading companies also support and guide production companies towards business excellence and continuous improvement. This cluster produced in 2016 the $94 \%$ of the total of the ceramic tiles manufactured in Spain. The $80 \%$ of Spanish ceramic tile companies are located in this area

(ASCER, 2016). It is composed of about 100 end-product companies and over 1000 related-companies that are performing secondary activities. The business volume achieved in 2016 reached 4800 million of euros (ANFFECC, 2016; ASCER, 2016).

Focusing exclusively on the end-product companies, its annual production volume has reached in 2016 the 492 million of square meters. They generated in 2016 a turnover of 3,316 million of euros. These companies export the $80 \%$ of the total sales volume. The Spanish ceramic tile cluster is the first producer and exporter in Europe and the second exporter in the world. Finally, the Spanish ceramic tile industry is considered the third contributor sector to surplus of the Spanish coffers (ASCER, 2016).

In order to contextualize the innovation in the period [2000-2016], Tabla 42 and Figura 32 show the evolution of the cluster from a business point of view performed by the end-product manufacturers and by the frits, enamels and digital ceramic inks manufacturers (which are the main secondary industry of the cluster itself). In this respect we must emphasize that innovation was widely introduced in the cluster around 2009-2010. Unfortunately, we are not able to directly infer that the change of trend in the evolution of the business was exclusively due to this fact. 
Tabla 42: Evolution of sales of ceramic tiles manufacturers and frits, enamels and digital ink manufacturers in Mill $€$

\begin{tabular}{|c|c|c|c|c|c|c|c|}
\hline \multicolumn{4}{|c|}{$\begin{array}{l}\text { TOTAL SALES OF CERAMIC TILE } \\
\text { COMPANIES }\end{array}$} & \multicolumn{4}{|c|}{$\begin{array}{l}\text { TOTAL SALES OF FRITS AND } \\
\text { DIGITAL INKS COMPANIES }\end{array}$} \\
\hline & $\begin{array}{l}\text { Total } \\
\text { sales }\end{array}$ & $\begin{array}{l}\text { Exporting } \\
\text { sales }\end{array}$ & $\begin{array}{l}\text { Domestic } \\
\text { sales }\end{array}$ & & $\begin{array}{l}\text { Total } \\
\text { sales }\end{array}$ & $\begin{array}{l}\text { Exporting } \\
\text { sales }\end{array}$ & $\begin{array}{l}\text { Domestic } \\
\text { sales }\end{array}$ \\
\hline 2000 & $3.137,50$ & $1.872,10$ & $1.265,40$ & 2000 & 726,20 & 376,50 & 349,70 \\
\hline 2001 & $3.302,50$ & $1.987,80$ & $1.314,70$ & 2001 & 789,30 & 405,80 & 383,50 \\
\hline 2002 & $3.420,10$ & $2.059,30$ & $1.360,80$ & 2002 & 835,90 & 458,00 & 377,90 \\
\hline 2003 & $3.317,50$ & $1.939,10$ & $1.378,40$ & 2003 & 860,00 & 483,00 & 377,00 \\
\hline 2004 & $3.477,00$ & $1.977,30$ & $1.499,70$ & 2004 & 885,00 & 505,00 & 380,00 \\
\hline 2005 & $3.650,20$ & $2.040,90$ & $1.609,30$ & 2005 & 911,00 & 532,00 & 379,00 \\
\hline 2006 & $3.982,20$ & $2.183,10$ & $1.799,10$ & 2006 & $1.033,10$ & 602,00 & 431,10 \\
\hline 2007 & $4.166,00$ & $2.295,00$ & $1.871,00$ & 2007 & $1.097,50$ & 641,00 & 456,50 \\
\hline 2008 & $3.671,00$ & $2.210,00$ & $1.460,00$ & 2008 & $1.087,60$ & 700,27 & 387,33 \\
\hline 2009 & $2.591,00$ & $1.673,00$ & 918,00 & 2009 & 794,02 & 529,57 & 264,45 \\
\hline 2010 & $2.547,00$ & $1.746,00$ & 801,00 & 2010 & 976,98 & 640,79 & 336,19 \\
\hline 2011 & $2.597,00$ & $1.892,00$ & 705,00 & 2011 & $1.065,73$ & 733,27 & 332,46 \\
\hline 2012 & $2.656,00$ & $2.082,00$ & 575,00 & 2012 & $1.109,36$ & 768,55 & 354,75 \\
\hline 2013 & $2.800,00$ & $2.240,00$ & 560,00 & 2013 & $1.159,32$ & 792,10 & 367,21 \\
\hline 2014 & $2.900,00$ & $2.328,00$ & 575,00 & 2014 & $1.202,16$ & 845,62 & 356,53 \\
\hline 2015 & $3.095,00$ & $2.452,00$ & 643,00 & 2015 & $1.194,79$ & 853,77 & 341,02 \\
\hline 2016 & $3.316,00$ & $2.570,00$ & 746,00 & 2016 & $1.203,23$ & 843,02 & 360,22 \\
\hline
\end{tabular}

Source: elaborated by authors from ASCER (2016) and ANFFECC (2016) 


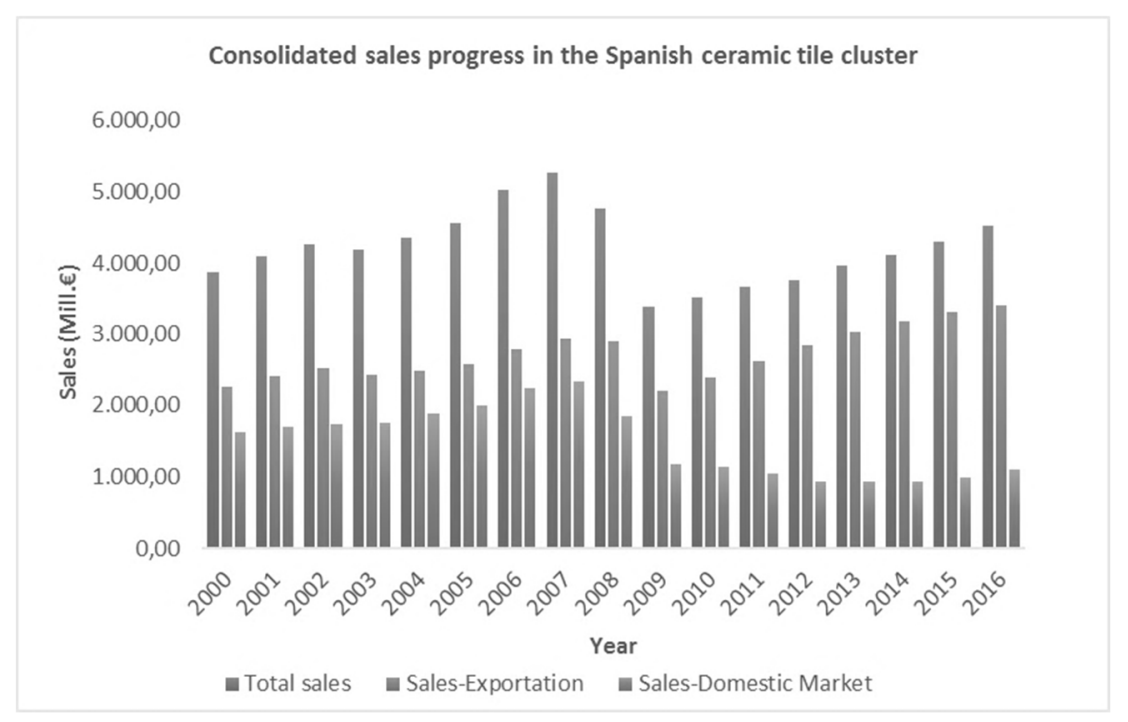

Figura 32: Consolidated sales of ceramic tiles manufacturers and frits, enamels and digital ink manufacturers

Source: elaborated by authors from ASCER (2016) and ANFFECC (2016)

\section{How new technology impacts on ceramic tile manufacturing process}

The disruptive technological innovation described in the present research is based on the introduction of digital printing technology (inkjet technology) as a new technique of tile decoration. In general terms, the ceramic tile manufacturing process consists of seven basic stages (see Figura 33).

In this context, it is important to highlight that decoration stage, in the ceramic industry, is one of the most relevant in the business value chain. In fact, decoration is the most important way to differentiate from competitors and to take position in the market. In addition, a significant part of the total manufacturing cost belongs to decoration. It is estimated that decoration cost constitutes from $30 \%$ to $50 \%$ of the total direct manufacturing cost. 


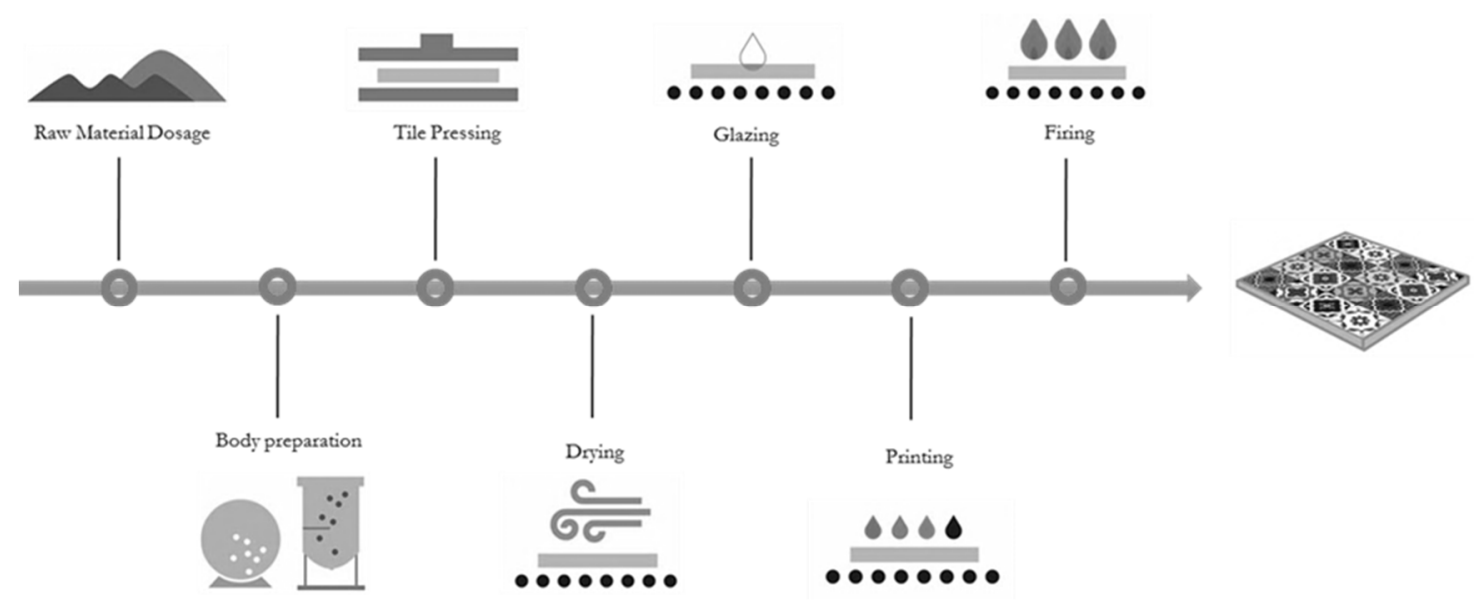

Figura 33: Ceramic tile manufacturing process

Source: elaborated by authors

Furthermore, decoration of tiles involves providing them with design and colour by means of a printing technique. For decades, this procedure has been carried out by the screen-printing technique. The screen-printing technique is a fully mechanical process which is performed by manual adjustments and therefore, it is rigid, inefficient and irreproducible.

\subsubsection{Data source}

\section{Participant observation}

We understand participant observation as the process that empowers researchers to learn about the activities which are being studied in their natural setting through observation and participating in their activities (Martínez, 2006). In our case, members of the research group have participated for a long period of time in the phenomenon under study being in permanent contact with the most relevant actors of the technological change. Moreover, they have participated actively in the development and diffusion of such change. Our research has benefited from the fact that one of the researchers has developed part of his professional career in one of the leading companies of the Spanish ceramic tile cluster. As a technical manager, taking responsibility of an applied digital inks research department, this author has collaborated in the development of the new 
technology through his investigations, obtaining information from the phenomenon under study from an internal perspective (Mayring, 2002). In this way, we have been able to observe the phenomenon: (a) in its natural situation; (b) in real time; (c) with a preferential situation to access to information related to the phenomenon (Punch, 2013).

From 2002 to 2016, we received the impressions and testimonies of those agents who were directly involved in the establishment, development and promotion of inkjet technology worldwide. We observed from a preferential position the impact that this new technology produced in the value chain of the ceramic tile industry, not only in Spain but also in other countries such as Italy, Brazil, China or India. On the other hand, we had the possibility of having a constant and durable contact with companies and actors in diverse countries such as Chile, Thailand, Portugal, Italy or Canada which, despite the fact of not being industries linked with ceramic manufacturing, they have been connected in some way with digital printing.

\section{Interviews and other secondary sources}

In order to understand and analyse the most relevant aspects of the present study, we have used triangulation techniques (a combination of different methods and data sources). We have conducted numerous interviews (around 50) with actors that have different professional profiles such as company managers, technical managers, commercial managers and manufacturing line managers or laboratory technicians. The interviews were carried out both for members of the Spanish ceramic tile cluster and members of other ceramic tile clusters in different places around the world. We had the opportunity to meet with other relevant figures as well which, not belonging to the ceramic tile industry, are directly linked to the innovation under study. The companies or organizations interviewed are listed below:

- New technology suppliers (digital ceramic printer manufacturers).

- New material suppliers (digital ceramic ink manufacturers). 
- Digital components suppliers (electronic components manufacturers for digital printing which belong to different inkjet clusters such as the Japanese or the English inkjet clusters).

- Chemical products suppliers. These components are part of the digital ceramic inks (solvents and additives suppliers).

- Tile manufacturers. These companies used the old printing technology and have assimilated the new technology over the time.

- Companies from diverse industries which adopted the new technology in recent past.

- Companies from diverse industries that were about adopting the new technology. These companies were willing to benefit from the ceramic sector experience in order to rapidly introduce the innovation in their respective sectors.

- Technological institutes, not only those which belong to the ceramic field but also those belonging to other sectors such as textiles, plastics or building materials where digital printing had already been introduced or were about to.

We performed semi-structured interviews where the information obtained was recorded and analysed in order to get a global overview about how, from different points of view (technical and business), the changes in the value chain of the ceramic tile industry were being developed. Along with this constant and close source of knowledge, data and information were also collected from a variety of secondary sources such as internal industry documents or reports, academic publications and well-informed opinions describing the inkjet phenomenon in all its magnitude. 


\subsubsection{Analysis method}

Our research is based on a case study as a method of analysis. This method allows us to explore the phenomenon in its own context making use of a variety of sources and data. The data comes largely from documentation, interviews, direct observations, participant observation and contacts (Yin, 1989). This ensures that our research addresses the phenomenon from different points of view and provides a holistic understanding of it. Through these stories, participants have expressed their own points of view and this has allowed researchers to better understand the actions of the participants (Lather, 1992).

Yin (2003) classifies case studies in explanatory, exploratory, and descriptive. According to this classification, our approach can be categorized as a descriptive case study as it describes a phenomenon as well as the actual context in which it occurs (Yin, 2003).

This approach has allowed us to know how and why this technology has become in one of the most important sources of innovation in recent decades in the ceramic tile industry.

\subsubsection{Results of the study}

\subsubsection{Description of the disruptive technological innovation: digital printing as a revolutionary way of decorating ceramic tiles.}

We consider the innovation under study as disruptive because it radically changes the way in which the tiles are printed. Tile printing technology shifts from a mechanical technique to a non-contact and digital one. The new printing system (which may be comparable to a home paper printer) is mainly based on software which process images and a digital inkjet system that shoots the ceramic dye on the tile. The basis of the innovation lies in the substitution of a mechanical and non-reproducible technique by a digital one considering everything that the digital term means. 
The origin of this new technology goes back to 1998, when a Spanish computer engineer- whom we could consider a visionary agent- designed and developed a digital tile printing prototype based on a printhead technology which was previously developed in inkjet clusters both from England and Japan. Later, this computer engineer founded Kerajet, a company that nowadays is the world leader in its sector (Albors-Garrigós \& Hervás-Oliver, 2013). Since the launch of the first digital printer in 2000, tile digital printing has undergone a series of further developments and improvements have been continuous. In fact, the massive adoption of the technology did not take place immediately after the innovation's emergence. A period of eight years elapsed before a real and effective diffusion of technology. In fact, it is estimated that in the period comprising 2000 and 2010, just around 100 printing machines were installed worldwide, while from 2010 to 2015 the number of machines installed reached approximately the figure of 6,500 (Ferrari, 2016).

It was on the first aforementioned period -more specifically between the years 2000 and 2008- when the innovation appeared and evolved up to the point of being considered as a robust technique, competitive and efficient enough to be massively adopted by the ceramic tile industry worldwide. At this early stage of development, three key factors can be considered as responsible for the innovation's success. These three factors can be summarized as follows:

- The initial resistance to change shown by some of the traditional technological leaders was counteracted by the emergence of new actors associated with emerging technology. They were led by the visionary agent who developed the technology in a first place. We are referring to digital ceramic printer manufacturers (led by the aforementioned company called Kerajet) and to digital ceramic ink manufacturers, who quickly developed new skills and specific knowledge related to inkjet technology. Indeed, in the early stages, Italian machinery companies - which were technological leaders at that moment- were very reluctant to adopt the innovation. They faced this threat trying to improve their own leading technology in an effort to persist in a technological environment much more controllable by them.

- The new players, who already had very strong ties within the ceramic tile cluster, because they were members of it, were able to develop new ties with 
diverse external agents to the ceramic sector. This fact was, from a strategic point of view, a key point in the stage of consolidation for the new technology. Key external agents included printhead manufacturers, colour management software developers, microelectronics manufacturers or manufacturers of ultrafine grinding systems.

- From a technical point of view, during this period, new technology improved and became feasible enough to be introduced as a reliable substitute of the traditional ceramic decorating process. These advances were crucial for the massive adoption of the technology. They were mainly focused on two fields:

- Printhead technology: printhead manufacturers early realized that the ceramic sector had a big potential in terms of business and decided to adapt their printheads to those new ceramics materials which were not printed before. They modified the printhead design to be more reliable and to increase the printing quality.

- Digital ceramic ink technology: ink formulations evolved from waterbased soluble inks to oil based-pigment dispersion inks. This fact led to a reduction in the cost of the inks as well as to an increase of their reliability. Besides, chromatic possibilities were widened as pigments offer a wider colour variety. In conclusion aesthetic possibilities were extended at a lower cost.

In summary, on the early stage of the innovation, some key factors led to the consolidation of the digital tile printing technology making the innovation into a success story. In fact, data in Tabla 43 shows the successful evolution of the conversion rate to the new technology in the world ceramic tile industry (number of decorative digital lines installed relative to existing decorative lines, digital and traditional). By 2015, the $72 \%$ of the world's decoration lines were digital (Ferrari, 2016). 
Tabla 43: Evolution of decorative lines conversion rate to digital technology. Number of digital printers installed over the last five years

\begin{tabular}{lcccccc}
\hline & $\mathbf{2 0 1 0}$ & $\mathbf{2 0 1 1}$ & $\mathbf{2 0 1 2}$ & $\mathbf{2 0 1 3}$ & $\mathbf{2 0 1 4}$ & $\mathbf{2 0 1 5}$ \\
\hline $\begin{array}{l}\text { Digital printers installed yearly } \\
\begin{array}{l}\text { Total number of digital printers in } \\
\text { operation. }\end{array}\end{array}$ & - & 397 & 951 & 2.049 & 1.537 & 1.216 \\
$\begin{array}{l}\text { Conversion rate to new technology } \\
\begin{array}{l}\text { Total number of estimated decorative } \\
\text { lines }\end{array}\end{array}$ & $5 \%$ & 730 & 1.681 & 3.730 & 5.267 & 6.483 \\
\hline
\end{tabular}

Source: elaborated by authors from Ferrari (2016).

\subsubsection{Main consequences of innovation}

Although, in a first approximation, this technological innovation may seem subtle or minor (it is simply a matter of evolving from analogue to digital), when analysing the consequences that derive from it, we can talk about a successful case. In fact, this innovation modifies and improves in a great extent different aspect of the ceramic tile industry, beyond the simple technical considerations.

The changes that digital printing has produced in the ceramic industry can be divided into: (a) sectorial leadership; (b) production process; (c) competitiveness and (d) product portfolio.

In terms of sectorial leadership, as we have introduced in the previous section, technological leaders faced innovation in different ways. This fact led to a major shift in leadership positions within the cluster. While some leaders - Italian machinery manufacturers - lost their dominant position, other actors -the Spanish manufacturers of frits and enamels- followed with interest the innovation since its appearance. As soon as they perceived the new opportunity that was coming up, they design a strong plan of investment focussed in $R \& D$ in order to adapt their business to the new technology. As a result, Spanish manufacturers of frits and enamels became the main producers of ceramic inks to supply the new printers. They soon created new and successful business 
units, achieving a stronger position and consolidating a technological leadership that still continues today. In relation with cluster roles, the case study shows how some actors that we could consider as gatekeepers, due to fact that they behave as focal agents that mobilize the knowledge in the clusters (Agrawal \& Cockburn, 2003), lost this intermediation role being replaced by a series of new technological leaders (among them the computer engineer who acted as a visionary agent of the new technology). This case reinforces the thesis of some authors who express the difficulty that the traditional gatekeepers have to introduce real new knowledge in the cluster (MolinaMorales, 2002). Regarding the manufacturing process benefits, the innovation has completely changed the layout of the printing lines as well as the manufacturing speed. The Inkjet technology allows not only to shorten the space required for the printing stage but also to increase the celerity of the manufacturing process.

Furthermore, and in relation with competitiveness aspects, the innovation has improved the efficiency of the printing process allowing to increase the average manufacturing quality and to reduce most of the costs associated with the decoration process. In fact, one of the major consequences on this point is the gap reduction between high-quality and low-quality producers. In fact, the new decorative technique stabilizes the quality making it more regular. It is precisely this point, which has led to a transversal adoption of the innovation by every single category of ceramic tile manufacturer, both those dedicated to low-cost product and those who bet on a differentiated high-end product.

On the other hand, the introduction of the digital printing, has reduced the threshold for an economy of scale as far as manufacture of short lots doesn't increase manufacturing costs significantly. In fact, costs associated to traditional ceramic tile decoration are relatively higher than those associated to digital even for large production lots. We are considering costs associated to wastes, the defective finished products (which are undeniably linked to traditional printing technology) and fruitless time consumption due to a continuous need of re-adjustment of the traditional machinery to avoid manufacturing defects (line breaks and workforce requirements). Digital decoration reduces these costs to virtually zero which makes it a much more competitive technology.

Finally, in terms of product portfolio, the digital printing technology has, somehow, opened new opportunities. The industry perceives now as feasible what was thought to 
be impossible with the traditional technique. Large tile formats, a wide variety of designs and a new and broad range of colours are the main elements that have favoured the expansion of the company portfolios.

\subsubsection{Implications of the innovation in the basic strategic lines of the companies and} the consequences on the overall strategy of the Spanish ceramic tile cluster

The consequences regarding the adoption of the digital printing technology have a twolevel impact on business strategy. On the one hand, there is an impact on basic business strategy for cluster firms but on the other hand, there is an impact on the overall strategy of the Spanish ceramic tile cluster.

\section{Impact on companies' basic business strategies}

As a result of our research, we may conclude that the disruptive technology allows ceramic tile companies to concurrently address the two basic strategies: product differentiation and cost reduction. Under this new perspective, companies can reconsider their strategic choice, since they can opt for new competitive positions. In accordance with the main strategic options proposed by Porter (1985), we can classify the main changes derived from the appearance of the digital printing technology based on the impact in terms of product differentiation or cost leadership.

Regarding product differentiation, it is important to emphasize that, as described above, the new technology enhance the aesthetic properties of the manufactured products, as well as the product portfolios offered by the companies. Both the design performance and the development of new products have benefited enormously from this technological change.

There are a variety of examples that could be used to explain the effect produced by the innovation on product differentiation. Tile formats, for example, can now be larger, as new non-contact technology makes it feasible. Products are richer, as well, in terms of graphic detail and amplitude of chromatic range. In addition, new product development process itself has been greatly simplified, allowing design departments to work faster 
and more efficiently and to expand the number of prototypes. Consequently, time-tomarket of new collections has been reduced considerably.

Regarding cost leadership, the shift from an analogue to a digital technology has led to the elimination of two low-efficient sub-stages linked to traditional printing process; the preparation of coloured dye and the colour set-up of the product. This drives to an increase in production efficiency and a reduction in decoration costs. In addition, costs associated with consumable materials (such as traditional silk screen displays) have been reduced. On the other hand, new technology reduces downtimes traditionally associated to ceramic decoration lines. The necessary adjustments to fit the graphic and tonality problems are reduced considerably since they are no longer manual. Generally speaking, downtimes are a major problem in the ceramic tile sector as in other industries operating continuously. They not only reduce the efficiency of the process, but also produce low-quality products, reducing profitability eventually.

Logistic costs are also significantly reduced. Manufacturing managers can shorten production batches because to switch from one printing design to another is, in digital, easier, faster and less costly. As a direct consequence, stocks of intermediate and final products can be limited, and the company's response can be adapted quicker to the market demand.

Finally, linked to the aforementioned productive and logistic advantages, firms' financial needs can be reduced. In fact, working capital requirements are lower due to the fact that the stocks of final product, secondary-quality products, raw materials and intermediate products are reduced.

In order to reinforce our conclusion, Figura 34 shows how, in 2015, four countries have fully adopted digital printing technology. They are Spain, Italy, China and India. It is well known in the sector that, on the one hand, Spain and Italy are markets focused on product differentiation strategy while, on the other hand, the strategy of China and India is based mainly on cost reduction. Furthermore, in terms of competition among companies, digital technology has shortened the competitive gap between those manufacturers who were focused on a product differentiation strategy and those whose strategy was cost reduction. Indeed, in a situation where legal protection of designs is not frequent, imitation is relatively easy, so any company is able to replicate any 
market-leading product in a reasonable time and without incurring significantly higher costs.

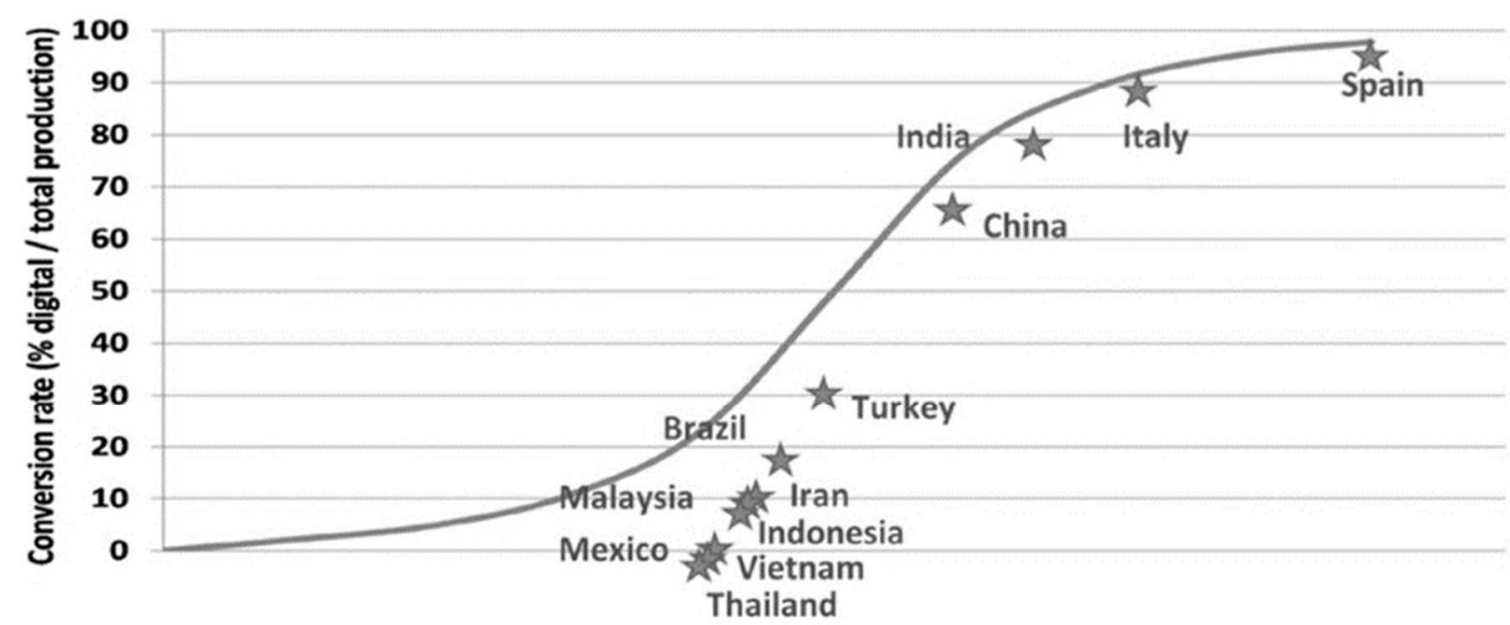

Figura 34: Conversion rate of decorative lines to digital in 2015. Level of digital printing penetration by country

Source: Ferrari (2016)

Impact on the overall strategy of the Spanish ceramic tile cluster

The innovation under study has shown a global strategic value for a cluster as an entity beyond the individual firms's strategic value previously mentioned. The mature Spanish ceramic tile cluster has been renovated and nowadays it is considered as a paradigm of industrial innovation case. The ceramic industry in Spain is currently deemed as a model of dynamism and modernization that is able to compete with many other ceramic tile clusters around the world in terms of cost or quality. In addition, this important value is not only perceived by other ceramic tile districts but also by other different industries which are using traditional printing and are willing to carry out a technological transformation as well. The use of printing as a method for adding value to the final product is a paramount aspect for many industries, not only for ceramics. Different industries, such as wood panelling, fibercement boards, glass, corrugated boards or the textile industries, among others, entrust an important part of their 
competitive strategy on design and, therefore, on printing. Nowadays different sectors are benefiting from the ceramic technological leaders' expertise to reduce uncertainty and accelerate the technological shift.

In conclusion, industrial digital printing has given the Spanish ceramic tile cluster the opportunity to open new diversification strategies. Significant firms from different subsectors such as ceramic printer manufacturers, ink producers or peripheral equipment manufacturers are successfully penetrating other industrial sectors.

\subsubsection{Conclusions of the study}

This work addressed the processes which lead to creation, development and diffusion of a disruptive technological innovation in the context of an industrial cluster. At the same time, we wondered if it is possible to create such kind of innovations in a mature cluster beyond the usual incremental ones. Findings of the case study revealed that the usual cluster dynamics may prevent present gatekeepers from leading these radical changes. Lack of a distant vision from the cluster itself, limited resources, or the fact of being focused on short-term challenges can be inhibiting factors of more radical solutions.

In this context, the new actors, or visionary agents -which may come even from outside the clusters- are called to play a decisive role as sources of innovation. These actors are able to supply clusters with new ideas or original visions far from the clusters' state of the art. In our opinion is interesting to highlight how in this case, innovation was created by a visionary agent, an actor that did not belong to conventional gatekeepers (companies, local institutions or support organizations) (Molina-Morales \& MartínezCháfer, 2016).

Findings of this case revealed that disruptive innovations can be generated in other contexts that are different to large companies where organizational structures, usually are able to perfectly align $\mathrm{R} \& \mathrm{D}$ resources towards an innovative idea. In clusters as entities this point is more difficult as there isn't an articulated hierarchy or a coordination in the actions. 
This research work has addressed the analysis of the innovation consequences from two different perspectives: (a) the ceramic tiles industry's value chain; (b) the role played by cluster members. In our opinion, the success of a disruptive innovation in a cluster will be influenced by these two elements. In other words, a deep impact of the innovation on the industry value chain alongside a close cooperation among relevant actors (gatekeepers) will be a good recipe. When this happens, the cluster's internal and external relationships are reconfigured and, as a consequence, not only the individual firms' strategies are reconsidered, but also the overall clusters's strategy.

Renewal of industrial clusters through disruptive technological innovations is shown in this research so, in our opinion, the case study contributes to the present discussion on the future of industrial clusters. Radical innovations, by increasing the competitiveness of firms and by opening up new opportunities, may become key elements to rejuvenate those clusters which are considered to be at the end of their life cycle. In addition, as opportunities may be opened not only in the same industry, but also in different sectors, radical innovations can be considered as powerful levers for industrial clusters' diversification.

In our opinion, our paper's findings mainly contribute to two different academic research lines. On the one hand, the group of studies which are focused on radical or disruptive innovations analysed by authors such as Christensen (1997), Markides (2006) or Tellis (2006) among others. These authors emphasize the importance of this type of innovations that allow the creation of new markets, beyond the mere incremental improvement of existing ones. On the other hand, this work supports the authors who have raised the need to redefine the internal and external relations of the clusters (Biggiero, 2006; Sammarra, 2005).

Finally, this paper presents a series of limitations, some related to the peculiarities of the case and others due to the descriptive approach we have used. We have performed a case study based on the specific conditions of this case. Therefore, we appeal to caution in generalization of conclusions, which might be suitable to other clusters or industrial realities. This research attempts to take a first step towards a more ambitious and broader analysis. To explore a comparative analysis of different disruptive technological 
innovations in the context of other clusters should be a potential future challenging research. 
5.2 Empirical Study II: Determinants and impact of disruptive technological innovations in industrial clusters. Insights from a comparative case study

Este estudio no puede ser mostrado en la version pública de la presente tesis por estar pendiente de publicación. 


\section{FASE DE INVESTIGACIÓN CUANTITATIVA}

Como se ha descrito en el capítulo 4, la segunda fase de nuestra investigación se ha planteado en base al objetivo de analizar de forma cuantitativa los determinantes y el impacto tienen los fenómenos de innovación disruptiva, ya no a nivel de clúster, sino a nivel de las empresas que lo conforman. A continuación presentamos los dos estudios empíricos que componen esta fase. 


\subsection{Empirical Study III: Early adoption of a disruptive technological innovation by clustered firms. The role of the Absorptive Capacity ${ }^{41}$}

\subsubsection{Introduction}

In recent years, the territorial dimension of innovation has attracted the attention of scholars and practitioners (Doloreux \& Parto, 2005; Moulaert, Martinelli, Swyngedouw, \& Gonzalez, 2005; Moulaert \& Sekia, 2003), particularly as a path in regional development. In many cases, authors have used the concept of district or cluster (Becattini, 1979; Porter, 1990b) as their framework of analysis (Kesidou \& Snijders, 2012; Munari et al., 2012). Moreover, there are many contributions that attempt to describe how proximity facilitates frequency of contacts and closeness among actors in a cluster network (Inkpen \& Tsang, 2005; Lorenz, 1992; Piore, 1990). According to a part of the cluster literature, this characterization would generate tacit knowledge and high quality information exchanges and, consequently, would promote innovation for firms (Bathelt et al., 2004; Molina-Morales, 2002).

Most authors, more or less explicitly, assume that the relational characterization of the cluster becomes far more appropriate for step-by-step or minor improvements and incremental innovations of products and technologies than for those considered as radical or disruptive changes (Maskell 2001; Bianchi \& Giordani 1993; Hassink 2005).

The existing literature on innovation in clusters, while acknowledging the value of real disruptive changes for cluster renewal and sustainability, is often focused exclusively on what is behind the incapability of these agglomerations to carry them out (Østergaard \& Park 2015; Maskell \& Malmberg 2007). Nevertheless, Saxenian (1991) found that in

\footnotetext{
${ }^{41}$ Este estudio corresponde a una versión pre-print de un artículo que ha sido ya publicado en la revista Enterpreneurship \& Regional Development (ISSN: 0898-5626) cuya cita es Molina-Morales, MartínezCháfer, \& Valiente-Bordanova. (2019). Disruptive technology adoption, particularities of clustered firms. $\begin{array}{lllll}\text { Entrepreneurship } \quad \& \quad \text { Regional } \quad \text { Development, } & \text { 31(1-2), }\end{array}$ https://doi.org/10.1080/08985626.2018.1537147
} 
the rapidly changing environment of the computer industry, mostly in Silicon Valley, firms have moved away from arm-length supplier relations in order to build close relationships with only a select number of them. More recently, some examples can be found describing how industrial clusters have renewed their possibilities of surviving through disruption (Hervás-Oliver, Albors-Garrigós, et al., 2017).

Some authors, following the exploring and exploiting dimensions of organizational learning proposed by March (1991), but under a cluster perspective, have tried to identify activities related to these two categories of innovation and suggested that, in some cases, clustered firms may benefit from both exploiting and exploring advantages (Fontes 2005; Giuliani 2007; Rullani 2002).

Our work aims to address the above-mentioned discussion by analysing what attributes of cluster companies are related to the adoption of disruptive technologies. In fact, disruptive innovation processes have rarely been studied in the cluster context. Literature has focused more on describing cluster decline when facing disruption or inertia as a factor restricting disruptive novelty (Crespo et al., 2013; Isaksen, 2014; Østergaard \& Park, 2013; Staber \& Sautter, 2011; Suire \& Vicente, 2009). These contributions are often focused on the cluster as a unit of analysis and stress the identification of key cluster elements supporting or inhibiting adaptation to disruption. They rarely address, from the firm perspective, the internal attributes of clustered firms as factors determining the adoption of disruptive innovations. In this vein, exceptionally, Hervás-Oliver et al. (2017) analysed how radical innovation occurs in Marshallian clusters and how they are able to overcome lock-in processes.

Exploratory in nature, our work uses the firm as a unit of analysis and captures their internal attributes using the Absorptive Capacity model (hereinafter ACAP), which was first defined by Cohen and Levinthal $(1994,1990)$. Contributions to previous industrial cluster literature have used this internal firm attribute to analyse how firms have different access to the knowledge provided by technological institutes (Hervás-Oliver et al., 2012) or how the heterogeneity of firms' knowledge builds a cluster ACAP (Giuliani 2005). By distinguishing among the four dimensions of ACAP proposed by Zahra and George (2002), we aim to determine the firm-specific attributes that allow 
individual clustered firms to access and exploit a new disruptive technology more rapidly.

Literature has frequently analysed ACAP as a one-dimensional concept, measuring it through different indicators such as R\&D activity (Cohen and Levinthal 1990), patents (Zhang, Li, Hitt, \& Cui, 2007) or number of employees with higher education qualifications (e.g. Caloghirou et al. 2004). These unidimensional indicators are receiving increasing criticism (Camisón \& Forés, 2010), and only a few papers have formulated a multidimensional operationalization of ACAP (e.g. Lane et al. (2001); Jansen et al. (2005) or Expósito-Langa et al. (2011)). A four-dimensional perspective becomes of interest, since each dimension requires distinct organizational processes and is developed in a different way in clusters. In short, this paper aims to focus on a particular line of inquiry, namely, to determine which dimensions of ACAP have a more significant influence on the early adoption of a disruptive innovation when this innovation is introduced in the cluster.

The context of our research is the cluster and innovation literature. Furthermore, we aim to contribute to the debate about the possibilities of the future development of these territorial agglomerations, which is in fact closely related to the debate on the cluster policy for mature phases of the life cycle. To develop these causal relations, the paper is centred on the Spanish ceramic tile cluster, where digital printing technology has recently been introduced. In fact, the characteristics and effects of this innovation represented a major transformation of existing products and technologies, making most of them obsolete. This characterization fits well with refinements of the definition of the term disruptive innovation proposed in the literature (Markides, 2006) after a critical review of the original concept proposed by Christensen (1997).

The expected contribution is particularly relevant since the importance of disruptive innovations has increased in the current context (Christensen, 1997; Markides, 2006; Tellis, 2006). In contrast to incremental innovations, these represent major transformations of existing products or technologies and often result in the prevailing product designs and technologies becoming obsolete (Chandy \& Tellis, 2000). In conclusion, we expect to contribute to the current debate about how industrial clusters are able to restart their life cycles and deal with important challenges with the aim of 
adapting their structures and strategies to the external global conditions. The paper also aims to contribute to a broader literature inspired by the controversy regarding the differential benefits of incremental and radical or disruptive innovations, as well as their specific differences according their specific contexts.

\subsubsection{Specific theoretical framework and hypotheses}

\subsubsection{Proximity and innovation}

Previous literature has suggested that firms find motivation in being located near others, as they may gain some benefit from common external resources (e.g. Folta et al. 2006; McCann and Folta, 2008). These arguments have traditionally been conceptualized as the industrial cluster or district (Becattini, 1979; Porter, 1990b).

In general, research on clusters assumes that by being in the same place, organizations take advantage of external knowledge exchanges, since knowledge spillovers are geographically localized and locally bound (Alcacer \& Chung, 2007; Jaffe et al., 1993; Krugman, 1991). The stocks of knowledge created through these exchanges are concentrated and, in some way, exclusively available to located actors (Bell et al., 2009). Innovation becomes, in consequence, a joint action among cluster members, where diverse relationships between firms and organizations foster not only trust and other shared norms and values but also the transmission of tacit knowledge (Bell et al., 2009). In fact, many contributions have attempted to describe how spatially concentrated firms capture externalities deriving from access to information and reciprocal exchanges of tacit knowledge (Waxell \& Malmberg 2007; Maskell 2001). To sum up, interactions among co-located actors probably have superior outcomes related to innovation compared to interactions among distant actors (Yli-Renko et al., 2001).

Since clustered firms operate within the boundaries of a close geographical scenario, they are idiosyncratic business networks (Sorenson, 2003). Proximity fosters the frequency of personal contacts, the social relations between actors and reciprocity of benefits (Roxas \& Chadee, 2011). Interconnections and interactions among network 
members are a manifestation of their relational proximity. Close and mutual relationships (strong ties) are necessary to transfer and gain access to particular information and knowledge from other firms (Hansen, 1999).

\subsubsection{Incremental and disruptive innovations. Technological change in industrial clusters}

The specificities in clusters, as an aforementioned idiosyncratic case of networks, have implications on the type of innovation that clustered firms develop. Clusters seem to be better adapted for incremental or contextual innovation. As is well known, incremental innovations involve minor changes and modifications which are introduced in order to refine or reinforce existing products and technologies. In contrast, radical or disruptive innovations consist in significant transformations that make current products and technologies obsolete (Chandy \& Tellis 2000).

Previous research has extensively analysed the concept of disruptive innovation and other similar notions with the intention of capturing the radical and discontinuous nature of some new technologies (Adner, 2002; Charitou \& Markides, 2002; Christensen, 1997; Christensen \& Raynor, 2003). We are aware that the emergence of several concepts capturing similar notions hampers their identification and clear delimitation (Gatignon et al., 2002). However, leaving aside the conceptual debate, we are interested in those technologies and innovations that go beyond incremental developments or small changes. This implies the replacement of products and technologies by new ones that can be created or (in our case) adopted by companies. In this sense, disruptive changes can broaden and develop new markets but may also disrupt existing market linkages (Adner 2006; Danneels 2004; Gilbert 2003). Thus, we adopt the proposal suggested by Markides (2006), who, on the basis of Christensen's work (1997), distinguished between radical innovation for products and disruptive innovation for technologies. In the same vein and for the purposes of this research, we refer to disruptive innovation as a technological change that incorporates new knowledge, resources or skills which make the value of incumbent systems and technologies in the cluster obsolete, following similar concepts suggested by different authors (Gilbert 2012; Danneels 2004; Markides 2006). 
In clusters, the lack of exploring capabilities to scan and respond to external and radical changes was reported in seminal work by Harrison (1994) and, in similar terms, by Glasmeier (1991), who described how the Swiss watch firms presented a vulnerability in responding to disruptive external technological changes. Most of the later research has been focused on the weakness of the strong ties in clusters (Grabher, 1993), the reduced capacity to create breakthrough innovations (Chiarvesio, Di Maria, \& Micelli, 2010) or how clusters are able to avoid decline through disruption (Østergaard \& Park 2015). However, the above line of reasoning is somehow controversial, since at least some counterexamples refute these arguments by describing cases of industrial clusters accessing new opportunities (Corò et al., 1998; Reig-Otero et al., 2014).

How clusters can overcome the limitations for generating these radical or disruptive advances has become a central research question. Previous studies have nevertheless provided some suggestions. Sammarra (2005) and Biggiero (2006) proposed a selective relocation of activities outside the cluster. And others, like Giuliani (2011), have focused on the role played by technological gatekeepers to feed the cluster with new ideas, knowledge and technologies. Being aware of the aforementioned contributions, whose approach is focused on considering the cluster as a homogeneous entity, we suggest taking a different approach grounded on the individual company level and analysing what firm characteristics or attributes lead to the early adoption of a disruptive technology. The rate at which innovations are adopted by firms constitutes an important part of the process of technological change. In fact, research focused on how both firm- and market-specific characteristics influence the decisions to adopt innovations has long been recognized as an important area of study. The diffusion theory provides different tools to assess the likely rate of adoption and diffusion of a certain technology. Numerous factors have been identified as facilitators or hinderers of the adoption and implementation of a technology. These factors include not only the characteristics of the technology but also, and more relevant for us, the characteristics of the adopters and the means by which they learn and are persuaded to adopt the technology (Rogers, 1983). 


\subsubsection{Clustered firm attributes through the Absorptive capacity perspective. Effects on innovation}

Extensive literature has already established a positive association between internal attributes (i.e. firm's capabilities) and firm performance (including innovation results). In the same vein, Stock et al. (2001) stressed the positive relationship between the capacity to assimilate and exploit knowledge and the company's capacity to innovate. In a cluster context, it is particularly relevant for firms to absorb and to exploit external knowledge resources from other co-located actors (McCann \& Folta 2011; Ahlin, Drnovšek, \& Hisrich 2014). In clusters, individual firms benefit from accessing a series of capabilities which are not exclusive to an individual organization and belong to the community. Thus, the cluster creates its own mechanisms to identify changes in the external environment and to facilitate access to new ideas or new opportunities.

Previous studies have demonstrated the existence of a common agreement in favour of a positive association between internal capacities, innovation and competitive advantage (Cassiman \& Veugelers 2006; Vega-Jurado et al. 2008; Barney 1991; Teece, Pisano, \& Shuen 1997; Wernerfelt 1984). In this regard, some specific findings can be found, such as the argument defended by Belso-Martínez \& Molina-Morales (2013), who suggested a curvilinear effect. They argued that, instead of investing continuously in internal resources, clustered firms should find an optimal balance since, at certain levels, costs would rise more than benefits. In the same vein, Molina-Morales and Expósito-Langa (2011) suggested that the connectivity among clustered firms amplifies the curvilinear effect of the R\&D effort focused on innovation.

Among firm internal capabilities as determinants of innovation, ACAP has received greater attention from scholars since the seminal work carried out by Cohen and Levinthal (1990). According to these authors, firms possessing a high ACAP would develop higher organizational learning and a better ability to apply external information and knowledge. ACAP can be considered as a firm's ability to identify valuable external knowledge, assimilate it and apply it for commercial purposes (Escribano, Fosfuri, \& Tribó, 2009). ACAP has been seen as a means of new knowledge creation through the development of problem-solving skills (Kim, 1998) or even as the ability to recognize and understand a potential new technology for further internal 
implementation (Mowery \& Oxley, 1995). Moreover, the additive systemic ACAP generated in clusters interacts with individual organization capacities and amplifies the potential access to and exploitation of external resources (Giuliani \& Bell 2005).

The notion of ACAP as an ability to anticipate future technological advances was introduced by Cohen and Levinthal (1994). These authors suggested that investments in ACAP were associated with the ability of firms to predict technological avenues and consequently to obtain time advantages with respect to their competitors (Lane \& Lubatkin 1998; Van den Bosch, Volberda, \& de Boer 1999). Following this argument, our work raises questions about the possible causal relationship between the ACAP of a company and its innovative capacity through the rate of adoption of a new disruptive technology within the context of industrial clusters. In this sense, we follow other research (Arne Isaksen \& Trippl, 2016, 2017) by considering novel technologies introduced on the market as the fundamental driving force behind new paths of development.

In our work, we follow Zahra and George (2002), who distinguished between the different dimensions of ACAP, and consequently we distinguish among a set of different routines and processes by which external knowledge is acquired, assimilated, transformed and exploited. More precisely, we refer to: (a) the acquisition dimension as the ability of the firm to identify and obtain knowledge from external sources; (b) the assimilation dimension as the ability to develop processes and useful routines by understanding, analysing and interpreting externally acquired knowledge (Szulanski, 1996); (c) the transformation dimension as developing and refining those routines that facilitate the combination of the existing knowledge with that which has already been acquired and assimilated for future use (Zahra \& George, 2002); and (d) the exploitation dimension as the capacity of a firm to improve, expand and use its existing routines, competencies and technologies to create something new based on the transformed knowledge (Del Carmen Haro-Domínguez, Arias-Aranda, Lloréns-Montes, \& Moreno, 2007).

In our case, we consider it appropriate to disaggregate the ACAP notion into these different dimensions, following authors such as Zahra and George (2002), Jansen et al. (2005) and Escribano et al. (2009). We agree that each dimension requires different 
paths of development in the organizations and that they should determine the development of differential innovative outputs (Leal-Rodríguez, Ariza-Montes, et al., 2014). Moreover, in the context of the industrial cluster, specific conditions that clustered firms may present and strong interactions between firms make this differentiation particularly interesting (Expósito-Langa et al., 2011).

In addition, the existence of systemic effects can affect the different ACAP dimensions in several ways, as we will try to justify in the following sections. Indeed, specific cluster peculiarities such as proximity, interactions or cooperation, among others, condition the behaviour of these dimensions (Zahra and George, 2002). Zahra and George (2002) defined and distinguished between two different dimensions of ACAP.

Under this perspective, knowledge acquisition and assimilation capacities are identified as potential ACAP, while knowledge transformation and exploitation are considered as realized ACAP.

Potential ACAP has been defined as the ability to identify and evaluate new knowledge flows (Escribano et al., 2009). It leads the firm to renew its knowledge base and skills, consequently favouring its flexibility. This first dimension allows companies to reconfigure their bases of resources in order to adapt to new emerging opportunities (Zahra \& George, 2002). Realized ACAP has been defined as the capability of firms to benefit from the external knowledge flows (Escribano et al., 2009). This second dimension comprises transformation capabilities (which enable firms to develop new processes or to add changes to existing ones) and exploitation capabilities (which enable firms to finally convert knowledge into new products and consequently enhance their performance and competitive advantage) (Zahra \& George, 2002) 


\subsubsection{Hypotheses}

\section{Potential ACAP and technology adoption in clusters}

The acquisition of external knowledge refers to the ability of a company to locate and acquire knowledge that is critical for its activity from external sources. This first dimension of identification corresponds to the notion of competitive scanning (McEvily \& Zaheer, 1999), which has been associated in the literature with the innovative capacity of the company. The development of this capacity implies a continuous control and analysis of the environment to detect opportunities and threats. The capacity for acquisition is influenced by several factors such as the prior knowledge that the company has (Cohen \& Levinthal 1990), recent scientific research and the effort devoted to generate routines for the acquisition of knowledge (Zahra \& George 2002).

On the other hand, belonging to an industrial cluster conditions the way in which firms identify external knowledge. In many cases these companies do not access external sources directly but do so through intermediaries. The existence of a series of local institutions, dedicated to supporting the cluster as a whole, and sometimes the leading companies themselves serve as links between internal-to-the-district companies and the external environment (Malipiero, Munari, \& Sobrero, 2005). In this way, internal companies can benefit from a low-level cost and high-quality exploration activities, since they usually have systematic contacts with various external circles, other industries, other innovation systems, and so forth.

In short, the existence of intermediaries can affect both the quality and the focus of the searching activities of clustered firms. Undoubtedly, the ability to identify knowledge from external sources carried out by the district requires a complementary capacity of absorption by the individual company. The larger and better the firm's sources of information are, the greater the firm's possibilities for exchanging and combining useful knowledge will be, and therefore the greater the capacity to create and develop new products is.

The assimilation of knowledge involves coupling novelties with the company knowledge base. External knowledge is found in specific contexts, which mostly make 
it difficult to understand and replicate outside the scope in which this knowledge has been generated. Therefore, it is crucial for the company to be provided with internal processes that make all this knowledge useful and available to the organization (Teece 1981). For Nelson and Winter (1982) this process of assimilation is highly influenced by the tacit knowledge of the company, based on experience, know-how and other similar values, which distinguish it from explicit or codified knowledge. In the particular case of industrial clusters, the dimension of assimilation of knowledge benefits from the access to and exchanges of tacit knowledge within it.

The individual company has some instruments for these assimilation processes. For example, information technologies provide systematic processes of acquisition, storage and dissemination of organizational knowledge. Proximity, direct (formal and informal) relationships among people and organizations, and high mobility of technicians and employees within the district are elements that allow emulation and tacit knowledge acquisition that is difficult to acquire in other circumstances (Tallman et al., 2004). However, despite these externalities, the routines and processes that manage knowledge and allow the generation of new products or adoption of new technologies occur, at the level of individual companies, by interacting with the aggregate level. We can therefore consider that the greater the firm's capacity for assimilation of external knowledge is, the greater its capacity will be to develop new products and technologies. In short, the assimilation of external knowledge is a key element in the innovation processes, and more specifically in the innovation processes of industrial clusters. Considering the theoretical development outlined above, we can expect Potential ACAP to have a positive effect on clustered firms by enabling them to be early adopters of the new technology. In other words, it will allow them to adopt and introduce the technological change in a moment when it may provide them with a higher competitive advantage. A new technology could improve manufacturing processes and/or services offered by reducing cost or time, enhancing quality or flexibility, etc. Early adoption of the disruptive technology can be expected to enable new and important opportunities for clustered firms to improve their performance. This can be expressed more formally as the following hypotheses in relation to the two dimensions of Potential ACAP: 
H1.1: Clustered firms having a high acquisition capacity increase their odds of being early adopters of disruptive technologies.

H1.2: Clustered firms having a high assimilation capacity increase their odds of being early adopters of disruptive technologies.

\section{$\underline{\text { Realized ACAP and technology adoption in clusters }}$}

In their research, Cohen and Levinthal (1990) emphasized the importance of the application of assimilated knowledge. The exploitation dimensions refer to the routines that allow a company to perfect, expand and exploit existing skills, or create new ones, by incorporating the knowledge identified and analysed in their activity (Tiemessen et al., 1997). This involves internalizing the previously created knowledge to develop and obtain, as a result, new products, processes, knowledge or new organizational forms (Spender, 1996). During this phase, high-quality information is required, and the ability of organizations and internal units to share and cooperate with other units and organizations acquires a prominent role.

In the context of industrial clusters, the literature has clearly proved how close contacts between organizations belonging to the same cluster generate a dense network of relationships. This density and recurrence in relationships provides organizations with a set of shared norms and values (for example, trust) that regulate exchanges of knowledge resources (Uzzi, 1996, 1997). In contrast to other characterizations, dense networks are more efficient in the processes of continuous improvement which are linked to strategies for exploiting knowledge resources (Rowley, Behrens, \& Krackhardt, 2000). However, as the company networks of relationships are heterogeneous and distinctive, the companies in the district will present different capacities to exploit external sources of knowledge. Thus, the greater the capacity for exploitation generated by the network of relationships of the individual company is, the greater its innovative capacity will be.

In clusters, the exploitation capacity of the individual firm may positively affect its capacity to innovate. Clustered firms receive a large amount of knowledge and other 
resources from the other members of the cluster. In consequence, innovation performance primarily depends on the individual firm's capacity to exploit these external knowledge resources. Therefore, we would expect a positive relationship between internal resources and capacities and innovation. More precisely, in line with what we stated in the previous hypotheses, we can expect Realized ACAP to have a positive effect on clustered firms in the sense of enabling them to be early adopters of the new technology. Accordingly, we can formulate the following hypotheses based on the different dimensions of Realized ACAP:

H2.1: Clustered firms having a high transformation capacity increase their odds of being early adopters of disruptive technologies.

H2.2: Clustered firms having a high exploitation capacity increase their odds of being early adopters of disruptive technologies.

\section{Summary of hypotheses}

All four hypotheses are summarized graphically in Figura 35, which illustrates our analytical framework.

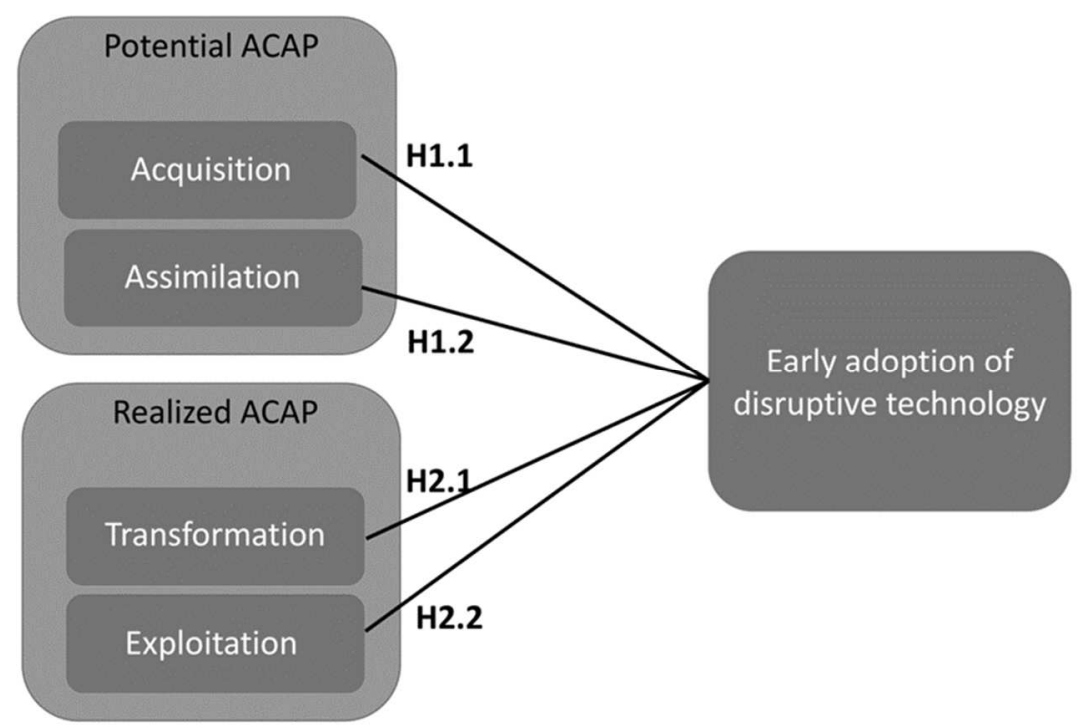

Figura 35: Analytical framework of the study 


\subsubsection{Specific empirical framework}

\subsubsection{Context of the research}

The empirical study is focused on the Spanish ceramic tile cluster. This cluster, which has previously been identified as a paradigm of a Marshallian-type industrial cluster (Boix, 2009; Molina-Morales \& Martínez-Fernández, 2009a; Reig-Otero et al., 2014), is located in the province of Castelló (Spain). Comprising an approximate area of 200 $\mathrm{km}^{2}$, the cluster is defined by its main activity, which is the production of ceramic wall and floor tiles.

This territorial entity, which is mainly composed of small-sized firms, is considered as the Spanish locus of ceramic tile production. Around a hundred ceramic tile manufacturing companies are located in this area and they produce over $95 \%$ of the total Spanish production of ceramic tiles. In 2016 this represented a sales volume of 3,300 million euros and provided 15,000 direct jobs according to $\mathrm{ASCER}^{42}$.

The cluster comprises not only end-product firms, those which produce ceramic wall and floor tiles, but also other related firms devoted to other activities in the ceramics value chain. Integrated firms and also specialized firms are considered important active members of the cluster. In this group of firms, the glaze industries are considered the most important actors not only from a value creation point of view but also from the perspective of cluster knowledge supply. In this sense, the cluster has been identified by different authors as supplier-dominated, according to Pavitt's (1984) classic taxonomy (Belso-Martínez, Molina-Morales, \& Mas-Verdú, 2011; Flor \& Oltra, 2004). In fact, according to ANFFECC ${ }^{43}$ this sub-sector achieved a sales volume of 1,200 million euros in 2016 and provided 3,700 direct jobs. Finally, together with these different

\footnotetext{
${ }^{42}$ Spanish Association of Wall and Floor tiles manufacturers. Data in this section come from ASCER website http://www.ascer.es checked on April 2018

43 Spanish Association of frit, glaze and ceramic colour manufacturers. Data in this section come from ANFFECC website http://www.anffecc.com/es/ checked on April, 2018
} 
kinds of firms, the cluster is also made of a number of local, regional or even national institutions and organizations which support the development of the cluster, mainly in terms of technological and business knowledge. Tabla 44 provides detailed information about the different actors comprising the cluster.

The Spanish cluster experienced a disruptive innovative phenomenon based on a radical change in the way of printing ceramic tiles, namely, the digital printing technology. As widely described in previous studies (Empirical Study I and Empirical Study II), this innovation, which was introduced into the cluster by a visionary agent, changed the value chain of the ceramic tile business, first in the Spanish ceramic tile cluster and later in the ceramic tile manufacturing industry worldwide.

Tabla 44: Profiles of the actors comprising the Spanish ceramic tile cluster

\begin{tabular}{c|c|c}
\hline $\begin{array}{c}\text { Cluster } \\
\text { members }\end{array}$ & Member description & Specific cluster activity \\
\hline $\begin{array}{c}\text { End-product } \\
\text { firms }\end{array}$ & $\begin{array}{c}\text { Firms carrying out the } \\
\text { cluster's defining activity }\end{array}$ & $\begin{array}{c}\text { Ceramic wall and floor tile } \\
\text { manufacturers }\end{array}$ \\
\hline $\begin{array}{c}\text { Specialized firms } \\
\text { (supporting } \\
\text { firms) }\end{array}$ & $\begin{array}{c}\text { Firms involved in supply } \\
\text { activities for end-product } \\
\text { firms }\end{array}$ & $\begin{array}{c}\text { Glaze industries, chemical additives } \\
\text { manufacturers, ceramic machinery } \\
\text { and equipment suppliers, atomized } \\
\text { clay producers, etc. }\end{array}$ \\
\hline $\begin{array}{c}\text { Integrated firms } \\
\text { activities belonging to } \\
\text { other industries but } \\
\text { integrated in the cluster }\end{array}$ & $\begin{array}{c}\text { Industrial services, project services, } \\
\text { shipping and road transport services, } \\
\text { design and marketing services, } \\
\text { packaging services, etc. }\end{array}$ \\
\hline $\begin{array}{c}\text { Institutions and } \\
\text { organizations }\end{array}$ & $\begin{array}{c}\text { Entities which support the } \\
\text { cluster }\end{array}$ & $\begin{array}{c}\text { Educational centres, research } \\
\text { institutes, trade associations, etc. }\end{array}$ \\
\hline
\end{tabular}




\subsubsection{Data source}

This research is grounded on primary data collected at the firm level from the Spanish ceramic tile cluster. Due to the fact that this study is focused on the adoption of an innovation (the digital printing disruptive technological innovation), data come exclusively from the so-called end-product firms (those firms which perform the cluster's defining activity and are able to introduce the new printing technology in their manufacturing processes). Other different cluster members such as specialized or integrated firms are, consequently, excluded from the present research.

Data collection was carried out through a survey based on a structured questionnaire. The selection of the respondents' profiles was, at this point, relevant, considering the information we intended to gather. The survey was aimed at members of the organization having appropriate knowledge regarding not only the specific peculiarities of the adoption process that had occurred in the company but also the general innovative profile and characteristic innovative dynamics of their respective companies. For this reason, the survey largely targeted CEOs or R\&D managers. These respondents had first-hand information about how the innovation under study was detected (or not), as well as on how it was introduced into the organization, if this was the case. To a lesser extent, some questionnaires were answered by different profiles of respondents directly involved in the process of adopting the innovation and, consequently, in possession of the detailed information required (e.g. marketing managers or technical production managers).

The survey was conducted in two rounds between October 2016 and December 2017 and finally we were able to gather 75 completed questionnaires from a total population of the 118 end-product firms present in the Spanish ceramic cluster at that time. In order to extend the characterization of the cluster firms, business and performance information was also gathered from the SABI database (Iberian Balances Analysis System). In more detail, year of foundation as well as data regarding total assets, total revenues and number of employees were gathered for the companies from 2007 until 2013. This period of time was selected so as to cover a representative period around 2010 in accordance with our definition of the dependent variable. This information will allow us to build two of our control variables, as described in the following section. 


\subsubsection{Analysis method and variables}

To test our hypotheses, we computed a Binomial Logistic Regression (LOGIT) performed with the SPSS software package. This model enables us to explore the association of ACAP-related factors with the fact of being an early adopter firm. Hence, the model can be written as follows:

$$
\begin{aligned}
& \text { Early adopter } \\
& =\alpha+\beta_{1} A C A P_{A C}+\beta_{2} A C A P_{A S}+\beta_{3} A C A P_{T R}+\beta_{4} A C A P_{E X}+\beta_{5} T I O+\beta_{5} O I O \\
& +\beta_{6} S I Z E+\beta_{7} A G E+\mu
\end{aligned}
$$

In Tabla 45 we describe all the main variables included in the LOGIT method that we used in this research. All the items used in the survey to build the variables are listed in Appendix A together with additional details and justification. The descriptive indicators for the dependent, control and independent variables are reported in Tabla 46 and Tabla 47. 


\section{Name of the variable}

Early adoption

Size of the company

Age of the company

Orientation to technological innovation

Control

Control

Control

Orientation to organizational innovation

Control

Absorptive capacity - Acquisition (ACAP_AC)

Independent

Absorptive capacity - Assimilation (ACAP_AS)

Independent

Absorptive capacity - Transformation (ACAP_TR)

Independent

Independent

Absorptive capacity - Exploitation

\section{Description}

This is a dichotomous variable. Its value is 1 when the company adopted the inkjet technology in 2010 or before and 0 otherwise

Factor analysis of total assets, total revenues and number of employees (Cronbach's alpha $=0.691$; $\mathrm{KMO}=0.864$ )

Calculated by subtracting the year of the company's foundation from 2017

Factorial analysis concerning five items from our survey about product development and processes $($ Cronbach's alpha $=0.860 ; \mathrm{KMO}=0.825)$

Factorial of eight items from our survey about organizational and marketing activities (Cronbach's alpha $=0.929 ; \mathrm{KMO}=0.868$ )

Factorial of three items concerning the previously described acquisition dimension of ACAP $($ Cronbach's alpha $=0.819 ; \mathrm{KMO}=0.695)$

Factorial of four items regarding this particular dimension (Cronbach's alpha $=0.925$; $\mathrm{KMO}=0.839$ )

Factorial analysis that comprises four items about transformation activities (Cronbach's alpha = $0.957 ; \mathrm{KMO}=0.869$ ) (ACAP_EX)

Three items about exploitation that are reduced to one dimension with a factorial analysis $($ Cronbach's alpha $=0.817 ; \mathrm{KMO}=0.650)$ 
Tabla 46: Descriptive statistics of the dependent variable

\begin{tabular}{|c|c|c|c|c|}
\hline & Code & Frequency & Percentage & Cumulative percentage \\
\hline Adopters after $2011 /$ non-adopters & 0 & 24 & 32.0 & 32.0 \\
\hline Adopters before 2010 (included) & 1 & 51 & 68.0 & 68.0 \\
\hline Total & & 75 & 100.0 & \\
\hline
\end{tabular}

Tabla 47: Descriptive statistics of the control and independent variables

\begin{tabular}{|c|c|c|c|c|c|c|c|c|c|}
\hline & $\mathbf{N}$ & Mean & Median & Mode & S. Deviation & Variance & Range & Minimum & Maximum \\
\hline Size of the company & 75 & 0.00 & -0.28 & -.49 & 1.00 & 1.00 & 7.62 & -0.48 & 7.14 \\
\hline Age of the company & 75 & 35.53 & 31.00 & 17.00 & 21.13 & 446.33 & 101.00 & 3.00 & 104.00 \\
\hline $\begin{array}{l}\text { Technological } \\
\text { innovation } \\
\text { orientation }\end{array}$ & 75 & 0.00 & 0.32 & 0.78 & 1.01 & 1.01 & 2.79 & -2.02 & 0.78 \\
\hline $\begin{array}{l}\text { Organizational } \\
\text { innovation } \\
\text { orientation }\end{array}$ & 75 & 0.00 & 0.58 & 0.83 & 1.01 & 1.01 & 2.59 & -1.76 & 0.83 \\
\hline Acquisition & 75 & 0.00 & 0.03 & 1.16 & 1.01 & 1.01 & 4.63 & -2.89 & 1.74 \\
\hline Assimilation & 75 & -0.01 & 0.14 & 0.14 & 1.00 & 1.00 & 4.96 & -3.33 & 1.63 \\
\hline Transformation & 75 & -0.01 & -0.05 & .11 & 1.00 & 1.01 & 6.09 & -3.83 & 2.26 \\
\hline Exploitation & 75 & -0.01 & 0.22 & 1.09 & 1.00 & 1.01 & 4.38 & -2.64 & 1.75 \\
\hline
\end{tabular}




\subsubsection{Results of the study}

The results show a general model that exhibits an $80 \%$ of correctness considering a cutoff value of 0.5. As we can see in Tabla 48, the model can correctly predict 60 cases out of a total of 75 that completed our data. Additionally, in this section we also report other significant indicators of the model that can be observed in Tabla 49

Tabla 48: The observed and predicted frequencies for Early Adoption in the Logistic Regression

\begin{tabular}{lccc}
\hline & \multicolumn{3}{c}{ Predicted } \\
\hline Observed & NO & YES & Correct \\
NO & 17 & 7 & (\%) \\
YES & 8 & 43 & 70.8 \\
Overall \% Correct & & & 84.3 \\
\hline
\end{tabular}

Tabla 49: General significance of the Binomial Logistic Regression (LOGIT)

\begin{tabular}{cccccc}
\hline & Chi-squared & df & Sig. & $\mathbf{R}^{2}$ (Cox \& Snell) & $\mathbf{R}^{2}$ (Nagelkerke) \\
\hline Model & 30.173 & 8 & 0.000 & 0.331 & 0.464 \\
\hline
\end{tabular}

Regarding the significance of the control variables (see Tabla 50), we observe how two control variables exert a positive and significant effect on the probability of being an early adopter of the technological innovation. On the one hand, the age of the company has an EXP (B) coefficient of 1.082, indicating that companies with more general experience in the market can multiply their probability of early adoption by this coefficient. On the other hand, companies with a high orientation on technological innovation can also multiply their probability of being early adopters by 4.737 . The rest of the control variables that we have considered (size of the company and orientation 
towards organizational innovation) both have negative, although not significant, coefficients on the regression.

Tabla 50: Binomial Logistic Regression results (LOGIT)

\begin{tabular}{lcccccc}
\hline & B & Std. Error & Wald & df & Sig. & $\operatorname{Exp}(\mathbf{B})$ \\
\hline Intercept & -1.443 & 0.780 & 3.423 & 1 & 0.064 & 0.236 \\
\hline $\begin{array}{l}\text { Size of the company } \\
\text { Age of the company }\end{array}$ & -0.166 & 0.421 & 0.155 & 1 & 0.693 & 0.847 \\
\hline $\begin{array}{l}\text { Technological innovation } \\
\text { orientation }\end{array}$ & 0.079 & 0.026 & 9.285 & 1 & 0.002 & 1.082 \\
\hline $\begin{array}{l}\text { Organizational innovation } \\
\text { orientation }\end{array}$ & 1.555 & 0.612 & 6.451 & 1 & 0.011 & 4.737 \\
\hline Acquisition & -0.421 & 0.664 & 0.402 & 1 & 0.526 & 0.656 \\
\hline Assimilation & -0.290 & 0.462 & 0.394 & 1 & 0.530 & 0.748 \\
\hline Transformation & 0.129 & 0.412 & 0.099 & 1 & 0.754 & 1.138 \\
\hline \begin{tabular}{l} 
Exploitation \\
\hline
\end{tabular} & -0.278 & 0.400 & 0.480 & 1 & 0.488 & 0.758 \\
\hline
\end{tabular}

In relation to the independent variables and regarding the different dimensions of ACAP, the results show how the exploitation dimension has a positive and significant effect on the dependent variable. Companies that perform exploitation-related activities have more than twice as much chance of being early adopters, as suggested by the EXP (B) coefficient. However, this is the only dimension of ACAP that affects the dependent variable in such a positive manner. Acquisition, assimilation and transformation activities do not seem to be relevant for our sample of tile producer companies when it comes to adopting the technology earlier.

This distribution of significances among the different dimensions also has some implications if we consider the separation between potential and realized ACAP. In fact, our results indicate that tile manufacturers benefit from doing internal activities that aim to enhance their realized rather than their potential ACAP. Hence, our results do not confirm H1, concerning the positive effects of the potential ACAP, and partially support $\mathrm{H} 2$, which refers to the realized ACAP. 


\subsubsection{Conclusions of the study}

This paper has attempted to determine the effect of ACAP on innovation through the adoption of a disruptive technological innovation in the context of an industrial cluster. By doing so, we aimed to provide a better understanding of the factors determining the earlier adoption of a disruptive technology by firms in an industrial cluster. The ACAP model has been studied through the potential (exploring) and realized (exploiting) domains, consequently distinguishing among the four dimensions proposed by Zahra and George (2002), namely acquisition, assimilation, transformation and exploitation.

Undoubtedly, the analysis of the association between individual attributes and exploration/exploitation activities concerning new technologies was not at all novel (McDermott \& O'Connor, 2002). However, adapting the ACAP perspective to clustered firms is, as far as we know, a relatively undeveloped avenue of research. Moreover, in our opinion, the study of the different factors comprising ACAP may contribute to clarify the innovative dynamics in clusters.

It must be mentioned that, whereas Hypotheses $1.1,1.2$ and 2.1 were not confirmed, Hypothesis 2.2 was statistically supported. This result suggests that the early adoption of a disruptive technology is not fostered by the acquisition and assimilation capacities of firms when they belong to a cluster. In other words, potential ACAP does not seem to have a clear effect on the early adoption of a technological novelty for clustered firms. Furthermore, the fact that the variable indicating the transformation capacity is not significant stresses its irrelevance for a clustered firm in the early adoption of a distant technological innovation. Conversely, the analysis shows how exploitation capabilities have a significant influence on this adoption.

What our study reveals, and in our opinion, what constitutes its main contribution is the uneven effect of the potential (exploring) and realized (exploiting) domains of the ACAP model on the early adoption of disruptive technologies for clustered firms. Network peculiarities and proximity in these kinds of territorial organizations may be underlying this result. 
Our results confirm that it makes sense to draw a distinction between the two dimensions of ACAP. This means that potential absorptive capacity does not seem to have a clear effect on the early adoption of a technological novelty for clustered firms. Firms belonging to a cluster have access to a number of systemic capacities that can cover their need for acquisition and assimilation capacities.

This research is relevant for many reasons, some of which may be the importance of industrial clusters as a regional development phenomenon, the predominant focus of previous research (mainly based on the dynamics of adopting incremental innovations) and the current challenges facing territorial agglomerations (aiming to adapt their structures and strategies to the external global conditions (Philip Cooke et al., 2012)). Disruptive technologies and innovation can be understood as possible alternatives for survival and for the further development of clusters (Østergaard \& Park 2015). Moreover, the factors that once explained clusters' success can today become their main threat and restraint. Indeed, clusters' relational structure - which is far more appropriate for incremental technological improvements than radical or disruptive ones (Maskell 2001) - or other related factors such as a leadership vacuum for the change or the resistance coming from core members of the cluster (Pinkse, Vernay, \& D'Ippolito, 2018) may prevent the introduction and development of breakthrough novelties into clusters, consequently thwarting to some extent their potential renewal.

As we understand things, and in contrast to what might happen in other contexts, proximity between firms in clusters may affect the mechanisms for introducing (and afterwards exploiting) new technologies or external knowledge. Dense and recurrent relational structures in clusters lead individual organizations to share norms and values that regulate exchanges of knowledge resources (Uzzi 1996, 1997). This peculiarity transforms clusters into efficient contexts for continuous improvement processes, linked to the exploitation strategies of knowledge resources (Rowley et al., 2000). In addition, individual companies are heterogeneous and distinctive, so they will vary their capacity to exploit external sources of knowledge coming from the other members of the cluster. The interactions between cluster and individual firm levels can be relevant in a close relational context. The finding that the dimensions of ACAP differentially influence innovation in a clustered firm contrasts with the way they have traditionally been regarded as a full benefit to organizations (Stock et al., 2001; Veugelers, 1997). An 
established stream of research contains a number of examples which are worth mentioning (Belso-Martinez et al., 2013; Expósito-Langa et al., 2011). In both these studies, ACAP was analysed as a factor to create innovative capacity in firms. Even though several researchers have suggested that some dimensions of ACAP could have a downside, our findings are particularly important to extend the existing literature. In fact, the different contributions of the dimensions of ACAP in a cluster context are, in our opinion, understudied and open a new line of research to better understand the internal efforts performed by firms. Clustered firms may benefit from those cluster externalities which are focused on exploring new technologies, consequently focusing their efforts on carrying out exploitation of the innovations.

The practical implication of our findings is for both the cluster and the individual firm levels. In order to foster adaptation and renewal, clusters should establish systematic mechanisms to detect and introduce new and exclusive ideas through cluster networks. On the other hand, first, clustered firms should develop their own portfolio of abilities to enhance their interaction with the actors in clusters and take advantage of the exchanged knowledge that naturally flows throughout the agglomeration. As a matter for further discussion, we suggest that, in order to access external sources of new and exclusive knowledge, firms in districts can use indirect ties by means of intermediary agents (Molina-Morales \& Martínez-Fernández, 2004). In particular, local institutions and supporting organizations are relevant actors in territorial networks that provide external scanning abilities for the cluster as we showed in Empirical Study II.

Second, they should concentrate especially on developing exploiting capabilities since, as our results suggest, they will play an important role in being able to benefit from a novelty and this is not easily obtained from the cluster. Commercial exploitation of new knowledge (through, for instance, the development of prototypes, the fast adaptation of existing technologies to upcoming knowledge or efficient work when adopting new technologies) would provide companies with a differential ability to obtain early advantage from it.

In short, our results highlight the importance of identifying the relevant dimensions of the ACAP in a certain cluster as not all of them have the same impact on the firm's development of competitive advantage. Consequently, developing the management 
areas in relation with those dimensions of ACAP that have a major influence on innovative performance can be crucial for the competitiveness of clustered firms.

We are aware that our research has some limitations. They are related with the specific conditions that are developed in the cluster, which were probably acting as a moderator of these causal relationships. On the other hand, only one industry has been analysed and, more precisely, just one type of cluster configuration has been studied. The Spanish ceramic tile cluster can be considered as supplier dominated, according to the taxonomy proposed by Pavitt (1984). In this sense, clustered firms are so particular and specific conditions are so difficult to replicate that general conclusions can be biased. We acknowledge the need to apply this approach to other contexts not only belonging to the same part of the taxonomy but also to different ones (production-intensive or science-based clusters according Pavitt (1984)). Comparison of similarities and dissimilarities among them would strengthen the results of the research and conclusions would gain broader validation. In this way, we would be able to observe whether or not the important ACAP dimensions correspond to the intrinsic cluster dynamics or typology.

The following points can also be viewed as possible future avenues of research for the development of this study. The fine-grained process through which network structure is created or modified is an interesting and important area for future research. It is critical to know to what extent firms are externally conditioned or, on the contrary, they have a degree of freedom to decide the pattern of internal interactions within the cluster. Another fruitful area of inquiry is the dynamics of how firms' networks evolve and change in response to external challenges and new opportunities, such as a disruptive technological innovation. 


\subsection{Empirical Study IV: Early adoption of a disruptive technological innovation by clustered firms. Its participation on different paths to high innovation performance ${ }^{44}$.}

\subsubsection{Introduction}

Over the last decades, a lot of research has been devoted to innovation in territorial contexts like clusters and regions (Giuliani \& Bell, 2005; Pouder \& St. John, 1996; Sammarra, 2005). This fertile literature has contributed significantly in different research lines. Among them, we find specially interesting a growing body of work which is highlighting the importance of innovation related to the territorial resilience development (Bristow \& Healy, 2018; Clark et al., 2010; Philip Cooke et al., 2012). This concept which was initially developed at the regional level, has become an increasingly popular topic to explain industrial clusters' ability to face current challenges (Crespo et al., 2013; Gilly et al., 2014; Pike et al., 2010).

The intensive relationships in the local context, and the existence of different levels of resources at both, systemic and individual firm levels (Foss, 1996), provide clustered firms with opportunities for innovation which may be difficult to benefit from in other different contexts. In short, cluster peculiarities lead to a characteristic context for firms' innovation.

More in detail, we develop an approach which is focused on two main potential determinants for clustered firms' innovation. First, we address the firm's positioning in relation to the adoption of new technologies, particularly, disruptive technologies (Hervás-Oliver, Albors-Garrigós, et al., 2017) and, second, we highlight the importance

\footnotetext{
${ }^{44}$ Este estudio corresponde a una versión pre-print de un artículo que ha sido ya publicado en la revista Applied Sciences (ISSN: 0898-5626) cuya cita es Molina-Morales, Martínez-Cháfer, \& ValienteBordanova (2019). Different Paths to Achieve High Technological Innovation in Clustered Firms: An Analysis of the Spanish Ceramic Tile Industry, Applied Sciences 2019, 9(18), 3710; https://doi.org/10.3390/app9183710
} 
of individual firm's attributes (i.e. absorptive capacity) which are supposed to be critical on this highly connected context (Molina-Morales \& Expósito-Langa, 2013).

Previous studies explained success or failure of firms regarding the quick adoption of a new technology associated to factors such as the investment in developing the new technology; the inhouse technical capabilities or the specialized complementary assets (Tripsas, 1997). Firms' leaders, which normally control the well-established technology, are likely to show less adaptability to disruptive change. Consequently, they present more difficulties in retaining their dominant position when new technology becomes the new standard. Their rigid and established organizational routines (Leonard-Barton, 1995) and their major focus on the benefits offered by existing products (Adner \& Zemsky, 2006; Burgelman, 1996; Christensen \& Bower, 1996; Reinganum, 1983) are suggested to be some of the reasons behind this situation.

On the other hand and in the previous literature, another traditional explanatory line of how companies differ in reacting to changes, comes from their absorption capacity level (Cohen \& Levinthal, 1990). In fact, this firm's internal attribute has been found to be determinant of its innovation performance by an important avenue of research (Cassiman \& Veugelers, 2006; Leal-Rodríguez, Roldán, Ariza-Montes \& Leal-Millán, 2014; Vega-Jurado, Gutiérrez-Gracia, Fernández-de-Lucio \& Manjarrés-Henríquez, 2008).

Although these explanatory factors have been already used in previous studies, even in the cluster context, a more integrated and global analysis is missing. Differences among cluster companies are rarely addressed by the literature. Consequently, considering internal heterogeneity in clusters in terms of firm's typologies, we suggest that there are diverse paths to reach innovation outcomes and we aim to gauge whether disruptive technology adoption and absorptive capacity are necessary and/or sufficient conditions to lead innovation performance. Addressing this gap, we aim to offer a more complete and real picture of the innovation determinants in clusters.

To develop this aim, we use a complex causality (Meyer et al., 1993) approach using the Qualitative Comparative Analysis (QCA) technique (Ragin, 2008; Ragin \& Davey 2016; Woodside, 2016). We applied it to a sample of 88 ceramic tile companies 
representing the $75 \%$ of the total population of independent tile manufacturing companies of the Spanish ceramic tile cluster. A disruptive technology was introduced in the last decade affecting significantly the structure of the whole cluster as well as the individual companies' strategies and performances.

The expected contribution of this paper is twofold. First, we advance in the understanding of the mechanisms that companies have to achieve technological innovation in clusters and second, we add to previous works on the issue by investigating the role of interactions between internal attributes and the speed of technology adoption.

The paper is structured as follows: first, we describe the theoretical framework, then we justify and formulate our propositions. After that, we introduce the empirical section and, finally, we address the discussion of results and further conclusions.

\subsubsection{Specific theoretical framework and propositions}

\subsubsection{New technology adoption and absorptive capacity in clusters}

Authors argued that clustered firms benefit from accessing a series of resources and capacities at the cluster level which are not exclusive of an individual organization. This type of resources have been identified by scholars as higher-order resources and capabilities (Foss, 1996). Moreover, clusters have specific mechanisms to identify changes of the external environment and to facilitate access to new ideas or new opportunities.

In addition to this systemic level, from an individual firm perspective, internal attributes influence on its individual outcomes. In fact, previous research address the fact that the cluster capacities interact with individual organization level capacities amplifying the potential access to knowledge and exploitation to external resources (Giuliani \& Bell, 2005). In consequence, absorbing and exploiting external stocks of knowledge from other co-located actors is particularly relevant for firms (McCann \& Folta, 2011). On the other hand, another avenue of research has extensively analysed disruptive 
innovations, and other similar notions, intending to capture the radicalness and discontinuous nature of some new technologies and innovations (Adner, 2002; Ansari, Garud, \& Kumaraswamy, 2016; Bergek, Berggren, Magnusson, \& Hobday, 2013; Bower \& Christensen, 1995; Charitou \& Markides, 2002; Christensen, 1997; O’Reilly III \& Tushman, 2016). In the context of our research, we are interested in technologies and innovations beyond incremental developments or little changes. These distant technologies, which may be created or adopted by companies, use to lead to the replacement of previous products and technologies by new ones that provide the market with higher value. In this sense, disruptive changes can broaden and develop new markets and may disrupt existing market linkages (Adner \& Zemsky, 2006; Christensen \& Bower, 1996; Govindarajan \& Kopalle, 2006; Slater \& Narver, 1998).

At that point, we adopted the suggestion made by Markides (2006) about the work by Christensen (1997) of distinguishing between radical innovations to refer to products and disruptive innovations for technologies. In conclusion, in a cluster context and for the purpose of this paper, we define disruptive innovation as a technological change that incorporates new knowledge, resources or skills that makes obsolete the value of incumbent systems and technologies in the cluster.

Previous literature has described how local cluster characteristics, such as intense relationships, trust, and other relational features, make these contexts particularly appropriate for flow, absorption and modification of existing knowledge and technologies (Nadvi \& Halder, 2005) rather than for generation of new and disruptive ones. As a result of the aforementioned argument, apparently, clusters rarely alter the stock of knowledge in more than an incremental way (Humphrey \& Schmitz, 2000). In fact, previous literature has critically analysed the role of those internal mechanisms which are developed into the boundaries of the cluster (Lagendijk, 2002). For example, in a seminal work, Glasmeier (1991) analysed the difficulties of Swiss watchmaking companies to face external radical technological changes, which involved the digital technology. Similar conclusions come from some other Italian failure cases that have been reported by Lazerson and Lorenzoni (1999). Despite this major dominant trend, previous research offers some counterexamples of cases showing both successful exploration and exploitation of disruptive technologies introduction in clusters (i.e. Saxenian, 1991). Besides, the ability of clusters to generate or adapt disruptive innovations has been recently addressed by different authors even though in a marginal 
way (Albors-Garrigos \& Hervás-Oliver, 2014; Hervás-Oliver et al., 2017; Reig-Otero at al., 2014).

In a complementary perspective, different responses may be observed regarding the way that clustered companies face the introduction of disruptive technologies. Some firms succeed, improving their competitive position and opening new development opportunities; nevertheless, others fail suffering catastrophic consequences. The latter are, probably, better adapted to the previous technological regime and feature a proper technological position (Bergek et al., 2013; Sull, Tedlow \& Rosenbloom, 1997).

To sum up, despite the short body of work developed, we highlight the possibility of generation and development of disruptive innovations in the cluster contexts. Therefore, we embrace the significant influence on the firm's outcomes, on the one hand, of the adoption of these new technologies and, on the other hand, of its internal attributes related to the exploration and exploitation of external knowledge.

In particular, those internal attributes of firms which are promoting absorptive capacity (Cohen \& Levinthal, 1990), are suggested to be directly related to organizational learning which, in turn, is critical in the assimilation of external information (Cohen \& Levinthal, 1990). Literature on innovation has analysed the role of organizational learning, particularly learning from external sources, on the innovation performance of firms as stressed by O'Connor (1998). In similar vein, since innovation can be identified as a knowledge-intensive process, Stock et al. (2001) explain how higher levels of absorptive capacity will be associated to more effective innovation outcomes. In fact, another avenue for fruitful research has shown a strong correlation between absorptive capacity indicators and innovation output of the firms (i.e. Kamien \& Schwartz, 1982).

In conclusion, we stress the fact that the internal attributes of the firms have been found to be determinants of firms' innovation performance as a growing body of work has also highlighted (Cassiman \& Veugelers, 2006; Leal-Rodríguez, Roldán, et al., 2014; Vega-Jurado et al., 2008b). 


\subsubsection{Propositions}

\section{Equifinality of the combinations of conditions leading to technological innovation}

In the context of our research, equifinality means that there are several paths or combinations of conditions which may lead to the same outcome, in our case, the innovation performance of the clustered firms and, more precisely, the technological innovation outcome as we are focusing on adoption of technologies.

Far to consider a cluster as a homogenous group of companies, it is normally composed of a wide variety of firms in terms of competitive positioning, knowledge bases or innovation strategies. Some contributions attempted to analyse, under a core-periphery network perspective, how larger and peripheral companies (having high amount of internal resources devoted to internal research) share the location with smaller companies which, having a limited amount of R\&D resources, are highly interconnected with other similar companies in the core of the cluster (Molina-Morales \& MartínezFernández, 2009a; A Morrison \& Rabellotti, 2009). Cluster categorization, following Morrison and Rabellotti's analysis (2009), divides cluster's network in two different areas. On the one hand, the network core, where the companies benefit from the intensive exchange of knowledge and information; and on the other hand, the network periphery, where relationships are more distant and the flow of knowledge among companies is less intensive. Previous studies have demonstrated how these two different network levels use different paths to explore and exploit the stocks of knowledge and technologies (Rowley, Behrens \& Krackhardt, 2000).

More precisely, to the purpose of the present research, what we find interesting is the way internal diversity which exists in clusters prevents to consider a unique path for reaching the major firms' innovation outcomes. Consequently, one company can alternatively develop internal or external factors to obtain higher level of technological innovation. More precisely, we stress the fact that diverse combinations of factors, including high values of internal attributes related to absorptive capacity, are likely to lead to the higher level of technological innovation. 
The methodological approach we adopt, the Qualitative Comparative Analysis (QCA) technique, more specifically, fuzzy-sets QCA, is grounded on the complex causality which in turn translates into multiple conjunctural causation. In other words: Different causal paths may lead to the same outcome (De Meur \& Rihoux, 2002) which introduce the notion of equifinality. Under this perspective and in the context of our research, we presume some equifinality in the sense that there may be several alternative paths to reach technological innovation for cluster firms. Consequently, this outcome will be reached through a series of the logical combinations of factors. Thus, we state the following proposition:

Proposition 1: Diverse configurations of firms' attributes are equifinal to strong technological innovation in clustered firms.

\section{Effects of early adoption of disruptive technologies in clusters}

Early adoption of new technologies has been already studied in previous research. According to Tripsas (1997), factors such as the investment in developing new technology; the improvement of technical capabilities and the ability to appropriate the benefits of technological innovations through specialized complementary assets, are factors associated to success in the adoption of new technologies. In an opposite sense, previous studies have demonstrated that incumbent leaders may have difficulties in preserving their dominant technological position when a novel technology bursts into the market. In a similar vein, authors such as Leonard-Barton (1995), Adner \& Zemsky (2006); Burgelman (1996) or Christensen \& Bower (1996) illustrated how, among other reasons, established organizational routines, to be focused on current demand or the fear of losing the benefits offered by existing products may be considered as inhibitor factors to adaptation of incumbent firms to new and disruptive technologies.

In a territorial context such as an industrial cluster, disruptive innovations have been studied and revised by authors like Hervás-Oliver et al. (2017) or Reig-Otero et al. (2014) who stressed the implications from a cluster perspective of the new technology adoption. Different contributions attempted to describe how disruptive technologies produce changes in the technological trajectories of clusters and open new windows of 
opportunity for all types of present companies (even to new, modest or small ones) because during the technological shift previous technological advantages disappear (Markman \& Waldron, 2014; Park \& Lee, 2006). By accepting so, we argue that these set of opportunities are likely related with improvement of the firm's innovation performance. Consequently, disruptive technologies are called to enhance properties of the products as well as the product portfolios offered by the companies. In short, design performance and the development of new products may widely benefit from this technological change. Similarly, a new technology could improve firm's processes and services offered through different elements such as cost reduction, decrease of processing time, increase of flexibility among others.

In conclusion, we embrace a perspective grounded in the adoption of disruptive technologies as enablers of new and important opportunities for clustered firms to improve their technological innovation performance. And more precisely, we emphasise not only the adoption but the early adoption as an important driver for clustered firms to achieve a distinctive advantage in terms of technological innovation outcomes. We stress the fact that, especially in the cluster context, it is particularly important for firms to be early adopters due to the existence of important emulation mechanisms caused by specific cluster dynamics like the ease of knowledge flows and ideas, intense exchange and others (Molina-Morales, 2002).

Considering the aforementioned arguments, we expect that clustered firms adopting first a new disruptive technology previously developed in the cluster will achieve a higher innovation performance in its technological dimension. In the context of the fuzzy-sets QCA methodology (FsQCA) that we are using in this research, we can suggest that being an early adopter will be present in the paths (or combinations of conditions) leading to a higher technological innovation for the clustered firms. Indeed, all given paths towards our outcome usually consist in a combination of conditions which are sufficient to produce that outcome. In addition, it is possible to find a necessary path to reach the outcome, which means that this combination of conditions must be present if the outcome is present. However, despite this possibility, normally paths are not necessary combinations as usually some other alternative paths (with different combinations, at least partially) could produce the same outcome. Hence, we propose the following proposition: 
Proposition 2: Configurations including the condition of being an early adopter of the disruptive technology are path to strong technological innovation in clustered firms.

\section{Effects of internal attributes on innovation performance of the clustered firms}

A wide body of theoretical and empirical work has highlighted the importance of absorptive capacity (Cohen \& Levinthal, 1990) exerting a positive effect on innovation performance of the firms (Cassiman \& Veugelers, 2006; Vega-Jurado et al., 2008b). In the context of clusters, firms can amplify their opportunities of innovation through new and valuable resources since the knowledge base of the individual firms has an additive effect to the systemic absorptive capacity characteristic of these territorial contexts (Giuliani, 2005). In similar vein, Belso-Martínez and Molina-Morales (2013) describe how $R \& D$ results are related to the knowledge base of the firm, and consequently to its absorptive capacity. Thus, it is expected a positive relationship between internal attributes related to absorptive capacity and innovation performance of clustered firms. However, literature offers different explanations, even divergent ones, in the way that his relationship can be represented. Some authors found a curvilinear effect between both variables (Belso-Martinez et al., 2013). This result advocates the need of reaching an optimal balance, since costs arising from internal resources development would rise, beyond a certain level, more than benefits. In similar vein, it is suggested that connectivity among the clustered firms amplifies the curvilinear effect of the R\&D effort focussed on innovation (Expósito-Langa et al., 2011). Clustered firms receive a large amount of knowledge and other technological-related resources from the other members co-located in the cluster. In consequence, firms' technological innovation performance, primarily depends on their capacity to benefit from these external sources of knowledge.

Consequently, we expect that clustered firms developing high levels of those internal attributes related to absorptive capacity are likely to lead to a higher innovation performance in its technological dimension. In the context of fuzzy-sets QCA methodology, we can express that absorptive capacity may be present in those 
combination of factors leading to higher technological innovation for clustered firms. In the same vein of the previous proposition, we stress the fact that these combinations may be necessary or sufficient paths for the outcome. Thus, we state the following proposition:

Proposition 3: Configurations including the condition of having internal attributes related to absorptive capacity are path to strong technological innovation in clustered firms.

\subsubsection{Specific empirical framework}

\subsubsection{Context of the research}

This paper is based in the Spanish ceramic tile cluster located in the province of Castellón. This cluster has already been studied by many authors that recognize its interest as a representative of these type of industrial agglomerations (Albors-Garrigos \& Hervas-Oliver, 2013; Expósito-Langa et al., 2011; Molina-Morales \& MartínezCháfer, 2016; Molina-Morales \& Martínez-Fernández, 2009b). In particular, the ceramic tile cluster of Castellón accounts with several aspects that make it very relevant for the worldwide ceramic industry. Among its main attributes we can find technological knowledge, highly skilled labour, strong identity, cultural embeddedness, the institutional ecosystem, knowledge transmission activities, internal business and technological networks, etc.

In the current economic scenario, the ceramic tile industry of Castellón produces the $94 \%$ of the total Spanish production of wall and floor tiles according to ASCER ${ }^{45}$. The main industrial activities involved in the production of wall and floor tiles are represented in the Castellón cluster. These main activities are wall and floor tile production, frits and glazes manufacturing, related machinery and equipment manufacturing, atomizing of raw materials, chemical additives production,

\footnotetext{
${ }^{45}$ Spanish Association of Wall and Floor tiles manufacturers. Data in this section come from ASCER website http://www.ascer.es checked on September 2018
} 
complementary tiles manufacturing or digital designing, among others. As a representative of the cluster agglomeration model, the ceramic tile industry in Castellón also accounts with a rich institutional ecosystem that provides support to the cluster firms. Among these supporting organizations, either with a national or regional span, we can name research centers such as the Ceramic Technological Institute of Castellón (ITC), the local university (Universitat Jaume I), important trade associations (ASCER, $\mathrm{ASEBEC}^{46}$ and $\mathrm{ANFFECC}^{47}$ ), chambers of commerce and many more. The range of activities and its positive effect on the cluster has been analyzed previously in the literature where the research show their implication either in the business or the technological networks (Molina-Morales \& Martínez-Cháfer, 2016). Regarding the sales volume of the sector in 2017, the global result comprising the most important and representative activities on the cluster was 5.255 million of Euros. This result comprises the tile sales volume (3.510 million of Euros, according to $\mathrm{ASCER}^{48}$ ), the frits and glazes sales volume (1.322 million of Euros, according to ANFFECC ${ }^{49}$ ) and the machinery sales volume (423 million of Euros, according to $\mathrm{ASEBEC}^{50}$ ). The sector accounts with an associated employment of approximately 15.000 people according data from ASCER trade association.

This cluster experienced at the beginning of the 2000's a disruptive innovative phenomenon based on a radical change in the way of printing the ceramic tiles, the digital printing technology. As widely described by different authors such as AlborsGarrigos and Hervás-Oliver (2013) or Reig-Otero et al. (2014) this innovation, which was introduced into the cluster by a visionary agent, changed the value chain of the ceramic tile business, first in the Spanish ceramic tile cluster and later on in the ceramic tile manufacturing industry worldwide.

\footnotetext{
${ }^{46}$ Spanish Association of machinery manufacturers.

${ }^{47}$ Spanish Association of frit, glaze and ceramic colour manufacturers.

${ }^{48}$ Data in this section come from ASCER website http://www.ascer.es checked on September 2018

${ }^{49}$ Data in this section come from ANFFECC website http:// https://www.anffecc.com/es/ checked on September 2018

${ }^{50}$ Data in this section come from ASEBEC website http:// www.asebec.org checked on September 2018
} 


\subsubsection{Data source}

A survey, based on a structured questionnaire, provided the primary data needed for this research. The aim of these survey was to gather detailed information about the adoption process of the technological innovation, the digital printing technology, developed to improve the tile manufacturing value chain. Consequently, among all firm categories which comprise the cluster, interviews were only addressed to the final tile producer category: the wall and floor ceramic tile manufacturers. They are those members of the cluster who, potentially and exclusively, are able to adopt the digital printing technology. Other different company categories belonging to the cluster such as, specialized or integrated firms were, in consequence, are out of the purpose of present research.

The survey was conducted in two rounds from October 2016 to February 2018, gathering a total amount of 88 completed questionnaires. At that time, total population of independent tile manufacturing firms in the cluster reached the amount of 118. The targeted group of respondents were mainly CEOs or R\&D managers. These respondents were considered by the researchers as the most suitable profiles because, considering the specific structure of the ceramic tile companies in the cluster, they are those who were expected to have a first-hand information about the impact of the new technology as well as how innovative dynamics are developed in their own companies. Nevertheless, and to a lesser extent, some questionnaires were answered by different profiles of respondents such as marketing managers or technical production managers. They are similarly involved in the innovation processes of their corresponding companies.

Moreover, secondary information was gathered from SABI database (Iberian Balances Analysis System) in order to obtain other relevant features of the companies as well as their business and performance information. In more detail, data regarding total assets, total revenues and number of employees were gathered for the respondent companies from 2007 until 2013. This period of time was selected so as to cover a representative period around 2010 in accordance with the consideration of this year as the threshold for a company to be considered as early adopter of the disruptive technology as described in the previous section. 


\subsubsection{Methodology: Qualitative Comparative Analysis}

The Qualitative Comparative Analysis (QCA) consists of a combination of qualitative and quantitative methodological approaches that was originally developed for sociological and political sciences (Ordanini, Parasuraman \& Rubera, 2014; Ragin, 2014; Sager \& Andereggen, 2012). However, other fields of science are devoting interest in QCA. This is the case of studies that focus on configurations of constructs characterized by a certain degree of complexity in fields like strategic management, innovation or marketing, among others (Fan, Li \& Chen, 2017; Fiss, 2007; Greckhamer, Misangyi, Elms \& Lacey, 2008; Ordanini \& Maglio, 2009; Ordanini et al., 2014; RoigTierno, Gonzalez-Cruz, \& Llopis-Martinez, 2017). QCA methodology focuses its analysis on causal recipes leading to an output (Ragin, 2008). More precisely, this configurational comparative method identifies one or some alternative combinations (recipes) of antecedent conditions (ingredients) that lead to a specific outcome or to the outcome's negation. In this sense, it unravels causal complexity of conditions rather than to analyse its net effects (Woodside \& Baxter, 2013). Consequently, QCA is characterised by its equifinality, meaning that the same outcome might be a result of different combination of causal conditions (Ragin, 2008; Woodside \& Baxter, 2013).

In this section, we will carry out the analysis in two steps. The first step consists in assessing the presence of necessary conditions for the outcome (strong technological innovator); that is, to evaluate whether the presence or absence of any of the conditions under study (or a logical combination of them) is necessary for the final manufacturing companies to be strong technological innovators. The second step consists in analysing which conditions or patterns (paths) are sufficient for final companies to intensively perform technological innovations (product and/or process innovations).

The idea behind QCA is complex causality. Under this notion: "social phenomena have multiple and conjectural causes. The way in which a certain condition $X$ affects a specific outcome Y depends on the presence or absence of other conditions. Similarly, a specific outcome can be caused by different combinations of conditions" (Befani, Ledermann \& Sager, 2007, p. 173). This implies the presence (or absence) and interaction of various forces and diverse configurations of elements having into account that an outcome (or result) in one case may not be the same in other occurrences. Thus, 
conjunction, equifinality and asymmetry are characteristics considered in the solution portfolio that emanates from QCA analysis (Meyer et al., 1993). This allows the results to be a better proxy of reality they represent. In this sense, QCA provides an interesting approach and some advantages for managerial and innovation studies (Ordanini et al., 2014; Woodside, 2016). In any case, the general perception for the authors that compare the QCA results with other traditional methods and conventional techniques is that QCA is a very good complement. In fact, some of these studies point to the fact that relying solely on regression analysis, for example, can be misleading in certain occasions (Woodside, 2016).

In this research paper we have used fuzzy-sets QCA (FsQCA) which is the latest version of QCA (Crilly, Zollo \& Hansen, 2012; Fiss, 2007, 2011; Ragin, 2008). By doing this we perform a cross-case systematic analysis to find out about the relationships among variables in terms of set membership. To do so, QCA is based on Boolean algebra in order to uncover combinations and configurations of variables that yield to necessary and sufficient conditions to obtain a certain outcome.

The sequence of steps to perform the analysis, according to Fiss (2011), involves the following tasks: defining the property space, developing the membership measures to the different sets, evaluation of consistency among set relationships and the final logical reduction. In the first phase, we must identify all the possible conditions that cause the outcome (property space). This means that we need to define the possible configurations of drivers or attributes that enable the result under study. This is an important step due to the fact that choosing the correct drivers is key to a successful analysis. This selection, consequently, has to be done according to existing theoretical knowledge (Ordanini et al., 2014). In short, we are dealing on the one hand with an outcome (the feature we are aiming to explain) and, on the other hand, with different conditions (or attributes). In the present research, the outcome is related with the technological innovativeness of the companies, as previously stated in the theoretical propositions. Regarding the conditions, they have been defined from a set of variables (or internal features of the companies) which may be related with the outcome. Among them, early adoption and absorptive capacity are suggested to play an important role as previously justified in the theoretical framework. In Tabla 51, the outcome scope, the variables and the conditions are listed. All the items used in the survey to build the outcome as well as 
the variables, which in turn, will lead to the conditions, are listed in Appendix B together with additional details and justification for them. Finally, Tabla 52 identifies the property space in our analysis in terms of outcome and sets (condition) definition.

Once we have the sets defined, we need to assign a value of memberships. In other words, and applying to our research, we need to know the extent to which the cluster firms are a member of the different sets defined in the first phase. This step is also known in the QCA literature as the calibration process which can be either direct or indirect (Ragin, 2008). In our case we used the direct calibration method, following the recommendations of Ragin (2008) for medium to large samples. Direct calibration is performed by indicating whether a certain condition is fully in or fully out of a particular set at the point of maximum ambiguity. In our case we used the fsQCA package in $\mathrm{R}$ to do our calibration (Duşa \& Thiem, 2014) whose results are shown in Tabla 53. This table shows the cut-off points for the memberships that we used for every single condition we previously defined.

After calibrating our variables, the next step was building the truth table to organize all the possible configurations of conditions and their correspondence to the outcome presence. In order to do so we used the software package fsQCA 3.0 (Ragin \& Davey, 2016). This software package, by means of logical reduction, is able to provide the solutions that are relevant. Finally, we conclude the analysis focusing on the necessary and sufficient conditions. Hence, we can identify whether a particular condition, or a combination of them, yields to the outcome or are always present in every combination that cause the outcome. To evaluate the importance and suitability of every solution in the portfolio we use the measures of consistency and coverage provided by the software, also for the overall coverage. 
Tabla 51: Outcome scope, variables and associated conditions

\begin{tabular}{c|c|c}
\hline Outcome scope & $\begin{array}{c}\text { Variables for explaining } \\
\text { the outcome }\end{array}$ & $\begin{array}{c}\text { Associated condition to the } \\
\text { variables }\end{array}$ \\
\hline \multirow{4}{*}{$\begin{array}{c}\text { Technological } \\
\text { Innovativeness }\end{array}$} & Early Adoption & Early Adopter \\
\cline { 2 - 3 } & Experience in R\&D activities & Experienced R\&D Firm \\
\cline { 2 - 3 } & Sizorptive Capacity & Strong Absorptive capacity \\
\cline { 2 - 3 } & Intensity in R\&D activities & $\begin{array}{c}\text { High intensity in R\&D } \\
\text { activities }\end{array}$ \\
\cline { 2 - 3 } & & Sirm \\
\hline
\end{tabular}


Tabla 52: Outcome and conditions: description and codifications

\begin{tabular}{|c|c|c|}
\hline Type & Name and Code & Description \\
\hline Outcome & $\begin{array}{l}\text { Strong Technological Innovator } \\
\text { (INN_TEC) }\end{array}$ & $\begin{array}{l}\text { Being a strong technological } \\
\text { innovator means to introduce, } \\
\text { intensely, product and process } \\
\text { innovations into the company. }\end{array}$ \\
\hline \multirow{5}{*}{ Condition } & Early Adopter (EARLY) & $\begin{array}{l}\text { Being early adopter means to adopt } \\
\text { the technology before its massive } \\
\text { adoption in the cluster. }\end{array}$ \\
\hline & $\begin{array}{l}\text { Strong } \\
\text { (ACAP) }\end{array}$ & $\begin{array}{l}\text { To have a strong Absorptive Capacity } \\
\text { means to have a high capacity of } \\
\text { acquiring, assimilating, transforming } \\
\text { and exploiting new knowledge } \\
\text { coming from outside. }\end{array}$ \\
\hline & Experienced R\&D Firm (ARD) & $\begin{array}{l}\text { Being an experienced } R \& D \text { firm } \\
\text { means to have an experienced } R \& D \\
\text { department in terms of years of } \\
\text { activity. }\end{array}$ \\
\hline & Big firm (SIZE) & $\begin{array}{l}\text { Being a big firm means to have a big } \\
\text { size in terms of employees, assets y } \\
\text { revenues. (Average values from 2007- } \\
2013 \text { ) }\end{array}$ \\
\hline & $\begin{array}{l}\text { High intensity in } R \& D \text { activities } \\
\text { (PID) }\end{array}$ & $\begin{array}{l}\text { To have a high intensity in } R \& D \\
\text { activities have been defined by having } \\
\text { a high number of employees in } R \& D \\
\text { Departments (\% over total employees } \\
\text { of the company) }\end{array}$ \\
\hline
\end{tabular}


Tabla 53: Descriptive statistics and calibration points

\begin{tabular}{c|c|c|c|c|c|c}
\hline & \multicolumn{3}{|c|}{ Descriptive statistics } & \multicolumn{3}{c}{ Calibration Anchors } \\
\hline & Max & Min & Mean (S.D) & Fully-in & Crossover & Fully-out \\
\hline INN_TEC & 5 & 0 & $3.52(1.76)$ & 5 & 4 & 1 \\
\hline EARLY & 17 & 0 & $8.05(3.88)$ & 9 & 6 & 4 \\
\hline ACAP & 2.0 & -3.4 & $0.00(0.99)$ & 1.3 & -0.6 & -1.5 \\
\hline ARD & 100 & 0 & $11.97(12.34)$ & 20 & 13 & 5 \\
\hline SIZE & 7.7 & -0.50 & $0.00(0.99)$ & 0.3 & 0 & -0.4 \\
\hline PID & 40 & 0 & $6.23(7.88)$ & 10 & 5 & 0 \\
\hline
\end{tabular}

NOTE: As in Crilly et al. (2012), values of 1.99 and 2.99 have been computed as 2 and

3 in the fsQCA software. 


\subsubsection{Results of the Study}

\subsubsection{Analysis of necessary conditions}

As proposed by Schneider and Wagemann (2010) and Rihoux and Ragin (2009), Tabla 54 presents the results of the FsQCA test of necessary conditions for the outcome Strong Technological Innovator as well as its absence (indicated by the symbol “ ”). In our study, test of necessary conditions is checking whether the presence or absence of any of the conditions under study is necessary for the final tile companies to be strong technological innovators in terms of product and process development. A condition, or a combination of conditions, is considered as necessary if the consistency score exceeds the threshold of 0.90 while the coverage score exceeds the threshold of 0.50 (Schneider \& Wagemann, 2010).

In case of the outcome Strong Technological Innovator, the logical combination "OR" of conditions: Early adopter and Strong Absorptive capacity of the company exceeds the threshold of 0.9. Despite this, we cannot state that this logical combination can be considered as a necessary condition due to the fact that RoN score (Relevance of Necessity) does not exceed the threshold of 0.6 (Ragin, 2008; Schneider \& Wagemann, 2010). Consequently, we can suggest that there is not a specific feature that necessarily leads the final tile producers to be strong technological innovators in terms of product and/or process development. 
Tabla 54: Analysis of necessary conditions

\begin{tabular}{lll}
\hline Outcome: Strong technological innovator & & \\
\hline Conditions & Consistency & Coverage \\
\hline Early Adopter (EARLY) & 0.762 & 0.635 \\
\hline$\sim$ Early Adopter (EARLY) & 0.331 & 0.597 \\
\hline High intensity in R\&D activities (PID) & 0.581 & 0.729 \\
\hline$\sim$ High intensity in R\&D activities (PID) & 0.580 & 0.606 \\
\hline Experienced R\&D Firm (ARD) & 0.512 & 0.750 \\
\hline$\sim$ Experienced R\&D Firm (ARD) & 0.623 & 0.580 \\
\hline Strong Absorptive capacity (ACAP) & 0.814 & 0.698 \\
\hline$\sim$ Strong Absorptive capacity (ACAP) & 0.335 & 0.569 \\
\hline Big firm (SIZE) & 0.442 & 0.826 \\
\hline$\sim$ Big firm (SIZE) & 0.684 & 0.560 \\
\hline EARLY and ACAP & 0.663 & 0.727 \\
\hline EARLY or ACAP & 0.913 & 0.627 \\
\hline Outcome: $~$ Strong technological innovator & & \\
\hline Conditions & Consistency & Coverage \\
\hline Early Adopter (EARLY) & 0.704 & 0.443 \\
\hline$\sim$ Early Adopter (EARLY) & 0.419 & 0.571 \\
\hline High intensity in R\&D activities (PID) & 0.500 & 0.474 \\
\hline$\sim$ High intensity in R\&D activities (PID) & 0.714 & 0.563 \\
\hline Experienced R\&D Firm (ARD) & 0.403 & 0.447 \\
\hline$\sim$ Experienced R\&D Firm (ARD) & 0.775 & 0.545 \\
\hline Strong Absorptive capacity (ACAP) & 0.664 & 0.430 \\
\hline$\sim$ Strong Absorptive capacity (ACAP) & 0.534 & 0.685 \\
\hline Big firm (SIZE) & 0.291 & 0.410 \\
\hline$\sim$ Big firm (SIZE) & 0.877 & 0.543 \\
\hline EARLY and ACAP & 0.516 & 0.428 \\
\hline EARLY or ACAP & 0.851 & 0.442 \\
\hline No: All condition & & \\
\hline
\end{tabular}

Note: All condition listed above has been calibrated. Absence of the condition is indicated by $(\sim)$. 


\subsubsection{Analysis of sufficient conditions}

In order to analyse the sufficient conditions related with the outcome (and its absence), the construction and examination of the truth table is required (Mas-Verdú, RibeiroSoriano, \& Roig-Tierno, 2015; Ragin, 2008). The truth table contains all possible logical combinations (Fiss, 2011; Ragin, 2008). Specifically, in our study, there are 32 possible configurations $\left(2^{5}\right)$, where 5 is the number of suggested conditions in this study. Categorization of the conditions were followed (Schneider, Schulze-Bentrop, \& Paunescu, 2010).

Depending on the approach used to simplify assumptions a fsQCA analysis yields three different solutions: complex, intermediate and parsimonious (Ragin, 2008). The causal recipes proposed by these three different solutions may differ more or less from each other, nevertheless they are always equal in terms of logical truth and never will contain contradictory information (Legewie, 2013). Firstly, the complex solution does not allow for any simplifying assumptions to be included in the analysis; therefore, this solution term is often hardly reduced in complexity and barely helps with the data analysis, especially when operating with more than a few causal conditions. Secondly, the parsimonious solution reduces the causal recipes to the smallest number of conditions possible. The conditions included in it are prime implicants, i.e., they cannot be left out of any solution to the truth table. The decisions on logical remainders are made automatically, without regard to theoretical or substantive arguments on whether a simplifying assumption makes sense, so some authors strongly argues against it (Ragin, 2008; Schneidr and Wagemann, 2007).

Finally, the intermediate solution includes selected simplifying assumptions to reduce complexity, but on the other hand does not include assumptions that might be inconsistent with theoretical and/or empirical knowledge introduced by the researchers (Legewie, 2013). In summary, it could be understood as a complex solution simplified in some extent through fundamental theoretical or substantive knowledge (Schneider \& Wagemann, 2012). At this point, the knowledge and experience of researchers is paramount to drive the qualitative side of the logical methodology. The intermediate solution is widely used in literature as can be considered as a good compromise between the other two solutions for unravelling causal complexity of conditions in fsQCA 
analysis (Crilly et al., 2012; Eng \& Woodside, 2012; Fiss, 2011; Henriques et al., 2017; Mas-Verdú et al., 2015; Santos, Mota, \& Baptista, 2018; Schneider et al., 2010). In this study the assumptions carried out are the presence of the conditions early adoption of the disruptive technology and strong absorptive capacity for the outcome as in our opinion, they are the most driving conditions for the ceramic tile companies to be really strong innovators in terms of product and processes taking into account the innovative history of the ceramic tile cluster in the last decade. These proposed assumptions allow our analysis to match up to our theoretical expectations as proposed by Schneider and Wagemann (2010).

Tabla 55 presents the results of the analysis of the sufficient conditions according the intermediate solution for the outcome (highly technological innovator). The results are validated according the insights from expert authors such as Fiss (2011); Ragin (2006b, 2008); Ragin, Drass, \& Davey (2006) or Rihoux (2003). This Tabla 55 shows the different combinations of conditions that comprise alternative sufficient paths or recipes to the outcome. We used the notation proposed by Ragin (2009) and Fiss (2011) according to which black circles indicate the presence of a condition, white circles indicate the absence of the condition and blank spaces don't care. Furthermore, big circles indicate core conditions and small circles indicate peripheral conditions. While core conditions are considered as essential for the outcome, peripheral ones are less important or in some cases, expendable or exchangeable (Fiss, 2011). The author defines: "core elements as those causal conditions for which the evidence indicates a strong causal relationship with the outcome of interest and peripheral elements as those for which the evidence for a causal relationship with the outcome is weaker" (Fiss, 2011 , p. 394). In our case, all recipes shown in the table contain a combination of core and peripheral conditions.

Each of these paths are characterised by three different scores: raw and unique coverages and consistency. The raw coverage score reflects the extent to which this recipe can explain the outcome. The lower a coverage score, the less empirically relevant a causal recipe; it is able to explain fewer cases in which the outcome occurred (Legewie, 2013). On the other hand, the unique coverage score shows the proportion of cases that can be explained exclusively by that recipe. It is meaningful because it indicates how many cases a given recipe can explain without any other recipe offering 
explanation. Often there is considerable overlap between recipes, so it is not unusual for the unique coverage scores to be rather low $(<0.15)$ (Legewie, 2013). Recipes with higher unique coverage thus gain relevance because without them more cases would be beyond the explanatory reach of the model. Finally, the recipe's consistency score reflects the amount of cases that are not fitting with this specific path. The lower a consistency score of a path, the more cases do not fit the patterns identified by it or, in other words, the more substantial are the contradictions that certain cases pose to this recipe. Ragin (2009) recommends a consistency threshold of 0.80; in our case, all recipes's scores comply with this threshold.

Moreover, table 61 shows the overall coverage and consistency for the solution which indicates the robustness of our solution. The solution's coverage score reflects the empirical importance of a given solution. It should be as high as possible, usually above a score of 0.25 . The solutions' consistency score confirms that the specific configuration of antecedents is sufficient for explaining the outcome condition (Ragin, 2008). Different authors consider a robust solution those whose consistency threshold are at least 0.75 , but preferably 0.85 or higher (Ragin, 2006b, 2006a; Rihoux \& Ragin, 2009; Woodside \& Baxter, 2013). Regarding the overall consistency and coverage values obtained from the intermediate solution of our research, we stress the fact that they surpass the minimum values which are considered suitable; the consistency score is 0.84 (indicating that the combined recipes account for about $84 \%$ of the membership to the outcome) while coverage score is 0.56 .

Finally, Table 5 shows the overlapping coverage score. The extent of overlap indicates two things. On the level of the data set, it shows how strongly the cases gather along certain dimensions on the causal conditions. On the level of the single cases, it shows in how many cases with the occurrence of the outcome that can be explained in more than one way (Legewie, 2013). In our case, overlapping coverage score is 0.33 .

Our sufficiency analysis shows five different paths to the outcome. Actually, as stated before, all of them comply with the threshold of 0.8 recommended by Ragin (2008). The analysis suggests two differentiated tendencies for achieving the outcome (to be a highly technological innovator). On the one hand, configurations 1, 2, 3 and 4 refer to those companies which are early adopters of the disruptive technology, have a strong 
absorptive capacity or both together; this group of configurations in which size of the company is not present, presents a higher raw coverage scores and consequently represents a higher amount of cases. This means that regardless of the size firm can reach high levels of technological innovation through different paths. On the other hand, configuration 5 refers to those companies that do not present the previous conditions, but they are large and experienced in R\&D tasks as well as they invest important amount of resources in $R \& D$ activities.

In four out of the five paths proposed by the fsQCA analysis, early adoption, strong absorptive capacity (or both) are present as antecedent conditions to be a strong technological innovator, in terms of product or process developments. While in three of them early adoption is present, in other three recipes strong absorptive capacity is an ingredient to reach an intense activity from a technological innovation point of view. These findings show that early adoption and high absorptive capacity may be important conditions which match up to our theoretical expectations and is in line with the innovation and knowledge management literature. Hence, our results are aligned with the propositions that we outlined in the theoretical framework. We should note that their contribution is considered by the fsQCA analysis as peripheral in comparison with other elements. Despite this fact, we consider that the repeated presence of both factors in paths obtained (four out five paths contains the early adoption or the high absorptive capacity or both) highlight their important influence as determinants of innovation.

Path 1 is especially interesting because its raw coverage is 0.356 . This means that around $36 \%$ of the cases can be explained through this configuration of antecedent conditions. On the other hand, this configuration also has a unique coverage value of 0.157 which means that it is able to exclusively explain almost $16 \%$ of all cases. Moreover, it shows two core conditions, high amount of R\&D resources and to be an experienced $R \& D$ firm. This configuration leads to the conjecture that companies may be highly technological innovators (regardless of their size) if they adopt early a new technology and they combine a strong absorptive capacity, a high amount of R\&D resources and an extensive experience in $R \& D$ tasks. Concurrently path 2 , having a similar raw coverage score but a lower unique coverage one, substitute the big size of the firm for high amount of $R \& D$ resources and an extensive experience in $R \& D$ tasks in relation to path 1 . This result points out that companies may be strong technological innovators (regardless of their size and experience of the R\&D department) if they 
adopt early a new technology and they are big enough. This path presents only a core condition, large size of the firm.

On the other side, path 5 corresponds to highly innovative companies that are characterised by big size, high investment in R\&D (both conditions are core) even with the absence of an experienced $\mathrm{R} \& \mathrm{D}$ department. This path is the less representative as the raw coverage score is 0.157 meaning that just the $16 \%$ of the cases can be explained through it. This finding is in line with the researchers' expectations as, not only in the Spanish ceramic tile cluster but also generally in the ceramic tile industry, big tile companies have easy access to knowledge and innovation capabilities through the specialized companies. In this sense, the Spanish ceramic tile cluster is considered as a supplier dominated cluster (Pavitt, 1984) where technological innovation is developed and provided by the specialized suppliers, mainly the frit, glazes and digital ink suppliers, to their customers, the final tile manufacturing companies. 
Tabla 55: Results of the intermediate solution

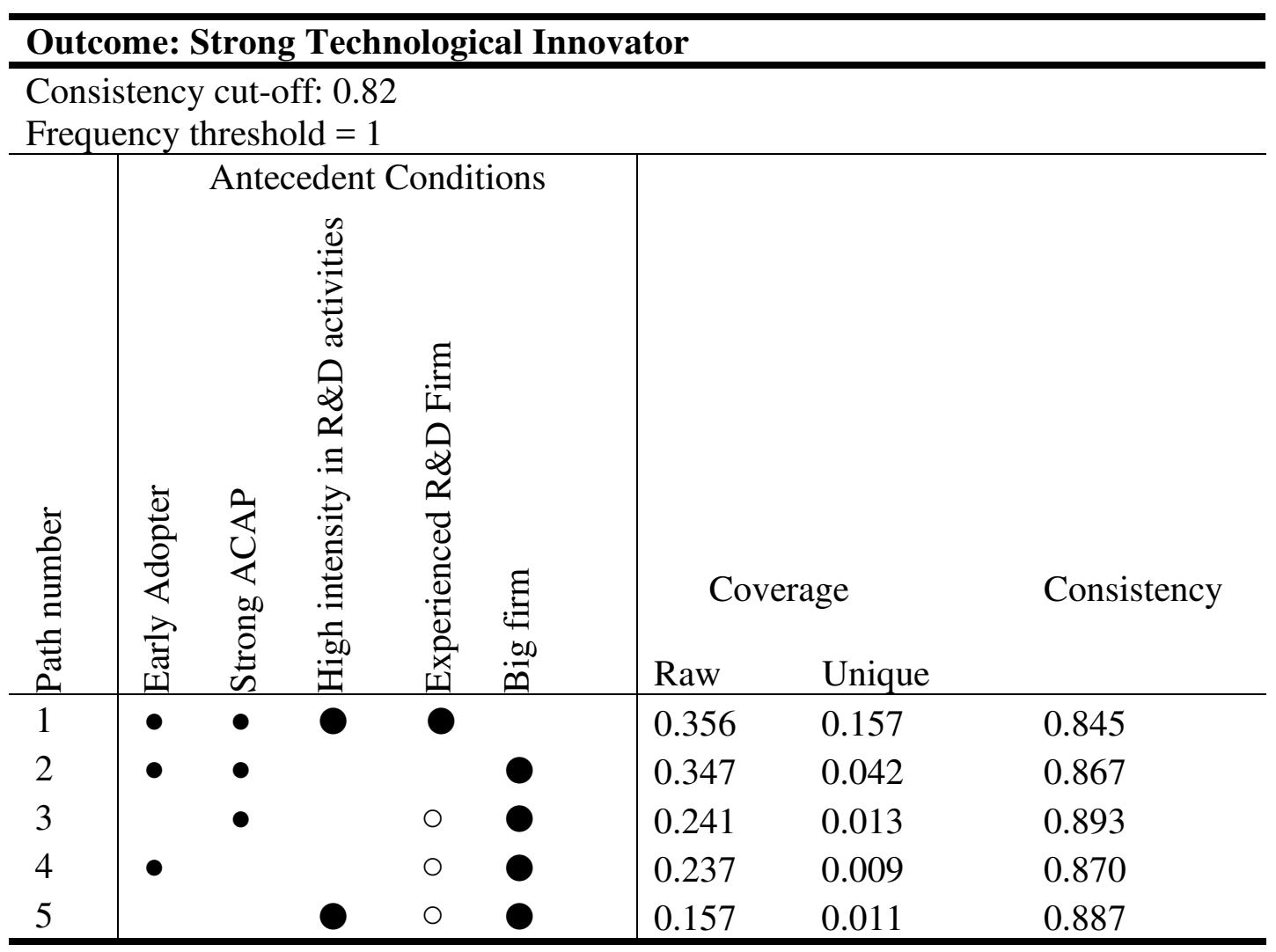

Solution coverage: 0.56

Solution consistency: 0.84

Overlapping coverage score: 0.33

Note: black circles “ $\bullet$ " indicate the presence of antecedent conditions. White circles " $\bigcirc$ " indicate the absence or negation of antecedent conditions. The blank cells represent ambiguous conditions.

Furthermore, large circles indicate core conditions, and small circles refer to peripheral conditions. 


\subsubsection{Conclusions of the Study}

In this paper we attempted to uncover the combinations of factors and properties present in the clustered firms that exhibit strong technological innovation behaviour. To do so we have performed a fsQCA analysis. This technique provides a very interesting approach that enables to obtain causal recipes leading to an output (Ragin, 2008). Our results show an interesting equifinality as we can see how the same outcome, being a strong technological innovator, can be obtained by combination of the presence and/or the absence of different conditions.

Our results highlight the importance of early adoption of new and disruptive technologies jointly with the absorptive capacity in becoming a firm with high results of technological innovation. Indeed, these two factors are present in most of the paths proposed which lead to high technological innovation performance. In conclusion, the analysis shows how the early adoption of disruptive technologies, in combination with the absorptive capacity, is a strong determinant of innovation for those companies belonging to industrial clusters. This is quite clear in sufficient analysis, where both conditions are present in the majority of paths leading to our outcome. In this sense, we argue how industrial clusters can benefit from uncovering the ingredients that shape firms as strong technological innovators. In our perspective, this knowledge can be profitable firstly for firm's managers, who look to increase the innovative performance of their companies as they recognize innovation as an important drive of competitive advantage and, in short, as a paramount source of value creation. In this sense our results, enabling different possibilities in terms of internal and external capabilities combinations, open a handful of possibilities for them. It is worth noting that our analysis suggests that size is not a limitation for firms to achieve high innovation performance. In fact, small clustered companies may obtain similar performance (in terms of innovation results) to larger ones by different combination of factors including the early adoption of a disruptive technology, the ACAP and R\&D expertise, for example. On the one hand, our results show how large clustered companies can benefit from a new technology and / or the ability of detecting and assimilating external knowledge in order to become a strong technological innovator even without having strong R\&D capabilities. We highlight the relevance of this result in the ceramic tile 
cluster which can be considered as supplier dominated according to the taxonomy proposed by Pavitt (1984). In this context, large companies have a prevalent position in capturing knowledge and expertise through technological leaders as those leaders (who provide the companies with different ceramic raw materials and machinery) are in turn their main providers. Therefore, we stress the fact that large firms are in a favourable position for increasing their innovation performance through a close relationship with their own providers.

Secondly, we emphasize that our results may guide policymakers who are looking to enhance the performance of their territories. In the literature, there is an emerging consensus highlighting the importance of innovation and networks of innovative companies as determinant of resilience of territories and clusters (Bristow \& Healy, 2018; Crespo et al., 2013; Eisingerich et al., 2010; Østergaard \& Park, 2013). In this sense we follow the avenue of research acknowledging the influence of innovation in the development of: "the adaptive capability that allows a cluster to make changes to overcome internal and external disturbance and still function with its identity as a cluster” (Østergaard \& Park, 2013, p. 4).

In doing so, we suggest the important role that early adoption of a new technology by clustered firms may play in the development of resilience at a cluster level and beyond the individual innovation performance achieved by individual firms through this adoption. Policymakers, in short, have in new technologies and their adoption a significant option to boost new trajectories of development in cluster (mainly if they are facing a maturity stage). This is, in our opinion, a key point as nowadays clusters are facing important challenges mainly caused by globalization. This global phenomenon is forcing them to design new strategies in order to be able to face new and changing global conditions.

We consider that our research work also contributes to the cluster literature reinforcing the argument that companies belonging to these agglomerations benefit from externalities whose impact may be amplified by its combination with internal capabilities. In this line, our results are complementary to other studies that show how the relationship between internal capabilities and innovation is often diverse or contingent to the firm's access to external resources (Belso-Martinez et al., 2013; 
Expósito-Langa et al., 2011). Furthermore, the proposed methodological framework based on the introduction of QCA analysis has direct implications as it complements the insights obtained through widely used correlational statistics. Indeed, the use of complex causality enables to open an interesting avenue for future research on cluster literature. This empirical approach would offer different necessary or sufficient configurations of factors (or paths) leading to important outcomes acknowledged in cluster literature such as innovation, business performance or resilience, among others. In this sense, in sum, this study opens new opportunities to new approaches using the QCA methodology to reinforce argumentations and insights about cluster firms' dynamics.

Finally, we are aware that our research has some limitations. First, we acknowledge the limited room for generalization of the results, the implications and the conclusions obtained as just a particular cluster reality has been analysed. Indeed, the innovation dynamics of the cluster under analysis may be conditioned by the peculiarity of being a supplier dominated cluster (Pavitt, 1984). Further research should be carried out in order to strengthen the results of the research and to gain broader validation. For instance, a comparative analysis of this case with other cases of clusters, not only belonging to the same part of the Pavitt's taxonomy (1984) but also to different ones (i.e. production-intensive or science-based clusters). Additionally, our study is a crosssectional approach opening the opportunity of extending with a longitudinal perspective as a future line of research. 
CAPÍTULO 7

\section{CONCLUSIONES DE LA INVESTIGACIÓN}




\section{CONCLUSIONES DE LA INVESTIGACIÓN}

\subsection{Introducción}

En la presente tesis doctoral hemos estudiado cómo los clústeres industriales son capaces de evolucionar gracias a determinados procesos innovadores y, más concretamente, mediante el desarrollo y asimilación de las denominadas innovaciones tecnológicas disruptivas. De forma particular nos hemos centrado en el estudio de los determinantes y de los efectos de estas innovaciones, a dos niveles diferentes: por un lado, a nivel de clúster, como entidad integrada, y por otro, a nivel de las empresas individuales que lo conforman. De hecho, este objetivo general se ha concretado en cuatro estudios específicos; dos de ellos se han centrado en analizar este proceso innovador desde una perspectiva de clúster, y los otros dos, desde la perspectiva de las empresas individuales que lo integran.

El primero de los estudios, ha analizado en profundidad el caso de la introducción, desarrollo y difusión de la impresión digital, llevado a cabo en el clúster cerámico de Castellón, como un ejemplo de innovación tecnológica disruptiva. El segundo de los estudios -buscando la posible generalización de los resultados obtenidos en el primeroha consistido en un estudio comparativo entre el caso del clúster de Castellón y un segundo caso de introducción de una tecnología disruptiva similar, la inyección de 
plástico, en el clúster industrial italiano de Montebelluna (en la región del Véneto), dedicado a la fabricación de calzado deportivo.

El tercer estudio se ha realizado desde una perspectiva de empresa individual que forma parte de un clúster. Nos hemos centrado en la identificación de aquellos atributos internos que favorecen la adopción de este tipo de innovaciones disruptivas. Finalmente, el último de los estudios ha consistido en evaluar cómo la adopción temprana de la tecnología disruptiva puede impulsar la capacidad innovadora de las empresas; de forma particular aquellos respecto a la innovación de producto y proceso.

Una vez citado brevemente su contenido, en los puntos siguientes de este capítulo, presentamos los principales resultados y conclusiones que se pueden desprender de esta tesis. Para ello, en primer lugar expondremos conclusiones generales, así como las implicaciones que éstas pueden tener. Para finalizar, analizaremos las limitaciones del estudio, así como las posibles líneas de investigación futuras que se pueden desprender de las mismas.

\subsection{Principales conclusiones de los estudios empíricos}

\subsubsection{Las conclusiones del primer estudio empírico}

En el primer estudio empírico hemos tratado de analizar cómo un clúster industrial puede desarrollar y difundir una innovación disruptiva, así como el impacto que ésta genera sobre el propio clúster. Este objetivo tiene, en nuestra opinión, un interés adicional debido a que el análisis de este complejo proceso innovador se ha hecho en el contexto de un clúster industrial maduro.

Cabe considerar que tal como han argumentado algunos autores, -como por ejemplo Elche-Hortelano, Martínez-Pérez, \& García-Villaverde (2015); Humphrey \& Schmitz (2000); Maskell (2001); Molina-Morales, 2002 o Nadvi \& Halder (2005)- los clústeres industriales presentan, en principio, condiciones mucho más adecuadas para el desarrollo de innovaciones incrementales (de menor trascendencia e impacto), que no 
radicales o disruptivas. Estos autores atribuyen este hecho a las propias dinámicas internas que en ellos se generan, resaltando la importancia de la intensidad y densidad de las relaciones internas de los mismos.

En el primer trabajo empírico hemos podido mostrar cómo en los clústeres industriales se pueden dar procesos de innovación disruptiva y, por tanto, que éstas no son exclusivas de contextos de grandes empresas en los que las estructuras organizacionales se encuentran mejor integradas. Sin embargo, al igual que parte de la literatura centrada en contextos de gran empresa integrada ha sugerido en estudios anteriores -como por ejemplo por Beck, Lopes-Bento, \& Schenker-Wicki (2016) o Leifer et al. (2000)nuestro análisis ha mostrado cómo en este tipo de aglomeraciones territoriales las posibilidades de iniciar y desarrollar procesos innovadores disruptivos se ven limitadas por diversos factores. Entre ellos, podemos destacar la falta de una visión externa a los límites del propio clúster, lo recursos limitados a las estrategias de exploración, la falta de una jerarquía que facilite a coordinación de las mismas, o la predominancia de una visión centrada en el corto plazo.

En definitiva, podemos concluir que las dinámicas propias del clúster, aun propiciando el mantenimiento de competitividad, sin embargo, limitan la capacidad que tienen los denominados gatekeepers tecnológicos existentes (Molina-Morales \& Martínez-Cháfer, 2016) para liderar los cambios más disruptivos o radicales. De hecho, nuestros resultados han mostrado la existencia de una resistencia al cambio por parte de éstos. Los resultados, también ponen de manifiesto el papel realizado por otros actores, por ejemplo, los agentes visionarios, los cuales sin formar parte del núcleo de liderazgo tecnológico -por situarse en muchas ocasiones en los límites del clúster- juegan un papel fundamental en el proceso de introducción y asimilación de información y conocimiento realmente novedoso dentro del mismo.

Finalmente, este primer estudio también ha analizado los efectos que la innovación disruptiva genera en un clúster industrial. Hemos observado cómo estas innovaciones generan un impacto positivo y muy importante a distintos niveles; tanto a nivel de la cadena de valor de la industria cerámica, reconfigurándola y haciéndola más eficiente, como a nivel de clúster como entidad, consiguiendo generar nuevas oportunidades de desarrollo y diversificación. Como consecuencia, podemos concluir que estos procesos innovadores son capaces de favorecer etapas de rejuvenecimiento en estos contextos 
territoriales. De este modo, el estudio contribuye a ampliar la línea de investigación abierta por otros autores como Hervás-Oliver, Albors-Garrigos, Estelles-Miguel, \& Boronat-Moll (2017); Markides (2006) o Østergaard \& Park (2015). Por último, pensamos que a través de este estudio se abren nuevas trayectorias para los clústeres maduros en la línea de lo que sugieren aquellos autores que analizan cómo estos modelos de organización territorial pueden iniciar nuevas etapas de desarrollo a través de distintos factores, principalmente denominados relacionales. Entre otros podemos destacar los estudios llevados a cabo por Belussi, Sammarra, \& Sedita (2008); Staber \& Sautter (2011) o Zucchella (2006).

\subsubsection{Las conclusiones del segundo trabajo empírico}

En el segundo estudio empírico hemos analizado si los resultados y conclusiones obtenidos del primer estudio -estando basados en el clúster industrial cerámico de Castellón- podían ser considerados como específicos y afectados por la caracterización del caso concreto o, por el contrario, podían ser generalizables en otros casos. Se trataba, en consecuencia, de poder enriquecer nuestro análisis inicial a través de un análisis comparativo con otro fenómeno similar. De hecho, las similitudes observadas a partir del estudio comparativo entre el caso de Castellón y el italiano de Montebelluna, nos ha permitido no sólo confirmar los resultados obtenidos en el primer estudio, sino también establecer unos patrones comunes tanto por lo que hace referencia a los determinantes como a sus consecuencias en los procesos innovadores disruptivos en clústeres industriales.

En primer lugar, hemos identificado tres elementos que consideramos necesarios para la introducción y el desarrollo de este tipo de innovaciones: (1) la presencia de los agentes visionarios (empresas i/o instituciones), que son capaces de detectar conocimiento realmente novedoso fuera del clúster y adecuarlo a las particularidades del mismo. Desde un punto de vista Schumpeteriano, podemos identificar este proceso como de inicio nuevo ciclo de innovación sobre el que se podrían sustentar nuevas rentas futuras; (2) la presencia de gatekeepers tecnológicos (normalmente empresas especializadas del propio clúster), que favorecen no sólo la asimilación del conocimiento externo sino también la adopción masiva de la novedad por parte de los miembros del clúster y, (3) 
la presencia outsiders (agentes externos al clúster) los cuales, con un amplio conocimiento de las tecnología disruptiva en cuestión, cooperan con los miembros del clúster para su adaptación y optimización.

La identificación de estos actores necesarios en el proceso innovador disruptivo contribuye y va en la dirección de la línea de investigación anterior que analiza el papel que juegan los diversos actores en los procesos de innovación en clústeres. En este campo podemos destacar las aportaciones de Giuliani (2011); Graf (2010); HervásOliver \& Albors-Garrigos (2014) o Morrison (2008). Además son coincidentes con los resultados obtenidos por Giuliani (2005) al reforzar la idea de que la capacidad de desarrollo de las innovaciones más distantes se encuentra limitado a un número selectivo de actores y no se distribuye de forma homogénea a lo largo de todos los miembros el clúster.

En segundo lugar, hemos podido observar cómo la difusión de la nueva tecnología es fundamental para que genere un impacto significativo a nivel de clúster, más allá del impacto que, de forma individual, pueda producir en las empresas. En este sentido, nuestros resultados son coincidentes con los obtenidos por otros autores como Jaffe, Trajtenberg, \& Henderson (1993). Nuestro estudio comparativo ha puesto de manifiesto el papel importante que juegan las empresas especializadas (supporting industries) en este contexto. Estas empresas, como suministradoras de servicios avanzados y de conocimiento altamente específico, son capaces de favorecer la difusión de la novedad tecnológica, reduciendo la incertidumbre y la resistencia al cambio de las empresas susceptibles de adoptar la innovación (en nuestro caso las empresas finales de fabricación cerámica). Se convierten así, en grandes prescriptores no sólo de los avances incrementales sino también de los más disruptivos. En este sentido, nuestra investigación contribuye al debate abierto respecto al papel que juega el conocimiento externo a la red, así como de las oportunidades de exploración de este conocimiento por parte de las empresas e incluso de su posterior explotación (Foss, Lyngsie, \& Zahra, 2013).

Por último, consideramos que este segundo estudio contribuye a la literatura de la resiliencia regional. En primer lugar, hemos podido identificar una trayectoria específica a través de la cual los clústeres pueden desarrollar su resiliencia: el desarrollo 
de innovaciones disruptivas. En segundo lugar, hemos sugerido una serie de indicadores que pueden ayudar a evaluar en qué medida se desarrolla esta característica en un contexto de clúster. Este conjunto de indicadores de resiliencia -que se ha definido tanto a nivel del clúster entidad como a nivel de empresa individual- puede considerarse como una alternativa a otras formas de medida propuestas a nivel regional por autores como Davies (2011); Dubé \& PolèSe (2016) o Sensier, Bristow, \& Healy (2016).

\subsubsection{Las conclusiones del tercer trabajo empírico}

En el tercer estudio hemos profundizado en el análisis de los factores internos a la empresa que favorecen la adopción temprana de las innovaciones disruptivas por parte de las empresas que integran el clúster.

Para ello, nos hemos basado en la capacidad de absorción (ACAP), un concepto ampliamente estudiado y aplicado en ámbito de la literatura de innovación (Cohen \& Levinthal, 1990). La ACAP se relaciona con el aprendizaje organizativo, elemento crítico para el aprovechamiento de información y conocimiento externo a la empresa (Cohen \& Levinthal, 1990). Más concretamente, en este estudio hemos adoptado una perspectiva bidimensional de la ACAP (exploración-ACAP potencial/explotaciónACAP realizada) para identificar los factores internos de las empresas con relación a su capacidad de explorar y explotar conocimiento externo. Esta aproximación ha tenido una gran presencia en la literatura, donde podemos destacar los trabajos de Becker \& Peters (2000); Jansen, Van Den Bosch, \& Volberda (2005); McDermott \& O'Connor (2002) o Zahra \& George (2002). No obstante, no se encuentran de demasiados precedentes en el estudio de la asimilación de nuevas tecnologías en el contexto del clúster. En efecto, no han sido frecuentes las investigaciones que han aplicado esta perspectiva en este contexto específico del clúster; como excepciones podemos mencionar los trabajos de autores como Expósito-Langa, Molina-Morales, \& CapoVicedo (2011) o Tomás-Miquel, Molina-Morales, \& Expósito-Langa (2015).

Los resultados del análisis que hemos realizado sugieren que el desarrollo de habilidades internas relacionadas con la $A C A P$ potencial no parece tener un efecto claro en la adopción temprana de una novedad tecnológica por parte de las empresas del 
clúster industrial. Por el contrario, es la dimensión correspondiente con la explotación (ACAP realizada) de las nuevas tecnologías la que tiene una influencia significativa en la adopción de las mismas. En este sentido, nuestros resultados serían coincidentes con otros estudios anteriores realizados en este mismo contexto. En efecto, la literatura de clústeres ha mostrado cómo las empresas que pertenecen a estas aglomeraciones tienen fácil acceso a una serie de capacidades sistémicas que pueden cubrir su necesidad de desarrollar de forma individual habilidades de adquisición y asimilación. En esta línea podemos poner como ejemplo las investigaciones llevadas a cabo por Expósito-Langa et al. (2011); Hervás-Oliver et al. (2017); Molina-Morales, Martínez-Fernández, \& Torlò (2011) o Molina-Morales \& Mas-Verdú (2008). Las capacidades sistémicas (conceptualizadas como capacidades de orden superior, Foss, 1996)- pueden catalizar la transformación de estas aglomeraciones en contextos altamente eficientes en la explotación del conocimiento (Rowley et al., 2000).

Este resultado es, en muestra opinión, muy relevante ya que permite a las empresas centrarse en el desarrollo de habilidades relacionadas con la explotación del conocimiento y no tanto en su exploración. En efecto, la sola pertenencia al clúster permite a las empresas acceder a conocimiento novedoso a través de otros actores clave como son, por ejemplo, las instituciones locales o las empresas líderes- especializadas, las cuales desarrollan unas habilidades y estrategias claves de exploración tecnológica. De este modo, el hecho de poder centrarse en la explotación comercial de nuevos conocimientos (mediante, por ejemplo, el desarrollo de prototipos, la rápida adaptación de las tecnologías existentes al nuevo conocimiento o el trabajo eficiente al adoptar nuevas tecnologías) les permite obtener ventaja competitiva respecto a otras empresas competidoras de su mismo contexto.

En conclusión, este estudio pone de manifiesto que no todas las habilidades internas relacionadas con la capacidad de absorción contribuyen de forma análoga al desarrollo de una ventaja competitiva por parte de las empresas que integran un clúster. En consecuencia, la labor directiva debería ir encaminada a identificar y desarrollar aquellas habilidades más relevantes para la consecución de esta importante ventaja. 


\subsubsection{Las conclusiones del cuarto trabajo empírico}

El cuarto de los estudios ha analizado el efecto de la adopción temprana de una tecnología disruptiva en la capacidad innovadora de las empresas de un clúster con relación al desarrollo de nuevos productos y procesos (innovación tecnológica).

Este análisis ha partido de la idea de heterogeneidad entre las empresas que conforman un clúster (Morrison \& Rabellotti, 2005). Además de compartir una seria de recursos y capacidades proporcionados por el hecho de pertenecer al clúster, las empresas varían significativamente unas de otras; esto conduce a la existencia de distintos caminos para explorar y explotar el conocimiento (Rowley et al., 2000). El estudio ha utilizado el denominado Análisis Comparativo Cualitativo (QCA). Esta técnica -asumiendo el principio de equifinalidad, es decir, considerando que distintos caminos pueden conducir a un mismo resultado- identifica aquellos atributos de las empresas (o combinación de atributos) que son necesarios o suficientes para conseguir un resultado determinado, en nuestro caso, que las empresas sean en su vertiente tecnológica, altamente innovadoras. De este modo, hemos podido identificar distintas combinaciones de factores internos que conducen a las empresas a ser altamente innovadoras.

Este estudio participa de la corriente de literatura abierta por autores como por ejemplo Assink (2006); Fagerberg \& Verspagen (2002); Tsai \& Ghoshal (1998) o Vega Jurado, Gutiérrez Gracia, \& Fernández de Lucio (2005). Esta línea se centra en el estudio de los determinantes de la innovación como fuente principal de ventaja competitiva y valor en las empresas

En primer lugar, nuestros resultados nos indican que, en efecto, existen varios caminos (paths) a través de los cuales las empresas pueden obtener altos resultados de innovación tecnológica. Estos caminos son combinaciones de factores como, entre otros, el tamaño de las empresas, a través del cual, por ejemplo, hemos podido identificar claramente la forma en la que las grandes empresas de un clúster suelen obtener sus resultados de innovación. Los resultados obtenidos son coincidentes con otros estudios anteriores que sugieren la existencia de subredes innovadoras de empresas dentro del clústeres a partir de los distintos atributos de las empresas. Los 
factores que caracterizan las subredes pueden ser, por ejemplo, la distinta posición tecnológica que ocupan en la industria, la pertenencia a las redes core o periphery del clúster o la capacidad de comunicación con otras empresas (Morrison \& Rabellotti, 2009; Ozman, 2006; Rodan \& Galunic, 2004; Stuart \& Podolny, 1996).

En segundo lugar, nuestro análisis sugiere que la adopción temprana de una tecnología disruptiva no es una condición necesaria per se para que una empresa sea altamente innovadora. Este resultado podría considerarse esperable puesto que, en un contexto de clúster, la capacidad innovadora de las empresas puede depender de otros muchos factores, como la capacidad de absorción, las conexiones entre ellas o los intensos mecanismos de intercambio tal como han argumentado estudios anteriores (BelsoMartínez, Molina-Morales, \& Mas-Verdú, 2013; Expósito-Langa et al., 2011; MolinaMorales, 2002). No obstante, nuestro estudio prueba que la adopción temprana, en combinación con el desarrollo de habilidades relacionadas con la obtención y explotación de conocimiento procedente de fuentes externas, es un determinante importante y suficiente para que las empresas sean altamente innovadoras.

Podemos concluir, de este modo, que la adopción temprana de una tecnología disruptiva tiene un impacto positivo sobre la innovación tecnológica de las mismas. La rapidez en la adopción es crítica especialmente en el contexto del clúster en el que los fenómenos de imitación y emulación tienden a reducir el valor conseguido a través de la adopción de una tecnología (Molina-Morales, 2002).

\subsection{Las implicaciones de los resultados de la investigación}

Las implicaciones de los resultados y las conclusiones obtenidos en la presente investigación no sólo se circunscriben al ámbito académico (contribuyendo a diversas literaturas específicas tal como hemos descrito en el apartado anterior) sino que también permiten proponer una serie de recomendaciones y prescripciones dirigidas, tanto a las instituciones y organismos responsables de las políticas de promoción y desarrollo de los clústeres como a las empresas que los integran. 
En el ámbito público, las conclusiones de este estudio tienen implicaciones relevantes en particular para las instituciones y organismos encargados de dirigir y diseñar las políticas destinadas a la dinamización del territorio y el desarrollo de una economía local sostenible.

En nuestra opinión, las acciones destinadas a fomentar y desarrollar las aglomeraciones territoriales de empresas deben reconocer la importancia de las innovaciones disruptivas como mecanismo importante de creación de valor. Más aún, en un contexto como el actual en el que la globalización y otros importantes factores suponen importantes retos para los tejidos territoriales de algunos países europeos (De Marchi \& Grandinetti, 2014). Por lo tanto, conocer en profundidad qué impacto pueden tener estas innovaciones, así como qué dinámicas las generan puede proporcionar un conocimiento muy valioso a la hora de desarrollar políticas específicas.

De modo más específico, nuestra investigación sugiere que las instituciones presentes en el clúster podrían y deberían jugar un papel importante en los procesos innovadores disruptivos; tanto en su generación como en su difusión. Estas entidades deberían establecer mecanismos sistemáticos para detectar, introducir y difundir ideas nuevas y exclusivas dentro de las redes de negocio y conocimiento existentes en los clústeres. De esta manera, favorecerían la propia renovación de los clústeres, así como la mejora su capacidad de adaptación y, en definitiva, de serían capaces de fortalecer su resiliencia. Por este motivo consideramos que nuestra investigación contribuye al actual debate sobre el futuro de estas aglomeraciones de empresas. Tal como esta investigación ha puesto de manifiesto, las innovaciones disruptivas mejoran la competitividad de las empresas y abren nuevas oportunidades, tanto a nivel de empresa individual como a nivel general de clúster. Estas nuevas posibilidades, como se ha visto a lo largo de la tesis, pueden por ejemplo posibilitar la diversificación de productos y servicios. En definitiva, se sugiere que las innovaciones disruptivas pueden convertirse en un elemento clave de rejuvenecimiento de los clústeres industriales.

Continuando en el ámbito público -y respecto a las prescripciones sugeridas a partir de los resultados obtenidos en esta tesis- podemos destacar el hecho de que se ofrece a los responsables institucionales la posibilidad de abrir nuevas trayectorias para los clústeres maduros que consideramos complementarias a otras propuestas por autores como 
Belussi et al. (2008); De Marchi, Gereffi, \& Grandinetti (2018) o Zucchella (2006) quienes se centran en otras perspectivas como el desarrollo de arraigo múltiple, las cadenas globales de valor o el desarrollo de una diversidad en los procesos aprendizaje.

Por último, en este mismo ámbito, nuestro estudio también sugiere la existencia de una serie de actores y figuras clave en el desarrollo y difusión de las innovaciones disruptivas; entre otros, destacamos: los agentes visionarios, los gatekeepers tecnológicos y los agentes externos (outsiders) al clúster. Estas tres categorías de actores son relevantes en los procesos de innovación, en consecuencia, deberían tener protagonismo en las políticas y estrategias públicas correspondientes. Nos referimos a actividades relacionadas con el fenómeno innovador como la detección de conocimiento fuera de los límites del clúster, la generación de ideas alejadas del estado del arte existente, la adaptación de nuevas tecnologías a las realidades concretas del territorio o el suministro de un conocimiento tecnológico que se encuentra muy alejado de aquel que fluye de forma natural.

En segundo lugar, nos centramos en el ámbito empresarial destacando las implicaciones que este estudio tiene para las empresas que forman parte de las aglomeraciones territoriales. Por un lado, planteamos la necesidad de que las empresas reconozcan la importancia que tienen las innovaciones disruptivas como fenómenos que pueden mejorar sus resultados de innovación y, por tanto, generar mayor valor para las mismas (Leifer et al., 2000; Tsai \& Ghoshal, 1998). En este sentido, nuestro análisis se sitúa en línea de otros estudios que han enfatizado la importancia de este tipo de innovaciones que permiten realizar verdaderos avances más allá de las mejoras incrementales. Como por ejemplo, podemos destacar los trabajos de Christensen (1997); Markides (2006) o Tellis (2006). En efecto, los resultados obtenidos en la presente tesis sugieren que este tipo de innovaciones son una oportunidad para que las empresas generen ventajas competitivas sostenibles a través un modelo de competencia dinámico basado en la innovación y la obtención de las denominadas rentas Schumpeterianas (Schumpeter, 1934). Con este enfoque, las empresas que integran un clúster deberían intentar desarrollar mecanismos internos para favorecer la generación o adopción temprana de innovaciones disruptivas (a través, por ejemplo, del diseño de unas rutinas de exploración o del desarrollo de una cultura empresarial con baja aversión al riesgo). 
Por otro lado, nuestra investigación pone de manifiesto la importancia de la capacidad de absorción de nuevas tecnologías en los resultados de innovación de las empresas. Esta confirmación nos llevar a sugerir que las empresas deberían fomentar el desarrollo un conjunto de habilidades centradas en mejorar su interacción con actores clave tanto dentro como fuera del clúster; de este modo no sólo se podría aprovechar el flujo de conocimiento generado dentro del mismo sino también acceder a fuentes externas de conocimiento sin necesidad de comprometer elevados recursos propios. Con este fin, por ejemplo, las empresas en los clústeres industriales pueden hacer uso de mecanismos indirectos de acceso a estos recursos externos a través de agentes intermediarios (Molina-Morales \& Martínez-Fernández, 2004). En particular, nos referimos a las instituciones locales y las empresas especializadas. Este conjunto de organizaciones realiza una labor de exploración para las empresas del clúster de gran valor estratégico.

Complementariamente, sugerimos que las empresas deberían invertir recursos en el desarrollo de capacidades de explotación. Estas capacidades van a desempeñar un papel importante a la hora de sacar mayor provecho de una novedad disruptiva. Nos referimos a capacidades tales como la explotación comercial de nuevos conocimientos (a través, por ejemplo, del diseño de prototipos o nuevas formas de venta); la actualización de las tecnologías en uso a los nuevos avances tecnológicos o el desarrollo de capacidades dinámicas que permitan la adopción temprana y eficiente de nuevas tecnologías (Teece et al., 1997). En definitiva, el desarrollo de capacidades de explotación por parte de las empresas puede suponer una ventaja diferencial que puede mejorar su posición competitiva. Esta recomendación, siendo aplicable a cualquier contexto empresarial, adquiere mayor sentido, en el marco de los clústeres industriales. Estos contextos, como ya hemos descrito, son especialmente propensos a fenómenos de imitación y la emulación (Molina-Morales, 2002) por lo que tienden a reducir los gaps tecnológicos entre las empresas. Ante este situación, el desarrollo de capacidades relacionadas con la rápida explotación de las nuevas tecnologías permitirá las empresas obtener un diferencial competitivo clave con respecto al resto de empresas co-localizadas. 


\subsection{Limitaciones y futuras líneas de investigación}

Este trabajo de investigación no está exento de limitaciones de diversa naturaleza. De no existir estas limitaciones, el mismo no sólo aumentaría su robustez, sino también su capacidad de generalización de los resultados y las conclusiones obtenidas. Nos referimos básicamente al posible sesgo del objeto de estudio y a las propias limitaciones de la aproximación metodológica elegida. Con todo, entendemos que estas limitaciones no solo son comunes a otras muchas investigaciones de nuestra disciplina, sino que su superación puede ser entendida como una oportunidad para el desarrollo de futuras líneas de investigación.

En primer lugar, cabe destacar que nuestra investigación ha sido desarrollada en el contexto específico del clúster cerámico de Castellón, centrándose en el análisis de la innovación disruptiva que en él se produjo. Este hecho podría generar un sesgo en los resultados obtenidos y cuestionar la capacidad de generalización de los mismos a otros contextos. Entendemos que el hecho de haber centrado nuestro análisis fundamentalmente en un sólo caso nos ha permitido un mayor control de las circunstancias particulares que lo rodean, así como de los efectos que éste ha desencadenado. Sin embargo, la elección de este objeto de estudio puede haber condicionado los resultados obtenidos, ya que las dinámicas de asimilación tecnológica se han podido ver influenciadas por las particularidades propias del clúster estudiado. En efecto, en el ámbito de los clústeres industriales, se reconoce una gran diversidad de casos, que, aunque se basen en principios organizativos similares, pueden presentar diferencias significativas en los procesos innovadores, en el entramado institucional que los soporta o en la propia trayectoria tecnología, factores todos ellos que podrían modificar o matizar alguna de las conclusiones obtenidas en nuestro caso. En concreto, desde una perspectiva más operativa, consideramos que el hecho de que el clúster de Castellón pueda ser considerado del tipo dominado por el proveedor -según la taxonomía propuesta por Pavitt (1984)- puede condicionar el modo en el que las empresas finales exploran y explotan el conocimiento. En consecuencia, podría ser cuestionable la aplicación de los resultados a empresas que pertenecen a otro tipo de clústeres como, por ejemplo, el intensivo en producción o el basado en la ciencia (Pavitt, 1984). Consideramos que, en parte, esta limitación ha sido superada por la 
inclusión de un análisis comparativo, en el segundo de los estudios empíricos. No obstante, creemos necesaria la extensión de nuestro estudio y la comparación con los de otras realidades industriales, que nos permita observar el grado de especificidad de nuestros resultados.

En segundo lugar, los resultados de esta tesis se basan en un estudio transversal (crosssectional analysis) centrado en un único momento temporal. Esto nos ha permitido evaluar la magnitud del fenómeno estudiado en un momento preciso y decisivo. Aunque a lo largo de la tesis, hemos considerado determinados periodos de tiempo -dando una perspectiva evolutiva al analizar la velocidad en la adopción de la tecnología disruptivaes cierto que el conjunto del estudio se basa en una fotografía más bien estática del fenómeno. Como consecuencia, si se pretende profundizar en las causas del fenómeno estudiado, sería necesario realizar un estudio de carácter longitudinal. Este tipo de estudio nos permitirá, por un lado, estudiar el impacto de las innovaciones disruptivas en periodos de tiempo más amplios y, por tanto, obtener conclusiones acerca del impacto que tienen a largo plazo. Por otro lado, también nos permitirían estudiar cómo las redes de empresas cambian y evolucionan en respuesta a la aparición de nuevas oportunidades como son las innovaciones tecnológicas disruptivas.

Sin embargo, a pesar de todas estas limitaciones y restricciones, pensamos que el presente estudio constituye un avance en la mejora de la compresión de las innovaciones disruptivas en el contexto de los clústeres industriales.

Otra posible nueva dirección de la investigación seria aquella que se origina de la necesidad de analizar también factores inhibidores de estos procesos. Estos factores inhibidores, tan ampliamente estudiados en los contextos de empresa individual, no han obtenido la misma atención por parte de la literatura de clústeres; a este respecto, desde una perspectiva de redes, planteamos como futura línea de investigación la determinación de los patrones de interacción entre los distintos actores claves del clúster con relación a la introducción y difusión de conocimiento novedoso.

Por último, aun asumiendo todas las limitaciones anteriormente expuestas, pensamos que esta investigación ha ofrecido una alternativa de supervivencia y evolución tecnológica a los clústeres industriales y por lo tanto a los territorios en los que éstos se 
localizan. Con todo, creemos necesario destacar el hecho de que los clústeres industriales no sólo se enfrentan a retos de tipo tecnológico, como el analizado en esta tesis, sino a otro tipo de fenómenos y circunstancias (por ejemplo, la tercerización de algunas economías desarrolladas o las crisis globales (Boix, Sforzi, Galletto, \& LlobetDomingo, 2015) que están condicionando sus trayectorias. El estudio holístico de la evolución de los clústeres industriales requiere aplicar un enfoque amplio más allá del proporcionado exclusivamente por el análisis de las innovaciones disruptivas. Consideramos necesario, por tanto, integrar otras líneas de investigación dirigidas al análisis de otros fenómenos significativos en estos contextos territoriales como son la globalización o los flujos migratorios. A este respecto, nos alineamos con la idea de integración de la perspectiva tecnológica con otras perspectivas llevadas a cabo por autores como Molina, Martínez-Cháfer, Molina-Morales, \& Lubbers, (2018) en el ámbito de la emigración o como Belussi (2018) o De Marchi, Di Maria, \& Gereffi (2018) en el ámbito de la globalización y el papel de las multinacionales.

En conclusión, a través de un análisis global de los distintos retos y trayectorias que los clústeres industriales están desarrollando podremos mejorar nuestra comprensión acerca de su evolución, lo cual en nuestra opinión resulta necesario dada la situación de declive o maduración en la que se encuentran una gran cantidad de este tipo de aglomeraciones territoriales, principalmente de los países desarrollados. 


\section{CAPÍTULO 8 \\ CONCLUSIONS OF THE RESEARCH}




\section{CONCLUSIONS OF THE RESEARCH}

\subsection{Introduction}

In the present doctoral thesis, we have studied how industrial clusters are able to evolve thanks to a specific kind of innovative process. More precisely, we have focused on how industrial clusters are transformed through the development and assimilation of the so-called disruptive technological innovations. In particular, we have studied the determinants and effects of these innovations, at two different levels: on the one hand, at the cluster level, as an integrated entity and, on the other, at the clustered firm level. In fact, this general objective has been addressed in four specific studies; two of them have focused on analysing this innovative process from a cluster perspective, while the other two, from the clustered firm's perspective.

In the first study, a deep analysis of the case of the introduction, development and diffusion of digital printing in the ceramic tile cluster of Castellón has been carried out, as an example of disruptive technological innovation. The second study -seeking the possible generalization of the results- has consisted in a comparative study between the aforementioned case and a similar one. This is the case of the introduction of a disruptive technology, the plastic injection, in the manufacturing process of sports shoes that occurred in the Italian industrial cluster of Montebelluna (in the Veneto region). 
The third study has been made from an individual clustered firm's perspective. We have focused on the identification of those firm's internal attributes that favour the adoption of this type of disruptive innovations. Finally, the last of the studies has consisted in the evaluation of how the early adoption of a disruptive technology can boost the innovative capacity of companies; in particular, the product and process innovation performance.

In the following points of this chapter, we present the main results and conclusions that can be drawn from this research. To do this, we will first present the general conclusions obtained and its implications. Finally, we will analyse the limitations of the study, as well as the possible future research lines that can be derived from them.

\subsection{Main conclusions of the empirical studies}

\subsubsection{The conclusions of the first empirical study}

In this empirical study we tried to analyse how an industrial cluster can develop and diffuse a disruptive innovation, as well as the impact that the innovation produces on the cluster itself. This objective has, in our opinion, an additional interest because the analysis of this complex innovative process has been carried out in the context of a mature industrial cluster.

As some authors like, among others, Elche-Hortelano, Martínez-Pérez, \& GarcíaVillaverde (2015); Humphrey \& Schmitz (2000); Maskell (2001); Molina-Morales, 2002 or Nadvi \& Halder (2005)) have argued, industrial clusters present, a priori, much more suitable conditions for the development of incremental innovations (having less importance and impact), instead of radical or disruptive ones. These authors attribute this fact to the internal dynamics that are generated within these territorial agglomerations, highlighting the importance of the intensity and density of their internal relationships.

In this first empirical work, we have been able to show how disruptive innovation processes can be developed in industrial cluster contexts and, therefore, we suggest that 
they are not exclusive to those contexts related to large companies, in which organizational structures are well integrated. However, as part of the literature focused on large integrated business contexts has suggested in previous studies -such as Beck, Lopes-Bento, \& Schenker-Wicki (2016) or Leifer et al. (2000)- our analysis has also shown how in this type of territorial agglomerations the possibilities of initiating and developing disruptive innovative processes are limited by several factors. Among them, we can highlight the lack of an external vision beyond the boundaries of the cluster, the limited resources allocated to exploration strategies, the lack of a clear hierarchy which coordinates their common activities, or the predominance of a short-term vision. In short, we can conclude that the dynamics of the cluster, while promoting the maintenance of competitiveness, however, limit the capacity of the so-called existing technological gatekeepers (Molina-Morales \& Martínez-Cháfer, 2016) to lead the most disruptive or radical changes. In fact, our results have shown the existence of an important resistance to change by their side. The results also highlight the role played by other actors, for example, the visionary agents, who -being out of the technological core of the cluster- play a fundamental role in the process of introduction and assimilation of information and novel knowledge.

Finally, this study has also analysed the effects that disruptive innovations generate over the industrial cluster where they are diffused. We have observed how this innovation generates a positive and important impact not only on the ceramic tile industry value chain, but also on the cluster itself, generating new opportunities for development and diversification. As a consequence, we can conclude that these innovative processes may favour new rejuvenation phases in these territorial contexts. In this sense, our study contributes to expand the venue of research opened by other authors such as HervásOliver, Albors-Garrigos, Estelles-Miguel, \& Boronat-Moll (2017); Markides (2006) o Østergaard \& Park (2015). Finally, we think that, through this study, we are highlighting the importance of the disruptive innovations as new trajectories of development for mature clusters different from those suggested by other authors mainly based on relational factors; for instance, the studies carried out by Belussi, Sammarra, \& Sedita (2008); Staber \& Sautter (2011) or Zucchella (2006). 


\subsubsection{The conclusions of the second empirical study}

In this empirical study we analysed whether the results and conclusions obtained in the previous one could be as dependent on the peculiarities of the specific case or, on the contrary, they could be generalizable in other cases. Our purpose was, therefore, to improve our previous analysis through a comparative analysis with another similar case of introduction and development of a disruptive technological innovation. In fact, the similarities observed from the comparative study between the case of Castellón and the Italian one (in Montebelluna), allowed us not only to confirm the results obtained in the first study, but also to define common patterns in terms of the determinants and consequences of the disruptive innovative processes in industrial clusters.

In the first place, we have identified three elements that we can consider as necessary for the introduction and development of this type of innovation: (1) the presence of visionary agents (companies and/or institutions), which are capable of detecting really novel knowledge outside the cluster and adapt it to its particularities. From a Schumpeterian point of view, we can identify this process as the beginning of a new innovative cycle on which new future rent may be sustained; (2) the presence of technological gatekeepers (usually specialized companies belonging to the cluster), which not only favour the assimilation of external knowledge but also catalyse the adoption of the novelty among the members of the cluster and, (3) the presence of outsiders (external agents to the cluster) which, having a deep knowledge regarding the disruptive technology, cooperate with the members of the cluster for its adaptation and optimization. The identification of these necessary actors in the disruptive innovation process, contributes and is in line with previous research which analyses the role played by the different actors in the innovation processes in clusters. In this field we can highlight contributions from Giuliani (2011), Graf (2010), Hervás-Oliver \& AlborsGarrigos (2014) or Morrison (2008). Our results are also consistent with those obtained by Giuliani (2005) reinforcing the idea that the capacity for developing distant innovations in clusters is restricted to a limited number of actors. Quite the opposite, this valuable capability is not uniformly distributed among the members of the cluster. 
Secondly, thanks to this study, we were capable of observing how the diffusion rate of the new technology is paramount to generate a significant impact at a cluster level, beyond the impact that, individually, it can produce over companies. In this sense, our results are in line with those obtained by other authors such as Jaffe, Trajtenberg, \& Henderson (1993). Our comparative study has addressed the important role played by specialized companies (supporting industries) in this context. These companies -having a highly specific knowledge and being providers of advanced services- play an important role by promoting the spreading of the technological innovation, reducing the uncertainty and, consequently, decreasing the resistance to change of the potential adopting companies (in our case the final manufacturing companies of ceramic tiles). Thus, specialized companies become important prescribing agents not only for incremental advances but also for the most disruptive ones. In this sense, our research contributes to the open debate regarding the role played by external-to-the-network knowledge, as well as the limited opportunities for firms to explore and exploit this knowledge (Foss, Lyngsie, \& Zahra, 2013).

Finally, we consider that this second study contributes to the literature on regional resilience. In the first place, we have identified a specific path through which clusters can develop their resilience: the development of disruptive innovations. Secondly, we have suggested a series of indicators that can help to assess the extent to which this characteristic develops in a cluster context. This set of resilience indicators -which has been defined a two different levels (cluster as entity and clustered firms levels)- can be considered as an alternative to other forms of measurement proposed at a regional level by authors such as Davies (2011); Dubé \& PolèSe (2016) or Sensier, Bristow, \& Healy (2016).

\subsubsection{The conclusions of the third empirical study}

In this study we have delved into the analysis of the firm's internal factors that favour the early adoption of disruptive innovations by clustered companies. To carry out this objective, we have grounded the analysis on the notion of absorptive capacity (ACAP); this concept has been widely studied and applied in the innovation literature (Cohen \& Levinthal, 1990). ACAP is related to organizational learning, a crucial element for the 
use of information and external-to-the-company knowledge (Cohen \& Levinthal, 1990). More specifically, in this study we have adopted a two-dimensional perspective of the ACAP (potential ACAP - exploration / realized ACAP- exploitation) to identify the internal factors of the companies in relation to their capacity to explore and exploit external knowledge. This approach has had an important presence in the literature, where we can highlight the works of Becker \& Peters (2000); Jansen, Van Den Bosch, \& Volberda (2005); McDermott \& O'Connor (2002) or Zahra \& George (2002). However, precedents are not so abundant in terms of amount of studies focused on the assimilation of new technologies in the cluster context. In fact, the former research have barely addressed this perspective in this specific contexts; as exceptions we can mention the works of authors such as Expósito-Langa, Molina-Morales, \& Capo-Vicedo (2011) or Tomás-Miquel, Molina-Morales, \& Expósito-Langa (2015).

The results of the analysis we have carried out suggest that the development of internal skills related to the potential ACAP does not seem to have a clear effect on the early adoption of a technological innovation by clustered firms. On the contrary, it is the ACAP dimension corresponding to the exploitation of new technologies (realized $A C A P)$ that reveals a significant influence on their adoption during the first stages of their introduction. In this sense, our results go in line with previous research conducted in cluster context. Indeed, the cluster literature has shown how companies belonging to this kind of territorial agglomerations have easy access to a series of systemic capacities that can cover their individual need to develop specific skills related to acquisition and assimilation of external knowledge. In this line we can give as examples the investigations carried out by Expósito-Langa et al. (2011); Hervás-Oliver et al. (2017); Molina-Morales, Martínez-Fernández, \& Torlò (2011) or Molina-Morales \& MasVerdú (2008). These systemic capacities - conceptualized as higher-order capabilities by Foss (1996)- are able to transform these entities into highly efficient contexts regarding the exploitation of knowledge (Rowley et al., 2000). This result is, in our opinion, very relevant since it allows the companies to focus on the development of those skills related to the exploitation of knowledge instead of exploration. In effect, the membership of firms to a cluster, allows them to obtain new knowledge through other players such as, local institutions or leading-specialized companies. These important players develop key skills and key strategies regarding technological exploration. In this way, firms who are able to focus on the commercial exploitation of new knowledge 
(through, for example, the proper prototype development, the rapid update of technologies or the efficient adoption new technologies) will obtain a larger competitive advantage than other competitors in the same context.

In conclusion, this study shows that not all internal skills related to absorptive capacity contribute similarly to the competitive advantage development for clustered firms. Consequently, practitioners should consider the relevance of those specific capabilities, in this particular context, when they try to achieve of this important advantage.

\subsubsection{The conclusions of the fourth empirical study}

This study has analysed the role of the early adoption of a disruptive technology on the innovative capacity of clustered companies regarding the development of new products and processes (technological innovation). This analysis is grounded in the idea of heterogeneity among the clustered companies (Morrison \& Rabellotti, 2005). Companies in clusters are significantly different beyond the series of those common resources and capabilities provided by the cluster membership; this variety of firms leads to the existence of different ways to explore and exploit the knowledge (Rowley et al., 2000). The study has used the so-called Qualitative Comparative Analysis (QCA) technique. This technique -assuming the principle of equifinality, meaning that different paths can lead to the same result- identifies those attributes of the companies (or combination of attributes) that are necessary or sufficient to achieve a specific outcome, in our case, the fact of being highly innovative, in its technological aspect. In this way, we have identified different combinations of internal factors that lead the companies to be highly innovative. This study follows the venue of research opened by the authors such as Assink (2006); Fagerberg \& Verspagen (2002); Tsai \& Ghoshal (1998) or Vega Jurado, Gutiérrez Gracia, \& Fernández de Lucio (2005). This research line is focused on determinants of innovation as the main source of competitive advantage and value in companies

In the first place, our results stress the fact that there are several paths through which companies can obtain high results of technological innovation. These paths are combinations of factors such as the size of firms; in fact, we have clearly identified how 
the large companies usually achieve their innovation results; this path is significantly different from others carried out for not large companies in clusters. The results obtained address -as other studies have previously analysed- the existence of innovative sub-networks of companies within the cluster based on their different attributes. The factors that characterize these sub-networks can be, for instance, their relative technological position in the industry, their level of relevance to the core/periphery networks or the communication capacity with other clustered firms (Morrison \& Rabellotti, 2009; Ozman, 2006; Rodan \& Galunic, 2004; Stuart \& Podolny, 1996).

Second, our analysis suggests that early adoption of a disruptive technology for clustered firms is not a necessary condition per se to become a strong innovator. This result could be, in a sense expected given the fact that, in cluster contexts, the innovative capacity of companies may depend on many other factors, such as the absorptive capacity, the links with other companies or the existence of exchange mechanisms (Belso-Martínez, Molina-Morales, \& Mas-Verdú, 2013; Expósito-Langa et al., 2011; Molina-Morales, 2002). However, our study highlights that the early adoption of a disruptive technology, combined with the development of skills focused on the obtaining and exploitation of knowledge from external sources, is an important and sufficient determinant for companies to be highly innovative.

In short, we can conclude that the early adoption of a disruptive technology has a positive impact on the technological innovation of clustered companies. In this sense, the speed of adoption is critical especially in the cluster context. In effect, phenomena such as imitation and emulation tend to reduce the value achieved through the adoption of a technology (Molina-Morales, 2002).

\subsection{The implications of the results of the research}

In our opinion, the implications of the results and the conclusions obtained in this research are not limited to the academic field (as we described in the previous section). Besides, they give us an opportunity to propose a series of recommendations and prescriptions aimed at both the institutions or policy makers, who are in charge of promoting clusters, and the clustered companies. 
In the public sphere, the conclusions of this study have relevant implications in particular for the institutions and agencies who are responsible for managing and designing policies which are aimed at promoting the territory and developing a sustainable local economy. In our opinion, all these policies should recognize the importance of disruptive innovations as important mechanisms for value creation. Moreover, in the current socioeconomical context which comes mainly marked by globalization and other important factors representing important challenges for the industrial structures of some European countries (De Marchi \& Grandinetti, 2014). In this context, a valuable knowledge can be obtained from a deep understanding of what these innovations can generate, as well as what are their main determinants. More specifically, our research suggests that the institutions in clusters should play an important role in disruptive innovative processes; both in its generation and in its diffusion. They should establish systematic mechanisms to detect, introduce and diffuse new and external ideas within the boundaries of existing business and knowledge networks. By doing this, they are promoting the cluster renewal and its capacity for adaptation and, in short, they are strengthening its resilience. For this reason, we consider that our research contributes to the current debate about the future of these agglomerations of companies. As this research has shown, disruptive innovations improve the competitiveness of companies and open up new opportunities, both at the individual firm level and at the general cluster level. These new possibilities can be opened, as seen in this research, through the diversification of products and services. In short, disruptive innovations may become a key element of rejuvenation of industrial clusters.

The results obtained in this research offer to institutional managers a new trajectory to be considered for mature clusters: the development of disruptive innovations. It may be considered as complementary to other alternative trajectories proposed by different authors such as Belussi et al. (2008); De Marchi, Gereffi, \& Grandinetti (2018) or Zucchella (2006). These perspectives are mainly grounded in relational aspects such as the development of multiple embeddedness, the design of global value chains or the diversity in learning processes. Finally, in this same public sphere, our study also highlights the existence of key actors who play a paramount role in the development and diffusion of disruptive innovations; among others, we underline: the visionary agents, the technological gatekeepers and the external agents (outsiders) to the cluster. 
These three leading figures should be considered during the design of public policies as they play an important role in the disruptive innovation process. Namely, we refer to activities such as the detection of knowledge out of the boundaries of the cluster, the generation of new ideas away from the state of existing art, the adjustment of new technologies to the specific realities of the cluster dynamics or the increase of the stock of technological knowledge.

In second place, we will address the implications of this study from a business perspective namely for clustered firms.

We propose the importance for firms to recognize disruptive innovations as phenomena that can improve their innovation results and, therefore, create a greater value for them (Leifer et al., 2000; Tsai \& Ghoshal, 1998). In this sense, our analysis is in line with other studies that have emphasized the importance of this type of innovations as they lead to real progress and value creation beyond incremental improvements. Among others we underline works such as Christensen (1997), Markides (2006) or Tellis (2006). Indeed, the results obtained in this thesis suggest that disruptive innovations create opportunities of development of sustainable competitive advantages. We are, consequently, adopting the dynamic competition model based on innovation, proposed by Schumpeter (1934). These innovations can be considered as starting points of the innovative cycles which lead to the so-called Schumpeterian rents. Under this perspective, clustered firms should try to introduce internal mechanisms to favour the generation or early adoption of disruptive innovations (through, for example, the design of exploration routines or the development of a business culture characterized by a low risk-aversion).

On the other hand, our research highlights the importance of the absorptive capacity of new technologies to improve the innovation results of companies. This confirmation will lead us to suggest that companies should promote the development of those skills focused on improving their interaction with key actors both inside and outside the boundaries of the cluster; by doing this, firms -not having to commit high amount of own resources- would benefit not only from the stock of knowledge which is generated inside the cluster but also from the external sources of knowledge. In this sense, companies in industrial clusters can make use of intermediary agents (or other indirect 
mechanisms) to access these stocks of external resources (Molina-Morales \& MartínezFernández, 2004). In particular, we refer to local institutions and specialized companies. These entities carry out an important exploration activity which may be use by clustered firms to create an important strategic value.

In addition, the results of our analysis stress the need of allocating resources to boost the development of exploitation capacities in clustered firms. These capabilities will allow them to take a large profit from a disruptive technology. We refer to the commercial exploitation of new knowledge (through, for example, the design of prototypes or new selling methods), the permanent updating of the technologies in use or the development of dynamic capacities that will favour the early and efficient adoption of new technologies (Teece et al., 1997). In short, the development of exploitation capacities can entail a differential advantage and therefore improve competitive position of clustered firms. This consideration, being applicable to any business context, acquires greater value for industrial clusters. These contexts are especially prone to phenomena of imitation and emulation (Molina-Morales, 2002) and, consequently, technological gaps among companies tend to be rapidly reduced. Against with this situation, the development of capabilities related to the rapid exploitation of new technologies will allow companies to obtain a key competitive differential with respect to other colocated companies.

\subsection{Limitations and future research lines}

A final remark is required about the limitations of this research. This should be the focus of

future research in order to increase its robustness as well as widen its ability to generalize the results and conclusions obtained. In particular, we acknowledge the possible bias of the specific context of this research and the distinctive limitations of the methodological approach we used. However, we understand that these limitations are not exclusive to our research, but they come up in many other investigations of our discipline. In fact, we consider them as an opportunity for future venues of research. 
First, it should be noted that our research has been developed in the specific context of the ceramic tile cluster in Castellón. Besides, it is focused on the analysis of the particular disruptive innovation that took place in it. We understand that this has allowed us to get a better control of the particular circumstances surrounding it, as well as of the effects that it has unleashed. However, it may have conditioned the results obtained, since the dynamics of technological assimilation may have been influenced by the peculiarities of this specific cluster. In fact, a great diversity of clusters is recognized regarding the typologies of these industrial agglomerations. In spite of being based on similar organizational principles, they can present significant differences regarding, for instance, innovative patterns, institutional supporting frameworks or even evolutionary technological trajectories. All these distinctive factors could modify or qualify any of the conclusions obtained in our research. Specifically, the fact that the cluster in Castellón has been considered as a supplier dominated cluster-according to the taxonomy proposed by Pavitt (1984)- can condition the way in which the final companies explore and exploit the knowledge in this specific reality. Consequently, to generalize the results to other contexts such as the intensive production clusters or science-based ones -following the aforementioned Pavitt's classification (1984)- can be questionable to some degree. In a way, we consider that this limitation has been overcome through the conduction of a comparative analysis in the second of the empirical studies. However, we believe it is necessary to extend our analysis and confront it with other industrial realities.

In second place the results of this thesis are based on a cross-sectional analysis focused on a single temporal moment. In spite of adopting an evolutionary perspective when analysing the speed in the adoption of the disruptive technology by clustered firms in Castellón, we acknowledge that our study is based on a rather static picture of this phenomenon. In order to delve into their causes, we suggest carrying out a longitudinal study. This type of analysis will allow us, on the one hand, to draw conclusions about the impact they have in the long term. On the other hand, they would provide us with information about how networks of firms change and evolve in response to the emergence of new opportunities such as disruptive technological innovations. Despite all these limitations and restrictions, we believe that the present study contributes to the better understanding of disruptive innovations in the context of industrial clusters. Nevertheless, further research is needed to build on this baseline and, in particular, 
regarding the factors that inhibit these processes. Indeed, inhibiting factors -which have been widely studied in individual firm contexts- have not received the same attention from a cluster perspective in literature. In particular, from a network approach, we propose as a future line of research the determination of the patterns of interaction between the different actors being part of the introduction and diffusion of new knowledge within the cluster network.

In addition, we think that this research is offering an alternative path of evolution to the industrial clusters and therefore an alternative way of development in those territories where they are located. However, nowadays industrial clusters are not only facing technological challenges. They are also challenged by other phenomena that are conditioning their trajectories such as the wide power of the service industry in most of the developed economies or the global crises (Boix, Sforzi, Galletto, \& LlobetDomingo, 2015). A holistic approach to the evolution of industrial clusters requires, in our opinion, a broader perspective beyond that one exclusively provided by the analysis of disruptive innovations. Therefore, we highlight the importance of integrating other existing lines of research focused on other significant phenomena for clusters such as globalization or migratory flows. In this respect, we suggest to integrate our technological perspective with other aspects addressed by authors such as Molina, Martínez-Cháfer, Molina-Morales, \& Lubbers (2018) regarding migratory phenomena or Belussi (2018) and De Marchi, Di Maria, \& Gereffi (2018) in the field of globalization and the role played by multinational companies. In conclusion, we suggest that a holistic approach of the different trajectories developed against different challenges may broaden our understanding of the patterns of evolution for the industrial clusters. In our opinion, this is very important given the situation of decline or maturity that these territorial agglomerations are facing, mainly for the developed economies. 


\section{REFERENCIAS}




\section{REFERENCIAS}

Abernathy, W. J., \& Clark, K. B. (1985). Innovation: Mapping the winds of creative destruction. Research Policy, 14(1), 3-22.

Abernathy, W. J., \& Utterback, J. M. (1978). Patterns of Industrial Innovation. Technology Review, 80(7), 40-47.

Adner, R. (2002). When are technologies disruptive? A demand-based view of the emergence of competition. Strategic Management Journal, 23(8), 667-688.

Adner, R. (2006). Match your innovation strategy to your innovation ecosystem. Harvard Business Review, 84(4), 98.

Adner, R., \& Zemsky, P. (2006). A demand-based perspective on sustainable competitive advantage. Strategic Management Journal, 27(3), 215-239.

Agrawal, A., \& Cockburn, I. (2003). The anchor tenant hypothesis: exploring the role of large, local, R\&D-intensive firms in regional innovation systems. International Journal of Industrial Organization, 21(9), 1227-1253.

Ahlin, B., Drnovšek, M., \& Hisrich, R. D. (2014). Exploring the moderating effects of absorptive capacity on the relationship between social networks and innovation. Journal for East European Management Studies, 213-235.

Ahuja, G., Lampert, C. M., \& Tandon, V. (2008). 1 moving beyond Schumpeter: management research on the determinants of technological innovation. Academy of Management Annals, 2(1), 1-98.

Alberti, F. (2004). The crisis of the industrial district of Como: a longitudinal analysis of its evolution. In 20th Egos Colloquium (pp. 1-3).

Alberti, F. G. (2006). The decline of the industrial district of Como: recession, relocation or reconversion? Entrepreneurship \& Regional Development, 18, 473501.

Albors-Garrigós, J., \& Hervás-Oliver, J. L. (2013). Disruptive technology in mature industries: Its contribution to industry sustainability. 2013 Proceedings of PICMET 2013: Technology Management in the IT-Driven Services, 585-596. Retrieved from https://www.scopus.com/inward/record.uri?eid=2-s2.084890814589\&partnerID $=40 \&$ md5=49b4c26e6216c4e2c76be861a46da62d

Albors-Garrigós, J., \& Hervás-Oliver, J. L. (2014). Creative destruction in clusters: From theory to practice, the role of technology gatekeepers, understanding 
disruptive innovation in industrial districts. PICMET 2014 - Portland International Center for Management of Engineering and Technology, Proceedings: Infrastructure and Service Integration, 710-722. Retrieved from http://www.scopus.com/inward/record.url?eid=2-s2.084910157036\&partnerID=tZOtx3y1

Albors, J. G. (2002). Networking and technology transfer in the Spanish ceramic tiles cluster: its role in the sector competitiveness. The Journal of Technology Transfer, 27(3), 263-273.

Alcacer, J., \& Chung, W. (2007). Location strategies and knowledge spillovers. Management Science, 53(5), 760-776.

Allen, T. J. (1977). Managing the flow of technology: Technology transfer and the dissemination of technological information within the R \& D organization(Book). Research Supported by the National Science Foundation. Cambridge, Mass., MIT Press, 1977. $329 P$.

Allen, T. J., \& Mowery, D. C. (1983). The relationship between intrafirm and contractual forms of industrial research in American manufacturing, 1900-1940. Explorations in Economic History, 20(4), 351-374.

Amara, N., Landry, R., \& Ouimet, M. (2005). Milieux innovateurs: Determinants and policy implications. European Planning Studies, 13(6), 939-965.

Amighini, A., Rabellotti, R., Amin, A., \& Robins, K. (2006). How do Italian footwear industrial districts face globalization? European Planning Studies, 14(4), 485-502.

Amin, A, \& Robins, K. (1990). Industrial districts and regional development: limits and possibilities. In F Pyke, G. Becattini, \& W. Sengenberger (Eds.), Industrial Districts and Inter-firm Co-operation in Italy. Ginebra: International Institute for Labour Studies.

Amin, Ash, \& Thrift, N. (1995). Globalization, institutions, and regional development in Europe. Oxford university press.

Amit, R., \& Schoemaker, P. J. H. (1993). Strategic assets and organizational rent. Strategic Management Journal, 14(1), 33-46.

Anderson, N., De Dreu, C. K. W., \& Nijstad, B. A. (2004). The routinization of innovation research: A constructively critical review of the state-of-the-science. Journal of Organizational Behavior, 25(2), 147-173.

Anderson, P., \& Tushman, M. L. (1990). Technological discontinuities and dominant designs: A cyclical model of technological change. Administrative Science 
Quarterly, 604-633.

ANFFECC. (2016). Retrieved from www.anffecc.com

Ansari, S., \& Garud, R. (2009). Inter-generational transitions in socio-technical systems: The case of mobile communications. Research Policy, 38(2), 382-392.

Ansari, S., Garud, R., \& Kumaraswamy, A. (2016). The disruptor's dilemma: TiVo and the US television ecosystem. Strategic Management Journal, 37(9), 1829-1853.

Ansari, S. S., \& Krop, P. (2012). Incumbent performance in the face of a radical innovation: Towards a framework for incumbent challenger dynamics. Research Policy, 41(8), 1357-1374.

Anthony, S. D., Johnson, M. W., Altman, E. J., \& Sinfield, J. V. (2008). The innovator's guide to growth : putting disruptive innovation to work. Boston, Mass.: Harvard Business Press.

Antonelli, C. (2000). Collective Knowledge Communication and Innovation: The Evidence of Technological Districts. Regional Studies. Journal of Regional Studies Association, 34(6), 535-547.

Antonio Belso-Martínez, J. (2006). Do industrial districts influence export performance and export intensity? Evidence for Spanish SMEs' internationalization process. European Planning Studies, 14(6), 791-810.

Archibugi, D., \& Michie, J. (1995). The globalisation of technology: a new taxonomy. Cambridge Journal of Economics, 19(1), 121-140.

Argote, L., Beckman, S. L., \& Epple, D. (1990). The persistence and transfer of learning in industrial settings. Management Science, 36(2), 140-154.

Arrow, K. J. (1962). Studies in applied probability and management science (Vol. 7). Stanford University Press.

ASCER. (2016). Retrieved from www.ascer.es

Asheim, Bjørn T. (1999). Interactive learning and localised knowledge in globalising learning economies. GeoJournal, 49(4), 345-352.

Asheim, Bjørn T, Boschma, R., \& Cooke, P. (2011). Constructing regional advantage: Platform policies based on related variety and differentiated knowledge bases. Regional Studies, 45(7), 893-904.

Asheim, Bjørn T, \& Coenen, L. (2005). Knowledge bases and regional innovation systems: Comparing Nordic clusters. Research Policy, 34(8), 1173-1190.

Asheim, Bjørn T, \& Isaksen, A. (2002). Regional innovation systems: the integration of local 'sticky'and global 'ubiquitous' knowledge. The Journal of Technology 
Transfer, 27(1), 77-86.

Asheim, Bjorn T, Smith, H. L., \& Oughton, C. (2011). Regional innovation systems: theory, empirics and policy. Regional Studies, 45(7), 875-891.

Assink, M. (2006). Inhibitors of disruptive innovation capability: a conceptual model.

European Journal of Innovation Management, 9(2), 215-233. https://doi.org/10.1108/14601060610663587

Audretsch, D. B., \& Feldman, M. P. (1996). R\&D spillovers and the geography of innovation and production. The American Economic Review, 86(3), 630-640.

Audretsch, D. B., \& Frisch, M. (1999). The industry component of regional new firm formation processes. Review of Industrial Organisation, 15, 239-252.

Aydalot, P. (1986). Présentation de Milieux innovateurs en Europe, Ph. Aydalot (Éd), GREMI.

Aydalot, Philippe, \& Keeble, D. (1988). High technology industry and innovative environments: the European experience. Routledge.

Aydalot, Philippe, Keeble, D., Sabel, C. F., Hirst, P., \& Zeitlin, J. (1989). Flexible Specialization and the Re-emergence of Regional Economies. Routledge.

Azzariti, F., \& Candoni, I. (2007). Oltre il distretto: interviste, modelli aziendali $e$ teorie di un fenomeno italiano. FrancoAngeli.

Baden-Fuller, C., \& Morgan, M. S. (2010). Business models as models. Long Range Planning, 43(2-3), 156-171.

Baldwin, C. Y. (2007). Where do transactions come from? Modularity, transactions, and the boundaries of firms. Industrial and Corporate Change, 17(1), 155-195.

Baptista, R. (2000). Do innovations diffuse faster within geographical clusters? International Journal of Industrial Organization, 18(3), 515-535.

Baptista, R., \& Swann, P. (1998). Do firms in clusters innovate more? Research Policy, 27(5), 525-540.

Baraldi. (2016). World production and consumption of ceramic tiles. Ceramic World Review, 118, 68-81.

Baraldi, L. (2017). World production and consuption of ceramic tiles. Ceramic World Review, 123, 56-72.

Baregheh, A., Rowley, J., \& Sambrook, S. (2009). Towards a multidisciplinary definition of innovation. Management Decision, 47(8), 1323-1339. https://doi.org/10.1108/00251740910984578

Barkema, H. G., \& Nadolska, A. (2003). HOW INTERNATIONALIZING FIRMS 
DEVELOP THEIR ABSORPTIVE CAPACITY OVER TIME: THE CASE OF ACQUISITIONS. In Academy of Management Proceedings (Vol. 2003, pp. I1-I6). Academy of Management Briarcliff Manor, NY 10510.

Barney, J. B. (1991). Firm Resources and Sustained Competitive Advantage. Journal of Management, $\quad$ 17(1), $99 . \quad$ Retrieved from http://search.ebscohost.com/login.aspx?direct=true\&db=bsh\&AN=5978921\&lang $=$ es\&site $=$ ehost-live

Bathelt, H., Malmberg, A., \& Maskell, P. (2004). Clusters and knowledge: local buzz, global pipelines and the process of knowledge creation. Progress in Human Geography, 28, 31-56.

Baum, J. A. C., \& Mezias, S. J. (1992). Localized competition and organizational failure in the Manhattan hotel industry, 1898-1990. Administrative Science Quarterly, 580-604.

Bayona Sáez, C., García Marco, T., \& Huerta Arribas, E. (2003). ¿ Cooperar en I+ D? Con quién y para qué. Revista de Economía Aplicada, 11(31).

Bayus, B. L., Griffin, A., \& Lehmann, D. (1998). From the Special Issue Editors. Journal of Product Innovation Management, 15(2), 108-110.

Becattini, G. (1979). Dal settore industriale al distretto industriale. Rivista Di Economia e Politica Industriale, 1, 1-8.

Becattini, G. (1987). Il Mercato e forze locali, Il distretto industriale. Bolonia: Il Molino.

Becattini, G. (1990). The Marshallian Industrial District as a Socio-Economic Concept. Industrial Districts and Inter-Firm Co-operation in Italy. Geneva: F. Pyke, G. Becattini and W. Sengerberger.

Becattini, Giacomo. (1986). Del'sector industrial'al'districte industrial': algunes consideracions sobre la unitat de recerca de l'economia industrial. Revista Econòmica de Catalunya, (1), 4-11.

Becattini, Giacomo. (1989). Sectors and/or districts: some remarks on the conceptual foundations of industrial economics. Small Firms and Industrial Districts in Italy, $123-135$.

Becattini, Giacomo. (2001). The caterpillar and the butterfly: An exemplary case of development in the Italy of the industrial districts. BOOK, Felice Le Monnier.

Becattini, Giacomo. (2006). Vicisitudes y potencialidades de un concepto: el distrito industrial. Economía Industrial, 359, 21-27. 
Becchetti, L., \& Rossi, S. P. S. (2000). The positive effect of industrial district on the export performance of Italian firms. Review of Industrial Organization, 16(1), 5368.

Beck, M., Lopes-Bento, C., \& Schenker-Wicki, A. (2016). Radical or incremental: Where does R\&D policy hit? Research Policy, 45(4), 869-883.

Becker, W., \& Peters, J. (2000). Technological opportunities, absorptive capacities, and innovation. Volkswirtschaftliche Diskussionsreihe, Institut für Volkswirtschaftslehre der Universität Augsburg.

Befani, B., Ledermann, S., \& Sager, F. (2007). Realistic evaluation and QCA: conceptual parallels and an empirical application. Evaluation, 13(2), 171-192.

Bell, S. J., Tracey, P., \& Heide, J. B. (2009). The organization of regional clusters. Academy of Management Review, 34(4), 623-642.

Bellandi, M. (1986). El distrito industrial en Alfred Marshall. Estudios Territoriales, (20), 31-44.

Bellandi, M. (1989). The role of small firms in the development of Italian manufacturing industry. Routledge London and New York.

Bellandi, M. (1993). Structure and change in the industrial district. Università degli studi, Dipartimento di scienze economiche.

Bellandi, M. (1996). Innovation and change in the Marshallian industrial district. European Planning Studies, 4(3), 357-368.

Bellandi, M., \& Russo, M. (1994). Distretti industriali e cambiamento economico locale. Rosenberg \& Sellier, Torino.

Belso-Martínez, J. A. (2008). Differences in survival strategies among footwear industrial districts: the role of international outsourcing. European Planning Studies, 16(9), 1229-1248.

Belso-Martinez, J. A., Molina-Morales, F. X., \& Mas-Verdú, F. (2013). Combining effects of internal resources, entrepreneur characteristics and KIS on new firms. Journal of Business Research, 66(10), 2079-2089.

Belso-Martínez, J. A., Molina-Morales, F. X., \& Mas-Verdú, F. (2011). Clustering and internal resources: moderation and mediation effects. Journal of Knowledge Management, 15(5), 738-758.

Belussi, F, Gottardi, G., \& Rullani, E. (2000). Il futuro dei distretti. Piccola Impresa/Small Business, 2.

Belussi, F, Sammarra, A., \& Sedita, S. R. (2008). Industrial districts evolutionary 
trajectories: localized learning diversity and external growth. In Artículo presentado en la 25th Celebration Conference 2008 sobre Entrepreneurship and innovation - organizations, institutions, systems and regions, Copenhage.

Belussi, Fiorenza. (1993). Il distretto industriale della Riviera del Brenta: tipologia delle imprese e tendenze evolutive. Oltre Il Ponte.

Belussi, Fiorenza. (1996). Local systems, industrial districts and institutional networks: Towards a new evolutionary paradigm of industrial economics? European Planning Studies, 4(1), 5-26.

Belussi, Fiorenza. (2003). The changing governance of IDs: the entry of multinationals in local nets. In B. T. Ashaim \& A. Mariussen (Eds.), Innovations, Regions and Projects: Studies in New Forms of Knowledge Governance (pp. 317-346). Stockholm: Nordregio.

Belussi, Fiorenza. (2018). New perspectives on the evolution of clustersNo Title. $\begin{array}{llll}\text { European } & \text { Planning } & \text { Studies, } & 26(9),\end{array}$ https://doi.org/10.1080/09654313.2018.1492059

Belussi, Fiorenza, Gottardi, G., \& Rullani, E. (2012). The technological evolution of industrial districts (Vol. 29). Springer Science \& Business Media.

Belussi, Fiorenza, \& Sedita, S. R. (2012). Industrial districts as open learning systems: Combining emergent and deliberate knowledge structures. Regional Studies, 46(2), $165-184$.

Benner, M. J. (2010). Securities analysts and incumbent response to radical technological change: Evidence from digital photography and internet telephony. Organization Science, 21(1), 42-62.

Benner, M. J., \& Tushman, M. L. (2003). Exploitation, exploration, and process management: The productivity dilemma revisited. Academy of Management Review, 28(2), 238-256.

Bergek, A., Berggren, C., Magnusson, T., \& Hobday, M. (2013). Technological discontinuities and the challenge for incumbent firms: Destruction, disruption or creative accumulation? Research Policy, 42(6-7), 1210-1224. https://doi.org/10.1016/j.respol.2013.02.009

Bernard, H. R. (2017). Research methods in anthropology: Qualitative and quantitative approaches. Rowman \& Littlefield.

Bessant, J. R., \& Tidd, J. (2007). Innovation and entrepreneurship. Chichester, England; Hoboken, NJ: John Wiley \& Sons. Retrieved from 
http://www.loc.gov/catdir/toc/ecip074/2006036087.html

Bhaskaran, S. (2006). Incremental innovation and business performance: small and medium-size food enterprises in a concentrated industry environment. Journal of Small Business Management, 44(1), 64-80.

Bianchi, G. (1998). Requiem for the Third Italy? Rise and Fall of a too succesful concept. Entrepreneurship \& Regional Development, 10(2), 93-116.

Bianchi, P., \& Giordani, M. G. (1993). Innovation policy at the local and national levels: The case of Emilia-Romagna. European Planning Studies, 1(1), 25-41.

Biggiero, L. (1999). Markets, hierarchies, networks districts: A cybernetic approach. Human Systems Management, 18, 71-86.

Biggiero, L. (2001). Self-organizing processes in building entrepreneurial networks: A theoretical and empirical investigation. Human Systems Management, 20(209222).

Biggiero, L. (2006). Industrial and knowledge relocation strategies under the challenges of globalization and digitalization: the move of small and medium enterprises among territorial systems. Entrepreneurship \& Regional Development, 18, 443471.

Boari, C., Molina-Morales, F. X., \& Martínez-Cháfer, L. (2017). Direct and interactive effects of brokerage roles on innovation in clustered firms. Growth and Change, 48(3), 336-358.

Boix, R. (2009). The empirical evidence of industrial districts in Spain. In G Becattini, M. Bellandi, \& L. De Propris (Eds.), A Handbook of Industrial Districts. Cheltenham: Edward Elgar.

Boix, R., \& Galletto, V. (2006). El nuevo mapa de los distritos industriales de España y su comparación con Italia y el Reino Unido. Documento de trabajo 06.04. Departament d'Economia Aplicada. Universitat Autònoma de Barcelona.

Boix, R., Sforzi, F., Galletto Ciocia, V., \& Llobet-Domingo, J. (2015). Sistemas locales de trabajo y distritos industriales en España 2001-2011. In International Conference on Regional Science. Tarragona Nov. 2015 (pp. 1-30).

Boschma, R., Van Oort, F., \& Balland, P. A. (2011). Related variety, knowledge transfer and economic territorial resilience: Some research options,. T-RES Kick-off Meeting. Toulouse: LEREPS., 24-25.

Boschma, R A, \& Ter Wal, A. L. J. (2007). Knowledge networks and innovative performance in an industrial district. Industry and Innovation, 14(2), 177-199. 
Boschma, Ron A. (2005). Proximity and innovation: A critical assessment. Regional Studies, 39(1), 61-74. https://doi.org/10.1080/0034340052000320887

Boschma, Ron A., \& Frenken, K. (2006). Why is economic geography not an evolutionary science? Towards an evolutionary economic geography. Journal of Economic Geography. https://doi.org/10.1093/jeg/lbi022

Boschma, Ron A, \& Lambooy, J. G. (2002). Knowledge, market structure, and economic coordination: Dynamics of industrial districts. Growth and Change, 33(3), 291-311.

Boschma, Ron A, Lambooy, J. G., \& Schutjens, V. (2002). Embeddedness and innovation. Embedded Enterprise and Social Capital: International Perspectives, $19-35$.

Bower, J. L., \& Christensen, C. M. (1995). Disruptive technologies: catching the wave. Harvard Business Review, (73), 43-53.

Bower, J. L., \& Christensen, C. M. (1996). Disruptive technologies: Catching the wave. The Journal of Product Innovation Management, 1(13), 75-76.

Braczyk, H.-J., Cooke, P. N., \& Heidenreich, M. (1998). Regional innovation systems: the role of governances in a globalized world. Psychology Press.

Bramanti, A., \& Senn, L. (1990). Product innovation and strategic patterns of firms in a diversified local economy: The case of Bergamo. Entrepreneurship \& Regional Development, 2, 153-180.

Brenner, T. (2000). Industrial districts: A typology from an evolutionary perspective. In Artículo presentado en la DRUID Conference 2000, Rebild, Jutland.

Breschi, S, \& Lissoni, F. (2009). Mobility of skilled workers and co-invention networks: an anatomy of localized knowledge flows. Journal of Economic Geography, 9(4), 439.

Breschi, Stefano, \& Lissoni, F. (2001). Knowledge Spillovers and Local Innovation Systems: A Critical Survey. Industrial \& Corporate Change, 10(4), 975-1005. Retrieved from http://search.ebscohost.com/login.aspx?direct=true\&db=bth\&AN=11578746\&site $=$ ehost-live

Breschi, Stefano, \& Malerba, F. (1997). Sectoral innovation systems: technological regimes, Schumpeterian dynamics, and spatial boundaries. Systems of Innovation: Technologies, Institutions and Organizations, 130-156.

Briguglio, L., Cordina, G., Farrugia, N., \& Vella, S. (2006). Conceptualizing and 
measuring economic resilience. Building the Economic Resilience of Small States, Malta: Islands and Small States Institute of the University of Malta and London: Commonwealth Secretariat, 265-288.

Bristow, G. (2010). Resilient regions: re-'place'ing regional competitiveness. Cambridge Journal of Regions, Economy and Society, 3(1), 153-167.

Bristow, G., \& Healy, A. (2018). Innovation and regional economic resilience: an exploratory analysis. The Annals of Regional Science, 60(2), 265-284. https://doi.org/10.1007/s00168-017-0841-6

Brown, D. W., \& Konrad, A. M. (2001). Granovetter was right the importance of weak ties to a contemporary job search. Group \& Organization Management, 26(4), $434-462$.

Brusco, S. (1982). The Emilian Model: productive decentralisation and social integration. Cambridge Journal of Economics, 6, 167-184.

Brusco, Sebastiano. (1990). The idea of the industrial district: its genesis. Industrial Districts and Inter-Firm Co-Operation in Italy, 10-19.

Budí-Orduña, V. (2008). El distrito de la Cerámica de Castellón. Mediterráneo Económico, 13, 383-407.

Buenstorf, G., \& Klepper, S. (2009). Heritage and agglomeration: the Akron tyre cluster revisited. The Economic Journal, 119(537), 705-733.

Buesa Blanco, M. (2002). El sistema regional de innovación de la Comunidad de Madrid.

Buesa, M., Martínez, M., Heijs, J., \& Baumert, T. (2002). Los sistemas regionales de innovación en España . Economía Industrial, 5(1987), 15-32.

Burgelman, R. A. (1996). A process model of strategic business exit: Implications for an evolutionary perspective on strategy. Strategic Management Journal, 17(S1), 193-214.

Burgleman, E. A. (1991). Intraorganizational ecology of strategy making and organizational adaptation: Theory and research. Organization Science, 2(3), 239262.

Burns, T. E., \& Stalker, G. M. (1961). The management of innovation.

Caloghirou, Y., Kastelli, I., \& Tsakanikas, A. (2004). Internal capabilities and external knowledge sources: complements or substitutes for innovative performance? Technovation, 24(1), 29-39.

Camisón, C., \& Forés, B. (2010). Knowledge absorptive capacity: New insights for its 
conceptualization and measurement. Journal of Business Research, 63(7), 707715.

Capello, R. (1999). Spatial transfer of knowledge in high technology milieux: learning versus collective learning processes. Regional Studies, 33(4), 353-365.

Capó-Vicedo; Exposito-Langa; Molina-Morales. (2008). El Efecto del Capital Social y la Capacidad de Absorción en la Innovación Empresarial. Universitat Politécnica de Valencia.

Capó-Vicedo, J., Expósito-Langa, M., \& Molina-Morales, F. X. (2008). Improving SME competitiveness reinforcing interorganisational networks in industrial clusters. International Entrepreneurship and Management Journal, 4(2), 147-169.

Carbonara, N. (2004). Innovation processes within geographical clusters: a cognitive approach. Technovation, 24(1), 17-28.

Carlsson, B. (2012). Technological systems and economic performance: the case of factory automation (Vol. 5). Springer Science \& Business Media.

Carlsson, B., \& Stankiewicz, R. (1991). On the nature, function and composition of technological systems. Journal of Evolutionary Economics, 1(2), 93-118.

Carminucci, C., \& Casucci, S. (1997). Il ciclo di vita dei distretti industriali: ipotesi teoriche ed evidenze empiriche. L'industria, 18(2), 283-316.

Cassiman, B., \& Veugelers, R. (2006). In search of complementarity in innovation strategy: Internal R\&D and external knowledge acquisition. Management Science, $52(1), 68-82$.

Cassiolato, J. E., Lastres, H. M. M., \& Maciel, M. L. (2003). Systems of innovation and development : evidence from Brazil. New horizons in the economics of innovation. Cheltenham, UK: Edward Elgar.

Castro Martínez, E., \& Fernández de Lucio, I. (2001). Innovación y Sistemas de innovación. Disponible En Www Imedea. Csic. Es/Public/Cursoid/Html/Textos/Tema.

Cattani, G. (2005). Preadaptation, firm heterogeneity, and technological performance: A study on the evolution of fiber optics, 1970-1995. Organization Science, 16(6), $563-580$.

Chandler, A. D. (1962). Strategy and structure: Chapters in the history of the American enterprise. Massachusetts Institute of Technology Cambridge.

Chandy, Rajesh K.Tellis, G. J. (2000). The Incumbent's Curse? Incumbency, Size, and Radical Product Innovation. Journal of Marketing, 64(3), 1-17. 
https://doi.org/10.1509/jmkg.64.3.1.18033

Charitou, C. D., \& Markides, C. C. (2002). Responses to disruptive strategic innovation. MIT Sloan Management Review, 44(2), 55-64.

Chesbrough, H. (1999). Arrested development: the experience of European hard disk drive firms in comparison with US and Japanese firms. Journal of Evolutionary Economics, 9(3), 287-329.

Chiarvesio, M., Di Maria, E., \& Micelli, S. (2010). Global value chains and open networks: the case of Italian industrial districts. European Planning Studies, 18(3), $333-350$.

Child, J. (1984). Organization: A guide to problems and practice. Sage.

Child, J. (1997). Strategic choice in the analysis of action, structure, organizations and environment: retrospect and prospect. Organization Studies, 18(1), 43-76.

Christaller, W. (1966). Central places in southern Germany. Prentice-Hall.

Christensen, C. (1997). The innovator's dilemma: When New Technologies Cause Great Firms to Fail. (Harvard Business School Press., Ed.). Boston, MA.

Christensen, C. M. (1997). The innovator's dilemma: when new technologies cause great firms to fail. The management of innovation and change series. Boston, Mass.: Harvard Business School Press.

Christensen, C. M. (2006). The ongoing process of building a theory of disruption. Journal of Product Innovation Management, 23(1), 39-55.

Christensen, C. M., Aaron, S., \& Clark, W. (2003). Disruption in Education. Geophys. Res, 116, E00F23.

Christensen, C. M., \& Bower, J. L. (1996). Customer power, strategic investment, and the failure of leading firms. Strategic Management Journal, 17(3), 197-218.

Christensen, C. M., McDonald, R., Altman, E., \& Palmer, J. (2018). Dsiruptive Innovation: An intellectual History and directions for future research. Journal of Management Studies. https://doi.org/10.1002/000.00000

Christensen, C. M., \& Raynor, M. E. (2003). The innovator's solution: creating and sustaining successful growth. Boston, Mass.: Harvard Business School Press.

Christensen, C. M., \& Tedlow, R. S. (2000). Patterns of Disruption in Retailing. Harvard Business Review, 78(1), 42-45.

Ciappei, C., \& Simoni, C. (2005). Drivers of new product success in the Italian sport shoe cluster of Montebelluna. Journal of Fashion Marketing and Management: An International Journal, 9(1), 20-42. 
Clark, J., Huang, H.-I., \& Walsh, J. P. (2010). A typology of 'innovation districts': what it means for regional resilience. Cambridge Journal of Regions, Economy and Society, 3(1), 121-137.

Codara, L., \& Morato, E. (2002). il distretto di Montebelluna tra locale e globale. In P. G. (Ed.), Le istituzioni dello sviluppo. I distretti industriali tra storia, sociologia ed economia. Rome: Donzelli.

Cohen, \& Levinthal. (1989). Innovation and learning: the two faces of $\mathrm{R} \& \mathrm{D}$. The Economic Journal, 99(397), 569-596.

Cohen, W M, \& Levinthal, D. A. (1994). Fortune favors the prepared firm. Management Science, 40(2), 227-251.

Cohen, Wesley M, \& Levinthal, D. a. (1990). A new perspective on learning and innovation. Administrative Science Quarterly, 35(1), 128-152. https://doi.org/10.2307/2393553

Colonna, M., Nicotra, M., \& Moncalero, M. (2013). Materials, Designs and Standards Used in Ski-Boots for Alpine Skiing. Sports, 1(4), 78-113.

Contreras Navarro, J. L., del Saz Salazar, S., \& Tomás Carpi, J. A. (2000). Institutos tecnológicos y política sectorial en distritos industriales: el caso del calzado. Economía Industrial, (334), 25-34.

Cooke, P. (2001). Sistemas de innovación regional: conceptos, análisis y tipología. In M. Olazarán \& M. Gómez (Eds.), Sistemas Regionales de Innovación (pp. 73-91). Bilbao: Universidad del País Vasco.

Cooke, Philip. (2001). Regional innovation systems, clusters, and the knowledge economy. Industrial and Corporate Change, 10(4), 945-974.

Cooke, Philip. (2002). Knowledge economies. Clusters, learning and cooperative advantage. Routledge Studies in International Business and the World Economy, (26), xii, 218 p. https://doi.org/10.4324/9780203445402

Cooke, Philip. (2013). Global production networks and global innovation networks: Stability versus growth. European Planning Studies, 21(7), 1081-1094.

Cooke, Philip, Parrilli, M. D., \& Curbelo, J. L. (2012). Innovation, global change and territorial resilience. Edward Elgar Publishing.

Cooke, Philip, Uranga, M. G., \& Etxebarria, G. (1997). Regional innovation systems: Institutional and organisational dimensions. Research Policy, 26(4), 475-491.

Coombs, R. (1996). Core competencies and the strategic management of R\&D. $R \& D$ Management, 26(4), 345-355. 
Corò, G, \& Grandinetti, R. (1999). Evolutionary patterns of Italian industrial districts. Human Systems Management, 18, 117-129.

Corò, G, Gurisatti, P., \& Rossi, A. (1998). Il distretto sport system di Montebelluna. Percorsi Di Internazionalizzazione. Competenze e Auto-Organizzazione Nei Distretti Industriali Del Nord-Est. Franco Angeli, Milan.

Corò, Giancarlo, \& Grandinetti, R. (2001). Industrial district responses to the network economy: vertical integration versus pluralist global exploration. Human Systems Management, 20(3), 189-199.

Corò, Giancarlo, Gurisatti, P., \& Rossi, A. (1998). Il distretto Sport System di Montebelluna. In Percorsi locail di internazionalizzazione. Competenze e autoorganizzazione nei distretti industriali del Nord-Est. Milan: Franco Angeli.

Courvisanos, J., Jain, A., \& K. Mardaneh, K. (2016). Economic resilience of regions under crises: A study of the Australian economy. Regional Studies, 50(4), 629643.

Cowell, M. M. (2013). Bounce back or move on: Regional resilience and economic development planning. Cities, 30, 212-222.

Crespo, J., Suire, R., \& Vicente, J. (2013). Lock-in or lock-out? How structural properties of knowledge networks affect regional resilience. Journal of Economic Geography, 14(1), 199-219.

Crestanello, P. (1997). I distretti industriali in Veneto: cambiamenti e tendenze. In Le risposte locali e regionali alla pressione globale: il caso dell'Italia e dei suoi distretti industriali (pp. 101-140).

Crewe, L. (1996). Material culture: embedded firms, organizational networks and the local economic development of a fashion quarter. Regional Studies, 30(3), 257272.

Crilly, D., Zollo, M., \& Hansen, M. T. (2012). Faking it or muddling through? Understanding decoupling in response to stakeholder pressures. Academy of Management Journal, 55(6), 1429-1448.

d'Arbeloff, A. (1996). Teradyne: Corporate Management of Disruptive Change. Cambridge, Massachusetts: Harvard Business School.

Daft, R. L. (1978). A dual-core model of organizational innovation. Academy of Management Journal, 21(2), 193-210.

Daft, R. L., \& Damanpour, F. (1996). Organizational complexity and innovation: developing and testing multiple contingency models. Management Science, 42(2), 
$193-210$.

Dahlin, K. B., \& Behrens, D. M. (2005). When is an invention really radical?: Defining and measuring technological radicalness. Research Policy, 34(5), 717-737.

Dalum, B. (1995). Local and global linkages. The radiocommunications cluster in northern Denmark. Journal of Industry Studies, 2(2), 89-109.

Dalum, Bent, Pedersen, C. Ø. R., \& Villumsen, G. (2005). Technological life-cycles: lessons from a cluster facing disruption. European Urban and Regional Studies, 12(3), 229-246.

Damanpour, F. (1992). Organizational size and innovation. Organization Studies, 13(3), $375-402$.

Damanpour, F., \& Gopalakrishnan, S. (1998). Theories of organizational structure and innovation adoption: the role of environmental change. Journal of Engineering and Technology Management, 15(1), 1-24.

Damanpour, F., \& Gopalakrishnan, S. (2001). The dynamics of the adoption of product and process innovations in organizations. Journal of Management Studies, 38(1), $45-65$.

Dandi, R., Sammarra, A., Muzzi, C., \& Biggiero, L. (2006). The identification of innovation catalysts in the Triple helix: empirical evidence in the aerospace industrial cluster in central Italy. In XVIth ISA World Congress of Sociology, Durban (South Africa) (pp. 23-29).

Danneels, E. (2003). Tight-loose coupling with customers: the enactment of customer orientation. Strategic Management Journal, 24(6), 559-576.

Danneels, E. (2004). Disruptive technology reconsidered: A critique and research agenda. Journal of Product Innovation Management, 21(4), 246-258.

Das, S. (2017). Banking on Disruption: Digitization, FinTech and the future of retail banking. Available at: Https:// Www.Christenseninstitute.Org/WpContent/Uploads/2017/06/Digitization-FinTech-and-the-Future-Ofretail-Banking1.Pdf.

Datta, A., \& Jessup, L. M. (2013). Looking beyond the focal industry and existing technologies for radical innovations. Technovation, 33(10-11), 355-367.

Davies, S. (2011). Regional resilience in the 2008-2010 downturn: comparative evidence from European countries. Cambridge Journal of Regions, Economy and Society, 4(3), 369-382.

Davoudi, S., Shaw, K., Haider, L. J., Quinlan, A. E., Peterson, G. D., Wilkinson, C., ... 
Davoudi, S. (2012). Resilience: a bridging concept or a dead end? Planning Theory \& Practice, 13(2), 299-333.

De Marchi, V., Di Maria, E., \& Gereffi, G. (2018). Industrial Districts, Clusters and Global Value Chains: Toward an Integrated Framework. In V. De Marchi, E. Di Maria, \& G. Gereffi (Eds.), Local Clusters in Global Value Chains: Linking Actors and Territories Through Manufacturing and Innovation. Abingdon: Routledge.

De Marchi, V., Gereffi, G., \& Grandinetti, R. (2018). Evolutionary Trajectories of Industrial Districts in Global Value Chains. In V. De Marchi, E. Di Maria, \& G. Gereffi (Eds.), Local Clusters in Global Value Chains: Linking Actors and Territories Through Manufacturing and Innovation. Abingdon: Routledge.

De Marchi, V., \& Grandinetti, R. (2014). Industrial districts and the collapse of the Marshallian model: looking at the Italian experience. Competition \& Change, 18(1), 70-87.

De Meur, G., \& Rihoux, B. (2002). L'analyse quali-quantitative comparée (AQQCQCA): approche, techniques et applications en sciences humaines.

Decarolis, D. M., \& Deeds, D. L. (1999). The impact of stocks and flows of organizational knowledge on firm performance: an empirical investigation of the biotechnology industry. Strategic Management Journal, 20, 953-968.

Del Carmen Haro-Domínguez, M., Arias-Aranda, D., Lloréns-Montes, F. J., \& Moreno, A. R. (2007). The impact of absorptive capacity on technological acquisitions engineering consulting companies. Technovation, 27(8), 417-425.

Denhardt, J., \& Denhardt, R. (2010). Building organizational resilience and adaptive management. Handbook of Adult Resilience, 333-349.

DeWalt, K. M., \& DeWalt, B. R. (2011). Participant observation: A guide for fieldworkers. Rowman Altamira.

Dewar, R. D., \& Dutton, J. E. (1986). The adoption of radical and incremental innovations: An empirical analysis. Management Science, 32(11), 1422-1433.

Di Stefano, G., Gambardella, A., \& Verona, G. (2012). Technology push and demand pull perspectives in innovation studies: Current findings and future research directions. Research Policy, 41(8), 1283-1295.

Doeringer, P. B., \& Terkla, D. G. (1995). Business strategy and cross-industry clusters. Economic Development Quarterly, 9(3), 225-237.

Doloreux, D., \& Parto, S. (2005). Regional innovation systems: Current discourse and unresolved issues. Technology in Society, 27(2), 133-153. 
Dosi, G. (1988). Sources, Procedures, and Microeconomic Effects of Innovation. Journal of Economic Literature, 26(3), 1120-1171.

Dosi, G., Pavitt, K., \& Soete, L. (1990). The economics of technical change and international trade. LEM Book Series.

Du Plessis, M. (2007). The role of knowledge management in innovation. Journal of Knowledge Management, 11(4), 20-29.

Dubé, J., \& PolèSe, M. (2016). Resilience revisited: assessing the impact of the 200709 recession on 83 Canadian regions with accompanying thoughts on an elusive concept. Regional Studies, 50(4), 615-628.

Duşa, A., \& Thiem, A. (2014). QCA: A package for Qualitative Comparative Analysis, R package version 1.1-4. URL: Http://Cran. -Project. Org/Package = QCA.

Edquist, C. (1997). Systems of innovation: technologies, institutions, and organizations. Psychology Press.

Edquist, C. (2005). Systems of Innovation. Perspectives and Challenges. In The Oxford Handbook of Innovation (pp. 181-208). Oxford University Press.

Edquist, C., Hommen, L., \& McKelvey, M. D. (2001). Innovation and employment: Process versus product innovation. Edward Elgar Publishing.

Eisenhardt, K. M. (1989). Building theories from case study research. Academy of Management Review, 14(4), 532-550.

Eisenhardt, K. M., \& Graebner, M. E. (2007). Theory building from cases: opportunities and challenges. Academy of Management Journal, 50(1), 25-32. https://doi.org/10.1002/job.

Eisenmann, T., Parker, G., \& Van Alstyne, M. W. (2006). Strategies for two-sided markets. Harvard Business Review, 84(10), 92.

Eisingerich, A. B., Bell, S. J., \& Tracey, P. (2010). How can clusters sustain performance? The role of network strength, network openness, and environmental uncertainty. Research Policy, 39(2), 239-253.

Elche-Hortelano, D., Martínez-Pérez, Á., \& García-Villaverde, P. M. (2015). Bonding capital, knowledge exploitation and incremental innovation in clusters of cultural tourism: the World Heritage Cities in Spain. Investigaciones Europeas de Dirección y Economía de La Empresa (IEDEE), 21(3).

Ellison, G., \& Glaeser, E. L. (1997). Geographic concentration in US manufacturing industries: a dartboard approach. Journal of Political Economy, 105(5), 889-927.

Elola, A., Parrilli, M. D., \& Rabellotti, R. (2013). The Resilience of Clusters in the 
Context of Increasing Globalization: The Basque Wind Energy Value Chain. European Planning Studies, 21(7), 989-1006. https://doi.org/10.1080/09654313.2013.734456

Eng, S., \& Woodside, A. G. (2012). Configural analysis of the drinking man: Fuzzy-set qualitative comparative analyses. Addictive Behaviors, 37(4), 541-543.

Enright, M. J. (1995). Organization and coordination in geographically concentrated industries. In Coordination and information: Historical perspectives on the organization of enterprise (pp. 103-146). University of Chicago Press.

Enright, M. J. (2003). Regional clusters: what we know and what we should know. Innovation Clusters and Interregional Competition, 99-129.

Ernst, D. (2009). A new geography of knowledge in the electronics industry? Asia's role in global innovation networks.

Escorsa, P.; Valls, J. (2003). Tecnología e innovación en la empresa: Dirección y gestión. Ediciones UPC.

Escribano, A., Fosfuri, A., \& Tribó, J. A. (2009). Managing external knowledge flows: The moderating role of absorptive capacity. Research Policy, 38(1), 96-105.

Estornell, M. L., Verdú, F. M., \& Morales, F. X. M. (2008). Política tecnológica aplicada a los distritos industriales. Mediterráneo Económico, (13), 435-458.

Estrada, I., Faems, D., Cruz, N. M., \& Santana, P. P. (2016). The role of interpartner dissimilarities in Industry-University alliances: Insights from a comparative case study. Research Policy, 45(10), 2008-2022.

Ettlie, J. E. (1983). Organizational policy and innovation among suppliers to the food processing sector. Academy of Management Journal, 26(1), 27-44.

Ettlie, J. E., Bridges, W. P., \& O’Keefe, R. D. (1984). Organization Strategy and Structural Differences for Radical versus Incremental Innovation. Management Science, 30(6), 682-695.

Evans, R., \& Karecha, J. (2014). Staying on top: why is Munich so resilient and successful? European Planning Studies, 22(6), 1259-1279.

Expósito-Langa, M., Molina-Morales, F. X., \& Capo-Vicedo, J. (2011). New product development and absorptive capacity in industrial districts: a multidimensional approach. Regional Studies, 45(3), 319-331.

Fagerberg, J. (1988). Why growth rates differ, inDosi. Technical Change and Economic Theory, London, PinterPublishers.

Fagerberg, Jan. (1987). A technology gap approach to why growth rates differ. 
Research Policy, 16(2-4), 87-99.

Fagerberg, Jan. (1994). Technology and international differences in growth rates. Journal of Economic Literature, 32(3), 1147-1175.

Fagerberg, Jan. (2004). Innovation: a guide to the literature. Georgia Institute of Technology.

Fagerberg, Jan, Mowery, D. C., \& Nelson, R. R. (2005). The Oxford handbook of innovation. Oxford : Oxford University Press.

Fagerberg, Jan, \& Verspagen, B. (2002). Technology-gaps, innovation-diffusion and transformation: an evolutionary interpretation. Research Policy, 31(8), 1291-1304.

Fan, D., Li, Y., \& Chen, L. (2017). Configuring innovative societies: The crossvergent role of cultural and institutional varieties. Technovation, 66-67, 43-56. https://doi.org/10.1016/j.technovation.2017.05.003

Felzensztein, C., Gimmon, E., \& Carter, S. (2010). Geographical co-location, social networks and inter-firm marketing co-operation: the case of the salmon industry. Long Range Planning, 43(5-6), 675-690.

Fernandez, A.-S., Le Roy, F., \& Chiambaretto, P. (2018). Implementing the right project structure to achieve coopetitive innovation projects. Long Range Planning, 51(2), 384-405.

Fernández Sánchez, E. (2005). Estrategia de innovación. Thomson Paraninfo, SA.

Fernández, Z., \& Suárez, I. (1996). La estrategia de la empresa desde una perspectiva basada en los recursos. Revista Europea de Dirección y Economía de La Empresa, 5(3), 73-92.

Ferrari, A. (2016). Esmalglass-itaca: New developments on digitalisation of the ceramic tile production process. ACIMAC Ceramic World Review, (Digital glazing and decoration of ceramic tiles), 6-11.

Fingleton, B., Igliori, D., \& Moore, B. (2005). Cluster dynamics: new evidence and projections for computing services in Great Britain. Journal of Regional Science, 45(2), 283-311.

Fiss, P. C. (2007). A set-theoretic approach to organizational configurations. Academy of Management Review, 32(4), 1190-1198.

Fiss, P. C. (2011). Building better causal theories: A fuzzy set approach to typologies in organization research. Academy of Management Journal, 54(2), 393-420.

Flatten, T. C., Engelen, A., Zahra, S. A., \& Brettel, M. (2011). A measure of absorptive capacity: Scale development and validation. European Management Journal, 
29(2), 98-116.

Flor, M. L., \& Oltra, M. J. (2004). Identification of innovating firms through technological innovation indicators: an application to the Spanish ceramic tile industry. Research Policy, 33(2), 323-336.

Folke, C., Carpenter, S., Walker, B., Scheffer, M., Chapin, T., \& Rockström, J. (2010). Resilience thinking: integrating resilience, adaptability and transformability. Ecology and Society, 15(4).

Folta, T. B., Cooper, A. C., \& Baik, Y. (2006). Geographic cluster size and firm performance. Journal of Business Venturing, 21(2), 217-242.

Fontes, M. (2005). Distant networking: The knowledge acquisition strategies of'outcluster'biotechnology firms. European Planning Studies, 13(6), 899-920.

Fornahl, D., Henn, S., \& Menzel, M.-P. (2010). Emerging clusters: theoretical, empirical and political perspectives on the initial stage of cluster evolution. Edward Elgar Publishing.

Forrest, J. F. (1991). Models of the process technological innovation. Technology Analysis \& Strategic Management, 3(4), 439-453.

Foss, J. N., Lyngsie, Z., \& Zahra, S. . (2013). The role of external knowledge sources and organizational design in the process of opportunity exploitation. Strategic Management Journal, 34(12), 1453-1471. https://doi.org/10.1002/smj.2135

Foss, N. J. (1996). Higher-order industrial capabilities and competitive advantage. Journal of Industry Studies, 3, 1-20.

Foster, K. A. (2007). A Case Study Approachto Understanding Regional Resilience.

Foster, R., \& Kaplan, S. (2011). Creative Destruction: Why Companies That Are Built to Last Underperform the Market--And How to Success fully Transform Them. Crown Business.

Freel, M. S. (2003). Sectoral patterns of small firm innovation, networking and proximity. Research Policy, 32(5), 751-770.

Freeman, Chris. (1987). Technology policy and economic policy: Lessons from Japan. Frances Pinter, London.

Freeman, Christopher, Clark, J., \& Soete, L. (1982). Unemployment and technical innovation: a study of long waves and economic development. Burns \& Oates.

Freeman, Christopher, \& Paredes, E. (1975). La teoría económica de la innovación industrial. Alianza.

Freeman, Christopher, \& Soete, L. (1987). Technical change and full employment. 
Wiley-Blackwell.

Freeman, Christopher, \& Soete, L. (1990). Fast structural change and slow productivity change: some paradoxes in the economics of information technology. Structural Change and Economic Dynamics, 1(2), 225-242.

Friedman, D. B. (1988). The misunderstood miracle: Industrial development and political change in Japan. Cornell University Press.

Fuchs, P. H., Mifflin, K. E., Miller, D., \& Whitney, J. O. (2000). Strategic integration: Competing in the age of capabilities. California Management Review, 42(3), 118147.

Gabaldón-Estevan, D. (2010). El sistema distritual de innovación cerámico de Castellón. Universidad de Valencia.

Gans, J. (2016). The disruption dilemma. MIT Press.

Garofoli, G. (1995). Desarrollo económico, organización de la producción y territorio. In A. Vázquez Barquero \& G. Garofoli (Eds.), Desarrollo económico local en Europa . Madrid: Colegio de Economistas de Madrid.

Garofoli, G, \& Mazzoni, R. (1994). Sistemi produttivi locali: struttura $e$ trasformazione. Milano: Franco Angeli.

Garofoli, Gioacchino. (1992). Endogenous development and southern Europe. Avebury. Garwin, D. A. (1993). Building a learning organization. Harvard Business Review, 71(4), 73-91.

Gatignon, H., Tushman, M. L., Smith, W., \& Anderson, P. (2002). A structural approach to assessing innovation: Construct development of innovation locus, type, and characteristics. Management Science, 48(9), 1103-1122.

Gawer, A., \& Cusumano, M. A. (2008). How companies become platform leaders. MIT Sloan Management Review.

Gee, S. (1981). Technology transfer, innovation and international competitiveness.

Gegenhuber, T., \& Dobusch, L. (2017). Making an impression through openness: how open strategy-making practices change in the evolution of new ventures. Long Range Planning, 50(3), 337-354.

Ghoshal, S., \& Bartlett, C. A. (1990). The multinational corporation as an interorganizational network. Academy of Management Review, 15(4), 603-625.

Gilbert, B. A. (2012). Creative destruction: Identifying its geographic origins. Research Policy, 41(4), 734-742.

Gilbert, C. (2003). The disruption opportunity. MIT Sloan Management Review, 44(4), 


\section{7-33. JOUR.}

Gilbert, C. G. (2005). Unbundling the structure of inertia: Resource versus routine rigidity. Academy of Management Journal, 48(5), 741-763.

Gilbert, C. G. (2006). Change in the presence of residual fit: can competing frames coexist? Organization Science, 17(1), 150-167.

Gilly, J.-P., Kechidi, M., \& Talbot, D. (2014). Resilience of organisations and territories: The role of pivot firms. European Management Journal, 32(4), 596602.

Giuliani, E. (2007a). Networks and heterogeneous performance of cluster firms. In K. Frenken (Ed.), Applied Evolutionary Economics and Economic Geography. Cheltenham: Edward Elgar.

Giuliani, E. (2007b). The selective nature of knowledge networks in clusters: evidence from the wine industry. Journal of Economic Geography, 7, 139-168.

Giuliani, E. (2011). Role of technological gatekeepers in the growth of industrial clusters: Evidence from chile. Regional Studies, 45(10), 1329-1348.

Giuliani, E, \& Bell, M. (2005). The micro-determinants of meso-level learning and innovation: evidence from a Chilean wine cluster. Research Policy, 34, 47-68.

Giuliani, Elisa. (2005). Cluster absorptive capacity: why do some clusters forge ahead and others lag behind? European Urban and Regional Studies, 12(3), 269-288.

Giuliani, Elisa. (2011). Role of Technological Gatekeepers in the Growth of Industrial Clusters: Evidence from Chile. Regional Studies, 45(10), 1329-1348. https://doi.org/10.1080/00343404.2011.619973

Giuliani, Elisa. (2013). Network dynamics in regional clusters: Evidence from Chile. Research Policy, 42(8), 1406-1419.

Glaeser, E. L., Kallal, H. D., Scheinkman, J. A., \& Shleifer, A. (1992). Growth in cities. Journal of Political Economy, 100(6), 1126-1152.

Glasmeier, A. (1991). Technological discontinuities and flexible production networks: The case of Switzerland and the world watch industry. Research Policy, 20, 469485.

Govindarajan, V., \& Kopalle, P. K. (2006). Disruptiveness of innovations: Measurement and an assessment of reliability and validity. Strategic Management Journal, 27(2), 189-199. https://doi.org/10.1002/smj.511

Grabher, G. (1993). The Weakness of Strong Ties: The Lock-in of Regional Development in the Ruhr Area. In G Grabher (Ed.), The Embedded Firm: On the 
Socioeconomics of Industrial Networks. Londres: Routledge.

Grabher, Gernot. (2009). Yet another turn? The evolutionary project in economic geography. Economic Geography, 85(2), 119-127.

Grabher, Gernot, \& Stark, D. (1997). Organizing diversity: evolutionary theory, network analysis and postsocialism. Regional Studies, 31(5), 533-544.

Graf, H. (2010). Gatekeepers in regional networks of innovators. Cambridge Journal of Economics, 35(1), 173-198.

Graf, H., \& Kruger, J. J. (2011). The performance of gatekeepers in innovator networks. Industry and Innovation, 18(1), 69-88.

Grandinetti, R. (2003). The chair manufacturing district of Manzano: evolutionary processes and the role of the institutions. In The technological evolution of industrial districts (pp. 463-479). Springer.

Granovetter, M. S. (1973). The strength of weak ties. American Journal of Sociology, 78(6), 1360-1380.

Granovetter, M. (1985). Economic action and social structure: The problem of embeddedness. American Journal of Sociology, 91, 481-510.

Granovetter, Mark. (1992). Problems of explanation in economic sociology. Networks and Organizations: Structure, Form, and Action, 25, 56.

Grant, R M. (1996). Prospering in dynamically-competitive environments: Organizational capability as knowledge integration. Organization Science, 7(4), $375-387$.

Grant, Robert M. (1999). The resource-based theory of competitive advantage: implications for strategy formulation. In Knowledge and strategy (pp. 3-23). Elsevier.

Grant, Robert M, Fernández, Z., Gómez, J. D. L., \& Navarro, J. R. (2006). Dirección estratégica: conceptos, técnicas y aplicaciones.

Greckhamer, T., Misangyi, V. F., Elms, H., \& Lacey, R. (2008). Using qualitative comparative analysis in strategic management research: An examination of combinations of industry, corporate, and business-unit effects. Organizational Research Methods, 11(4), 695-726.

Gripsrud, G., \& Gronhaug, K. (1985). Structure and strategy in grocery retailing: A sociometric approach. The Journal of Industrial Economics, 33(3), 339-347.

Gulati, R., \& Garino, J. (2000). Get the right mix of bricks \& clicks. Harvard Business Review, 78(3), 107-114. 
Hall, R. (1993). A framework linking intangible resources and capabiliites to sustainable competitive advantage. Strategic Management Journal, 14(8), 607618.

Hamel, G., \& Valikangas, L. (2003). The quest for resilience. Harvard Business Review, 81(9), 52.

Hang, C. C., Chen, J., \& Yu, D. (2011). An assessment framework for disruptive innovation. Foresight, 13(5), 4-13.

Hansen, M. T. (1999). The search-transfer problem: The role of weak ties in sharing knowledge across organization subunits. Administrative Science Quarterly, 44(1), 82-111.

Harrison, A. E. (1994). Productivity, imperfect competition and trade reform: Theory and evidence. Journal of International Economics, 36(1-2), 53-73.

Harrison, B. (1992). Industrial districts: old wine in new bottles? Regional Studies, 26(5), 469-483.

Harrison, B. (1994). The italian industrial crisis and the crisis of the cooperative form. European Planning Studies, 2(1), 3-22.

Hassink, R. (2005). How to unlock regional economies from path dependency? From learning region to learning cluster. European Planning Studies, 13(4), 521-535. https://doi.org/10.1080/09654310500107134

Hassink, R. (2010). Regional resilience: a promising concept to explain differences in regional economic adaptability? Cambridge Journal of Regions, Economy and Society, 3(1), 45-58.

Henderson, J. V. (1986). Efficiency of resource usage and city size. Journal of Urban Economics, 19(1), 47-70.

Henderson, R. (1993). Underinvestment and incompetence as responses to radical innovation: Evidence from the... RAND Journal of Economics. https://doi.org/10.2307/2555761

Henderson, R. M., \& Clark, K. B. (1990). Architectural innovation: The reconfiguration of existing product technologies and the failure of established firms. Administrative Science Quarterly, 9-30.

Henriques, P. L., Matos, P. V., Jerónimo, H. M., Mosquera, P., da Silva, F. P., \& Bacalhau, J. (2017). University or polytechnic? A fuzzy-set approach of prospective students' choice and its implications for higher education institutions' managers. Journal of Business Research. 
Herrigel, G. (1996). Crisis in German decentralized production: unexpected rigidity and the challenge of an alternative form of flexible organization in Baden Württemberg. European Urban and Regional Studies, 3(1), 33-52.

Hervás-Oliver, J.-L., \& Albors-Garrigós, J. (2008). The role of the firm's internal and relational capabilities in clusters: when distance and embeddedness are not enough to explain innovation. Journal of Economic Geography, 9(2), 263-283.

Hervás-Oliver, J.-L., \& Albors-Garrigós, J. (2014). Are technology gatekeepers renewing clusters? Understanding gatekeepers and their dynamics across cluster life cycles. Entrepreneurship \& Regional Development, 26(5-6), 431-452. https://doi.org/10.1080/08985626.2014.933489

Hervás-Oliver, J.-L., Albors-Garrigós, J., De-Miguel, B., \& Hidalgo, A. (2012). The role of a firm's absorptive capacity and the technology transfer process in clusters: How effective are technology centres in low-tech clusters? Entrepreneurship \& Regional Development, 24(7-8), 523-559.

Hervás-Oliver, J.-L., Albors-Garrigós, J., Estelles-Miguel, S., \& Boronat-Moll, C. (2017). Radical innovation in Marshallian industrial districts. Regional Studies, 110.

Hervás-Oliver, J.-L., Lleo, M., \& Cervello, R. (2017). The dynamics of cluster entrepreneurship: Knowledge legacy from parents or agglomeration effects? The case of the Castellon ceramic tile district. Research Policy, 46(1), 73-92.

Hervás Oliver, J. L., Dalmau Porta, J. I., \& Albors Garrigós, J. (2008). Influencia de los recursos y capacidades territoriales sobre las empresas en un distrito industrial. Evidencia empírica para el sector cerámico en España. Economía Industrial, (369), 213-224.

Hill, C., \& Deeds, D. L. (1996). The importance of industry structure for the determination of firm profitability: A neo-Austrian perspective. Journal of Management Studies, 33(4), 429-451.

Hill, C. W. L., \& Rothaermel, F. T. (2003). The performance of incumbent firms in the face of radical technological innovation. Academy of Management Review, 28(2), $257-274$.

Hill, E., Wial, H., \& Wolman, H. (2008). Exploring regional economic resilience. Working Paper, Institute of Urban and Regional Development.

Hippel, E. von. (1988). The sources of innovation. Oxford University Press,.

Hirsch, P. M., \& Levin, D. Z. (1999). Umbrella advocates versus validity police: A life- 
cycle model. Organization Science, 10(2), 199-212.

Hirschman, A. O. (1958). The strategy of economic development.

Hitt, M. A., Ireland, R. D., \& Hoskisson, R. E. (2012). Strategic management cases: competitiveness and globalization. Cengage Learning.

Hobday, M. (2005). Firm-level Innovation Models: Perspectives on Research in Developed and Developing Countries. Technology Analysis \& Strategic Management, 17(2), 121-146. https://doi.org/10.1080/09537320500088666

Hoetker, G. (2005). How much you know versus how well I know you: selecting a supplier for a technically innovative component. Strategic Management Journal, 26(1), 75-96.

Holm, J R, \& Østergaard, C. R. (2011). Regional growth, the bubble and resilience in the Danish ICT sector. JR Holm, Adaptive Evolution through Selection, 169-204.

Holm, Jacob R, \& Østergaard, C. R. (2015). Regional employment growth, shocks and regional industrial resilience: a quantitative analysis of the Danish ICT sector. Regional Studies, 49(1), 95-112.

Hoover, E. M. (1948). The location of economic activity. Mcgraw-Hill Book Company, Inc; London.

Humphrey, J., \& Schmitz, H. (2000). Governance and upgrading: linking industrial cluster and global value chain research (Vol. 120). Institute of Development Studies Brighton.

ICONO. (2016). Indicadores del Sistema Español de Ciencia, Tecnología e Innovación.

INGENIO. (2004). La innovación en el sector de pavimentos y revestimientos cerámicos de la Comunidad Valenciana.

Inkjet Report. (2010). Técnica Cerámica, 369, 1306-1315.

Inkpen, A. C., \& Tsang, E. W. K. (2005). Social capital, networks, and knowledge transfer. The Academy of Management Review, 30, 146-165.

Isaksen, A, \& Hauge, E. (2002). Regional clusters in Europe. European Commission. Observatory of European SMEs: Brussels.

Isaksen, Arne. (2014). Industrial development in thin regions: trapped in path extension? Journal of Economic Geography, 15(3), 585-600.

Isaksen, Arne, \& Trippl, M. (2016). Path development in different regional innovation systems. New York and London Routledge.

Isaksen, Arne, \& Trippl, M. (2017). Exogenously led and policy-supported new path development in peripheral regions: Analytical and synthetic routes. Economic 
Geography, 93(5), 436-457.

Jaffe, A. B., Trajtenberg, M., \& Henderson, R. (1993). Geographic localization of knowledge spillovers as evidenced by patent citations. The Quarterly Journal of Economics, 108(3), 577-598.

Jaikumar, R., \& Bohn, R. E. (1986). The development of intelligent systems for industrial use: A conceptual framework. Jai Press.

Jansen, J. J. P., Van Den Bosch, F. A. J., \& Volberda, H. W. (2005). Managing potential and realized absorptive capacity: how do organizational antecedents matter? Academy of Management Journal, 48(6), 999-1015.

Jasso, J. (2004). Tecnología y organizaciones: consideraciones acerca de una propuesta teórica de la innovación. Revista Del Colegio de San Luis, 6(18), 51-69.

Kamien, M., \& Schwartz, N. Lou. (1982). Market structure and innovation. Cambridge surveys of economic literature. Cambridge; New York: Cambridge University Press.

Kaplan, H. B. (2002). Toward an understanding of resilience. In Resilience and development (pp. 17-83). Springer.

Kapoor, R., \& Klueter, T. (2015). Decoding the adaptability-rigidity puzzle: Evidence from pharmaceutical incumbents' pursuit of gene therapy and monoclonal antibodies. Academy of Management Journal, 58(4), 1180-1207.

Karlsson, C., \& Klaesson, J. (2000). Success in manufacturing employment in an industrial district: Higher productivity or lower wages? Investigaciones Europeas de Dirección y Economía de La Empresa, 6(2), 65-90.

Kawulich, B. B. (2005). Participant observation as a data collection method. In Forum Qualitative Sozialforschung/Forum: Qualitative Social Research (Vol. 6).

Kennedy, S., Whiteman, G., \& Van den Ende, J. (2017). Radical innovation for sustainability: The power of strategy and open innovation. Long Range Planning, 50(6), 712-725.

Kesidou, E., \& Snijders, C. (2012). External knowledge and innovation performance in clusters: empirical evidence from the Uruguay software cluster. Industry and Innovation, 19(5), 437-457.

Kim, L. (1998). Crisis construction and organizational learning: Capability building in catching-up at Hyundai Motor. Organization Science, 9(4), 506-521.

Kim, W. C., \& Mauborgne, R. (1999). Creating new market space. Harvard Business Review, 77(1), 83-93. 
Kleinke, J. D., Christensen, C. M., Grossman, J. H., \& Hwang, J. (2009). The Innovator's Prescription: A Disruptive Solution for Health Care. PROJECT HOPE 7500 OLD GEORGETOWN RD, STE 600, BETHESDA, MD 20814-6133 USA.

Klepper, S. (2010). The origin and growth of industry clusters: The making of Silicon Valley and Detroit. Journal of Urban Economics, 67(1), 15-32.

Klepper, S., \& Simons, K. L. (2000). Dominance by birthright: entry of prior radio producers and competitive ramifications in the US television receiver industry. Strategic Management Journal, 21(10-11), 997-1016.

Kline, S. J. (1985). Innovation is not a linear process. Research Management, 28(4), $36-45$.

Knight, K. E. (1967). A descriptive model of the intra-firm innovation process. The Journal of Business, 40(4), 478-496.

Kodama, F. (1992). Japans unique capacity to innovate: Technology fusion and its international implications. Japan's Growing Technological Capability: Implications for the US Economy, 147-164.

Krackhardt, D. (1992). The strength of strong ties: The importance of Philos in organizations Chapter 8 in N. Networks and Organizations: Structure, Form, and Action, 216-239.

Krugman, P. R. (1991). Geography and trade. MIT press.

Kumar, S., \& Seth, A. (2001). KNOWLEDGE, ABSORPTIVE CAPACITY, AND THE THEORY OF THE DIVERSIFIED FIRM. In Academy of Management Proceedings (Vol. 2001, pp. E1-E6). Academy of Management Briarcliff Manor, NY 10510.

Lagendijk, A. (2002). Beyond the regional lifeworld against the global systemworld: towards a relational-scalar perspective on spatial-economic development. Geografiska Annaler: Series B, Human Geography, 84(2), 77-92.

Lam A. (2005). Organizational Innovation. In Fagerberg; Mowery; Nelson (Ed.), The Oxford Handbook of Innovation (pp. 115-147). Oxford: Oxford University Press.

Lane, P J, \& Lubatkin, M. (1998). Relative absorptive capacity and interorganizational learning. Strategic Management Journal, 19, 461-477.

Lane, Peter J, Koka, B. R., \& Pathak, S. (2006). The reification of absorptive capacity: A critical review and rejuvenation of the construct. Academy of Management Review, 31(4), 833-863.

Lane, Peter J, Salk, J. E., \& Lyles, M. A. (2001). Absorptive capacity, learning, and 
performance in international joint ventures. Strategic Management Journal, 22(12), 1139-1161.

Lange, R. B., \& Lange, P. B. (1966). 3239952. United States.

Langley, A. (1999). Strategies for theorizing from process data. Academy of Management Review, 24(4), 691-710.

Langrish, J., Gibbons, M., Evans, W. G., \& Jevons, F. R. (1972). Wealth from knowledge: Studies of innovation in industry. Springer.

Lather, P. (1992). Critical frames in educational research: Feminist and post-structural perspectives. Theory into Practice, 31(2), 87-99.

Laursen, K., \& Salter, A. (2006). Open for innovation: the role of openness in explaining innovation performance among UK manufacturing firms. Strategic Management Journal, 27(2), 131-150.

Lavie, D. (2006). Capability reconfiguration: An analysis of incumbent responses to technological change. Academy of Management Review, 31(1), 153-174.

Lazerson, M. H. (1995). A New Phoenix?: Modern putting-out in Modena knitwear industry. Administrative Science Quarterly, 40, 34-59.

Lazerson, M. H., \& Lorenzoni, G. (1999a). Resisting organizational inertia: the evolution of industrial districts. Journal of Management and Governance, 3, 361377.

Lazerson, M. H., \& Lorenzoni, G. (1999b). The firms that feed industrial districts: A return to the italian source. Industrial and Corporate Change, 8, 235-266.

Lazzeretti, L. (2006). Distritos industriales clusters y otros: un análisis trespassing entre la economía inustrial y la gestión estratégica. Economía Industrial, (359), 59-79.

Lazzeretti, L., Sedita, S. R., \& Caloffi, A. (2013). Founders and disseminators of cluster research. Journal of Economic Geography, 14(1), 21-43.

Le, H. P. (1998). Progress and trends in ink-jet printing technology. Journal of Imaging Science and Technology, 42, 49-62.

Leal-Rodríguez, A. L., Ariza-Montes, J. A., Roldán, J. L., \& Leal-Millán, A. G. (2014). Absorptive capacity, innovation and cultural barriers: A conditional mediation model. Journal of Business Research, 67(5), 763-768.

Leal-Rodríguez, A. L., Roldán, J. L., Ariza-Montes, J. A., \& Leal-Millán, A. (2014). From potential absorptive capacity to innovation outcomes in project teams: The conditional mediating role of the realized absorptive capacity in a relational learning context. International Journal of Project Management, 32(6), 894-907. 
Lee, B., Liu, L., \& Stafford, H. A. (2000). Industrial districts: measuring local linkages. Industrial Networks and Proximity, 87-104.

Legewie, N. (2013). An introduction to applied data analysis with qualitative comparative analysis. In Forum Qualitative Sozialforschung/Forum: Qualitative Social Research (Vol. 14).

Leifer, RichardLeifer, R., McDermott, C. M., O’connor, G. C., Peters, L. S., Rice, M. P., \& Veryzer Jr, R. W. (2000). Radical innovation: how mature companies can outsmart upstarts. Boston: Harvard Business School Press.

Lenox, M., \& King, A. (2004). Prospects for developing absorptive capacity through internal information provision. Strategic Management Journal, 25(4), 331-345.

Leonard-Barton, D. (1995). Wellsprings of knowledge building and sustaining the sources of innovation. Boston, Mass.: Harvard Business School Press,. Retrieved from http://www.netlibrary.com/urlapi.asp?action=summary\&v=1\&bookid=7256

Leonhardt, D. (2006). What netflix could teach Hollywood. The New York Times, C1.

Lewin, A. Y., Massini, S., \& Peeters, C. (2011). Microfoundations of internal and external absorptive capacity routines. Organization Science, 22(1), 81-98.

Lieberman, M. B. (1984). The learning curve and pricing in the chemical processing industries. The RAND Journal of Economics, 15(2), 213-228.

Liebowitz, S. J., \& Margolis, S. E. (1995). Path dependence, lock-in, and history. JL Econ. \& Org., 11, 205.

Lin, H.-L., Li, H.-Y., \& Yang, C.-H. (2011). Agglomeration and productivity: Firmlevel evidence from China's textile industry. China Economic Review, 22(3), 313329.

Lissoni, F. (2001). Knowledge codification and the geography of innovation: the case of Brescia mechanical cluster. Research Policy, 30(9), 1479-1500.

Liu, X., \& White, R. S. (1997). The relative contributions of foreign technology and domestic inputs to innovation in Chinese manufacturing industries. Technovation, 17(3), 119-125.

López-Sintas, J. (1996). Los recursos intangibles en la competitividad de las empresa: un análisis desde la teoría de los recursos. Economía Industrial, (307), 25-35.

López, J. E. N., Martínez, P. A., \& Riveros, P. H. (2004). La diversificación desde la Teoría de Recursos y Capacidades. Cuadernos de Estudios Empresariales, (14), 87-104.

Lorenz, E. H. (1992). Toward a theory of industrial districts1. Pathways to 
Industrialization and Regional Development, 175.

Lösch, A. (1940). The Economics of Location, 1954. New Haven, Yale.

Lundvall, B.-A. (1992). National systems of innovation: An analytical framework. London: Pinter.

Lundvall, B. A., Johnson, B., Andersen, E. S., \& Dalum, B. (2002). National systems of production, innovation and competence building. Research Policy, 31(2), 213-231.

Luthar, S. S., Cicchetti, D., \& Becker, B. (2000). The construct of resilience: A critical evaluation and guidelines for future work. Child Development, 71(3), 543-562.

Macher, J. T., \& Richman, B. D. (2004). Organisational responses to discontinuous innovation: a case study approach. International Journal of Innovation Management, 8(01), 87-114.

Mahoney, J. T., \& Pandian, J. R. (1992). The resource-based view within the conversation of strategic management. Strategic Management Journal, 13(5), 363380 .

Malerba, F. (2002). Sectoral systems of innovation and production. Research Policy, $31(2), 247-264$.

Malerba, F. (2004). Sectoral systems of innovation: concepts, issues and analyses of six major sectors in Europe. Cambridge University Press.

Malipiero, A., Munari, F., \& Sobrero, M. (2005). Focal firms as technological gatekeepers within industrial districts: knowledge creation and dissemination in the Italian packaging machinery industry. In Communication to the DRUID Winter Conference (p. 5).

Mangematin, V., \& Mandran, N. (2001). Do non-R\&D intensive industries benefit of spillovers from public research? The case of the Agro-food industry. Palgrave.

Mangematin, V., \& Nesta, L. (1999). What kind of knowledge can a firm absorb? International Journal of Technology Management, 18(3-4), 149-172.

March, J. G. (1991). Exploration and exploitation in organizational learning. Organization Science, 2(1), 71-87.

Marcos, J., \& Macaulay, S. (2008). Organisational resilience: the key to anticipation, adaptation and recovery. Cranfield School of Management, Cranfied University, Manuscript.

Markides, C. (2006). Disruptive innovation: In need of better theory. Journal of Product Innovation Management, 23(1), 19-25. https://doi.org/10.1111/j.15405885.2005.00177.x 
Markman, G. D., \& Waldron, T. L. (2014). Small entrants and large incumbents: A framework of micro entry. Academy of Management Perspectives, 28(2), 179-197.

Markusen, A. (1996). Sticky Places in Slippery Space: A Typology of Industrial Districts. Economic Geography, 293-313.

Marquis, D. G. (1969). The anatomy of successful innovations. Innovation, 1(7), 28-37.

Marshall, A. (1920). Principles of Economics: An Introductory Volume, Eight Edition. London: The Macmillan Press.(First edition published 1890).

Martin, R, \& Sunley, P. (2003). Deconstructing clusters: chaotic concept or policy panacea? Journal of Economic Geography, 3(1), 5-35.

Martin, Ron. (2011). Regional economic resilience, hysteresis and recessionary shocks. Journal of Economic Geography, 12(1), 1-32.

Martin, Ron, \& Sunley, P. (2015). On the notion of regional economic resilience: Conceptualization and explanation. Journal of Economic Geography, 15(1). https://doi.org/10.1093/jeg/lbu015

Martinez-Chafer; Molina-Morales. (2012). El efecto de las redes inter-organizativas sobre los resultados de la innovación. Una aplicación al cluster industrial cerámico valenciano. Universitat Jaume I Castellón.

Martínez, M. (2006). La investigación cualitativa: síntesis conceptual. Iipsi, 9(1), 123146. https://doi.org/1560 - 909X

Mas-Verdú, F., Ribeiro-Soriano, D., \& Roig-Tierno, N. (2015). Firm survival: The role of incubators and business characteristics. Journal of Business Research, 68(4), 793-796.

Mascitelli, R. (2000). From experience: harnessing tacit knowledge to achieve breakthrough innovation. Journal of Product Innovation Management: AN INTERNATIONAL PUBLICATION OF THE PRODUCT DEVELOPMENT \& MANAGEMENT ASSOCIATION, 17(3), 179-193.

Maskell, P. (2001). Knowledge creation and diffusion in geographic clusters. International Journal of Innovation Management, 5(2), 213-237.

Maskell, Peter, \& Malmberg, A. (1999). Localised learning and industrial competitiveness. Cambridge Journal of Economics, 23(2), 167-185.

Maskell, Peter, \& Malmberg, A. (2007). Myopia, knowledge development and cluster evolution. Journal of Economic Geography, 7(5), 603-618.

Mattsson, H. (2009). Innovating in cluster/cluster as innovation: The case of the Biotechvalley cluster initiative. European Planning Studies, 17(11), 1625-1643. 
Mayring, P. (2002). Qualitative Sozialforschung. Eine Anleitung Zu Qualitativen Denken, 5.

McAdams, D., \& Reavis, C. (2008). DeBeers's Diamond Dilemma. MIT Sloan Teaching Innovation Resources (MSTIR).

McCann, B T, \& Folta, T. B. (2011). Performance differentials within geographic clusters. Journal of Business Venturing, 26(1), 104-123.

McCann, Brian T, \& Folta, T. B. (2008). Location matters: where we have been and where we might go in agglomeration research. Journal of Management, 34(3), $532-565$.

McCann, P., \& Gordon, I. R. (2000). Industrial Clusters: Complexes, Agglomeration and/or Social Networks? Urban Studies, 37, 513-532. https://doi.org/10.1080/0042098002096

McDermott, C. M., \& O’Connor, G. C. (2002). Managing radical innovation: An overview of emergent strategy issues. Journal of Product Innovation Management, 19(6), 424-438. https://doi.org/10.1016/S0737-6782(02)00174-1

McEvily, B., \& Zaheer, A. (1999). Bridging ties: A source of firm heterogeneity in competitive capabilities. Strategic Management Journal, 20(12), 1133-1156.

Melnyk, S. A., Hanson, J. D., \& Calantone, R. J. (2010). Hitting the target... but missing the point: resolving the paradox of strategic transition. Long Range Planning, 43(4), 555-574.

Menzel, M.-P., \& Fornahl, D. (2009). Cluster life cycles-dimensions and rationales of cluster evolution. Industrial and Corporate Change, 19(1), 205-238.

Meyer, A. D. (1991). Visual data in organizational research. Organization Science, 2(2), 218-236.

Meyer, A. D., Tsui, A. S., \& Hinings, C. R. (1993). Configural approaches to organizational analysis. Academy of Management Journal, 36(6), 1175-1195.

Micelli, S., \& De Pietro, L. (1997). Reti senza tecnologie: la diffusione delle tecnologie nelle imprese del Nordest. Economia e Società Regionale.

Mintzberg, H. (1979). The structuring of organizations (Vol. 203). Prentice hall Englewood Cliffs, NJ.

Mistri, M. (1999). Industrial districts and local governance in the italian experience. Human Systems Management, 18, 131-139.

Molina-Morales, F., \& Expósito-Langa, M. (2013). Overcoming undesirable knowledge redundancy in territorial clusters. Industry and Innovation, 20(8), 739-758. 
Molina-Morales, F. X. M., \& Camisón-Zornoza, C. (1998). El Distrito industrial cerámico Valenciano:¿ mito o realidad competitiva? Revista Valenciana d'estudis Autonomics, (22), 83-102.

Molina-morales, F. X., \& Mas-Verdú, F. (2010). The role of supporting organisations in regional innovation policies : lessons learnt from the cases of Øresund and Veneto Francisco Mas-Verdú. Int. J. Innovation and Regional Development, 2(3), 221239.

Molina-Morales, F Xavier. (2001). European industrial districts: Influence of geographic concentration on performance of the firm. Journal of International Management, 7(4), 277-294.

Molina-Morales, F Xavier, Martínez-Fernández, M. T., Ares-Vázquez, M. A., \& Valmir Emil Hoffmann. (2008). La estructura y naturaleza del capital social en las aglomeraciones territoriales de empresas: Una aplicación al sector cerámico español. Fundacion BBVA.

Molina-Morales, F Xavier, Martínez-Fernández, M. T., \& Torlò, V. J. (2011). The dark side of trust: The benefits, costs and optimal levels of trust for innovation performance. Long Range Planning, 44(2), 118-133.

Molina-Morales, Francesc Xavier. (2002). Industrial districts and innovation: the case of the Spanish ceramic tiles industry. Entrepreneurship \& Regional Development, 14(4), 317-335.

Molina-Morales, Francesc Xavier. (2005). The territorial agglomerations of firms: A social capital perspective from the Spanish tile industry. Growth and Change, 36(1), 74-99.

Molina-Morales, Francesc Xavier, Gabaldón-Estevan, D., \& Fernández de Lucio, I. (2012). Sistemas distrituales de innovación.

Molina-Morales, Francesc Xavier, López-Navarro, M. A., \& Guia-Julve, J. (2002). The role of local institutions as intermediary agents in the industrial district. European Urban and Regional Studies, 9(4), 315-329.

Molina-Morales, Francesc Xavier, \& Martínez-Cháfer, L. (2016). Cluster Firms: You'll Never Walk Alone. Regional Studies, 50(5), 877-893.

Molina-Morales, Francesc Xavier, \& Martínez-Fernández, M. T. (2004). How much difference is there between industrial district firms? A net value creation approach. Research Policy, 33, 473-486.

Molina-Morales, Francesc Xavier, \& Mas-Verdú, F. (2008). Intended ties with local 
institutions as factors in innovation: An application to Spanish manufacturing firms. European Planning Studies, 16(6), 811-827.

Molina-Morales, F. X., \& Martínez-Fernández, M. T. (2009a). Does homogeneity exist within industrial districts? A social capital-based approach. Papers in Regional Science, 88(1), 209-229.

Molina-Morales, F. X., \& Martínez-Fernández, M. T. (2009b). Too much love in the neighborhood can hurt: How an excess of intensity and trust in relationships may produce negative effects on firms. Strategic Management Journal, 30(9), 10131023.

Molina, J. L., Martínez-Cháfer, L., Molina-Morales, F. X., \& Lubbers, M. J. (2018). Industrial districts and migrant enclaves: a model of interaction. European Planning Studies, 26(6), 1160-1180.

Molina Morales, F. X., Parra Requena, G., \& García Villaverde, P. M. (2010). The Mediating Effect of Cognitive Social Capital on Knowledge Acquisition in Clustered Firms.

Montero, C. (2004). Formación y desarrollo de un cluster globalizado: el caso de la industria del salmón en Chile (Vol. 145). Santiago de Chile: United Nations.

Moodysson, J., Coenen, L., \& Asheim, B. (2008). Explaining spatial patterns of innovation: analytical and synthetic modes of knowledge creation in the Medicon Valley life-science cluster. Environment and Planning A, 40(5), 1040-1056.

Morrison, A, \& Rabellotti, R. (2005). Knowledge and Information Networks: Evidence from an Italian Wine Local System. Working Paper 174/2005, CESPRI, Universit... Bocconi.

Morrison, A, \& Rabellotti, R. (2009). Knowledge and information networks in an Italian wine cluster. European Planning Studies, 17(7), 983-1006.

Morrison, Andrea. (2008). Gatekeepers of knowledge within industrial districts: who they are, how they interact. Regional Studies, 42(6), 817-835.

Moulaert, F., Martinelli, F., Swyngedouw, E., \& Gonzalez, S. (2005). Towards alternative model (s) of local innovation. Urban Studies, 42(11), 1969-1990.

Moulaert, F., \& Sekia, F. (2003). Territorial innovation models: a critical survey. Regional Studies, 37(3), 289-302.

Mowery, D. C., \& Oxley, J. E. (1995). Inward technology transfer and competitiveness: the role of national innovation systems. Cambridge Journal of Economics, 19(1), 67-93. 
Mowery, D. C., Oxley, J. E., \& Silverman, B. S. (1996). Strategic alliances and interfirm knowledge transfer. Strategic Management Journal, 17, 77-91.

Mowery, D., \& Rosenberg, N. (1979). The influence of market demand upon innovation: a critical review of some recent empirical studies. Research Policy, $8(2), 102-153$.

Munari, F., Sobrero, M., \& Malipiero, A. (2012). Absorptive capacity and localized spillovers: focal firms as technological gatekeepers in industrial districts. Industrial and Corporate Change, 21(2), 429-462.

Murmann, J. P., \& Frenken, K. (2006). Toward a systematic framework for research on dominant designs, technological innovations, and industrial change. Research Policy, 35(7), 925-952.

Muzzi, C. (2004). District Firms' Attitude towards Innovation: Possible Scenarios for Industrial Districts' Evolution. In 20th Egos Colloquium.

Mytelka, L., \& Farinelli, F. (2000). Local clusters, innovation systems and sustained competitiveness. UNU/INTECH Discussion Paper, (2005).

Nachum, L., \& Keeble, D. (2003). Neo-Marshallian clusters and global networks: the linkages of media firms in central London. Long Range Planning, 36(5), 459-480.

Nadvi, K, \& Schmitz, H. (1994). Industrial clusters in less developed countries: review of experiences and research agenda. Brighton: University of Sussex, Institute of Development Studies.

Nadvi, Khalid, \& Halder, G. (2005). Local clusters in global value chains: exploring dynamic linkages between Germany and Pakistan. Entrepreneurship \& Regional Development, 17(5), 339-363.

Nagy, D., Schuessler, J., \& Dubinsky, A. (2016). Defining and identifying disruptive innovations. Industrial Marketing 57. https://doi.org/10.1016/j.indmarman.2015.11.017

Navas López, J. E., \& Guerras Martín, L. A. (2002). La Dirección Estratégica de la Empresa. Teoria y aplicaciones. Civitas $3^{a}$ edición. Madrid.

Navas López, J. E., \& Ortiz de Urbina Criado, M. (2001). Gestión del conocimiento y capital intelectual: algunos aspectos conceptuales. Cuadernos Aragoneses de Economía, 11(1), 35-48.

Nebot, I; Dal, P. (2018). Introducción a la decoración cerámica digital. (E. D. de C. A. E. de T. Cerámicos, Ed.). Castellón de la Plana: Tecnigraf.

Negassi, S. (2004). R\&D co-operation and innovation a microeconometric study on 
French firms. Research Policy, 33(3), 365-384.

Nelson, R. (1959). The Simple Economics of Basic Scientific Research. The Journal of Political Economy, 67(3), 297-306. Retrieved from http://www.jstor.org/stable/1827448

Nelson, R. R. (1993). National innovation systems: a comparative analysis. New York: Oxford university press.

Nelson, R. R., \& Winter, S. G. (1982). An evolutionary theory of economic change. Cambridge, MA: Harvard University Press.

Nelson, R., \& Winter, S. (1977). Dynamic competition and technical progress. Economic Progress, Private Values and Public Policy, 57-101.

Newey, L. R., \& Shulman, A. D. (2004). Systemic absorptive capacity: creating earlyto-market returns through $\mathrm{R} \& \mathrm{D}$ alliances. $R \& D$ Management, 34(5), 495-504.

Nieto, M., \& Quevedo, P. (2005). Absorptive capacity, technological opportunity, knowledge spillovers, and innovative effort. Technovation, 25(10), 1141-1157.

Nijssen, E. J., Hillebrand, B., \& Vermeulen, P. A. M. (2005). Unraveling willingness to cannibalize: a closer look at the barrier to radical innovation. Technovation, 25(12), 1400-1409.

Niosi, J., Saviotti, P., Bellon, B., \& Crow, M. (1993). National systems of innovation: in search of a workable concept. Technology in Society, 15(2), 207-227.

Nonaka, I. (1994). A dynamic theory of organizational knowledge creation. Organization Science, 5(1), 14-37.

Nonaka, Ikujiro, \& Takeuchi, H. (1995). The knowledge-creating company: How Japanese companies create the dynamics of innovation. Oxford university press.

Nooteboom, B., \& Woolthius, R. K. (2005). Cluster dynamics. In Learning from Clusters (pp. 51-68). Springer.

Nordhaug, K. (2003). Globalization, embeddedness and disembeddedness.

North, D. C. (1991). Institutions. Journal of Economic Perspectives, 5(1), 97-112.

O'Connor, G. C. (1998). Market learning and radical innovation: A cross case comparison of eight radical innovation projects. Journal of Product Innovation Management: An International Publication of the Product Development \& Management Association, 15mdi(2), 151-166.

O'Connor, G. C. (2008). Grabbing lightning : building a capability for breakthrough innovation (1st ed.). San Francisco, CA: Jossey-Bass. Retrieved from http://www.loc.gov/catdir/enhancements/fy0805/2007045003-t.html 
O'Connor, G. C., \& McDermott, C. M. (2004). The human side of radical innovation. Journal of Engineering and Technology Management, 21(1-2), 11-30.

O'Reilly III, C. A., \& Tushman, M. L. (2016). Lead and disrupt: How to solve the innovator's dilemma. Stanford University Press.

Oerlemans, L. A. G., Meeus, M. T. H., \& Boekema, F. W. M. (1998). Do networks matter for innovation? The usefulness of the economic network approach in analysing innovation. Tijdschrift Voor Economische En Sociale Geografie, 89(3), $298-309$.

Oinas, P., \& Malecki, E. J. (2002). The evolution of technologies in time and space: from national and regional to spatial innovation systems. International Regional Science Review, 25(1), 102-131.

Onida, F., Viesti, G., \& Falzoni, A. (1992). I distretti industriali: crisi o evoluzione? Milán: EGEA.

Ordanini, A., \& Maglio, P. P. (2009). Market orientation, internal process, and external network: A qualitative comparative analysis of key decisional alternatives in the new service development. Decision Sciences, 40(3), 601-625.

Ordanini, A., Parasuraman, A., \& Rubera, G. (2014). When the Recipe Is More Important Than the Ingredients: A Qualitative Comparative Analysis (QCA) of Service Innovation Configurations. Journal of Service Research, 17(2), 134-149.

Ormerod, P. (2010). Resilience after localeconomic shocks. Applied Economics Letters, 17(5), 503-507.

Osiyevskyy, O., \& Dewald, J. (2018). The pressure cooker: When crisis stimulates explorative business model change intentions. Long Range Planning.

Oslo manual: guidelines for collecting and interpreting innovation data. (2005) (3rd ed.). Paris : Statistical Office of the European C.

Østergaard, C., \& Park, E. K. (2013). Cluster decline and resilience-The case of the wireless communication cluster in North Jutland, Denmark.

Østergaard, C. R., \& Park, E. (2015). What makes clusters decline? A study on disruption and evolution of a high-tech cluster in Denmark. Regional Studies, 49(5), 834-849.

Ostry, S., \& Nelson, R. R. (2000). Techno-nationalism and Techno-globalism: Conflict and Cooperation. Brookings Institution Press.

Ottati, G. D. (1994). Cooperation and competition in the industrial district as an organization model. European Planning Studies, 2(4), 463-483. 
Ottati, G. D. (2003). Exit, voice and the evolution of industrial districts: the case of the post-World War II economic development of Prato. Cambridge Journal of Economics, 27(4), 501-522.

Ozman, M. (2006). Networks and innovation: A survey of empirical literature. Beta Documents de Travail, (2006-07).

Paniccia, I. (1999). The performance of IDs. Some insights from the italian case. Human Systems Management, 18, 141-159.

Paniccia, Ivana. (1998). One, a hundred, thousands of industrial districts. Organizational variety in local networks of small and medium-sized enterprises. Organization Studies, 19(4), 667-699.

Paniccia, Ivana. (2002). Industrial districts. Books.

Park, K.-H., \& Lee, K. (2006). Linking the technological regime to the technological catch-up: analyzing Korea and Taiwan using the US patent data. Industrial and Corporate Change, 15(4), 715-753.

Parrilli, M Davide, Álvarez, E., Elola, A., Lorenz, U., \& Rabellotti, R. (2012). Análisis de la cadena de valor de la industria eólica vasca: oportunidades y ámbitos de mejora. Orkestra Instituto Vasco de Competitividad. Fundación Deusto.

Parrilli, Mario Davide, \& Sacchetti, S. (2008). Linking learning with governance in networks and clusters: key issues for analysis and policy. Entrepreneurship \& Regional Development, 20(4), 387-408.

Passaro, R. (1994). Le strategie competitive delle piccole imprese di una area interna del Mezzogiorno: il caso del settore conciario a Solofra. Piccola Impresa/Small Business, 3, 94-112.

Patel, P., \& Pavitt, K. (1997). The technological competencies of the world's largest firms: complex and path-dependent, but not much variety. Research Policy, 26(2), $141-156$.

Pavitt, K. (1984). Sectoral patterns of technical change: towards a taxonomy and a theory. Research Policy, 13(6), 343-373.

Pavon, J., \& Goodman, R. (1981). Proyecto MODELTEC. La planificación del desarrollo tecnológico. Proyecto MODELTEC: La Planificación Del Desarrollo Tecnológico.

Pendall, R., Foster, K. A., \& Cowell, M. (2010). Resilience and regions: building understanding of the metaphor. Cambridge Journal of Regions, Economy and Society, 3(1), 71-84. 
Penrose, E. (1959). The Theory of the Growth of the Firm. Oxford: Basil Blackwell.

Peris, M. L. F., Mestre, M. J. O., \& Palao, C. G. (2011). La relación entre la capacidad de absorción del conocimiento externo y la estrategia empresarial: un análisis exploratorio. Revista Europea de Dirección y Economía de La Empresa, 20(1), 69-88.

Perroux, F. (1955). Note sur la notion de Pole de Croissance. Economie Appliquee, 7, $307-320$.

Peteraf, M. A. (1993). The cornerstones of competitive advantage: a resource-based view. Strategic Management Journal, 14(3), 179-191.

Pettigrew, A. M. (1990). Longitudinal field research on change: Theory and practice. Organization Science, 1(3), 267-292.

Pietrobelli, C. (1998). The socio-economic foundations of competitiveness: An econometric analysis of italian industrial districts. Industry and Innovation, 5, 139155.

Pike, A., Dawley, S., \& Tomaney, J. (2010). Resilience, adaptation and adaptability. Cambridge Journal of Regions, Economy and Society, 3(1), 59-70.

Pinkse, J., Vernay, A.-L., \& D'Ippolito, B. (2018). An organisational perspective on the cluster paradox: Exploring how members of a cluster manage the tension between continuity and renewal. Research Policy, 47(3), 674-685.

Piore, M. (1990). Work, labor and action. Pike (Comp.) Industrial Districts and InterFirm Cooperation in Italy (Ginebra: ILO).

Piore, M, \& Sabel, C. (1984). The second industrial divide: Possibilities for prosperity. Nueva York: Basic Books.

Piore, Michael, \& Sabel, C. (1984). The second industrial divide: prospects for prosperity. New York.

Porter, M. (1997). Clusters and competition: New agendas for companies, governments. and Institutions.

Porter, M E. (1985). Competitive Advantage: Creating and Sustaining Superior Performance. Nueva York: The Free Press.

Porter, M E, \& Sölvell, Ö. (1998). The role of geography in the process of innovation and the sustainable competitive advantage of firms. In A. D. Chandler Jr., P. Hagström, \& Ö. Sölvell (Eds.), The dynamic firm. The role of technology, strategy, organization, and regions. Nueva York: Oxford University Press.

Porter, Michael E. (1990). The competitive advantage of notions. Harvard Business 
Review, 68(2), 73-93.

Porter, Michael E. (1998). Clusters and the New Economics of Competition. Harvard Business Review, December, 77-90.

Porter, Michael E. (2000). Location, competition and economic development: local clusters in a global economy. Economic Development Quarterly, 14(1), 15-34.

Porter, Michael E. (2008). The five competitive forces that shape strategy. Harvard Business Review, 86(1), 25-40.

Posner, M. V. (1961). International trade and technical change. Oxford Economic Papers, 13(3), 323-341.

Pouder, R., \& St. John, C. H. (1996). Hot spots and blind spots: Geographical clusters of firms and innovation. Academy of Management Review, 21(4), 1192-1225.

Powell, W. (1990). Neither Market Nor Hierarchy: Network Forms of Organization. Research in Organizational Behaviour, núm. 12. Remmele, B.(2004). The Moral Framework of Cyberspace. Journal of Information, Communication \& Ethics in Society, (2), 125-131.

Prahalad, C. K. (1990). Hamel, “The Core Competencies of the Corporation.” Harvard Business Review.

Prashantham, S., Dhanaraj, C., \& Kumar, K. (2015). Ties that bind: Ethnic ties and new venture internationalization. Long Range Planning, 48(5), 317-333.

Punch, K. F. (2013). Introduction to social research: Quantitative and qualitative approaches. Sage.

Pyke, Frank, Becattini, G., \& Sengenberger, W. (1990). Industrial districts and interfirm co-operation in Italy. International Institute for Labour Studies.

Rabellotti, R. (1995). Is there an "Industrial District Model”?: Footwear districts in Italy and Mexico compared. World Development, 23(1), 29-41.

Rabellotti, Roberta, Carabelli, A., \& Hirsch, G. (2009). Italian industrial districts on the move: where are they going? European Planning Studies, 17(1), 19-41.

Rafii, F., \& Kampas, P. J. (2002). How to identify your enemies before they destroy you. Harvard Business Review, 80(11), 115-123.

Ragin, C. C. (2006a). How to lure analytic social science out of the doldrums: Some lessons from comparative research. International Sociology, 21(5), 633-646.

Ragin, C. C. (2006b). Set relations in social research: Evaluating their consistency and coverage. Political Analysis, 14(3), 291-310.

Ragin, C. C. (2008). Redesigning social inquiry: Fuzzy sets and beyond. University of 


\section{Chicago Press.}

Ragin, C. C. (2014). The comparative method: Moving beyond qualitative and quantitative strategies. Oakland, Californica: Univ of California Press.

Ragin, C. C., \& Becker, H. S. (1992). What is a case?: exploring the foundations of social inquiry. Cambridge university press.

Ragin, C. C., Drass, K. A., \& Davey, S. (2006). Fuzzy-set/qualitative comparative analysis 2.0. Tucson, Arizona: Department of Sociology, University of Arizona.

Ragin, C., \& Davey, S. (2016). Fuzzy-Set/Qualitative Comparative Analysis 3.0. Irvine, California: Department of Sociology, University of California.

Ray, D. M., MacLachlan, I., Lamarche, R., \& Srinath, K. P. (2017). Economic shock and regional resilience: Continuity and change in Canada's regional employment structure, 1987-2012. Environment and Planning A, 49(4), 952-973.

Rayleigh, Lord. (1878). On the instability of jets. Proceedings of the London Mathematical Society, s1-10(1), 4-13.

Reig-Otero, Y., Edwards-Schachter, M., Feliú-Mingarro, C., \& Fernández-de-Lucio, I. (2014). Generation and diffusion of innovations in a district innovation system: The case of ink-jet printing. Journal of Technology Management and Innovation, 9(2), 56-76. https://doi.org/10.4067/S0718-27242014000200005

Reinganum, J. F. (1983). Technology adoption under imperfect information. The Bell Journal of Economics, 57-69.

Reinhardt, R., Gurtner, S., \& Griffin, A. (2018). Towards an adaptive framework of low-end innovation capability-A systematic review and multiple case study analysis. Long Range Planning, 51(5), 770-796.

Rihoux, B, \& Ragin, C. C. (2009). Configurational Comparative methods. Applied social research methods series. Thousand Oaks, CA: Sage.

Rihoux, Benoît. (2003). Bridging the gap between the qualitative and quantitative worlds? A retrospective and prospective view on qualitative comparative analysis. Field Methods, 15(4), 351-365.

Rocha, F. (1999). Inter-firm technological cooperation: effects of absorptive capacity, firm-size and specialization. Economics of Innovation and New Technology, 8(3), $253-271$.

Rodan, S., \& Galunic, C. (2004). More than network structure: How knowledge heterogeneity influences managerial performance and innovativeness. Strategic Management Journal, 25(6), 541-562. 
Rogers, E. (1983). Diffusion of innovations. New York. The Free Press.

Roig-Tierno, N., Gonzalez-Cruz, T. F., \& Llopis-Martinez, J. (2017). An overview of qualitative comparative analysis: A bibliometric analysis. Journal of Innovation \& Knowledge, 2(1), 15-23. https://doi.org/10.1016/j.jik.2016.12.002

Rosenberg, N. (1982). Inside the black box: technology and economics. Cambridge University Press.

Rosenbloom, R. S. (2000). Leadership, capabilities, and technological change: The transformation of NCR in the electronic era. Strategic Management Journal, 21(10-11), 1083-1103.

Rosenfeld, S. A. (1997). Bringing business clusters into the mainstream of economic development. European Planning Studies, 5(1), 3-23.

Rosenkopf, L., \& Nerkar, A. (2001). Beyond local search: boundary-spanning, exploration, and impact in the optical disk industry. Strategic Management Journal, 22(4), 287-306.

Rothaermel, F. T. (2001). Incumbent's advantage through exploiting complementary assets via interfirm cooperation. Strategic Management Journal, 22(6-7), 687-699.

Rothaermel, F. T., \& Hill, C. W. L. (2005). Technological discontinuities and complementary assets: A longitudinal study of industry and firm performance. Organization Science, 16(1), 52-70.

Rothwell, R. (1994). Towards the fifth-generation innovation process. International Marketing Review, 11(1), 7-31.

Rowley, T., Behrens, D., \& Krackhardt, D. (2000). Redundant governance structures: An analysis of structural and relational embeddedness in the steel and semiconductor industries. Strategic Management Journal, 369-386.

Roxas, H. B., \& Chadee, D. (2011). A resource-based view of small export firms' social capital in a Southeast Asian country. Asian Academy of Management Journal, $16(2), 1-28$.

Roy, R., \& Cohen, S. K. (2015). Disruption in the US machine tool industry: The role of inhouse users and pre-disruption component experience in firm response. Research Policy, 44(8), 1555-1565.

Rullani, E. (2002). The industrial cluster as a complex adaptive system. In Complexity and industrial clusters (pp. 35-61). Springer.

Russo, M. (1985). Technical change and the industrial district: the role of interfirm relations in the growth and transformation of ceramic tile production in Italy. 
Research Policy, 14(6), 329-343.

Russo, M. (2004). The ceramic industrial district facing challenge from China. Universita di Modena.

Russo, Margherita. (1997). Relazioni tra imprese e sviluppo locale. Economia e Politica Industriale, 93.

Russo, P. F., \& Rossi, P. (2001). Credit constraints in Italian industrial districts. Applied Economics, 33(11), 1469-1477. Retrieved from http://search.ebscohost.com/login.aspx?direct=true \&db=bsh\&AN=5180848\&lang $=$ es\&site $=$ ehost-live

Sager, F., \& Andereggen, C. (2012). Dealing with complex causality in realist synthesis: the promise of Qualitative Comparative Analysis. American Journal of Evaluation, 33(1), 60-78.

Sammarra, A. (2005). Relocation and the international fragmentation of industrial districts value chain: matching local and global perspectives. In Industrial Districts, Relocation, and the Governance of the Global Value Chain (Vol. en Belussi, pp. 61-70). Padua: CLEUP.

Sammarra, Alessia, \& Belussi, F. (2006). Evolution and relocation in fashion-led Italian districts: evidence from two case-studies. Entrepreneurship and Regional Development, 18(6), 543-562.

Samuels, R. J. (1987). The business of the Japanese state: Energy markets in comparative and historical perspective. Cornell Univ Pr.

Santos, J. N., Mota, J., \& Baptista, C. S. (2018). Understanding configurations of value creation functions in business relationships using a fuzzy-set QCA. Journal of Business Research, 89, 429-434.

Saren, M. A. (1984). A classification and review of models of the intra-firm innovation process. $R \& D$ Management, 14(1), 11-24.

Saxenian, A. (1991). The origin and dynamics of production networks in Silicon Valley. Research Policy, 20, 423-437.

Saxenian, A. (1994). Regional advantage: culture and competition in Silicon Valley and Route 128. Cambridge, Mass.

Saxenian, AnnaLee. (1996). Regional advantage. Harvard University Press.

Scheffran, J., Marmer, E., \& Sow, P. (2012). Migration as a contribution to resilience and innovation in climate adaptation: Social networks and co-development in Northwest Africa. Applied Geography, 33, 119-127. 
Schmidt, G. M., \& Druehl, C. T. (2008). When is a disruptive innovation disruptive? Journal of Product Innovation Management, 25(4), 347-369.

Schmitz, H., \& Musyck, B. (1994). Industrial districts in Europe: policy lessons for developing countries? World Development, 22(6), 889-910.

Schmookler, J. (1966). Invention and economic growth. Harvard University Press.

Schneider, C. Q., \& Wagemann, C. (2007). Qualitative comparative analysis (QCA) und fuzzy sets. Barbara Budrich.

Schneider, C. Q., \& Wagemann, C. (2010). Standards of good practice in qualitative comparative analysis (QCA) and fuzzy-sets. Comparative Sociology, 9(3), 397418.

Schneider, C. Q., \& Wagemann, C. (2012). Set-theoretic methods for the social sciences: A guide to qualitative comparative analysis. Cambridge University Press.

Schneider, M. R., Schulze-Bentrop, C., \& Paunescu, M. (2010). Mapping the institutional capital of high-tech firms: A fuzzy-set analysis of capitalist variety and export performance. Journal of International Business Studies, 41(2), 246266.

Schumpeter, J. (1942). Proceso de destrucción creadora. Capitalismo, Socialismo y Democracia, 118-124.

Schumpeter, J. A. (1934). The theory of economic development: An inquiry into profits, capital, credit, interest, and the business cycle (Vol. 55). Transaction publishers.

Scott, A J. (1991). The aerospace-electronics industrial complex of Southern California: The formative years, 1940-1960. Research Policy, 20, 439-456.

Scott, Allen John. (1988). New industrial spaces: Flexible production organization and regional development in North America and Western Europe (Vol. 3). Pion Ltd.

Sensier, M., Bristow, G., \& Healy, A. (2016). Measuring regional economic resilience across Europe: operationalizing a complex concept. Spatial Economic Analysis, 11(2), 128-151.

Sforzi, F. (1989). The geography of industrial districts in Italy. In Small firms and industrial districts in Italy (Vol. en Goodman). Londres: Routledge.

Sforzi, F. (2008). Unas realidades ignoradas: de Marshall a Becattini. In V. (coor) Soler (Ed.), Los Distritos Industriales (pp. 43-54). El Ejido (Almería): Cajamar.

Sforzi, F, \& Lorenzini, M. (2002). I distretti Industriali en L'experienza italiana dei distretti industriali. IPI-Istituto per La Promozione Industriale, Ministero Delle Attività Produttive, Roma. 
Sforzi, Fabio. (1987). L'identificazione spaziale. Mercato e Forze Locali: Il Distretto Industriale, Il Mulino, Bologna, 143-167.

Sforzi, Fabio. (1990). The quantitative importance of Marshallian industrial districts in the Italian economy. Industrial Districts and Inter-Firm Co-Operation in Italy, 75107.

Sforzi, Fabio. (1999). La teoría marshalliana para explicar el desarrollo local. Manual de Desarrollo Local, Asturias, Editorial Gijón.

Sforzi, Fabio. (2002). The industrial district and the'new'Italian economic geography. European Planning Studies, 10(4), 439-447.

Signorini, L. F. (1994). The price of Prato, or measuring the industrial district effect. Papers in Regional Science, 73(4), 369-392.

Simmie, J. (2004). Innovation and clustering in the globalised international economy. Urban Studies, 41(5-6), 1095-1112.

Simmie, J., \& Martin, R. (2010). The economic resilience of regions: towards an evolutionary approach. Cambridge Journal of Regions, Economy and Society, 3(1), $27-43$.

Sirilli, G., \& Evangelista, R. (1998). Technological innovation in services and manufacturing: results from Italian surveys. Research Policy, 27(9), 881-899.

Slater, S. F., \& Narver, J. C. (1998). Customer-led and market-oriented: let's not confuse the two. Strategic Management Journal, 19(10), 1001-1006.

Smith, K. G., Collins, C. J., \& Clark, K. D. (2005). Existing knowledge, knowledge creation capability, and the rate of new product introduction in high-technology firms. Academy of Management Journal, 48(2), 346-357.

Soler i Marco, V. E. (2000). Verificación de las hipótesis del distrito industrial: Una aplicación al caso valenciano. Economía Industrial, (334), 13-24.

Sölvell, Ö., \& Zander, I. (1995). Organization of the dynamic multinational enterprise: The home-based and the heterarchical MNE. International Studies of Management \& Organization, 25(1-2), 17-38.

Sonobe, T., Hu, D., \& Otsuka, K. (2002). Process of cluster formation in China: A case study of a garment town. Journal of Development Studies, 39(1), 118-139.

Sood, A., \& Tellis, G. J. (2011). Demystifying disruption: A new model for understanding and predicting disruptive technologies. Marketing Science, 30(2), 339-354.

Sorenson, O. (2003). Interdependence and adaptability: organizational learning and the 
long-term effect of integration. Management Science, 49(4), 446-463.

Sosa, M. L. (2011). From old competence destruction to new competence access: Evidence from the comparison of two discontinuities in anticancer drug discovery. Organization Science, 22(6), 1500-1516.

Spence, A. M. (1981). The learning curve and competition. The Bell Journal of Economics, 49-70.

Spencer, J. W., Murtha, T. P., \& Lenway, S. A. (2005). How governments matter to new industry creation. Academy of Management Review, 30(2), 321-337.

Spender, J. C. (1996). Making knowledge the basis of a Dynamic Theory of the firm. Strategic Management Journal, Summer Spe, 45-62.

Spender, J. C. (1998). The geographies of strategic competence: Borrowing from social and educational psychology to sketch and activity and Knowledge-Based Theory of the Firm. In A. D. Chandler Jr., P. Hagström, \& Ö. Sölvell (Eds.), The dynamic firm. The role of technology, strategy, organization, and regions. New York: Oxford University Press.

Spitzlinger, R. (2010). Mixed method research-qualitative comparative analysis. Grin Verlag.

Spradley, J. P. (2016). Participant observation. Waveland Press.

Staber, U. (2001). The structure of networks in industrial districts. International Journal of Urban and Regional Research, 25(3), 537-552.

Staber, U. (2011). Partners Forever? An Empirical Study of Relational Ties in Two Small-firm Clusters. Urban Studies, 48(2), 235.

Staber, Udo. (1998). Inter-firm co-operation and competition in industrial districts. Organization Studies, 19(4), 701-724.

Staber, Udo, \& Sautter, B. (2011). Who are we, and do we need to change? Cluster identity and life cycle. Regional Studies, 45(10), 1349-1361.

Starr, R., Newfrock, J., \& Delurey, M. (2003). Enterprise resilience: managing risk in the networked economy. Strategy and Business, 30, 70-79.

Stock, G. N., Greis, N. P., \& Fischer, W. A. (2001). Absorptive capacity and new product development. The Journal of High Technology Management Research, 12(1), 77-91.

Storper, M. (1992). The limits of the globalization: Technology districts and international trade. Economic Geography, 68, 60-93.

Storper, M. (1997). The regional world: territorial development in a global economy. 
Nueva York: The Guilford Press.

Storper, Michael, \& Harrison, B. (1991). Flexibility, hierarchy and regional development: the changing structure of industrial production systems and their forms of governance in the 1990s. Research Policy, 20(5), 407-422.

Story, V. M., Daniels, K., Zolkiewski, J., \& Dainty, A. R. J. (2014). The barriers and consequences of radical innovations: Introduction to the issue. Industrial Marketing Management, 43(8), 1271-1277.

Stuart, T. E., \& Podolny, J. M. (1996). Local search and the evolution of technological capabilities. Strategic Management Journal, 17(S1), 21-38.

Suire, Raphael, \& Vicente, J. (2014). Clusters for life or life cycles of clusters: in search of the critical factors of clusters' resilience. Entrepreneurship \& Regional Development, 26(1-2), 142-164.

Suire, Raphaël, \& Vicente, J. (2009). Why do some places succeed when others decline? A social interaction model of cluster viability. Journal of Economic Geography, 9(3), 381-404.

Sull, D. N., Tedlow, R. S., \& Rosenbloom, R. S. (1997). Managerial commitments and technological change in the US tire industry. Industrial and Corporate Change, $6(2), 461-500$.

Szulanski, G. (1996). Exploring internal stickiness: Impediments to the transfer of best practice within the firm. Strategic Management Journal, 17(S2), 27-43.

Tallman, S., Jenkins, M., Henry, N., \& Pinch, S. (2004). Knowledge, clusters, and competitive advantage. The Academy of Management Review, 29, 258-271.

Taylor, A., \& Helfat, C. E. (2009). Organizational linkages for surviving technological change: Complementary assets, middle management, and ambidexterity. Organization Science, 20(4), 718-739.

Teece, D J. (1981). The market for know-how and efficient international transfer of technology. Annals of the American Academy of Political and Social Science, November, 81-96.

Teece, D J, Pisano, G., \& Shuen, A. (1997). Dynamic capabilities and strategic management. Strategic Management Journal, 18(7), 509-533.

Teece, David J. (1981). Internal organization and economic performance: An empirical analysis of the profitability of principal firms. The Journal of Industrial Economics, 173-199.

Teece, David J. (1998). Capturing value from knowledge assets: The new economy, 
markets for know-how, and intangible assets. California Management Review, $40(3), 55-79$.

Tellis, G. J. (2006). Disruptive technology or visionary leadership? Journal of Product Innovation Management, 23(1), 34-38. https://doi.org/10.1111/j.15405885.2005.00179.x

Tellis, G. J., Prabhu, J. C., \& Chandy, R. K. (2009). Radical innovation across nations: The preeminence of corporate culture. Journal of Marketing, 73(1), 3-23.

Tidd, J., \& Bessant, J. R. (2009). Managing innovation: integrating technological, market and organizational change. Chichester [etc.] : John Wiley. Retrieved from http://cataleg.uji.es/record=b1269313 S1*cat

Tiemessen, I., Lane, H. W., Crossan, M. M., \& Inkpen, A. C. (1997). Knowledge management in international joint ventures. Cooperative Strategies: North American Perspectives, 370-399.

Tilton, J. E. (1971). International diffusion of technology: The case of semiconductors (Vol. 4). Brookings Institution Press.

Todorova, G., \& Durisin, B. (2007). Absorptive capacity: Valuing a reconceptualization. Academy of Management Review, 32(3), 774-786.

Todtling, F., \& Trippl, M. (2004). Like phoenix from the ashes? The renewal of clusters in old industrial areas. Urban Studies, 41(5-6), 1175-1195.

Tomás-Miquel, J.-V., Molina-Morales, F. X., \& Expósito-Langa, M. (2015). Innovation in clusters: exploration capacity, networking intensity and external resources. Journal of Organizational Change Management, 28(1), 26-42. https://doi.org/10.1108/JOCM-10-2013-0192

Tomás, J. A., \& Monzon, J. L. (1998). Libro blanco de la Economía Social en la Comunidad Valenciana. Valencia: Ciriec-España.

Tompkins, J. A. (2007). 4 Steps to Business Resilience. Industrial Management, 49(4).

Trigilia, C. (1986). Small-firm development and political subcultures in Italy. European Sociological Review, 2(3), 161-175.

Triglia, C. (1993). Distritos industriales italianos: ni mito ni interludio. Pyke, F. and Sengenberger, W.: Los Distritos Industriales y Las Pequeñas Empresas III. Distritos Industriales y Regeneración Económica Local, Ministerio de Trabajo y Seguridad Social, Madrid, 63-80.

Tripsas, M. (1997). Surviving radical technological change through dynamic capability: Evidence from the typesetter industry. Industrial and Corporate Change, 6(2), 
$341-377$.

Tripsas, M. (2008). Customer preference discontinuities: A trigger for radical technological change. Managerial and Decision Economics, 29(2-3), 79-97.

Tripsas, M., \& Gavetti, G. (2000). Capabilities, cognition, and inertia: Evidence from digital imaging. Strategic Management Journal, 21(10-11), 1147-1161.

Tsai, W. (2001). Knowledge transfer in intraorganizational networks: effects of network position and absorptive capacity on business unit innovation and performance. Academy of Management Journal, 44(5), 996-1004.

Tsai, W., \& Ghoshal, S. (1998). Social capital and value creation: The role of intrafirm networks. Academy of Management Journal, 41(4), 464-478.

Tushman, M. L., \& Anderson, P. (1986). Technological discontinuities and organizational environments. Administrative Science Quarterly, 439-465.

Tushman, M., \& Nadler, D. (1986). Organizing for innovation. California Management Review, 28(3), 74-92.

Tversky, A., \& Kahneman, D. (1986). Rational choice and the framing of decisions. Journal of Business, S251-S278.

Ughetto, E. (2009). Industrial districts and financial constraints to innovation. International Review of Applied Economics, 23(5), 597-624. Retrieved from http://search.ebscohost.com/login.aspx?direct=true\&db=bsh\&AN=43099297\&lang $=$ es\&site $=$ ehost-live

Utterback, J. M., \& Acee, H. J. (2005). Disruptive technologies: An expanded view. International Journal of Innovation Management, 9(01), 1-17.

Uzzi, B. (1996). The sources and consequences of embeddedness for the economic performance of organizations: The network effect. American Sociological Review, 674-698.

Uzzi, B. (1997). Social structure and competition in interfirm networks: The paradox of embeddedness. Administrative Science Quarterly, 35-67.

Van de Ven, A. H., Polley, D. E., Garud, R., \& Venkataraman, S. (1999). The innovation journey Oxford University Press. New York.

Van den Bosch, F., Volberda, H. W., \& de Boer, M. (1999). Coevolution of firm absorptive capacity and knowledge environment: Organizational forms and combinative capabilities. Organizational Science, 10, 551-568.

Varaldo, R., \& Ferrucci, L. (1996). The evolutionary nature of the firm within industrial districts. European Planning Studies, 4(1), 27-34. 
Vega-Jurado, J., Gutiérrez-Gracia, A., Fernández-de-Lucio, I., \& Manjarrés-Henríquez, L. (2008a). The effect of external and internal factors on firms' product innovation. Research Policy, 37(4), 616-632. https://doi.org/10.1016/j.respol.2008.01.001

Vega-Jurado, J., Gutiérrez-Gracia, A., Fernández-de-Lucio, I., \& Manjarrés-Henríquez,

L. (2008b). The effect of external and internal factors on firms' product innovation. Research Policy, 37(4), 616-632.

Vega Jurado, J., Gutiérrez Gracia, A., \& Fernández de Lucio, I. (2005). Los determinantes de la innovación tecnológica en la empresa: una aproximación a través del concepto de capacidad de absorción.

Veugelers, R. (1997). Internal R \& D expenditures and external technology sourcing. Research Policy, 26(3), 303-315.

Volberda, H. W., \& Elfring, T. (2001). Rethinking strategy. Sage.

Walker, B., Holling, C. S., Carpenter, S., \& Kinzig, A. (2004). Resilience, adaptability and transformability in social-ecological systems. Ecology and Society, 9(2).

Walsh, J. P., \& Ungson, G. R. (1991). Organizational memory. Academy of Management Review, 16(1), 57-91.

Wan, F., Williamson, P. J., \& Yin, E. (2015). Antecedents and implications of disruptive innovation: Evidence from China. Technovation, 39-40(1), 94-104. https://doi.org/10.1016/j.technovation.2014.05.012

Wang, J., Zhu, H., \& Tong, X. (2017). Industrial Districts in a Transitional Economy: The Case of Datang Sock and Stocking Industry in Zhej iang, China. In Proximity, Distance and Diversity (pp. 55-76). Routledge.

Waxell, A., \& Malmberg, A. (2007). What is global and what is local in knowledgegenerating interaction? The case of the biotech cluster in Uppsala, Sweden. Entrepreneurship and Regional Development, 19(2), 137-159.

Weeks, M. R. (2015). Is disruption theory wearing new clothes or just naked? Analyzing recent critiques of disruptive innovation theory. Innovation: Management, Policy and Practice, 17(4), 417-428. https://doi.org/10.1080/14479338.2015.1061896

Wernerfelt, B. (1984). A resource-based view of the firm. Strategic Management Journal, 5(2), 171-180.

West, M. A., \& Anderson, N. R. (1996). Innovation in top management teams. Journal of Applied Psychology, 81(6), 680.

Westerman, G., McFarlan, F. W., \& Iansiti, M. (2006). Organization design and 
effectiveness over the innovation life cycle. Organization Science, 17(2), 230-238. Williamson, O. E. (1975). Markets and hierarchies. New York, 2630.

Winter, S. G. (2000). The satisficing principle in capability learning. Strategic Management Journal, 21(10-11), 981-996.

Woodside, A. G. (2016). The good practices manifesto: Overcoming bad practices pervasive in current research in business. Journal of Business Research, 69(2), $365-381$.

Woodside, A. G., \& Baxter, R. (2013). Achieving accuracy, generalization-to-contexts, and complexity in theories of business-to-business decision processes. Industrial Marketing Management, 42(3), 382-393.

Working, H., \& Hotelling, H. (1929). Applications of the theory of error to the interpretation of trends. Journal of the American Statistical Association, 24(165A), $73-85$.

Wright, M. O., Masten, A. S., \& Narayan, A. J. (2013). Resilience processes in development: Four waves of research on positive adaptation in the context of adversity. In Handbook of resilience in children (pp. 15-37). Springer.

Yamawaki, H. (2002). The evolution and structure of industrial clusters in Japan. Small Business Economics, 18(1), 121-140.

Yashwant Sahu \& Sumiran Satsangi. (2017). Digital Textile Printing Inks Market. Global Opportunity Analysis and Industry Forecast, 2015-2023. Retrieved from https://www.alliedmarketresearch.com/

Ybarra, J. A. (1991). Determinación cuantitativa de distritos industriales: la experiencia del País Valenciano. Estudios Territoriales, 37, 53-67.

Yeung, H. W. (2009). Regional development and the competitive dynamics of global production networks: an East Asian perspective. Regional Studies, 43(3), 325-351.

Yin, R K. (1989). Case Study Research, Design and Methods. Beverly Hills: Sage.

Yin, Robert K. (2011). Case study research: design and methods. Evaluation \& $\begin{array}{llll}\text { Research in 221-222. } & \text { Education, }\end{array}$ https://doi.org/10.1080/09500790.2011.582317

Yin, Robert K. (1994). Case study research. Desing and methods. Thousand Oakz: Sage.

Yin, Robert K. (2003). Case Study Research, Design and Methods. Beverly Hills: Sage.

Yli-Renko, H., Autio, E., \& Sapienza, H. J. (2001). Social capital, knowledge acquisition, and knowledge exploitation in young technology-based firms. 
Strategic Management Journal, 22(6-7), 587-613.

Zahra, S. A., \& George, G. (2002). Absorptive capacity: A review, reconceptualization, and extension. Academy of Ranagement Review. https://doi.org/10.5465/APBPP.2000.5438568

Zeitlin, J. (1992). Industrial districts and local economic regeneration: Overview and comment. In F Pyke \& W. Sengenberger (Eds.), Industrial districts and local economic regeneration. Ginebra: International Institute for Labor Studies.

Zhang, Y., Li, H., Hitt, M. A., \& Cui, G. (2007). R\&D intensity and international joint venture performance in an emerging market: Moderating effects of market focus and ownership structure. Journal of International Business Studies, 38(6), 944960.

Zhang, Z., To, C., \& Cao, N. (2004). How do industry clusters success: a case study in China's textiles and apparel industries. Journal of Textile and Apparel, Technology and Management, 4(2), 1-10.

Zolli, A., \& Healy, A. M. (2012). Resilience: Why things bounce back. Hachette UK.

Zucchella, A. (2006). Local cluster dynamics: trajectories of mature industrial districts between decline and multiple embeddedness. Journal of Institutional Economics, 2(1), 21-44.

Zucchella, Antonella. (2006). Local cluster dynamics: trajectories of mature industrial districts between decline and multiple embeddedness. Journal of Institutional Economics, 2(2006), 21. https://doi.org/10.1017/S174413740500024X 
ANEXOS-APPENDICES 


\section{ANEXOS-APPENDICES}

\subsection{Appendix A}

Additional methodological details are provided in this Appendix for empirical study III. The list of items used in the survey for building the variables are:

\section{Early Adoption}

This is a dichotomous variable. Its value is 1 when the company adopted the inkjet technology in 2010 or before and 0 otherwise. We established 2010 as the cut-off year because different technical and business events (produced mainly between 2008 and 2010) led to a general feeling at that time that the disruptive innovation had been successfully introduced, developed and adapted in the cluster. There was no doubt from that point on that technological change would be a matter of time and diffusion of the new printing technique would be quite fast. In consequence, we consider early adopters as those firms which decided to adopt the novelty before all uncertainties and resistances were removed.

\section{Absorptive Capacity}

For the purposes of the present research, a multidimensional measure of ACAP was chosen. In more detail, we adopt the scale proposed by Flatten et al. (2011). These authors carried out the development and validation of a four-factor ACAP measure based on a relevant prior literature review, followed by a series of pre-tests and two large survey-based studies which validated it. This measure assesses the degree to which a company engages in knowledge acquisition activities, assimilates acquired information into existing knowledge, transforms the newly adapted knowledge and commercially exploits the transformed knowledge to its competitive advantage (Flatten et al., 2011). The four-factor ACAP measure is made up of 14 items, each of them 
based on an 11-point Likert scale (0: strongly disagree to 10: totally agree) grouped as follows: (a) acquisition: 3 items, (b) assimilation: 4 items, (c) transformation: 4 items, and (d) exploitation: 3 items. We asked respondents to use this scale to specify to what extent their company is aligned with the following statements regarding the four dimensions of ACAP proposed. Each dimension is measured as follows:

Absorptive capacity - Acquisition: Use of external resources to obtain information (e.g. personal networks, consultants, seminars, internet, database, professional journals, academic publications, market research, regulations, and laws concerning environment/ technical aspects/ health/ security):

- Acquire 1. The search for relevant information concerning our industry is everyday business in our company.

- Acquire 2. Our management motivates employees to use information sources within our industry.

- Acquire 3. Our management expects employees to deal with information beyond our industry.

Absorptive capacity - Assimilation: Communication structure in your company:

- Assimilate 1. In our company ideas and concepts are communicated crossdepartmentally.

- Assimilate 2. Our management emphasizes cross-departmental support to solve problems.

- Assimilate 3. In our company there is a quick information flow, e.g. if a business unit obtains important information, it communicates this information promptly to all other business units or departments.

- Assimilate 4. Our management demands periodical cross-departmental meetings to interchange new developments, problems and achievements. 
Absorptive capacity - Transformation: Knowledge processing in your company:

- Transform 1. Our employees have the ability to structure and to use collected knowledge.

- Transform 2. Our employees are used to absorbing new knowledge as well as preparing it for further purposes and making it available.

- Transform 3. Our employees successfully link existing knowledge with new insights.

- Transform 4. Our employees are able to apply new knowledge in their practical work.

Absorptive capacity - Exploitation: Commercial exploitation of new knowledge in your company (NB: Please think about all company divisions such as R\&D, production, marketing and accounting):

- Exploit 1. Our management supports the development of prototypes.

- Exploit 2. Our company regularly reconsiders technologies and adapts them according to new knowledge.

- Exploit 3. Our company has the ability to work more effectively by adopting new technologies.

Orientation towards technological innovations

In accordance with the product and process innovation questions of the Community Innovation Survey on Spanish manufacturing firms (PITEC), we asked respondents to specify whether their company is aligned with the following statements: 
- During the last three years, the company has introduced or improved new products/services based on those previously introduced by competitors.

- During the last three years, the company has introduced or improved new products/services before competitors.

- During the last three years, the company has introduced or improved new manufacturing methods.

- During the last three years, the company has introduced or improved new delivery or logistical methods.

- During the last three years, the company has introduced or improved new auxiliary processes.

\section{Orientation towards organizational innovations}

In accordance with the product and process innovation questions of the Community Innovation Survey on Spanish manufacturing firms (PITEC), we asked respondents to specify whether their company is aligned with the following statements:

- During the last three years, the company has introduced new practices to improve work organization in the company.

- During the last three years, the company has introduced new methods to improve the attribution of responsibilities and decision-making.

- During the last three years, the company has introduced new practices to improve the external relationships with other companies and institutions.

- During the last three years, the company has introduced new practices to improve knowledge management (internal or external knowledge). 
- During the last three years, the company has introduced significant changes into the design or packaging of products.

- During the last three years, the company has introduced new channels or techniques for product promotion.

- During the last three years, the company has introduced new practices to improve the positioning of products in the market or in the sales channels.

- During the last three years, the company has introduced new practices for pricing products. 


\subsection{Appendix B}

Additional methodological details are provided in this Appendix for empirical study IV. The list of items used in the survey for building the conditions are:

\section{Technological Innovativeness}

Companies are classified according their capabilities to develop technological innovations which means their intensity in terms of development of product and process innovations. For the purposes of the present research, a measure of Technological Innovativeness of the companies was built from questions belonging to the Community Innovation Survey on Spanish manufacturing firms (PITEC). Consequently, we asked respondents to specify whether their company was aligned with the following statements:

- During the last three years, the company has introduced or improved new products/services based on those previously introduced by competitors.

- During the last three years, the company has introduced or improved new products/services before competitors.

- During the last three years, the company has introduced or improved new manufacturing methods.

- During the last three years, the company has introduced or improved new delivery or logistical methods.

- During the last three years, the company has introduced or improved new auxiliary processes.

\section{Early Adoption}

Companies are classified in two groups (early adopters or non-early adopters) according when they adopted the digital printing technology as printing method for their manufacturing lines. We established 2010 as the cut-off year because different technical and business events (produced mainly between 2008 and 2010) led to the general feeling in the cluster that, finally, this disruptive innovation had been successfully 
introduced and adapted for the ceramic industry. In conclusion, we consider early adopters those companies who adopted from 2000 (when the first digital printer prototype was presented) until 2010 (included). There was no doubt after this cut-off year that the technological change would take place massively. That is the reason why we considered early adopters as those firms which decided to adopt the novelty before all uncertainties and resistances were removed.

\section{Absorptive Capacity}

For the purposes of the present research, a multidimensional indicator was chosen to measure the ACAP of the companies. In more detail, we adopted the scale proposed by Flatten et al. (2011). These authors carried out the development and validation of a fourfactor ACAP measure based on a relevant prior literature review, followed by a series of pre-tests and two large survey-based studies which validated it. This measure assesses the degree to which a company engages in knowledge acquisition activities, assimilates acquired information into existing knowledge, transforms the newly adapted knowledge and commercially exploits the transformed knowledge to its competitive advantage (Flatten et al., 2011). The four-factor ACAP measure is made up of 14 items, each of them based on an 11-point Likert scale (0: strongly disagree to 10: totally agree) grouped as follows: (a) acquisition: 3 items, (b) assimilation: 4 items, (c) transformation: 4 items, and (d) exploitation: 3 items. We asked respondents to use this scale to specify to what extent their company is aligned with the following statements regarding the four dimensions of ACAP proposed.

\section{Experience in $R \& D$ activities}

Firm experience in developing $R \& D$ activities was measured through the age of the R\&D department. 
Size of the company is measured through a factor built from the average values of the number of employees, the total assets and total revenues of the companies. The average values for the respondent companies were calculated from data gathered from 2007 until 2013. This period of time was selected so as to cover a representative period around 2010 in accordance with the consideration of this year as the threshold for a company to be considered as early adopter of the disruptive technology as previously described.

Intensity in $R \& D$ activities

The level of R\&D activity carried out by the companies was measured through the percentage of employees belonging to the $R \& D$ department over the total amount of employees. 